\title{
Local space and economic success : the role of spatial segregation of migrants in the Netherlands
}

Citation for published version (APA):

Beckers, P. J. (2011). Local space and economic success : the role of spatial segregation of migrants in the Netherlands. [Doctoral Thesis, Maastricht University]. Boekenplan. https://doi.org/10.26481/dis.20110119pb

Document status and date:

Published: 01/01/2011

DOI:

10.26481/dis.20110119pb

Document Version:

Publisher's PDF, also known as Version of record

\section{Please check the document version of this publication:}

- A submitted manuscript is the version of the article upon submission and before peer-review. There can be important differences between the submitted version and the official published version of record.

People interested in the research are advised to contact the author for the final version of the publication, or visit the DOI to the publisher's website.

- The final author version and the galley proof are versions of the publication after peer review.

- The final published version features the final layout of the paper including the volume, issue and page numbers.

Link to publication

\footnotetext{
General rights rights.

- You may freely distribute the URL identifying the publication in the public portal. please follow below link for the End User Agreement:

www.umlib.nl/taverne-license

Take down policy

If you believe that this document breaches copyright please contact us at:

repository@maastrichtuniversity.nl

providing details and we will investigate your claim.
}

Copyright and moral rights for the publications made accessible in the public portal are retained by the authors and/or other copyright owners and it is a condition of accessing publications that users recognise and abide by the legal requirements associated with these

- Users may download and print one copy of any publication from the public portal for the purpose of private study or research.

- You may not further distribute the material or use it for any profit-making activity or commercial gain

If the publication is distributed under the terms of Article $25 \mathrm{fa}$ of the Dutch Copyright Act, indicated by the "Taverne" license above, 


\section{Local space and economic success}

The role of spatial segregation of migrants in the Netherlands 
(C) 2010 Pascal Beckers

All rights reserved. No part of this publication may be reproduced, stored in a retrieval system, or transmitted in any form, or by any means, electronic, mechanical, photocopying, recording or otherwise, without the prior permission in writing, from the author.

\section{ISBN 9789086661756}

Cover pictures by Pascal Beckers and Jan Rath (Amsterdam and The Hague)

Published by Boekenplan, Maastricht, The Netherlands 


\section{Local space and economic success}

The role of spatial segregation of migrants in the Netherlands

\section{DISSERTATION}

to obtain the degree of Doctor at the Maastricht University, on the authority of the Rector Magnificus, Prof. mr. G.P.M.F. Mols, in accordance with the decision of the Board of Deans, to be defended in public on Wednesday, 19 January 2011, at 12:00 hours

by Pascal Jörg Beckers 
Supervisors:

Assessment Committee:
Prof. dr. Chris de Neubourg

Dr. Boris Blumberg

Prof. dr. Joan Muysken (chairman)

Prof. dr. Jaap Dronkers

Prof. dr. Valentina Mazzucato

Prof. dr. Sako Musterd (University of Amsterdam) 
Throughout the course of my PhD research, I have been fortunate to have received much support from colleagues in Maastricht and beyond, but also from friends and family. I am greatly indebted to so many people as this dissertation would not have been what it is now without all of their input. First and foremost, I would like to thank my family and especially my parents for their love and support of whatever I chose to do in my life. Your advice and guidance has helped me to make the right decisions while it never discouraged me to pursue my dreams. Thanks to my brother Patrick, my sister Anika and my cousins Sarah and Tanja for all the joyful childhood memories together as well as the special moments shared with our big family thereafter.

To Hannah, thank you so much for always being there for me, in happy and sad hours, in times of relaxation but also in stressful periods, for your understanding and emotional support during my $\mathrm{PhD}$ dips, for your academic and linguistic coaching relating to my dissertation. Also, thanks for sharing my affection for traveling and classical music, even though our interests remain somewhat divided between the baroque and opera genres. I look forward to many more special moments abroad or engulfed by Bach, Mozart or Verdi.

I am greatly indebted to my promoters Boris Blumberg and Chris de Neubourg for their many useful comments and suggestions on my work and for co-authoring two of my papers. Boris, thanks for always taking the time to discuss dissertationrelated problems with me, no matter how long it would take to solve them (I guess I also should thank your family). Thank goodness that calling between Amsterdam and Maastricht and to Germany has become so cheap by now.

To all the other busy bees at the School: thanks to the people downstairs for working so hard to keep the School running (Mindel, Franziska, Annemarie, Celine, Susan, Mieke, Monique, Janneke, Charlotte...), thanks to my colleague researchers of the ESPP cohort of 2005 and others (you know who you are) for exchanging academic ideas and thoughts and for all the fun moments together, special thanks to Robert, for the fun times sharing an office with you back in the Tongersestraat days and for traveling from Slovenia to Maastricht to be my paranymf.

Thanks to the Netherlands Bureau of Statistics (Gerhard Meinen and colleagues), to the Netherlands Chamber of Commerce (Jan Jans and colleagues) and to the 
Central Agency for the Reception of Asylum Seekers (COA) (Hennie van Rossum, Ineke Mos and colleagues) for making available data used in this dissertation.

A special thanks to all the other people who worked with me over the years, to my co-authors Robert Kloosterman, Metka Hercog, Lex Borghans, to the people at ROA for supporting me in my research at the CBS remote access computer (Raymond Montizaan, Charlotte Büchner, Bart Golsteyn, Anne Gielen, Ben Kriechel, Sander Dijksman...), to Joan Muysken and Katerina Kyrieri for building my knowledge in the field of migration and integration in Europe while developing training modules together, to Maren Wilmes and Michael Bommes for supporting me in hosting an IMISCOE workshop on local dynamics and immigrant economic outcomes in Maastricht, to Veronique Schutjens and Bart Sleutjes with whom I joined forces in part of my field research and the financial support we received from the University of Utrecht for this, to Rein Sohilait and Vera Marinelli of FORUM who secured the financial support for the other part of my field research and with whom I hosted a related workshop at the Bonn Conference of the International Metropolis Network, to all the student assistants who made the field research a success (Merel, Kim, Daphne, David, Bregje, Jorrit, Julie, Anneloes, Sjef, Gabriella) to my former colleagues at the IMES and AMIDSt institutes at the University of Amsterdam for the many academic discussions and social gatherings during my research visitorships there (Amanda Brandellero, Michael Deinema, Aslan Zorlu, Heike Pethe, Elif Keskiner, Laure Michon, Manolis Pratsinakis, Aimee Rindoks, Philipp Schnell...).

Thanks to the tri- and running team at the School that kept me in shape throughout my PhD (Melissa, Florian, Britta, and Robert). I hope there will be many more triathlons or other sport events where we can meet up again.

Finally, I am thankful to my colleagues and friends Sharon and Cyril Moyse, Kathleen Robbins, Melissa Siegel and David Evers for editing parts of my dissertation and to the members of the reading committee (Joan Muysken, Valentina Mazzucato, Jaap Dronkers, Sako Musterd) for their helpful comments and suggestions, which led to this final version of the dissertation.

Amsterdam, October 2010 


\section{Preface}

This dissertation is based on a collection of papers that were published or are in the process of being published as journal articles, working and consultancy papers and conference papers. I would like to express my gratitude to my co-authors, reviewers, conference-organizers, participants and discussants for their invaluable input to the work that now constitutes this dissertation. The below table provides an overview of the main sources of each dissertation chapter.

\begin{tabular}{|l|l|}
\hline Chapter & Main sources \\
\hline 2 & $\begin{array}{l}\text { Neubourg, C., Beckers, P. \& Hercog, M. (2008), "Burning Bridges, } \\
\text { Building Ships - Changes in immigration in the Netherlands; trends, } \\
\text { policies and incentives", World Bank study. }\end{array}$ \\
\hline 3 & $\begin{array}{l}\text { Beckers, P. \& Borghans, L. (2007), "Segregation in neighbourhoods and } \\
\text { labour market outcomes of immigrants - Evidence from random } \\
\text { assignment in the Netherlands", Conference paper at the Annual } \\
\text { Conference of the Society of Labor Economists, Chicago, May 2007. }\end{array}$ \\
\hline 4 & $\begin{array}{l}\text { Beckers, P. \& Blumberg, B. (2010), "Immigrant Entrepreneurship on the } \\
\text { move - A longitudinal analysis of first and second generation } \\
\text { immigrant entrepreneurship in the Netherlands", Conference paper at } \\
\text { the Academy of Management Annual Meeting, Montreal, August 2010. }\end{array}$ \\
\hline 5 & $\begin{array}{l}\text { Beckers, P. \& Kloosterman, R.C. (2010), "Between entrepreneurs and } \\
\text { business opportunities. The impact of the local built environment and } \\
\text { zoning regulations on small businesses in the Netherlands", } \\
\text { Conference paper at Annual Conference of the European Regional } \\
\text { Science Association, Jönköping, August 2010. }\end{array}$ \\
\hline
\end{tabular}




\section{Table of contents}

Acknowledgements $\quad i$

Preface $\quad$ iii

List of Figures vi vi

List of Tables viii

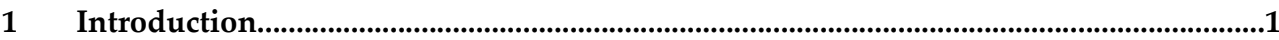

1.1 Motivation 1

1.2 Research objective 3

1.3 Immigration, the peculiar case of the Netherlands 3

1.4 Immigrant integration and the focus on non-Western immigrants 4

1.5 The relevance of 'local space'

1.6 The relevance of economic success of immigrants: the importance $\begin{array}{ll}\text { of 'the ability to pay' } & 7\end{array}$

1.7 Local space and economic success; central research questions 8

1.8 Methodology, data collection and use $\quad 8$

1.9 Outline of the dissertation 9

2 Migration and integration trends in the Netherlands..................................................13

$\begin{array}{ll}2.1 \text { Introduction } & 13\end{array}$

2.2 Dutch immigration history and trends 14

2.3 The immigrant population in the 21st century 18

2.4 Trends in integration of immigrants $\quad 25$

2.5 Concluding remarks 41

3 Segregation in neighbourhoods and labour market outcomes

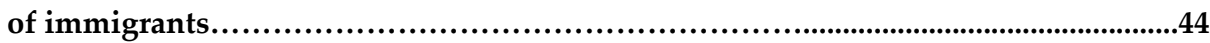

3.1 Introduction $\quad 44$

3.2 Literature review $\quad 47$

3.3 Random allocations of asylum seekers in the Netherlands 53

3.3.1 Natural experiments and endogeneity 53

3.3.2 Asylum inflows in the Netherlands and the role of COA 54

3.4 Data and methodology 59

$\begin{array}{lll}3.5 & \text { Findings } & 65\end{array}$

3.6 Concluding remarks $\quad 87$

3.7 Appendix to chapter three 92

4 Immigrant entrepreneurship on the move: A longitudinal analysis of first and second generation immigrant entrepreneurship..............................................101

4.1 Introduction 101

4.2 Migrant entrepreneurship in the Netherlands 102

4.3 Integration trajectories and immigrant entrepreneurship 104

$\begin{array}{ll}4.4 \text { Methodology } & 110\end{array}$

4.5 Findings 112

4.6 Discussion of the results $\quad 127$

$\begin{array}{lll}4.7 & \text { Conclusion } & 133\end{array}$ 
5 Between entrepreneurs and business opportunities. The impact of the local built environment and zoning regulations on small

businesses in the Netherlands.

5.1 Neighbourhoods and opportunities for migrant businesses

5.2 Built environment and zoning: a neglected issue 136

5.3 Methodology 139

5.3.1 Neighbourhood selection 139

5.3.2 Data collection and use 141

5.4 The built environment and zoning regulations in pre- and post-war migrant neighbourhoods $\quad 143$

5.4.1 Building history and general characteristics of neighbourhoods 143

5.4.2 Pre- and post-war neighbourhoods compared $\quad 145$

5.5 Business success of firms in pre- and post-war migrant neighbourhoods $\quad 146$

5.5.1 A snapshot of local business landscapes in pre- and post-war neighbourhoods

5.5.2 Firm survival rates in pre- and post-war neighbourhoods

5.5.3 Firm location factors and business success in preand post-war neighbourhoods

5.5.4 Other aspects affecting local business success in preand post-war neighbourhoods 156

5.6 Conclusions 159

5.7 Appendix to chapter five 162

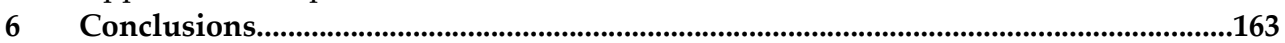

$\begin{array}{ll}\text { 6.1 Discussion of key findings } & 163\end{array}$

6.1.1 Implications of regional and municipal differences for immigrant economic success

6.1.2 The relevance of the local social environment for immigrant economic success

6.1.3 Implications of the local morphology and spatial regulations for firm economic success

6.1.4 Other (non-geographic) factors affecting economic performance 168

6.2 Limitations and suggestions for future research 170

$\begin{array}{lll}6.3 & \text { Policy implications } & 172\end{array}$

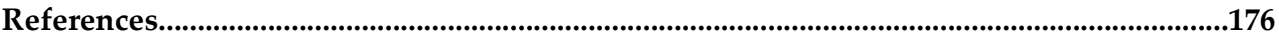

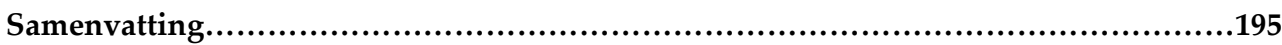

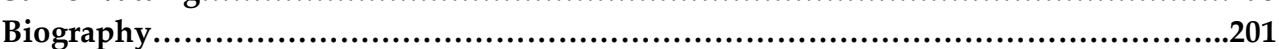

Maastricht Graduate School of Governance Dissertation Series...........................202 
2.1 Net migration in the Netherlands $1860-2000$

2.2 Non-Western immigrants in the Netherlands by the year of arrival and migration motive

2.3 Non-Western immigrants in the Netherlands by country of origin 1975-2004

2.4 Asylum claims and permits (1975-2005)

2.5 Immigration in the Netherlands: Non-Western and from Poland, Bulgaria and Romania 1995 - 2007

2.6 Age composition of the Netherlands per country of origin, 1 January 2007 20

2.7 Household characteristics per ethnic group, the Netherlands, $2006 \quad 29$

2.8 Educational level of population aged 15-64 the Netherlands, per ethnic group and generation, 2006

2.9 Early school dropouts during secondary education the Netherlands per ethnic group, 2005

2.10 Unemployment among higher educated, age 15-64 years per ethnic group, the Netherlands, 1996-2005

2.11 Working labour force per work level, ethnic group and gender, the Netherlands, 2006

2.12 Business per sector, non-Western migrants and natives, the Netherlands, 2005

2.13 Share household with low income, per ethnic group, the Netherlands, 2000-2005

3.1 Annual asylum claims and recognized claims in the Netherlands 1995-2004

3.2 Asylum procedure in the Netherlands and parties responsible for central housing provisions

3.3 Average concentration in the neighbourhood of living (1995-2004) conditional on the concentration in the neighbourhood of initial placement

3.4 Initial non-Western neighbourhood concentrations

3.5 Employment chances of initial asylum clusters per neighbourhood concentration

3.6 Mean annual log wages of initial asylum clusters per neighbourhood concentration 73

3.7a Employment chances by level of concentration, various models $\quad 78$

3.7b Annual wages by level of concentration, various models 79

3.8a Employment chances by level of concentration, male and female, various models $\quad 80$

$3.8 \mathrm{~b}$ Annual wages by level of concentration, male and female, various models $\quad 81$

3.9a Employment chances by level of concentration, experience groups, various models 82

$3.9 \mathrm{~b}$ Annual wages by level of concentration, experience groups, various models $\quad 83$

3.10a Employment chances by level of concentration, residential preference groups $\quad 86$

$3.10 \mathrm{~b}$ Annual wages by level of concentration, residential preference groups $\quad 87$

3.A1 Map of the Netherlands and its provinces $\quad 92$

3.A2 Regression outputs for 1-4 years experience group, non-linear models, annual wages

4.1 Distribution of native and non-Western migrant entrepreneurs across sectors for the first and second generation

5.1a Firm location factors and success: Entrepreneurs in pre-war neighbourhoods

5.1b Firm location factors and success: Entrepreneurs in post-war neighbourhoods 
5.2 Entrepreneurs' perceptions of and relations with their neighbourhoods, and valuations of contacts with local organizations

5.A1 Neighbourhood comparison of relevant characteristics, positioning of selected 5 neighbourhoods within distribution of 93 neighbourhoods 
2.1 Population composition of the Netherlands per country of origin, 1 January $2007 \quad 19$

2.2 'Allochtonen' in the Netherlands by country of origin in $2007 \quad 22$

2.3 Foreign nationals in the Netherlands by citizenship in $2006 \quad 22$

2.4 Immigration in the Netherlands by region of birth, 2003-2007 23

2.5 Characteristics of detained illegal migrants per year, person level data, the Netherlands $1997-2000$

2.6 Distribution of ethnic minorities across national regions and proportion living in the four major cities in the Netherlands, 2006

2.7 Distribution of municipalities and postal code areas per ethnic composition and ethnic concentration category in the Netherlands, 1 January 2000, 1 January 2007 and 1 January 2006 respectively

2.8 Estimate apartment selling prices in white, mixed, and concentration neighbourhoods of the largest four cities in the Netherlands, 2006

2.9 Average home sites in square meters and average number of square meters per household member the Netherlands, by ethnic group, 2002 and 2006

2.10 Population aged 15-64 the Netherlands, by origin and education level, 1996-2005

2.11 Dutch language skills per ethnic groups and relevant characteristics the Netherlands, 2006

2.12 Key trends in the supply side of the labour market, 1996-2006

2.13 Net labour market participation rates per ethnic group, the Netherlands, $2006 \quad 34$

2.14 Unemployed labour force per ethnic group, the Netherlands, 2006

2.15 Share employed with temporary or flexible contract per ethnic group and gender, age 15-64 year employees, the Netherlands, 2006

2.16 Share households with low income, per ethnic group and background characteristics, the Netherlands, 2002

2.17 Recipients of social benefits, age 15-64 years, September 2004, the Netherlands

3.1 Main communities with direct asylum inflows in the years 1995-1996

3.2 Asylum centres per province (1995-2004)

3.3 Characteristics of asylum seekers per cohort

3.4 Probabilities of asylum seekers to stay in the Netherlands

3.5 Annual wage distributions, per gender and experience groups

3.6 Annual non-Western neighbourhood concentrations

3.7 The relationship between migrant concentration and employment and income (linear specification)

3.8 The relationship between migrant concentration and employment (linear and non-linear IV specifications) 
3.A3 Characteristics of asylum seekers per province (1995-2005) 95

3.A4 List of countries per regions of origin 96

3.A5 Characteristics of asylum seekers per year 97

3.A6 Annual working days, by gender and experience group $\quad 97$

3.A7 Annual wages by country of origin group $\quad 98$

3.A8 Robustness check regressions, outputs linear specification 99

4.1 Entrepreneurship in the Netherlands 1999-2004 103

$\begin{array}{lll}4.2 & \text { Self-employment propensities per groups } & 104\end{array}$

4.3 Socio-cultural and structural integration for five groups of non-Western migrants in the Netherlands $\quad 106$

4.4 Description of variables $\quad 112$

4.5 Summary statistics per migrant group, entrepreneur/firm-based and firm location-based characteristics

4.6 Base random-effects regression estimates for dependent variable annual profits, by origin group

4.7 Base random-effects logistic regression estimates for dependent variable growth, by origin group

4.8 Base random-effects logistic regression estimates for dependent variable survival, by origin group

4.9 Selected random effects regression outputs from interaction models: migrant composite coefficients per independent variable and test results for hypotheses 2-5 126

5.1 Total firms, sector and neighbourhood cluster distributions 148

5.2 Mean ceased firms per total firms, per sector and neighbourhood cluster $\quad 150$ 



\section{Chapter 1: Introduction}

'Like many birds, but unlike most other animals, humans are a migratory species. Indeed, migration is as old as humanity itself. Of this fact there is no better proof than the spread of human beings to all corners of the earth from their initial ecological niche in sub-Saharan Africa. A careful examination of virtually any historical era reveals a consistent propensity towards geographic mobility among men and women, who are driven to wander by diverse motives, but nearly always with some idea of material improvement.' (Massey et al. 2005, Worlds in Motion)

\section{1 - Motivation}

Although migrations have been part of human history from its earliest times, international migration has increased substantially since 1945 and presently ranks among the most important factors in global change. According to the International Organization for Migration (IOM) the global number of international migrants has doubled from 75 million to 150 million between 1996 and 2000 (IOM 2000, Castles \& Miller 2003); the United Nations even estimates that this number will surpass 200 million in 2010, which would amount to about three per cent of the world's population ${ }^{1}$. Moreover, as migration affects the lives of many individuals, families and communities in origin countries, transit countries and destination countries, this also makes the study of international migration a highly complex endeavour. In sending countries, the departure of international migrants can have considerable social and economic consequences that may bear both positive effects (i.e. due to remittances) and negative effects (i.e. brain drain, disturbed family relations). In receiving countries, the arrival of newcomers from abroad impacts the lives of native and already established migrant communities in the predominantly industrialized areas and cities of settlement. As a consequence, there are few people in either industrialized or less-developed countries today, who have not felt the direct or indirect effects of migration on their lives.

From a European, destination-country perspective, the rising numbers of international immigrants over the past decades have brought about substantial challenges for many receiving countries and resulted in increased regulation of international migration flows. As newcomers often differ from the receiving populations, in terms of traditions, religions, political institutions, language, physical appearance and legal status, increased immigration implies a growing

1 Source: United Nations, Department of Economic and Social Affairs, Population Division (2009). Trends in International Migrant Stock: The 2008 Revision. 
diversity of the population, which in many cases puts the traditional nation-state ideology defined on the grounds of ethnic homogeneity to the test. Ethnic diversity may also complicate state provisions of social policy as, for instance, social services and education may need to be redesigned to meet the new needs of the population. Moreover, as immigration often coincides with economic restructuring and farreaching social change, people whose lives are characterized by hardship and/or uncertainty may blame the newcomers for this, which nourishes hostile stereotypes of the 'alient other' taking away jobs, pushing up housing prices and flooding the social security system (Castles \& Miller 2003).

Many Western European countries emphasized temporary labour recruitment in the 1960s and 1970s and aimed at preventing family reunification and permanent settlement. In doing so, these countries upheld their image as 'non-immigrant' countries denying citizenship and other rights to growing numbers of immigrants at the cost of growing marginalization of these groups in society. At present, nonWestern immigrants (from less-developed parts of the world) more often than not are unemployed or take up low-status and low-paying jobs with precarious working conditions. This economic marginalization is a cause and consequence of legal disabilities, low levels of education, exposure to crime and family breakdown and often coincides with spatial marginalization that drives non-Western immigrants to live in disadvantaged urban areas. It can be argued that the exclusion of certain groups from mainstream society has become the most pressing social issue of our time even surpassing the traditional conflict between labour and capital. Given the relevancy of this issue in many European countries and being particularly intrigued by the increasing spatial marginalization of non-Western immigrants, I posed the question to myself: Does the spatial location of immigrants in receiving countries matter for their economic success? With this basic question in mind, I scanned the academic literature at the time of starting my research in 2006 to surprisingly find no satisfying answers in the European context. Apart from a long-standing history of American literature on 'segregation and labour market effects' (i.e. Blalock 1957, Brown \& Fuguitt 1972, Wilcox \& Roof 1978, Tienda \& Lii 1987, Borjas 1987, Fossett and Seibert 1997, Lazear 1999, Bertrand, Luttmer and Mullainathan 2000, Chiswick \& Miller 2005) and selective studies on 'neighbourhood effects' and economic outcomes in Europe (i.e. Musterd \& Andersson 2006), I found little large-scale evidence to support my query. Given this, I chose to explore this issue further by making it my central research theme for my $\mathrm{PhD}$ dissertation. 


\section{2 - Research objective}

The objective of this dissertation is to explore whether and how the spatial location of non-Western immigrants (from less-developed parts of the world) in destination countries matters for their economic success in the labour market and in selfemployment. More specifically, I aim to find out how the local spatial environment in the place of residence, or place of firm location (for the self-employed), shapes immigrant economic prospects. To reach my objective, I opt to focus on a single country case, namely the Netherlands (for reasons stated in section 1.3), which enables me to thoroughly study the stated spatial implications on both labour market and self-employment outcomes by combining a number of thematic, complementary research projects that assess the socio-economic position of nonWestern immigrants in the country, analyse neighbourhood segregation effects on labour market outcomes, and examine spatial location effects on migrant business performance. I shall briefly explain the choices that I have made in the design of this dissertation in sections 1.3 to 1.6 before addressing the central research questions in section 1.7 again.

\section{3 - Immigration: the peculiar case of the Netherlands}

This dissertation opts to focus on the country case of the Netherlands for several reasons. First and foremost, to adequately study the potential implications of the local spatial environment on immigrant economic success, detailed geographical data on immigrants and their labour market and self-employment outcomes is required that is available for very few countries: the Netherlands is among these few countries. The Netherlands Bureau of Statistics grants researchers access to administrative data, which contains detailed information about demographic, labour market and self-employment characteristics of immigrants at the local (mostly neighbourhood) level of precision. Thus, given this unique data opportunity in the Netherlands, the country can serve as a meaningful case study to illustrate whether and how the spatial location of immigrants matters for their economic success.

Second, apart from the unique data availability, the Netherlands also has a peculiar immigration history as it is regarded as belonging to the European avant-garde in immigration and integration-related policy in Europe, but has seen substantial policy shifts in recent years as a consequence of increasing right-wing political populism. These developments are described in more depth in chapter 2. Although the Netherlands has a long history of migration, it was de facto not until 1967 that the flow of immigrants systematically exceeded the flow of emigrants (Lucassen and Penninx 1997, Roodenburg et al. 2003). Thus, the Dutch experience as an 
'immigration country' roughly relates to the period of the past four decades. The tidal change from emigration to immigration was brought about by large inflows of colonial repatriates as well as rising numbers of labour migrants who entered the country for post-war reconstruction of the economy. Since then, immigration flows to the Netherlands have gained in momentum, a trend largely driven by consecutive repatriation movements from former Dutch colonies, labour migrants and their families and asylum seekers in more recent years.

As of 1 January 2007, the population of the Netherlands reached 16.358 million people of whom 9 per cent originated from other Western countries ${ }^{2}$ and 11 per cent (1.739 million people) from non-Western countries. Two-thirds of the latter group of migrants is primarily originating in four source countries Turkey $(368,600$ persons, 21\% of non-Western migrants), Morocco (329,500 persons, 19\%), Surinam (333,500 persons, 19\%) and The Dutch Antilles/Aruba (130,000 persons, 7\%). This share has decreased over the past decade from three-quarters in the mid 90's with recent migration waves arriving as asylum seekers from other countries.

\section{4 - Immigrant integration and the focus on non-Western immigrants}

This dissertation focuses on the non-Western group of immigrants in the Netherlands for two reasons. First, while the group of Western migrants has remained relatively constant in recent years, the non-Western population has risen tremendously in numbers over the past decades as outlined in the previous section. Second, and most importantly, unlike the Western group, non-Western migrants have encountered many difficulties in gaining a foothold in Dutch society having low levels of education and being physically and culturally more different from the native population than their counterparts from Western countries. Consequently, starting from the Minorities Policy in the mid 1980s, this population group has been the target of many government initiatives aimed at improving the socio-economic status and living conditions of numerous economically and spatially marginalized immigrants more often than not living in disadvantaged urban neighbourhoods (see chapter 2 for more details). Given the increasing trend of spatial segregation of non-Western immigrants in the Netherlands and other European countries that coincides with their socio-economic marginalization in society, there has been a growing concern among policy makers and academics alike that this may lead to urban ghetto-like living circumstances as identified in

${ }^{2}$ According to socio-economic typology of Statistics Netherlands including EU15, Norway, Switzerland, Liechtenstein, Andorra, Monaco, Vatican City, San Marino, Cyprus, Malta, Israel, United States of America, Canada, Australia, New Zealand, South Africa, Indonesia, Japan (Netherlands Bureau of Statistics Statline 2007). 
the US-American literature. As counter measures to prevent further residential segregation of non-Western immigrants, many European governments, including that of the Netherlands, have implemented urban housing policies and/or newcomer dispersal policies for asylum seekers. It is however far from clear as to whether these policy measures have actually been effective as prior studies have struggled to clearly demonstrate the causality between policies and their effects. This discussion will be revisited for the case of newcomer dispersal policies in chapter three.

When studying the position of non-Western migrants in society, the term integration quickly enters the picture, however vague it may be, as it aims to capture to what extent groups of migrants differ from the native Dutch population along various dimensions that generally entail cultural, social and economic aspects (Fernandez-Kelly \& Haller 2008, Dagevos 2001). While opinions of researchers and policy makers on the precise conceptualization of integration tend to vary, a useful and widely-accepted definition of integration is the one by Vermeulen and Penninx $(1994,2000)$ as discussed in more depth in chapter 4. It distinguishes between two dimensions of integration, namely the socio-cultural and the structural dimensions. The socio-cultural dimension reflects interpersonal relations with the native Dutch population and the extent of cultural, attitudinal, and behavioural changes towards the host society. Structural integration refers to the participation of immigrants in core institutions of society and is usually measured by educational attainment, position in the labour market, and residential integration.

Integration-related aspects of migrants and children of migrants have been widely studied for the case of the Netherlands (e.g. Crul and Pásztor 2007, Pels and de Gruyter 2006, Coenen 2001, Lindo 1996, Klatter-Former 1996, Veraart 1996, Pels 1991). The studies' findings generally support the segmented assimilation model (Portes \& Zhou 1993), which proposes that different ethnic groups follow different assimilation pathways at different paces. Despite occasional concerns of intergenerational downward social mobility of disadvantaged immigrant groups, Alba and Nee (2004) point out that even in most disadvantaged groups, the dominant trend is still upward social mobility (see chapters 2 and 4 for more detailed discussions).

\section{5 - The relevance of 'local space'}

How does space matter in the prior discussion on integration of non-Western immigrants in the Netherlands? The answer seems to depend on the integration discourse chosen. For the case of the Netherlands, four dominant integration 
discourses can be distinguished with differing roles of space therein. ${ }^{3}$ These discourses see integration as equality in social norms, equality in social mobility, equality of different cultures, and equality in access to resources (Galle forthcoming). In the first discourse, the neighbourhood is of central importance as the integration objective is to safeguard the local liveability in segregated neighbourhoods that is challenged by divergent social norms and behaviour of the diverse local population. Policy initiatives aimed at improving the local living circumstances in disadvantaged neighbourhoods are good examples here, which focus on lowering the local level of non-Western population concentration, reducing tensions and conflicts between neighbourhood residents, and changing antisocial behaviour of certain residents. The lack of social cohesion and safety, and the presence of crime, disturbance and vandalism are viewed as failure of integration. The second integration discourse focuses on equal social mobility for ethnic minorities, whereby migrant social contacts with natives are seen as essential tool to achieve this goal since natives possess the social capital that most newcomers lack (i.e. networks that convey information about the host-country social norms and culture, language, job opportunities). According to this perspective, the problem of spatial segregation of immigrants is that this reduces social interactions with natives as many social interactions take place in the local neighbourhoods of residence. This in turn deprives immigrants of the ability to acquire adequate social capital to achieve social mobility (Van der Laan BoumaDoff 2005, Uunk 2002). The third discourse focuses on the equality of different cultures, whereby problems of non-Western immigrants in society are explained by the intolerance of culturally different behaviour on the part of the receiving society. Foreigners have difficulties in finding their way as they are not accepted, discriminated against, or even threatened by natives, who are not able or willing to accept the new reality of a multicultural society. Space, notably at the city level, is an important element in this discourse as it is believed that local encounters between natives and migrants in 'safe' public domains (including public spaces as parks, but also semi-public spaces as stores, holiday parks etc.) raise their levels of familiarity with each other whereby cultural diversity loses its threatening character (Lofland 2000, Galle forthcoming). Finally, space has a marginal role in the fourth integration discourse, which centres on equal access to resources of immigrants in society but has no specific spatial focus. It underscores the discriminatory nature of institutional practices and regulations that hamper newcomers in gaining a foothold in the receiving society. Examples of this are immigrants' selective access to the housing and labour markets, which have been

${ }^{3}$ Perhaps a fifth, but more contested, discourse is the homogeneity discourse, which emphasises the advantages of ethnic homogeneous neighbourhoods, such as more trust and the buildup of ethnic social capital (i.e. Lancee 2010, Lancee and Dronkers 2009). This discourse is left aside here, but it is revisited in chapter three. 
the target of consecutive government initiatives such as its special recruitment programmes for individuals with migrant background (Blokland 2002, Galle forthcoming).

In conclusion, although perspectives on integration differ, the review of the four dominant integration discourses in the Netherlands has shown that space is seen by many as an essential component of integration as the level of exposure to Dutch society reduces with increasing spatial segregation. Population compositions of neighbourhoods vary considerably in the Netherlands: On the one hand, there are neighbourhoods that have not seen a single immigrant; on the other hand, there are neighbourhoods in the major cities with such large co-ethnic communities that their members' daily lives could exclusively take place within their own circles. Moreover, as spatial segregation of non-Western immigrants is likely to increase in the future, academics and policy makers alike are concerned that this may hamper the socio-economic integration of this population subgroup due to less social interaction with natives at the local level.

1.6 - The relevance of economic success of immigrants: the importance of 'the ability to pay'

Within the debate on the integration of immigrants in receiving countries such as the Netherlands, one of the central questions is that of immigrants' 'ability to pay', or in other words, to what extent are immigrants able to make a living? It can be claimed that immigrants' ability to pay for goods and services is a base condition required for their participation in a market-based society and is thus regarded as a decisive step in the long process of integration shaping immigrant possibilities in all kinds of other realms of life. Next to gaining the ability to pay for themselves, immigrants more often than not also financially help their families and/or communities back home to make a living by means of sending remittances, which underscores the relevancy of the stated question in a two-folded way.

Apart from receiving social benefits, immigrants can adopt two main, active strategies to acquire monetary means enabling participation in a market-based society. They can sell their manpower in the regular (or irregular) labour market and/or become self-employed. It seems only natural that these two strategies are interdependent as individual choices of immigrants are subject to many factors such as their legal status in the receiving country, human, social and financial capital endowments. Moreover, all of the before factors can change over time. Also, the link between the individual migrant and his or her local environment is of key importance in determining the (potential) success in the labour market or in selfemployment as local social structures may support or harm immigrants' pursuits. 
This dissertation focuses on these two main, active strategies of immigrants to gain monetary means enabling participation in the receiving society.

1.7 - Local space and economic success; central research questions

As outlined in sections 1.1 and 1.2, this dissertation centres on the basic question: Does the spatial location of non-Western immigrants in the Netherlands matter for their economic success in the labour market and in self-employment? This basic question translates to a number of more specific research questions that are addressed in chapter two to five. A more in-depth outline of the chapters follows in section 1.9. Each chapter contains a distinct (set of) question(s) that sheds light on the potential implications of the local spatial environment for immigrant economic success in the labour market (chapter 3) and in self-employment (chapters 4 and 5), whereby chapter two provides more of a general introduction to the socio-economic situation of the non-Western immigrants in the country. Moreover, chapters three and five study this relationship at the neighbourhood level, while chapter four investigates this at the municipal level. In summary, the specific research questions of this dissertation are as follows: Chapter two wonders about the socio-economic situation of the non-Western immigrant community in the Netherlands in light of the country's peculiar immigration history and policy over the past half century. Chapter three considers the question as to whether living in high concentration non-Western migrant neighbourhoods benefits or harms immigrant labour market success. Chapter four contrasts business prospects of first and second generation groups of migrant entrepreneurs and inquires how these prospects are affected by local market prosperity, the local presence of the co-ethnic community (and business community), and the industry sector of business operations. Finally, chapter five questions the role of the local spatial environment and its regulations in shaping the developmental prospects of migrant businesses in residential neighbourhoods.

\section{8 - Methodology, data collection and use}

As stated above, this dissertation combines a number of thematic, complementary research projects to investigate potential implications of the local spatial environment on economic outcomes of non-Western immigrants. This also involves the use of various research methods, both quantitative and qualitative, as explained briefly in this section. More detailed descriptions of the research methodology, data collection and use are provided in each chapter. The first project (chapter 2) is a literature review aimed at collecting and summarizing relevant documentation on the socio-economic status of non-Western immigrants to lay the groundwork for the later analyses. In the second and third projects 
(chapters 3 and 4) I perform econometric analyses on quantitative secondary data originating from the Netherlands Bureau of Statistics. For the second project I also use quantitative secondary data from the Central Agency for the Reception of Asylum Seekers (COA). Finally, project four (chapter five) follows an exploratory research approach combining both quantitative secondary data from the regional chambers of commerce and qualitative primary data collected in eight focus group discussions and forty individual face-to-face interviews. Moreover, I review local zoning regimes ('bestemmingsplannen') as the study compares two contrasting types of migrant neighbourhoods with rather different spatial morphologies and local zoning regimes, which are expected to partially shape local business prospects of entrepreneurs.

\section{9 - Outline of the dissertation}

As indicated above, this dissertation combines a number of research projects investigating potential implications of the local spatial environment on economic success of non-Western immigrants in the labour market (chapter 3) and in selfemployment (chapters 4 and 5). In this section I outline the structure of the dissertation and provide a brief summary of the various projects documented in the chapters.

Before introducing the content of the individual chapters, I start with a short note on the logic of the chapter sequencing. I chose the sequencing to be in line with the chronological development of my dissertation work. I began with an international and Dutch literature review on migration and integration to gain a clear understanding of the historical and more recent context of immigration to, and immigrants in, the Netherlands. After this, I first opted to study immigrant labour market outcomes before turning towards immigrant self-employment; as the former subject had already been studied for some time, this gave me the advantage that I could learn by comparing my results with those of prior studies. Also, as the quality and availability of Dutch data on immigrant labour market outcomes greatly exceeds the one on immigrant self-employment outcomes, this enabled me to implement highly sophisticated econometric analyses in this project that could not be matched in later research projects. Given the much younger field of entrepreneurship research, this is hardly surprising. This also explains why the aim of the two research projects on the self-employed is somewhat different than the one on labour market outcomes as they set out to explore the subject rather than to provide concise answers to questions. The sequencing choice of chapters takes this into account by first presenting the findings from quantitative methodology in chapters 3 and 4 followed by the findings from mixed research methods in chapter 5. Finally, as the dissertation bundles a number of research 
projects, this also implies that the non-Western immigrant groups studied in the various chapters differ as demanded by the distinct research designs.

Following the introduction, chapter two discusses the current socio-economic situation of immigrants in the Netherlands with reference to the peculiar immigration history and policy in the country. This situation is analysed both in absolute terms as well as relative to natives, the latter with the aim of gaining insight in the group's level of integration in society, which is commonly measured by comparing migrant scores on key outcome variables with scores of natives. The chapter is structured in five parts. Following the introduction, part two discusses the Dutch immigration history and trends in a chronological order. Part three describes the immigrant population of the Netherlands in the 21st century, both legal and (as far as data permits) illegal. Part four offers an elaborate presentation of integration-related trends of the migrant population in the country, which includes aspects relating to the geographic spread and housing of immigrants, education and language skills, employment and self-employment, and finally income, poverty and social security. Part five closes this chapter with some general remarks on the socio-economic situation and integration of the immigrant community in the Netherlands.

Chapter three examines the causal effect of residential segregation of non-Western immigrants on labour market outcomes, exploiting the random assignment of asylum seekers to municipalities in the Netherlands. In other words, I wonder about the question: Does living in high concentration non-Western migrant neighbourhoods benefit or harm immigrant labour market performance? To address this question, the study makes use of a unique natural experiment, namely the random allocation of asylum seekers to initial housing locations in the Netherlands. This natural experiment enables me to use exogenous initial housing locations as instruments for endogenous later neighbourhood concentrations, which in turn makes causal estimation of the effect of neighbourhood concentration on immigrant labour market performance possible. The combination of various administrative sources enables me to track the labour market experiences of nearly 92,000 of these immigrants over the six year period from 1999-2004. Furthermore, the large number of instruments available in the data and the wide ranges of effects of these instruments make it possible to (1) break down the overall findings to subgroups, (2) investigate nonlinearities in the link between immigrant concentration and outcomes, and (3) take a look at possible selection effects related to unobserved characteristics. The chapter is structured in six parts. Following the general introduction, part two provides a review of background literature on immigrant residential concentration and labour market performance. Part three explains the endogeneity issue relating to neighbourhood concentration 
and presents key information on asylum seekers in the Netherlands together with required background information on Dutch asylum policy to set the stage for later analysis. Part four introduces data and methodology of this study while parts five and six contain the prime findings and concluding remarks respectively.

Chapter four investigates the claim that second generation migrant entrepreneurs hold substantially better economic positions with promising future prospects compared to their parents' generation. More specifically, it offers a systematic account of the main origin groups of first and second generation migrant entrepreneurs in the Netherlands with focus on firm and firm location characteristics. It also illustrates the heterogeneity across different non-Western immigrant groups and develops hypotheses relating this to entrepreneurial success of non-Western migrant entrepreneurs in the Netherlands. The chapter is structured in six parts. Following the introduction, part two provides a general overview of migrant entrepreneurship in the Netherlands with special focus on the recent developments for the non-Western group. Part three discusses prior literature on migrant integration trajectories and entrepreneurship to develop the research hypotheses of the study. Parts four to six present the research methodology, study findings and their discussion, while part seven marks the conclusion.

Chapter five takes a closer look at the potential relationship between neighbourhood characteristics and migrant business outcomes; specifically, it investigates whether and to what extent their neighbourhood spatial environment and its regulations may shape developmental trajectories of migrant entrepreneurs. It is expected that the physical spatial neighbourhood structure and its related regulations are a major determinant of the spatial allocation pattern and developmental prospects of ethnic businesses as first and foremost commercial activities are bound by availability of suitable business space. In this regard, an important distinction emerges from the literature namely between older, pre-WWII neighbourhoods with little functional separation between residential and commercial purposes (also called mixed neighbourhoods) and the predominantly mono-functional, residential neighbourhoods built after WWII. The described functional differences between the two neighbourhood types provide a promising starting point for the analysis in this chapter to find out how the local spatial environment and its regulations may shape local business prospects of entrepreneurs. The chapter is structured in six parts. Following the introduction, part two discusses background literature of the study with the aim to identify local factors shaping business development prospects of entrepreneurs in migrant neighbourhoods, especially factors to do with the spatial environment and its regulations. Part three presents the research methodology of the study, which 
provides information on the neighbourhood selection procedure, as well as details on data collection and use. Part four discusses the neighbourhood morphology and spatial regulations of the selected pre- and post-WWII migrant neighbourhoods. Part five investigates business success of local firms in pre- and post-WWII migrant neighbourhoods. Finally, part six contains the study's conclusions.

Chapter six concludes this dissertation by discussing selective results of the various chapters in light of the basic research question (Section 6.1). Moreover, it raises a number of limitations of the dissertation and derives suggestions for future research (Section 6.2) and finishes with policy implications (Section 6.3). 


\section{Chapter 2: Migration and integration trends in the Netherlands ${ }^{4}$}

\section{1 - Introduction}

The Netherlands, a country known for its high population density and strong international orientation, can look back more than many other countries to a long and rich history of migration. The greater part of this history, systematically documented from the mid-19th century onwards, illuminates the phenomenon of out-migration from the Netherlands. However, it was not until after World War II that the focus shifted towards immigration. This tidal change was brought about by large inflows of colonial repatriates as well as rising numbers of labour migrants who entered the country for post-war reconstruction of the economy. Since then, immigration flows to the Netherlands have gained in momentum, a trend largely driven by consecutive repatriation movements from former Dutch colonies, labour migrants and their families and asylum seekers in more recent years.

Despite this long history of migration, the country has been rather reluctant to acknowledge that it had de facto become a country of 'immigration' from 1967 onwards (from this year onwards numbers of immigrants have structurally exceeded those of emigrants). It was not until the mid-1980's that the government officially recognized this fact and implemented the Minorities Policy, which was mainly related to the integration of present migrants into the Dutch society. A decade earlier in 1974 the position of the Dutch government on the phenomenon of immigration was still rather different: 'The Netherlands is not an immigration country and should not become one' (Memorandum Foreign Employees - 'Nota Buitenlandse Werknemers'). Nonetheless, starting with the implementation of the Minorities Policy, the Netherlands has set the tone in immigration and integrationrelated policy in Europe over the past decades, which has arguably enhanced immigrant socio-economic outcomes over time although difficult to measure.

This chapter discusses the current socio-economic situation of immigrants in the Netherlands with reference to the unique migration history and policy in the country. This situation is analysed both in absolute terms as well as relative to natives, the latter with the aim to gain insight in the group's level of integration in

${ }^{4}$ This chapter is based on the paper: Neubourg, C., Beckers, P. \& Hercog, M. (2008), "Burning Bridges, Building Ships - Changes in immigration in the Netherlands; trends, policies and incentives", World Bank study. 
society, which is commonly measured by comparing migrant scores on key outcome variables with scores of natives. The chapter is structured in five parts. Following the introduction, part two discusses the Dutch immigration history and trends in a chronological order. Part three describes the immigrant population of the Netherlands in the $21^{\text {st }}$ century, both legal and (as far as data permits) illegal. Part four offers an elaborate presentation of integration-related trends of the migrant population in the country, which includes aspects relating to the geographic spread and housing of immigrants, education and language skills, employment and self-employment, and finally income, poverty and social security. Part five closes this chapter with some general remarks on the socio-economic situation and integration of the immigrant community in the Netherlands.

\section{2 - Dutch immigration history and trends}

The Netherlands has a long history of migration, but it was de facto not until 1967 that the flow of immigrants systematically exceeded the flow of emigrants (see Figure 2.1). In the period before (1865 to 1967), the net migration balance of the Netherlands was negative except for some immigration peaks around the World Wars and the crisis of the 1930s (Lucassen and Penninx 1997, Roodenburg et al. 2003). Thus, the Dutch experience as an 'immigration country' roughly relates to the period of the past four decades. This section describes the major trends in immigration the country has witnessed since the end of the Second World War and explains their historical setting.

Figure 2.1: Net migration in the Netherlands $1860-2000$

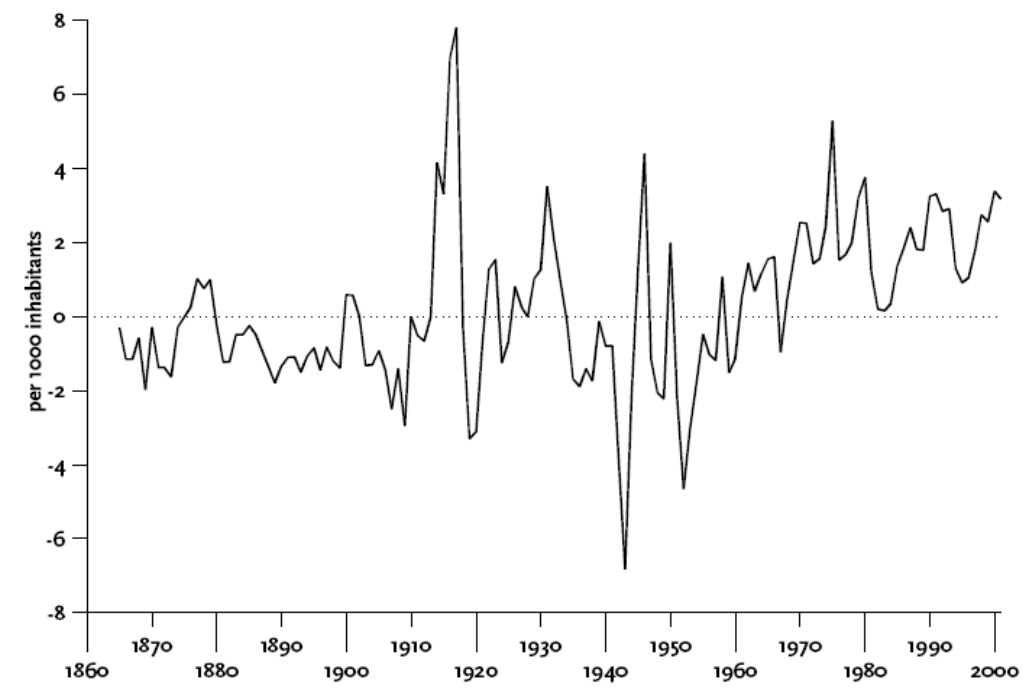

Source: Roodenburg et al. 2003 


\section{Decolonisation}

After the Second World War, migration was boosted by the decolonization process. The declaration of Indonesian independence in 1945 and an ensuing armed conflict were conducive to a large wave of immigration from the old colony. Approximately 350,000 people used the right to repatriate to the Netherlands although for many of them it was their first 'visit' to the country. Additionally, many Moluccan soldiers that served in the Dutch army, accompanied by their families, settled in the Netherlands. Further flows of immigration that came as a consequence of the past colonialism were from the overseas territories in the Caribbean. Large numbers of people from Surinam moved to the Netherlands in the 1970s in the anticipation of the colony's independence. Pending independence raised doubts for many Surinamese whether economic and political stability could be upheld. When the Dutch government in 1980 gave the Surinamese the choice to decide whether they wanted to become Surinamese or Dutch citizens, one third of Surinamese were settling in the Netherlands, choosing Dutch citizenship. The Netherlands Antilles and Aruba, the last overseas territories of the Kingdom of the Netherlands, have also been important sources of immigrants throughout the history. In the past it had been common that wealthy Antilleans came to look for better career opportunities or for education to the Netherlands. However, from the 1990s onwards, also the poorer strata of the Antillean society tried their chances in the European part of the Kingdom. This has been mainly due to the difficult and unstable economic conditions in their own part of the Kingdom.

\section{Active recruitment}

Since the 1960s, the booming economy and the active recruitment of guest-workers have led to large-scale labour immigration mainly from Mediterranean countries. Despite the anticipated temporary stay of the guest-workers and the expectation that a slowdown in economy would lead to fewer immigrants, the Netherlands was confronted with the continuing settling of newcomers even after the oil crises of 1973 and 1979. Workers from Southern Europe left the Netherlands in large numbers, but the Turkish and Moroccan migrants stayed. Many of them decided to stay in the Netherlands and were later joined by their families. Turkish and Moroccan communities grew to around ten times the size since the end of the period of active recruitment due to family migration and childbirth. While in the early seventies, there were 55,000 Turkish and Moroccan guest workers in the Netherlands and about 20,000 family members, 25 years later these ethnic groups, including the second generation, accounted for half a million people in total (Roodenburg, 2000). Instead of single men that had made up the large majority of immigrants in the sixties, the seventies witnessed the immigration of women and children. Family migration in the aftermath of the immigration of guest-workers remains the main reason for migration to the Netherlands until today (see Figure 
2.2). Immigrants from Turkey and Morocco still represent the main share of people that settle in the Netherlands on the grounds of family formation (see Figure 2.3).

Figure 2.2: Non-Western immigrants in the Netherlands by the year of arrival and migration motive (in absolute numbers)

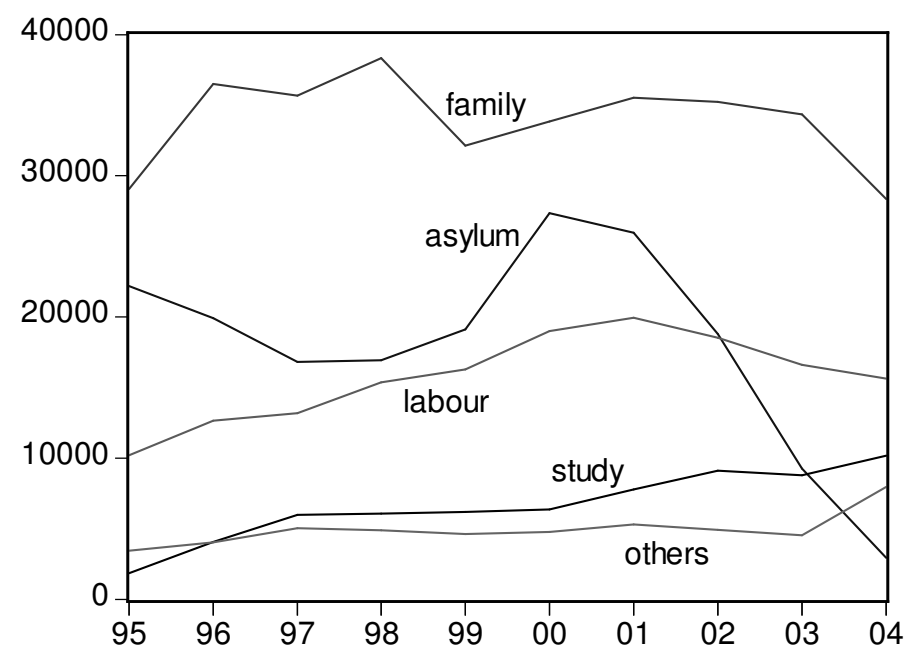

Source: SCP Jaarrapport Integratie 2007

Figure 2.3: Non-Western immigrants in the Netherlands by country of origin 19752004

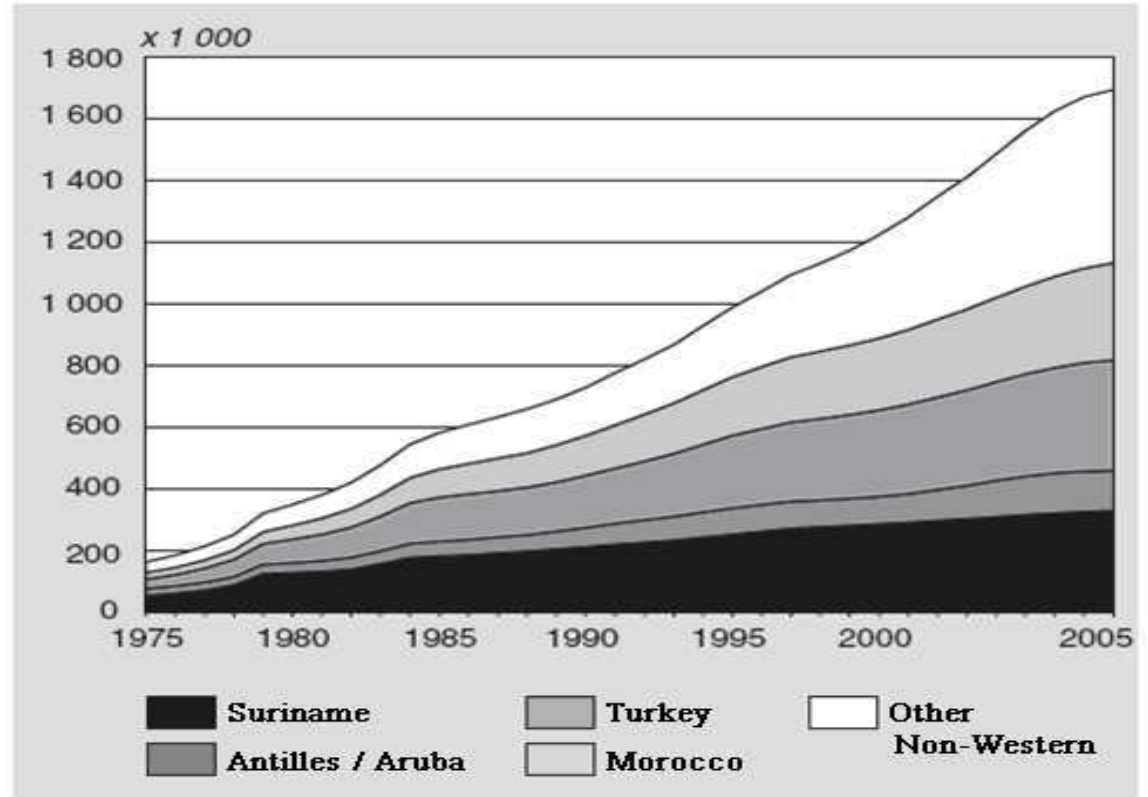

Source: Garssen et al. 2005 
$\underline{\text { Refugees and asylum seekers }}$

Next to decolonization-related migration and labour migration (consequentially leading to an increased family migration), the third relevant source of migration comes from the refugee and asylum requests. Since the 1980s, refugees have increasingly contributed to immigration in the Netherlands (see Figures 2.2 and 2.4). More than 450,000 people have requested asylum since 1985 (Roodenburg et al. 2003). The number of requests continued to be high throughout the 1990s, until 2001 when asylum regulations tightened. Consequentially the number of applications dropped significantly from 43,560 in 2000 to 9,780 in 2004 (Ersanili 2007). While in the times of heavy migration of asylum seekers to the Netherlands many applications for a refugee status were declined, in the last years more permits are granted than requested as to remedy the past inconsistencies. Subject to conditions, 27,500 persons are expected to qualify for the pardon scheme which grants a residency permit to aliens who submitted an asylum application under the old asylum regulations and still live in the Netherlands.

Figure 2.4: Asylum claims and permits (1975-2005)

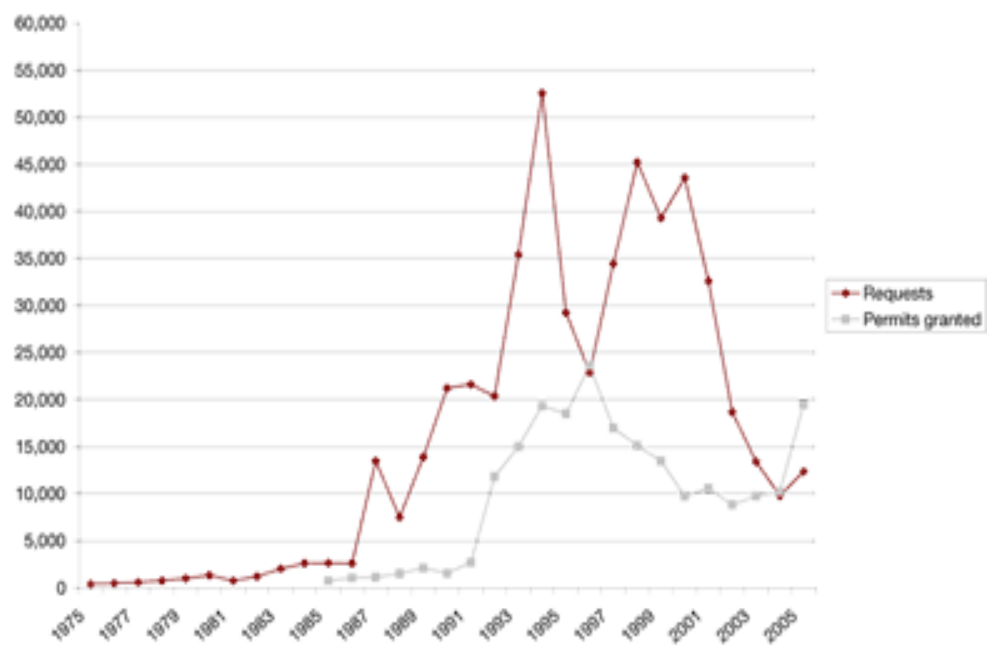

Source: Ersanili 2007

\section{New EU member states}

In recent years, an upsurge is noticeable in migration from the EU's new member states. When ten countries joined the European Union in May 2004, the Netherlands entered into a transition period, meaning that workers from eight Central and Eastern European countries (Malta and Cyprus were exempt from these regulations) were treated under a preferential regime, but still needed a work permit. It is estimated that over 100,000 people from the new member states that 
joined the European Union in May 2004 are currently employed in the Netherlands. This is about 1.5 per cent of the Dutch labour force. These labour migrants are partly in paid employment and partly self-employed. The vast majority, about 80 per cent, comes from Poland (Ministry of Social Affairs and Employment 2007). Since May 2007, workers from these countries are allowed to work in the Netherlands without any restrictions, which is visible in the slight increase in the number of labour migrants from Poland (see Figure 2.5). With the latest enlargement of the EU in January 2007, an increase in migration is noticeable from Romania and Bulgaria compared to previous years (see Figure 2.5). Absolute numbers of migrants from these two countries stay rather limited, which is among other reasons related to the fact that Romanian and Bulgarian employees still need a work permit to work in the Netherlands (comparable to the Polish and others between 2004 and 2007).

Figure 2.5: Immigration in the Netherlands: Non-Western and from Poland, Bulgaria and Romania 1995 - 2007

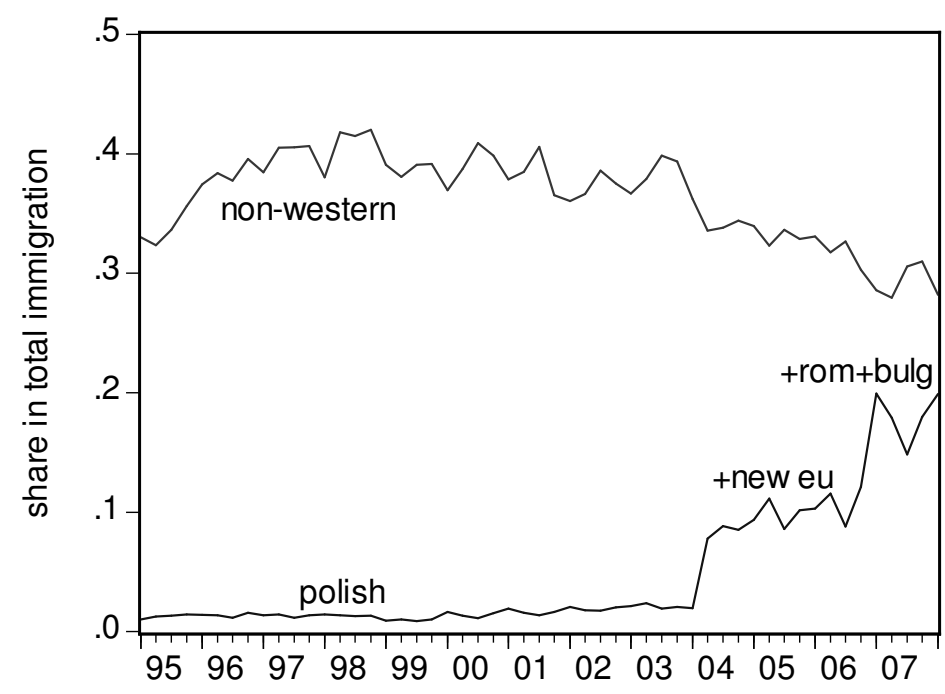

Source: Ministry of Social Affairs and Employment 2007

2.3 - The immigrant population in the $21^{\text {st }}$ century

As of 1 January 2007, the population of the Netherlands surmounted to 16.358 million people of which 80 per cent originated from the Netherlands and 20 per cent from abroad. Nine per cent of the immigrants came from Western countries ${ }^{5}$,

${ }^{5}$ See footnote 2 . 
predominantly from the neighbouring countries Germany, Belgium, and other EU countries, and 11 per cent (1.739 million people) from non-Western countries. Not disregarding the importance that Western migrants have played in the development of the country, policy interest has generally been directed at the nonWestern group for two reasons. First, while the group of Western migrants has remained relatively constant in recent history, the non-Western population has risen tremendously in numbers over the past decades. Second, unlike the Western group, non-Western migrants have encountered many difficulties in gaining a foothold in Dutch society. As a consequence policy and research have been directed primarily at this group of migrants.

Two-thirds of the latter group of migrants is from four prime source countries: Turkey $(368,600$ persons, $21 \%$ of non-Western migrants), Morocco $(329,500$ persons, $19 \%)$, Suriname (333,500 persons, $19 \%)$ and The Dutch Antilles/Aruba $(130,000$ persons, $7 \%)$. This share has decreased over the past decade from threequarters in the mid-90s with recent migration waves arriving as asylum seekers from countries as Afghanistan. Table 2.1 below shows the population composition of the Netherlands as of beginning 2007 including both absolute and relative figures of the immigrant population. A further distinction is made between first and second generation migrants. While the first generation was born abroad, the second generation includes individuals of whom at least one parent was born outside the country. The share of second generation migrants varies to a great extent across migrant groups reflecting underlying differences in their migration histories.

Table 2.1: Population composition of the Netherlands per country of origin, 1 January 2007

\begin{tabular}{llll}
\hline \hline & $\begin{array}{l}\text { persons } \\
\times 1000\end{array}$ & $\begin{array}{l}\text { share in total pop. } \\
\%\end{array}$ & $\begin{array}{l}\text { share second generation } \\
\%\end{array}$ \\
\hline Turkey & 368.6 & 2.3 & 47.1 \\
Morocco & 329.5 & 2.0 & 49.0 \\
Suriname & 333.5 & 2.0 & 44.2 \\
Antilles & 130.0 & 0.8 & 39.3 \\
Iraq & 43.9 & 0.3 & 20.9 \\
Afghanistan & 37.2 & 0.2 & 15.8 \\
Iran & 29.0 & 0.2 & 18.8 \\
Somalia & 18.9 & 0.1 & 31.5 \\
total non-Western & $1,738.6$ & 10.6 & 41.6 \\
natives & $13,187.6$ & 80.6 & \\
total population & $\mathbf{1 6 , 3 5 8 . 0}$ & & \\
\hline \hline
\end{tabular}

Source: CBS Population Statistics, SCP Jaarrapport Integratie 2007, 30 
The population of non-Western immigrants is on average considerably younger than the native Dutch population and thus will be less affected by aging in the coming decades. While the average age of natives in 2005 was 40 years, the average for the non-Western population was merely 28 . At the same time the non-Western population counted less than three per cent of individuals aged above 65 comparing to 15 per cent of the natives being older than 65. As shown in Figure 2.6 , this young age composition of the non-Western population will consequently have an important effect in countering the population aging problem faced by Dutch society in the coming decades (SCP Jaarrapport Integratie 2007, SCP Facts and Figures of the Netherlands 2008).

Figure 2.6: Age composition of the Netherlands per country of origin, 1 January 2007 (in percentages)

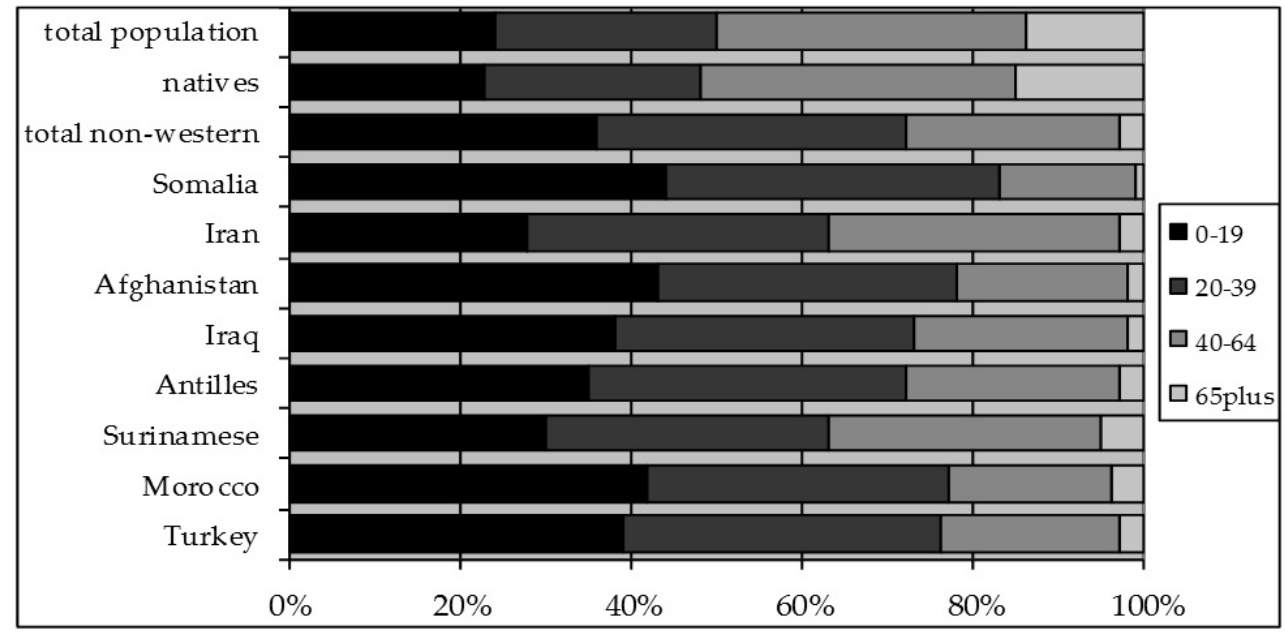

Source: CBS Population Statistics, SCP Jaarrapport Integratie 2007, 31

Statistically 'immigrants' can be defined in various ways and estimates of the share of immigrants in the total population largely depend on these definitions. Tables 2.2, 2.3 and 2.4 provide the figures for three definitions: the 'allochtoon' population (being defined as all persons born outside the Netherlands or with at least one parent born outside the country), the population born abroad, and people without Dutch citizenship. Table 2.2 reveals the discrepancy between the total immigrant population and the first generation immigrant population when divided into Western and non-Western 'allochtonen'. In the total population, non-Western and Western 'allochtonen' account for near equal shares: non-Western immigrants represent $54 \%$ of the total number of immigrants. However, non-Western immigrants count for over $63 \%$ of the first-generation immigrant population. This distinction is important, both demographically and culturally. It reveals that the non-Western immigration has been on the rise more recently, and it indicates that 
the Western 'allochtonen' have been in the Netherlands longer and are therefore probably also better integrated.

The comparison of the figures in Tables 2.2 and 2.3 illustrates an additional feature of the immigrant population in the Netherlands. The immigrants of Indonesian origin are the most numerous (Table 2.2) (just under a 390,000 people). Yet, Indonesia does not figure among the top ten foreign nationals in Table 2.3. This implies that most immigrants from Indonesian descent became Dutch citizens, a privilege that many from the ex-colonies were granted. That did, however not happen to immigrants from other origins. Few of the Turks, for example, that are counted as 'allochtoon' (again meaning being foreign born or having at least a parents that is foreign born) became Dutch citizens as can be concluded from the comparison between Table 2.2 and 2.3.

In addition to populations arriving from former colonies and guest-worker recruitment countries, there are those arriving from six fellow Western European countries: Belgium, France, Germany, Italy, Spain, and the United Kingdom. Such migration has been made easier with the open border policies of the European Union. An increase in migration from other European countries to the Netherlands is explained mainly by migration of Poles and people coming from former Soviet republics. The Polish arrival is rather recent, spiked by the large emigration that followed as many Polish left for Western Europe and elsewhere in search of work. The increase of (former) Yugoslavian immigrants is also notable. Immigrants from the former Yugoslavia republics arrived in the Netherlands generally seeking refuge from the wars that ravaged that region during the 1990s. Other major refugee communities in the Netherlands are from Afghanistan, Iraq, Iran and Somalia. 
Table 2.2: 'Allochtonen' in the Netherlands by country of origin in 2007

\begin{tabular}{|l|r|r|}
\hline Country of origin & \multicolumn{1}{c|}{ Total } & \multicolumn{1}{|c|}{$\mathbf{1}^{\text {st }}$ generation } \\
\hline 1. Indonesia & 389,940 & 126,048 \\
\hline 2. Germany & 381,186 & 101,221 \\
\hline 3. Turkey & 368,600 & 196,113 \\
\hline 4. Surinam & 333,504 & 186,025 \\
\hline 5. Morocco & 329,493 & 167,893 \\
\hline 6. Dutch Antilles \& Aruba & 129,965 & 78,907 \\
\hline 7. Belgium & 112,224 & 36,126 \\
\hline 8. (Former) Yugoslavia & 76,465 & 52,857 \\
\hline 9. UK & 75,686 & 42,604 \\
\hline 10. Poland & 51,339 & 34,831 \\
\hline Total ‘allochtonen' & $\mathbf{3 , 1 7 0 , 4 0 6}$ & $\mathbf{1 , 6 0 1 , 1 9 4}$ \\
\hline Total non-Western ‘allochtonen' & $\mathbf{1 , 7 3 8 , 4 5 2}$ & $\mathbf{1 , 0 1 4 , 4 7 6}$ \\
\hline
\end{tabular}

Source: CBS in Ersanili 2007

Table 2.3: Foreign nationals in the Netherlands by citizenship in 2006

\begin{tabular}{|l|r|r|}
\hline \multicolumn{1}{|c|}{ Citizenship } & Including dual nationals & \multicolumn{1}{c|}{ Excluding dual nationals } \\
\hline 1. Turkish & 359,143 & 98,920 \\
\hline 2. Moroccan & 313,921 & 86,229 \\
\hline 3. German & 105,601 & 58,503 \\
\hline 4. British & 84,774 & 41,508 \\
\hline 5. Belgian & 56,281 & 25,994 \\
\hline 6. Italian & 37,935 & 18,502 \\
\hline 7. Polish & 31,787 & 15,202 \\
\hline 8. French & 30,463 & 14,730 \\
\hline 9. (Former) Yugoslavian & 28,027 & 5,306 \\
\hline 10. Spanish & 27,795 & 16,851 \\
\hline Total & $\mathbf{1 , 7 0 4 , 8 4 6}$ & $\mathbf{6 9 1 , 3 5 7}$ \\
\hline
\end{tabular}

Source: CBS in Ersanili 2007 
Table 2.4: Immigration in the Netherlands by region of birth, 2003-2007

\begin{tabular}{|l|l|r|r|r|r|r|}
\hline & 2003 & 2004 & 2005 & 2006 & 2007 \\
\hline $\begin{array}{l}\text { Region } \\
\text { of } \\
\text { birth }\end{array}$ & Total & 104514 & 94019 & 92297 & 101150 & 116819 \\
\cline { 2 - 7 } & $\begin{array}{l}\text { non-Western } \\
\text { total }\end{array}$ & 48834 & 37313 & 34112 & 34492 & 36822 \\
\cline { 2 - 7 } & Western total & 55680 & 56706 & 58185 & 66658 & 79997 \\
\cline { 2 - 7 } & Africa total & 14939 & 10759 & 9299 & 8702 & 9088 \\
\cline { 2 - 7 } & America total & 15537 & 12964 & 12174 & 12866 & 13584 \\
\cline { 2 - 7 } & Asia total & 18039 & 14849 & 15130 & 16342 & 18261 \\
\cline { 2 - 7 } & Europe total & 54892 & 54461 & 54652 & 62106 & 74644 \\
\cline { 2 - 7 } & Oceania total & 1107 & 986 & 1042 & 1134 & 1242 \\
\hline
\end{tabular}

Source: CBS Statline 2009: http://statline.cbs.nl

Illegal migrants in the Netherlands

While little information is generally available on illegal migrants in the Netherlands, in the following section we present a number of estimates that aim to provide a first indication of the nature and extent of the phenomenon in the country. According to estimates of Heijden et al. (2006) for the period of April 2005-2006, the number of illegal residents in the country was situated around 129,000 people including 88,000 illegal residents of non-European origin and 41,000 illegal residents from European countries. The authors further estimate that this figure includes around 8,500 former asylum seekers.

Another indication on the illegal population is provided by Engbersen et al. (2002) based on data of detentions for the period of 1997-2000. Their dataset includes a total of 47,000 illegal residents that were brought in contact with the police due to criminal and non-criminal acts. The data are most probably heavily biased, but are presented anyway since they provide information not available from other sources. The estimates should, however, be handled with great care. The Engbersen et al. figures suggest a slight reduction in illegal residents, which is remarkable given the intensification of police patrolling over the period. Is it further not clear as to whether this increased police activity may have scared off illegal residents or whether the reasons are to be found elsewhere? In the period from 1997-2000, 8.7 per cent of the illegal residents were caught by police more than once, which suggests that these individuals have either remained within the country on a longterm basis or have returned to the country after deportation.

As presented in Table 2.5, most illegal residents were men (80\%) and young adults of age 20-40. As both of these indications remain constant over the period, this may suggest that fluctuation in illegal inflow is limited. The population of illegal 
residents originated from an increasingly diverse set of countries with big groups from Eastern Europe, followed by North Africa (Morocco, Algeria), Asia (China) and Turkey. The group of Western-Europeans is a unique group as they are not illegal residents as such but rather criminals due to drug trafficking. It is difficult to estimate the share of former asylum seekers among the illegal population. Nonetheless, it is observed that many of the origin countries of the illegal residents are also prime countries of origin of asylum seekers. Illegal employment is common especially in the hotel and catering, personal services, farming and cleaning sectors where labour inspections are relatively more difficult. The illegal population is estimated to be unequally spread throughout the country with high concentration in the four big cities of Amsterdam, Rotterdam, The Hague, Utrecht, as well as in the regions with high demand for low-skilled workers in the farming and horticulture industry.

Table 2.5: Characteristics of detained illegal migrants per year (in percentages), person level data, the Netherlands 1997 - 2000

\begin{tabular}{llllll}
\hline \hline & 1997 & 1998 & 1999 & 2000 & $1997-2000$ \\
\hline gender & & & & & \\
men & 79.2 & 78.9 & 78.7 & 79.9 & 79.2 \\
women & 20.8 & 21.1 & 21.3 & 20.1 & 20.8 \\
$\mathrm{~N}=$ & 13,546 & 11,464 & 11,162 & 11,461 & 47,633 \\
\hline age & & & & & \\
0-20 years & 14.5 & 14.8 & 15.2 & 14.2 & 14.7 \\
21-30 years & 49.7 & 48.8 & 48.3 & 49.9 & 49.2 \\
31-40 years & 26.7 & 26.2 & 26.8 & 26.0 & 26.4 \\
41-50 years & 7.0 & 7.6 & 7.7 & 7.5 & 7.4 \\
51 plus & 2.1 & 2.5 & 2.1 & 2.4 & 2.3 \\
mean age (years) & 28.8 & 29.0 & 28.9 & 29.0 & 28.9 \\
N= & 13,608 & 11,475 & 11,173 & 11,481 & 47,737 \\
\hline nationality & & & & & \\
Turkey & 8.8 & 8.5 & 6.8 & 8.2 & 8.1 \\
$\quad$ North Africa & 15.9 & 14.8 & 13.3 & 12.0 & 14.1 \\
Other Africa & 11.8 & 13.0 & 14.0 & 15.6 & 13.5 \\
Suriname & 2.7 & 2.4 & 2.2 & 1.8 & 2.3 \\
Western Europe & 14.2 & 12.8 & 12.4 & 10.6 & 12.6 \\
Eastern Europe & 25.8 & 28.4 & 30.7 & 32.3 & 29.1 \\
Asia & 14.0 & 13.5 & 14.0 & 13.8 & 13.8 \\
South/Middle America & 6.2 & 5.8 & 5.9 & 5.1 & 5.8 \\
$\quad$ North America/Oceanea & 0.5 & 0.7 & 0.7 & 0.6 & 0.6 \\
N= & 13,434 & 11,336 & 10,986 & 11,330 & 47,086 \\
\hline \hline
\end{tabular}

Source: Engbersen et al. 2002, 32 


\section{4 - Trends in integration of immigrants}

The socio-economic position of the non-Western migrant population is generally a lot worse than that of the indigenous population on whatever indicator is chosen to describe the differences. Since the recognition, however, that migrants are becoming permanent residents in the country in the mid-1970s, the situation has gradually improved. This section discusses the integration outcomes of migrants in the Netherlands in recent years, which have a multitude of facets ranging from geographic spread and housing circumstances, over education and language skills, employment and self-employment, to income, poverty and social security aspects.

Geographic spread and housing of immigrants in the Netherlands

Non-Western migrants (definition see previous section) are spread unequally across the country with a traditionally high share being concentrated in the Western part of the Netherlands, especially in the population-wise largest cities of Amsterdam, Rotterdam, The Hague and Utrecht. As shown in Table 2.6, one out of three residents of Amsterdam, Rotterdam, The Hague and Utrecht is of nonWestern origin, while this share is even higher among the younger (about 50 per cent in Amsterdam and Rotterdam). The concentration of immigrants in the four major cities further differs across the ethnic groups. It is particularly high for the Moroccans (46.9\%) and the Surinamese $(52.7 \%)$ as compared to the mean nonWestern concentration in this area (SCP Jaarrapport Integratie 2007).

Table 2.6: Distribution of ethnic minorities across national regions and proportion living in the four major cities in the Netherlands, 2006 (in percentages)

\begin{tabular}{|l|c|c|c|c|c|}
\hline & north & east & south & west & $\begin{array}{c}\text { 4 major } \\
\text { cities }\end{array}$ \\
\hline Turks & 2.1 & 21.2 & 16.3 & 60.3 & 35.4 \\
\hline Moroccans & 1.5 & 9.9 & 16.4 & 72.2 & 46.9 \\
\hline Surinamese & 3.2 & 11.9 & 6.5 & 78.3 & 52.7 \\
\hline Antilleans & 5.9 & 14.3 & 13.7 & 66.1 & 33.9 \\
\hline $\begin{array}{l}\text { Other non- } \\
\text { Western }\end{array}$ & 6.5 & 16.9 & 14.6 & 62.0 & 30.9 \\
\hline $\begin{array}{l}\text { Total non- } \\
\text { Western }\end{array}$ & 4.0 & 15.3 & 13.7 & 67.0 & 39.3 \\
\hline $\begin{array}{l}\text { Total Dutch } \\
\text { population }\end{array}$ & 10.4 & 21.2 & 21.7 & 46.7 & 12.8 \\
\hline
\end{tabular}

Source: CBS Population Statistics 2004, SCP Facts and Figures of the Netherlands 2008, 15

The geographic concentration of non-Western immigrants has increased in the period from 2000 to 2006 as shown in Table 2.7 below. While in the period the number of municipalities with below $5 \%$ non-Western concentration has fallen somewhat, it is striking that the number of municipalities with concentrations 
between 10 and $25 \%$ has increased from 36 to 52 . Furthermore, next to the traditional migrant cities of Amsterdam, Rotterdam and The Hague, the somewhat less renowned city of Almere calls for attention as its concentration share of nonWestern population (26\%) has passed the $25 \%$ threshold and thus ranks next to the top three cities. The described trend of increasing concentration becomes even more visible when considering the postal code areas ${ }^{6}$. While concentration is increasing throughout the country, the increase seems to be relatively larger in the already highly concentrated areas of the top three cities of Amsterdam, Rotterdam and The Hague. The trend can in part be explained by the residential preferences of migrants to cluster as well as the residential flight of the 'white population' from these neighbourhoods coupled with the lower fertility rates of the latter population group compared to the fertility rate of non-Western (CBS Statline, SCP Jaarrapport Integratie 2007).

Table 2.7: Distribution of municipalities ${ }^{7}$ and postal code areas per ethnic composition and ethnic concentration category in the Netherlands, 1 January 2000, 1 January 2007 and 1 January $2006^{8}$ respectively (absolute numbers)

\begin{tabular}{lllllll}
\hline \hline$\%$ non-western & $0 \%-5 \%$ & $5 \%-10 \%$ & $10 \%-25 \%$ & $25 \%-50 \%$ & $50 \%-100 \%$ & total \\
\hline municipalities 1/1/2000 & 408 & 90 & 36 & 3 & 0 & 537 \\
municipalities 1/1/2007 & 300 & 87 & 52 & 4 & 0 & 443 \\
postal code areas 1/1/2000 & 2908 & 537 & 378 & 107 & 28 & 3958 \\
postal code areas 1/1/2006 & 2760 & 571 & 469 & 156 & 44 & 4000 \\
\hline \hline
\end{tabular}

Source: CBS Statline, SCP Jaarrapport Integratie 2007, 193

Yet another interesting trend is the residential relocation of the non-Western population from city centres to suburbs and peri-urban areas in the main cities of the country. This pattern is clearly visible in the top three cities of Amsterdam, Rotterdam, and The Hague, where the growth of the non-Western population in the city surroundings has measured $48 \%, 25 \%$ and $33 \%$ respectively from $2001-$ 2007 , compared to $9 \%, 10 \%$, and $20 \%$ respectively for the city centres. This pattern may partially be explained by the increasing housing costs in these areas driving out non-Western low income earners on the one hand; on the other hand, the shifts are also the result of a series of urban renewal projects that have created lower cost housing alternatives just outside the big cities (peri-urban). While one of the aims of urban renewal projects since the 90 's was to reduce the degree of non-Western concentration, it is unclear as to whether this goal was accomplished overall as new ethnic neighbourhoods were created in the city surroundings.

${ }^{6}$ Postal code areas in the Netherlands define very small areas often not more than a street or a small number of streets. Concentration is thus measured as the percentage of non-Western 'allochtoon' in the total population in the specific area.

74 digit postal code areas

${ }^{8}$ Data from 2007 on postal code level are unavailable at date of publication of the corresponding paper. 
With the introduction of the ethnic minority policy in the $80^{\prime}$ s, regular policy attention is given to the housing situation of ethnic minorities. Ethnic concentration is generally viewed as problematic as it is perceived to hamper socio-cultural and economic integration in Dutch society and result in the geographic concentration of disadvantaged individuals and poverty (SCP Jaarrapport Integratie 2007). As presented in Table 2.8, housing prices in the top four cities differ to a great extent across high and low concentration neighbourhoods. For the sake of comparison, we distinguish between 'Caucasian', 'mixed', and 'concentration' neighbourhoods and compare the housing situation across these neighbourhood typologies. ${ }^{9}$ While the mean estimated housing price per square metre of an apartment built till 1996 in the 'Caucasian' neighbourhoods is $€ 2,440$, the corresponding selling price in 'concentration' neighbourhoods is about one-quarter less $(€ 1,850)$. The difference between 'white' neighbourhoods and 'concentration' neighbourhoods is somewhat less striking for apartments built after 1996, but square metre prices in the latter neighbourhoods are still about out one-eighth lower $(€ 2,560$ and $€ 2,252$ per apartment square metre in 'white' and 'concentration' neighbourhoods respectively).

Apartment size differs greatly across the neighbourhood typologies. In 'white' neighbourhoods average apartment size is around 140 square meters (136 and 147 square metres for apartments built before 1996 and after 1996 respectively), but in 'concentration' neighbourhoods average apartment size is more than one-quarter less than this (95 and 110 square metres for apartments built before 1996 and after 1996 respectively). As seen in Table 2.9, this leaves the non-Western population with considerably less living space than is the case for natives, especially considering that mean household size of the former group tends to be larger. These differences come out more clearly when comparing average square meters of rental space per household member. Turkish and Moroccans have by far the least rental space though their situation improves somewhat over the period 2002-2006. Except for the Antillean group, mean square metres per household member increases in the period 2002-2006 both for natives and non-Western migrants.

The housing supply in 'concentration' neighbourhoods consists to two-thirds of rental apartments next to flats and smaller apartments for sale. In the main three cities the share of rental properties is even higher. In 'white' neighbourhoods the

\footnotetext{
${ }^{9}$ Defined by the Dutch Ministry of VROM, where 'white' neighbourhoods have non-Western concentrations below $10 \%$ of total population and concentrations at least one-third below the mean of the respective municipalities. 'Concentration' neighbourhoods are defined as neighbourhoods with more than $10 \%$ non-Western concentration and at least one-third higher than the mean of the respective municipality. 'Mixed' neighbourhoods are in between 'white' and 'concentration' ones.
} 
situation is rather different as generally two-thirds of the housing market consists of apartments for sale. The low supply of housing for sale in the 'concentration' neighbourhoods and lower mean income levels of non-Western groups of migrants likely explain the low home ownership share among non-Western immigrants (around 25 per cent as compared to 55 per cent for natives). Nonetheless, with the exception of the Antillean group, the rate of home ownership increased significantly in the period 1998 to 2006, which indicates that ethnic minorities are slowly gaining a foothold on the housing market over time (SCP Facts and Figures on the Netherlands 2007). Finally, as shown in Figure 2.7, the limitations in the housing market in 'concentration' neighbourhoods are also likely to explain why around two-thirds of non-Western migrants resides in flats rather than alternative forms of housing (detached/semi-detached housing accounts for $5 \%$ ). This compares to a native share of merely 30 per cent living in flats, while another 30 per cent of the native population actually lives in detached or semi-detached houses.

Table 2.8: Estimate apartment selling prices in white ${ }^{1}$, mixed, and concentration neighbourhoods of the largest four cities in the Netherlands, 2006

\begin{tabular}{llll}
\hline \hline & & estimate selling & $\begin{array}{l}\text { estimate selling } \\
\text { price per m2 }\end{array}$ \\
\hline $\begin{array}{l}\text { build before 1996 }(€) \\
\text { white neighbourhood }\end{array}$ & 136 & & \\
mixed neighbourhood & 109 & 387,000 & 2440 \\
concentrated neighbourhood & 95 & 262,000 & 2360 \\
build 1996-2006 & 186,000 & 1850 \\
white neighbourhood & 147 & & \\
mixed neighbourhood & 129 & 419,000 & 2560 \\
concentrated neighbourhood & 110 & 306,000 & 2360 \\
\hline \hline
\end{tabular}

${ }^{1}$ The definition of neighbourhoods as 'white' (mainly inhabited by Caucasian residents), 'concentrated' (mainly inhabited by non-Caucasian migrant families) and mixed is taken from the official Dutch statistics.

Notes: Flat selling prices estimated by respondents. Flats valued at above one million $€$ are excluded in calculations.

Source: VROM WoON 2006, SCP Jaarrapport Integratie 2007, 205

Non-Western migrants are generally speaking less satisfied with their housing situation than natives; this seems hardly surprising given their limited housing space. It is furthermore more common for these groups to share housing with relatives or friends to lower the costs per person. Neighbourhood locations of nonWestern migrants are often either chosen in proximity to relatives or friends and/or 
are subject to economic affordability and availability of for instance social housing, which may limit the choices of low income earners considerably (SCP Jaarrapport Integratie 2007).

Table 2.9: Average home sites in square meters and average number of square meters per household member the Netherlands, by ethnic group, 2002 and 2006

\begin{tabular}{|c|c|c|c|c|}
\hline & \multicolumn{2}{|c|}{ home size in square meters } & \multicolumn{2}{|c|}{$\begin{array}{l}\text { square meters per } \\
\text { household member }\end{array}$} \\
\hline & 2002 & 2006 & 2002 & 2006 \\
\hline natives & 124 & 128 & 65 & 68 \\
\hline Surinamese & 89 & 89 & 49 & 50 \\
\hline Antilleans & 86 & 82 & 51 & 48 \\
\hline Turkish & 88 & 92 & 36 & 39 \\
\hline Moroccan & 81 & 85 & 33 & 38 \\
\hline other non-Western & 87 & 89 & 44 & 47 \\
\hline
\end{tabular}

Figure 2.7: Household characteristics per ethnic group, the Netherlands, 2006

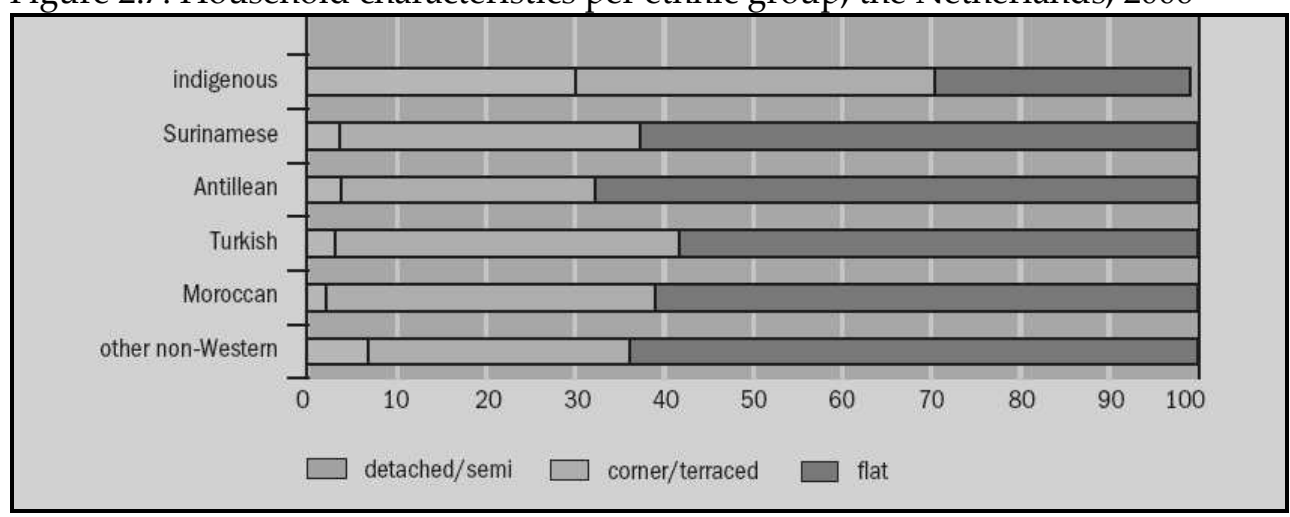

Source: VROM (WoOn'06), SCP Facts and Figures on the Netherlands 2007, 100

Education and language skills

Non-Western immigrants of working age tend to have lower levels of education than natives as shown in Table 2.10 below. This is especially the case for Turkish and Moroccans and to a lesser degree for Surinamese, Antilleans and other nonWestern foreigners. More than half of the Turkish and Moroccan working populations in 1996 have finished only primary education, comparing to 12 per cent for the native, and around 20-25 per cent for the other non-Western groups. At the same time only four per cent of the Turkish and Moroccan working populations have completed higher education. This compares to 20 per cent for the native and somewhat less for the other non-Western population. Over the period from 1996 to 2005, all non-Western migrant groups have realized considerable 
gains in terms of educational achievements both in absolute terms as well as compared to their native counterparts. The educational advancement of the Turkish and Moroccan populations has been particularly impressive as over the nine year period: the share of individuals holding primary education only has nearly halved while the share for higher education doubled. Nonetheless, while the gap in educational attainment of ethnic minorities is narrowing, this population groups will remain disadvantaged for time to come.

Table 2.10: Population aged 15-64 the Netherlands, by origin and education level, 1996-2005 (in percentages)

\begin{tabular}{|c|c|c|c|c|c|c|}
\hline & natives & Turks & Moroccans & Surinamese & Antilleans & $\begin{array}{c}\text { Other } \\
\text { non- } \\
\text { Western }\end{array}$ \\
\hline \multicolumn{7}{|l|}{1996} \\
\hline Primary & 12 & 56 & 57 & 26 & 19 & 24 \\
\hline Vbo/mavo & 27 & 24 & 23 & 27 & 34 & 25 \\
\hline Havo/vwo/mbo & 42 & 16 & 16 & 33 & 32 & 31 \\
\hline Hbo/wo & 20 & 4 & 4 & 13 & 16 & 20 \\
\hline Total & 100 & 100 & 100 & 100 & 100 & 100 \\
\hline \multicolumn{7}{|l|}{2005} \\
\hline Primary & 8 & 31 & 34 & 14 & 11 & 16 \\
\hline Vbo/mavo & 25 & 25 & 26 & 29 & 25 & 20 \\
\hline Havo/vwo/mbo & 41 & 36 & 33 & 43 & 45 & 43 \\
\hline Hbo/wo & 26 & 8 & 7 & 15 & 19 & 21 \\
\hline Total & 100 & 100 & 100 & 100 & 100 & 100 \\
\hline
\end{tabular}

Source: CBS Statline 2007, SCP Facts and Figures on the Netherlands, 38

Much of the educational advance of non-Western migrants can be ascribed to the educational achievements of the second generation as demonstrated in Figure 2.8. All ethnic groups of the second generation show similar patterns whereby the share of basic education has fallen sharply to under the 10 per cent level and higher educational obtainment has doubled for all groups.

Early school dropout remains a problem among non-Western groups of society. As shown in Figure 2.9, all foreign ethnic groups have dropout shares between 16 to 19 per cent comparing to around 12 per cent for natives. Somewhat surprising seem to be the relatively high shares among the Surinamese and Antillean groups that tend to do better than other ethnic groups in terms of educational achievements as outlined before. It seems thus that the benefits of the education system are not spread equally within these groups. 
Figure 2.8: Educational level of population aged 15-64 in the Netherlands, per ethnic group and generation, 2006 (in per cent)

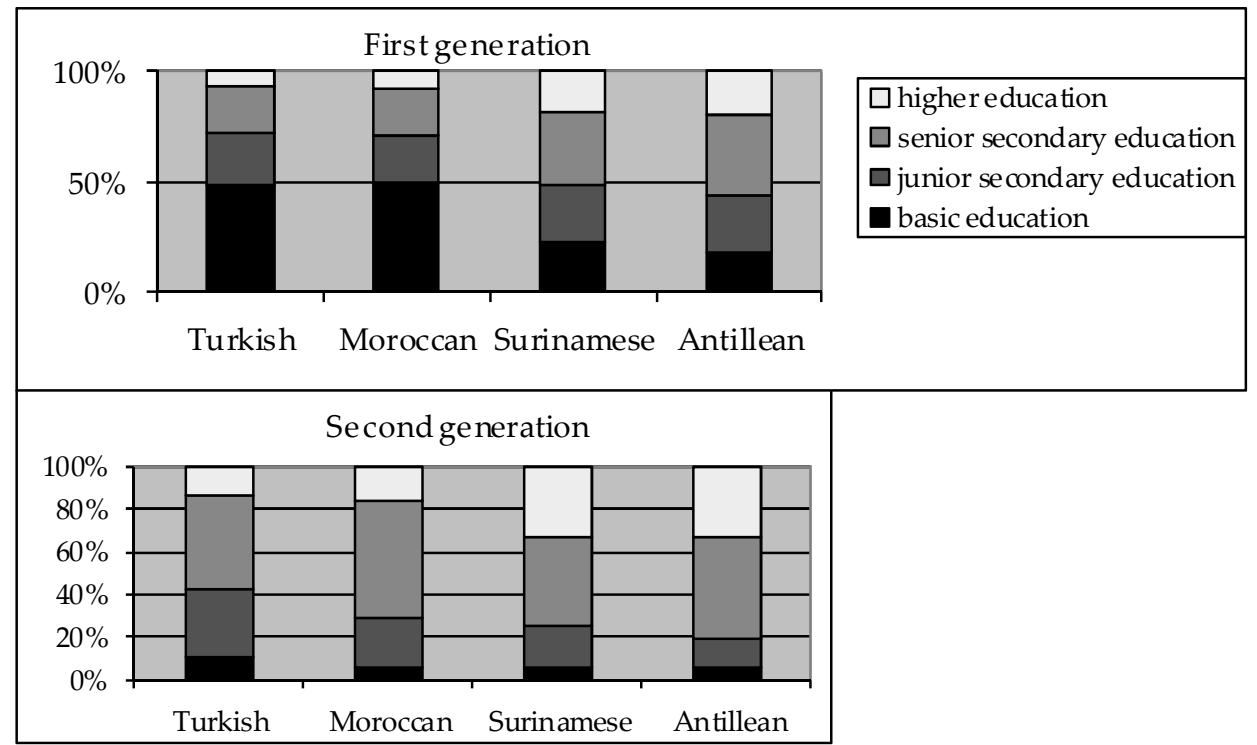

Source: SCP SIM 2006, SCP Jaarrapport Integratie 2007, 77

Figure 2.9: Early school dropouts during secondary education in the Netherlands per ethnic group, 2005 (in per cent of total school enrolment)

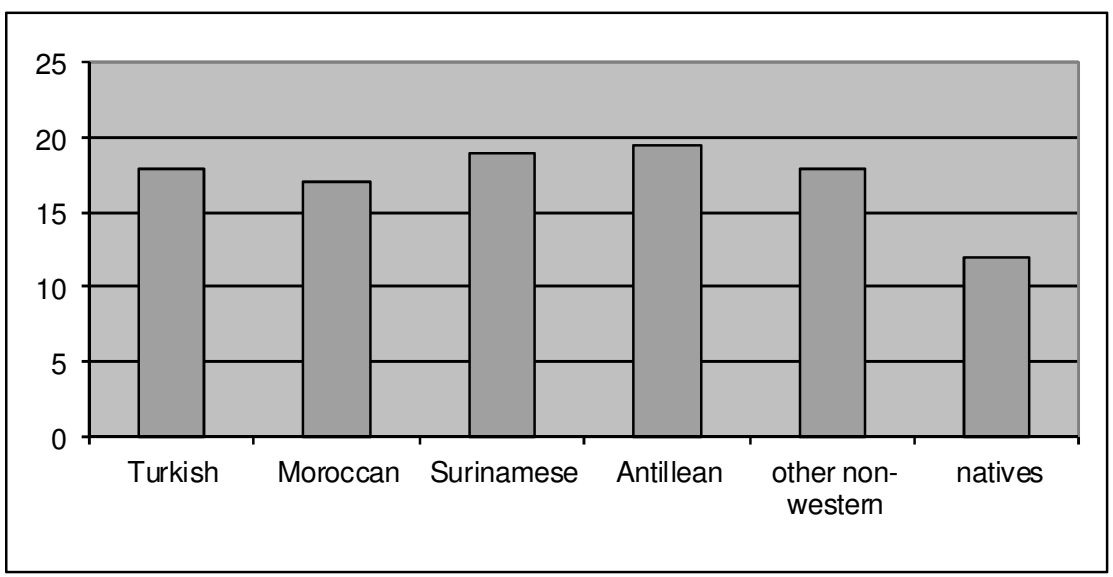

Notes: Including early school leavers older than 22 years of age.

Source: CBS Statline, SCP Jaarrapport Integratie 2007, 119

Dutch language skills are a general problem across non-Western immigrant groups, especially so for the Turkish and Moroccans as can be seen in Table 2.11. On the scale from 1 (bad) to 3 (good), based on an average score for Dutch speaking, reading and writing skills, the Turkish and Moroccan groups tend to perform considerably worse (2.2 and 2.4 respectively) than the Surinamese and 
Antillean ones (2.9 and 2.8 respectively). As can be expected given common colonial roots, Surinamese and Antilleans have near native command of the Dutch language irrespective of gender, age, or generation. For Turkish and Moroccan migrants these characteristics determine to a great extent the Dutch language command of the individuals. For these two groups, men tend to have slightly better language skills than women, younger and second generation migrants better skills than older and first generation ones respectively. Finally, as can be expected for all four ethnic groups, language skills increase with the level of the individual's education.

Table 2.11: Dutch language skills per ethnic groups and relevant characteristics the Netherlands, 2006 (average scores) ${ }^{10}$

\begin{tabular}{lllll}
\hline \hline & Turkish & Moroccan & Surinamese & Antillean \\
\hline total & $\mathbf{2 . 2}$ & $\mathbf{2 . 4}$ & $\mathbf{2 . 9}$ & $\mathbf{2 . 8}$ \\
men & 2.3 & 2.5 & 2.9 & 2.8 \\
women & 2.1 & 2.3 & 2.9 & 2.8 \\
\hline age 15-24 & 2.8 & 2.9 & 3.0 & 2.9 \\
age 25-44 & 2.2 & 2.5 & 2.9 & 2.8 \\
age 45 plus & 1.6 & 1.8 & 2.8 & 2.8 \\
\hline first generation & 2.0 & 2.2 & 2.9 & 2.8 \\
second generation & 2.9 & 2.9 & 3.0 & 2.9 \\
\hline max. basic education & 1.7 & 1.9 & 2.7 & 2.6 \\
lower secondary education & 2.4 & 2.7 & 2.9 & 2.8 \\
higher secondary education & 2.6 & 2.8 & 3.0 & 2.9 \\
higher education & 2.8 & 2.8 & 3.0 & 2.9 \\
\hline \hline
\end{tabular}

Source: SCP SIM 2006, SCP Jaarrapport Integratie 2007, 87

\section{Employment and self-employment}

Non-Western migrants in the Netherlands are significantly worse positioned on the labour market than migrants but are improving their position over the 19962006 period as can be seen in Table 2.12 below. The unemployment share among non-Western migrants is consistently more than twice as high as the one of natives while the net labour market participation has increased substantially throughout the period. While over time, unemployment has decreased, this development is characterized by many ups and downs suggesting that the labour market situation of non-Western migrants heavily depends on the economic cycle, far more so than is the case for natives. Since 2001, the unemployment among ethnic minorities has increased largely with first signs of improvement not showing until 2006 when the labour market was picking up again.

${ }^{10}$ The scale runs from 1 (bad) to 3 (good), based on the language skills, namely speaking, reading and writing. Crombach's alpha $=0.91$. 
Table 2.12: Key trends in the supply side of the labour market, 1996-2006

\begin{tabular}{llllllll}
\hline \hline & 1996 & 2001 & 2002 & 2003 & 2004 & 2005 & 2006 \\
\hline labour force - overall(x1000) & 6686 & 7273 & 7337 & 7401 & 7398 & 7401 & 7486 \\
working labour force - overall(x1000) & 6185 & 7021 & 7035 & 7001 & 6919 & 6918 & 7074 \\
employees - overall & 5456 & 6256 & 6256 & 6213 & 6116 & 6103 & 6195 \\
$\quad$ part-time workers & --- & 2294 & 2438 & 2494 & 2494 & 2559 & 2624 \\
$\quad$ permanent employment contract & 4911 & 5753 & 5774 & 5754 & 5646 & 5590 & 5631 \\
$\quad$ flexible employment contract & 545 & 503 & 482 & 459 & 471 & 513 & 564 \\
\hline labour force participation rates - overall (\%) & 63 & 67 & 68 & 68 & 68 & 68 & 68 \\
labour force participation rates - ethnic minorities (\%) & 51 & 55 & 56 & 56 & 56 & 56 & 55 \\
employment rates - overall (\%) & 59 & 65 & 65 & 64 & 63 & 63 & 65 \\
employment rates - ethnic minorities (\%) & 40 & 50 & 49 & 47 & 47 & 47 & 47 \\
unemployment - overall(\%) & 8 & 4 & 4 & 5 & 7 & 7 & 6 \\
unemployment - ethnic minorities(\%) & 22 & 9 & 11 & 15 & 16 & 16 & 16 \\
\hline \hline
\end{tabular}

Notes: labour force including working people with a job for at least 12 hours per week, and jobseekers looking for work for at least 12 hours per week. Gross participation rate defined as labour force as a percentage of the total population aged 15-64 years. Net participation rate defined as working labour force as a percentage of the total population aged 15-64 years.

Source: CBS Statline, CPB 2005, SCP Facts and Figures of the Netherlands 2008, 49

Labour market outcomes differ by gender, level of education, age and ethnic group. As shown in Table 2.13 below, net labour market participation of women, non-Western and natives alike, is considerably lower than for men. This is especially the case for Turkish and Moroccan women whose participation rates are around half those for men of the respective groups (even lower for Moroccans). For all women, participation rates have increased in the second half of the 90s, while decreasing after 2001 for non-Western women as a consequence of the beginning economic downturn at the time. The downturn further caused an increase in unemployment that affected women and non-Western migrants to a larger extent than other groups of the population. From 2004, participation has slowly improved again for non-Western women with the exception of the Turkish and Moroccan groups whose labour market activity further decreased. While native women have managed to sustain their foothold in the labour market throughout the economic downturn, this was not the case for women of ethnic origin. With the recovery of the economy from 2006, female participation has picked up for natives but the trend is not yet visible for the non-Western population (SCP Jaarrapport Integratie 2007).

Besides gender differences, labour market participation varies across the age groups and is generally the highest for the mid age group aged 25-44 as can be expected. Participation among the 45 plus year-olds is furthermore especially high for the Surinamese and Antillean groups. 
Table 2.13: Net labour market participation rates ${ }^{1}$ per ethnic group, the Netherlands, 2006 (in percentages)

\begin{tabular}{|c|c|c|c|c|c|c|c|}
\hline & & & & & & non- & \\
\hline & Turkish & Moroccan & $\begin{array}{l}\text { Suri- } \\
\text { namese }\end{array}$ & Antillean & $\begin{array}{l}\text { other non- } \\
\text { Western }\end{array}$ & $\begin{array}{l}\text { Western } \\
\text { total }\end{array}$ & natives \\
\hline total & 44 & 39 & 60 & 56 & 42 & 47 & 67 \\
\hline men & 57 & 53 & 65 & 60 & 49 & 55 & 76 \\
\hline women & 30 & 23 & 55 & 51 & 35 & 38 & 58 \\
\hline age $15-24$ years & 28 & 21 & 26 & 30 & 24 & 25 & 41 \\
\hline age $25-44$ years & 52 & 49 & 75 & 66 & 50 & 56 & 84 \\
\hline age $45-64$ years & 38 & 26 & 60 & 58 & 44 & 47 & 61 \\
\hline first generation & 46 & 40 & 65 & 55 & 42 & 48 & \\
\hline second generation & 38 & 35 & 48 & 59 & 44 & 43 & \\
\hline max. basic education & 28 & 21 & 40 & 35 & 21 & 26 & 38 \\
\hline lower secondary education & 41 & 33 & 45 & 55 & 31 & 39 & 51 \\
\hline higher secondary education & 56 & 53 & 68 & 58 & 48 & 56 & 72 \\
\hline higher education & 70 & 69 & 82 & 73 & 60 & 69 & 83 \\
\hline
\end{tabular}

${ }^{1}$ labour market participation rate are defined as employment plus unemployment as percentage of the working age population

Source: CBS EBB 2006, SCP Jaarrapport Integratie 2007, 135

Unlike expectations, labour market participation is not significantly higher for second generation non-Western migrants than for the first generation despite better labour market qualifications (see education). The lower participation coupled with higher unemployment rates of the second as compared to first generation Turkish, Moroccans and Surinamese may be explained by the lower degree of job matching success of these groups. As presented in Table 2.14, the unemployment among the younger non-Western migrants remains a problem as in 2006. Despite reduction over the past decade, nearly one-quarter of this group is unemployed.

Host country specific skills and Dutch education seems highly relevant for improved labour market positions of foreigners as higher levels of education coincide with lower unemployment. The command of the Dutch language is an important asset (SCP Jaarrapport Integratie 2007). Nonetheless, unemployment among highly educated migrants is substantially higher than for the native population, especially so for non-Western population as shown in Figure 2.10. This pattern is furthermore sustained throughout the 1996-2005 period, although the gap has narrowed in recent years where ethnic unemployment is decreasing in a period that it is respectively increasing and constant for natives and Westerners. This may be a sign of effective labour market policy stimulating ethnic employment in recent years. Initiatives by the Dutch government were, for instance, the Multicultural Talent Recruiting Events, or special funding to stimulate ethnic participation in scientific jobs. 
Table 2.14: Unemployed labour force per ethnic group, the Netherlands, 2006 (in percentages)

\begin{tabular}{|c|c|c|c|c|c|c|c|}
\hline & Turkish & Moroccan & $\begin{array}{l}\text { Suri- } \\
\text { namese }\end{array}$ & Antillean & $\begin{array}{l}\text { other non- } \\
\text { Western }\end{array}$ & $\begin{array}{l}\text { non-Western } \\
\text { total }\end{array}$ & natives \\
\hline total & 15 & 17 & 12 & 17 & 17 & 16 & 4 \\
\hline men & 12 & 15 & 11 & 16 & 17 & 14 & 3 \\
\hline women & 21 & 23 & 14 & 18 & 19 & 18 & 6 \\
\hline age $15-24$ years & 20 & 26 & 27 & --- & 17 & 22 & 9 \\
\hline age $25-44$ years & 15 & 15 & 11 & 15 & 17 & 15 & 3 \\
\hline age $45-64$ years & 11 & 20 & 8 & 13 & 18 & 14 & 4 \\
\hline first generation & 14 & 16 & 11 & 19 & 19 & 16 & \\
\hline second generation & 19 & 21 & 15 & 9 & 9 & 15 & \\
\hline max. basic education & 22 & 25 & 23 & --- & 19 & 22 & 9 \\
\hline lower sec. education & 15 & 19 & 13 & 13 & 20 & 16 & 7 \\
\hline higher sec. education & 15 & 14 & 12 & 22 & 19 & 16 & 4 \\
\hline higher education & 3 & 13 & 6 & 4 & 13 & 9 & 3 \\
\hline
\end{tabular}

Notes: --- insufficient observations in labour sample surveys

Source: CBS EBB, SCP Jaarrapport Integratie 2007, 143

Figure 2.10: Unemployment among higher educated, age 15-64 years per ethnic group, the Netherlands, 1996-2005 (in percentages)

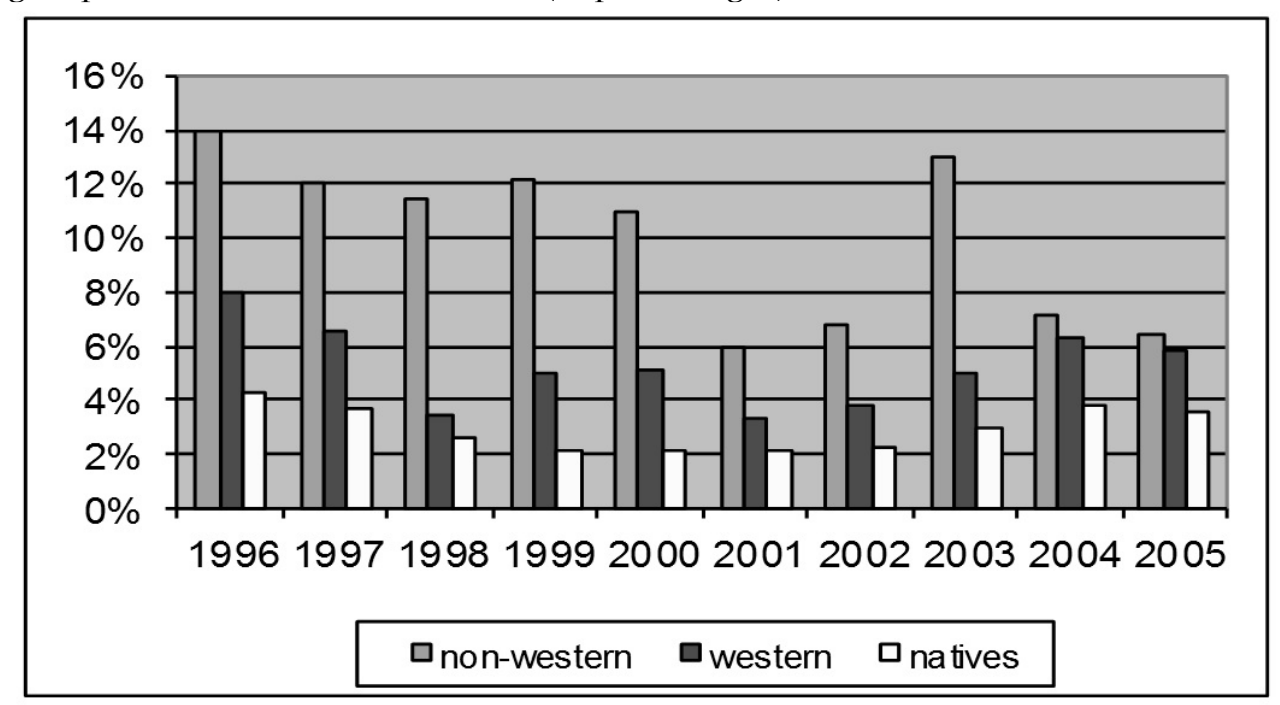

Source: CBS EBB, RWI 2006, 28

The labour market position of migrants is another important aspect apart from their access to jobs. As shown in Table 2.15, migrants have flexible work contracts far more often than natives, the extent of which differs across ethnic groups, but is generally two to threefold higher than for natives. The shares furthermore differ 
considerably between male and female migrants for some groups like the Moroccans (14\% and 19\% respectively) and Antilleans (13\% and 22\% respectively), while being about the same for the natives, Turkish, Surinamese and other nonWestern migrants. Finally, an interesting finding is that Surinamese women tend to have by far the least flexible work contracts and also work the least in part time of all ethnic groups. This has important implications for their income and economic independence (SCP Jaarrapport Integratie 2007).

Table 2.15: Share employed with temporary or flexible contract per ethnic group and gender, age 15-64 year employees, the Netherlands, 2006 (in percentages)

\begin{tabular}{lll}
\hline \hline & women & men \\
\hline Turkish & 22 & 20 \\
Moroccan & 19 & 14 \\
Surinamese & 13 & 12 \\
Antillean & 22 & 13 \\
other non-Western & 19 & 21 \\
natives & 7 & 9 \\
\hline \hline
\end{tabular}

Source: CBS EBB, SCP Jaarrapport Integratie 2007, 262

When comparing the mean level of employment of ethnic minorities with that of the native population, a number of interesting findings become apparent as seen in Figure 2.11. Ethnic minorities tend to work in lower employment functions than natives. Furthermore, minority women of all ethnic groups tend to function at higher professional levels than their male counterparts of the respective groups, while functional levels for natives are the same across genders. Turkish and Moroccan migrants compared to other ethnic groups are relatively more often found at the lower end of the labour market (SCP Jaarrapport Integratie 2007).

Another promising development in migrant economic activities is in the field of self-employment. Not only has the number of ethnic businesses increased rapidly over the past decades to 70,000 in April 2006, a promising trend of business activity diversification and rising survival rates has been observable over the recent years. This pattern may be related to the rising share of second generation ethnic entrepreneurs who, due to higher education and country-specific skill levels, are expected to be more successful in self-employment than the first generation. This share increased to $24 \%$ of ethnic entrepreneurship as of April 2006. The propensity of self-employment, defined as the share of self-employed of the total labour force, is furthermore particularly high for the Turkish group (13.5\%) comparing to the native share of around $10 \%$. The share is moreover considerably lower for the other major ethnic non-Western immigrant groups at $7.3 \%, 6.4 \%$ and $4.7 \%$ respectively for the Moroccans, Surinamese and Antilleans (Van den Tillaart 2007, SCP 
Jaarrapport Integratie 2007). In 2005, non-Western businesses were operating to a large degree in five sectors, namely business services $(21 \%$ of non-Western businesses), hotel/catering (18\%), retail $(17 \%)$, wholesale $(13 \%)$ and personal services $(11 \%)$. While figures suggest that migrant economic activities are still to some extent concentrated in the so-called traditional ethnic business niches found in hotel/catering, retail, wholesale, and personal services, an interesting intergenerational shift is observable towards higher skill business activities. This shift is captured in Figure 2.12: the second generation is far less active in the low skill sectors of hotel/catering, wholesale, and retail and it is greatly more represented in the higher skill business services sector.

Figure 2.11: Working labour force per work level, ethnic group and gender, the Netherlands, 2006 (in percentages)

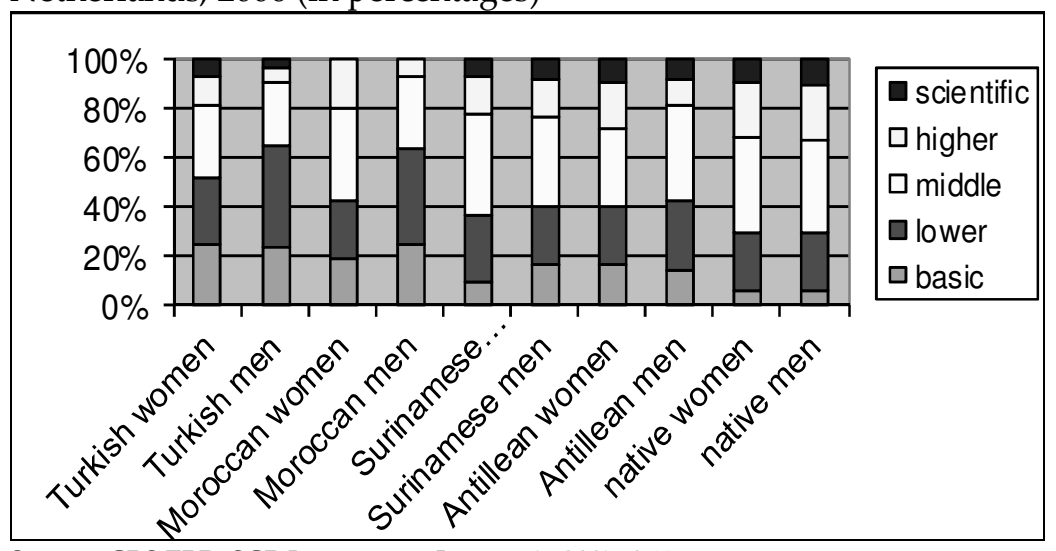

Source: CBS EBB, SCP Jaarrapport Integratie 2007, 261

Figure 2.12: Business per sector, non-Western migrants and natives, the Netherlands, 2005 (in percentages)

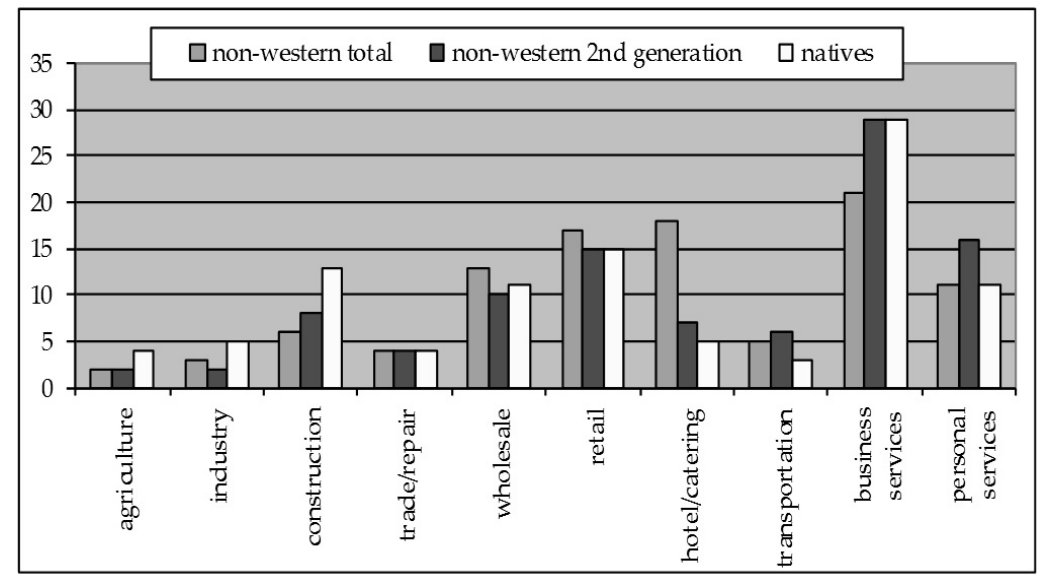

Source: : ITS/KvK/CBS (Handelsregister), Van den Tillaart 2007, SCP Jaarrapport Integratie 2007, 152 


\section{Income, poverty and social security}

The disadvantaged economic position of non-Western migrants becomes most visible when comparing income, poverty rates and dependency on social benefits for this group with the native population. While in 2005, average yearly disposable income for natives has been around $€ 18,700$, the equivalent for the first and second generation non-Western minorities has been considerable lower at $€ 15,400$ and $€$ 13,500 respectively. At the same point in time average disposable income of Western migrants has been approximately up to par with the one of natives, which indicates that overall it is the non-Western population that is most disadvantaged in the economy. Over the 1994-2005 period, the income situation of non-Western foreigners as compared to natives has, however, improved slightly (SCP Facts and Figures of the Netherlands 2008).

As can be seen in Figure 2.13, the share of households with low incomes ${ }^{11}$ was four times higher for non-Western migrants than for natives over the period from 20002005 (around 28\% and 7\% respectively). This share has overall decreased greatly over the period 2000-2002, but it increased again thereafter for the non-Western group. The share of low income households is further relatively small for the Surinamese group, while skyrocketing especially for refugee groups reaching levels of nearly $60 \%$ for the groups from Somalia and Afghanistan. Also, the levels for the Turkish, Moroccan and Antillean groups seem alarming with nearly onethird of the households being at low income levels. A promising patterns seems to evolve for the Moroccan group, whose share of low income households has decreased in recent years despite worsening situations for all other non-Western groups as well as natives.

It is, however, not clear as to whether this trend is a positive result of successful integration and emancipation policy on the part of the government, which in the recent years has focused on the stimulation of at least a starter qualification (basic secondary education), work of minimum twelve hours per week and the enabling of economic independence of migrant women (i.e. minimum personal income above social subsistence level). Turkish and Moroccan women are far from reaching these policy targets as $56 \%$ and $57 \%$ of the Turkish and Moroccan populations respectively (and even higher shares for women only) have not completed basic secondary education as was shown in Table 2.10. Furthermore, their degree of economic independence is considerably lower than for Surinamese and Antillean women given net labour market participation of half - and unemployment rates of double the ones of the latter female groups. An interesting

${ }^{11}$ This refers to households disposing of less to or equal $100 \%$ of the low-income threshold as defined by social security. The threshold is defined in absolute terms and is adjusted according to the household composition and to inflation over time. At 2004 price levels it was set at $€ 10,301$ for the year 2005 . 
case is the Surinamese group of women, which seems by far the most economically independent female ethnic group. Education levels are relatively high as are net labour market participation rates, unemployment is low. Antillean women are economically situated somewhere in between on the one side the disadvantaged Turkish and Moroccan groups and on the other side the successful Surinamese one.

Figure 2.13: Share household with low income (households disposing up to and including $100 \%$ of the low-income threshold), per ethnic group, the Netherlands, 2000-2005 (in percentages)

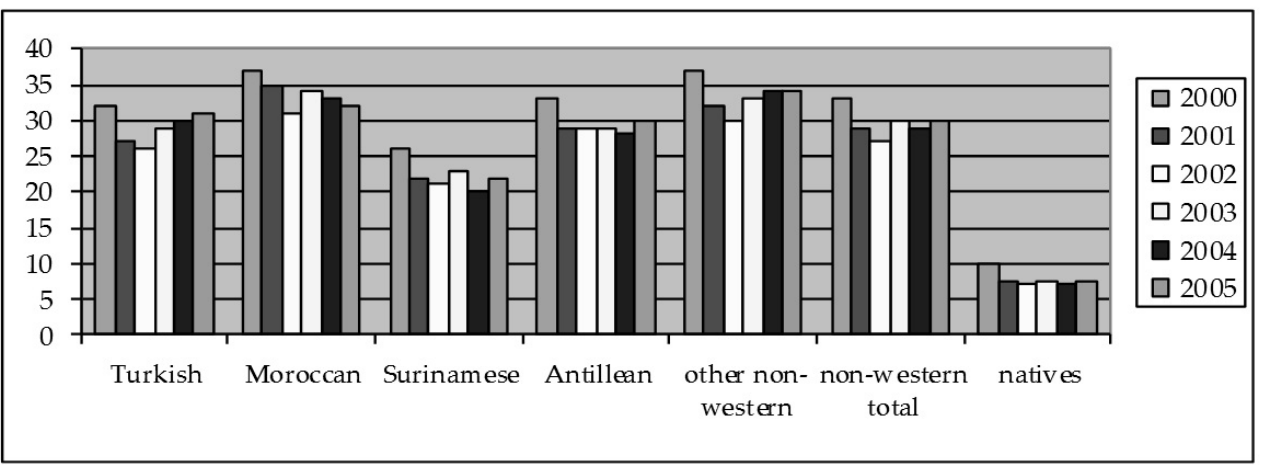

Source: CBS Statline 2009, SCP Jaarrapport Integratie 2007, 157

Table 2.16 further shows that the occurrence of low income households varies according to a number of relevant background characteristics as the socioeconomic category of the main income earner, the household composition, and age of the main income earner. The occurrence of low income households is extremely high among non-Western pensioners with one-third of households being poor comparing to merely 3 per cent among native pensioners. This high poverty rate among migrant pensioners can be explained by the pension entitlement scheme in the country that relates pension benefits directly to the time period contributions were paid to the system. As migrants in many cases have shorter contribution periods than natives, this naturally yields lower pension entitlements and explains the high occurrence of old age poverty among this group. Finally, one-person households and households with children are showing higher shares of lower incomes than multi-person households without children. These findings seem to be driven by high poverty in single pensioner households as well as the commonly lower income levels in migrant households with many children (SCP Jaarrapport Integratie 2007). 
Table 2.16: Share households with low income, per ethnic group and background characteristics, the Netherlands, 2002 (in percentages)

\begin{tabular}{lll}
\hline \hline & non-western & natives \\
\hline $\begin{array}{l}\text { socio-economic category of main income earner } \\
\text { active in labour market }\end{array}$ & 13 & 5 \\
non-active in labour market & 33 & 3 \\
$\quad$ pensioner & 63 & 37 \\
$\quad$ recipient of social welfare & & 12 \\
\hline household composition & 34 & 4 \\
one-person household & & 7 \\
multi-person household & 18 & 9 \\
$\quad$ without kids & 29 & 9 \\
$\quad$ with kids & & 3 \\
\hline age of main income earner & 28 & \\
below 45 years & 30 & 38 \\
$45-65$ years & & \\
65 plus & & \\
\hline \hline
\end{tabular}

Source: CBS RIO 2002, SCP Armoedemonitor 2005, 92

Another interesting observation is the high degree of dependency on social benefits among the non-Western migrants as shown in Table 2.17. One fourth of non-Western migrants aged 15-65 received social benefits on the last Friday of September of 2004 compared to 13 per cent of natives. Social assistance benefits are by far the most common among ethnic minorities (14\%), followed by disability benefits $(7 \%)$ and unemployment benefits $(3 \%)$. Natives are predominantly receiving disability benefits more often than non-Western migrants do.

Table 2.17: Recipients of social benefits, age 15-64 years, September 2004, the Netherlands (in percentage of population)

\begin{tabular}{|c|c|c|c|c|c|}
\hline & total share social security & & of $w$ & ich: & \\
\hline & $\begin{array}{l}\text { beneficiaries within } \\
\text { group }\end{array}$ & $\begin{array}{l}\text { inability } \\
\text { benefits }\end{array}$ & $\begin{array}{l}\text { unemployment } \\
\text { benefits }\end{array}$ & $\begin{array}{l}\text { socialwelfare } \\
\text { benefits }\end{array}$ & $\begin{array}{l}\text { Other } \\
\text { benefits }\end{array}$ \\
\hline Turkish & 29 & 13 & 4 & 11 & 3 \\
\hline Moroccan & 29 & 9 & 3 & 16 & 2 \\
\hline Surinamese & 23 & 8 & 4 & 10 & 2 \\
\hline Antillean & 24 & 4 & 3 & 16 & 2 \\
\hline other non-Western & 22 & 3 & 2 & 16 & 1 \\
\hline non-Western total & 25 & 7 & 3 & 14 & 2 \\
\hline natives & 13 & 8 & 2 & 2 & 2 \\
\hline
\end{tabular}

Source: CBS Statline 2009, SCP Jaarrapport Integratie 2007, 154 
Among non-Western migrants, the Turkish and Moroccans are receiving social benefits relatively more often than other ethnic groups, whereby especially Moroccans are dependent upon social welfare payments. On the contrary, social welfare dependency is considerably lower for Surinamese migrants than for other non-Western groups, which may be explained by the relatively high level of female economic activity and in turn independence (CBS Statline, SCP Jaarrapport Integratie 2007).

\section{5 - Concluding remarks}

This chapter has discussed the socio-economic situation of the immigrant community in the Netherlands in light of the country's peculiar immigration history and policy over the past half century. This situation is assessed both absolutely as well as relative to natives, the latter with the aim of gaining insight into the group's level of integration in society, which is commonly measured by performance on key outcome variables vis-à-vis natives.

The socio-economic position of the non-Western migrant population is generally significantly less favourable than that of the indigenous population on whatever indicator is chosen to describe the differences (i.e. housing market situation, education and labour market outcomes, income). Since the recognition, however, that migrants have been becoming permanent residents in the country since the mid 1980's, the situation has gradually improved, which seems to indicate that the extensive measures taken to enhance the group's integration into society have shown some effect. Nevertheless, the differences between the indigenous population and the non-Western immigrant community remain striking. The housing situation has improved considerably especially during and after the big cities' policies in the 1990's that paid a lot of attention to housing. Nevertheless, immigrants live generally concentrated in specific areas and parts of the Dutch cities and use smaller and less well equipped dwellings. While only 8 per cent of the indigenous population finished primary education as their only degree, 31 and 34 per cent of the respective Turkish and Moroccan migrants pertain to that category in 2005. This is down from more than 50 per cent only 10 years earlier, but still considerably higher than the percentage for the native Dutch.

Significant progress is seen among the second generation of whom almost 20 per cent held a higher education degree in 2006; still 7 per cent less than among the indigenous population, but well above the earlier rates. Early school drop-out in secondary education is as high as 17 per cent among the migrants compared to 12 per cent for natives (2005). Employment rates of migrants are generally 13 per cent below the overall employment rates during the entire period between 1996 and 
2006. Unemployment rates are very high and in the order of magnitude of $15-16$ per cent, which is well above the unemployment rate of the overall population of 5 to 7 per cent for the same period. Really worrisome are the unemployment rates for the age group $16-24$ years, which are as high as 20 per cent for the Turkish migrants and 26 per cent for the Moroccan and Surinamese groups of young adults. For these groups, the before outcomes of the second generation are actually worse than for the first generation. Unemployment is even relatively high among the higher educated non-Western migrants, but the good news is that the unemployment rates for this category are declining relatively fast during the last 7 years.

In general it might be somewhat surprising to find the second generation migrants being worse off than the first generation migrants. However, the differences are also due to the fact that many first generation migrants came to the Netherlands to fill specific labour market vacancies while the second generation still needs to find its place in the labour market. The second generation thus faces the same problems that all young entrants on the labour market face aggravated by the fact that they are on average less well educated and trained than their Dutch peers, giving them a problematic start in their labour market career. Roughly 30 per cent of nonWestern households had a disposable income below the low-income threshold in 2005 (and the years before) against less than 7 per cent of the native Dutch households (the Surinamese households are doing slightly better than the other migrants: 20 per cent of them are below the low income threshold). Low disposable household income is a problem for almost all non-Western groups but relatively more problematic for recipients of social welfare, for one-person households and for elderly persons. While on average 13 per cent of the native Dutch aged between 15 and 64 are welfare recipients, this percentage is close to 30 per cent for the same age group among the Turkish and the Moroccan populations and around 22 per cent for the other nationalities in the non-Western migrant group. All in all it seems that despite all the policy attention devoted to non-Western immigrants, still a lot has to be done in order to realise a result that is more in line with the outcomes for the indigenous population.

In concluding this chapter, two important remarks are outstanding: one on the social and ethnic component in analysing the labour and educational outcomes and one on the differences between Western and non-Western migrants. The data on the labour market- and educational position of the migrant populations as they are presented in the previous sections may lead to the conclusion that the differences all originate in the differences in ethnicity. This is, however, only partially true; the figures also hide that many immigrant households belong to the lower part of the income distribution and thus are for that reason less likely to be 
successful in education and in the labour market (just as is the case for the Dutch native population). This means that the differences between the native Dutch and the non-Western migrants are not only to be attributed to the ethnicity factor but also to a set of social factors that associates lower income with less success on the labour market and in education.

It seems that the conclusion of this chapter is that 'integration' problems are only related to non-Western migrants, which is certainly how the problems are defined in the political arena. Undeniably, Western immigrants generally fit easier into the Dutch society because they have advantages in acquiring Dutch language skills (due to its higher language proximity with the languages spoken in their origin countries), because they immigrate from cultures that are close to the Dutch and they generally have higher levels of education. However, the traditional grouping of immigrants in 'integration-unproblematic' Western migrants and 'integrationproblematic' non-Western migrants has also resulted in a one-directional line of research over the past years focusing on integration of non-Western migrants only and especially on the major four groups therein (Turkish, Moroccan, Surinamese, Netherlands Antillean). Thus, while this research has documented the consistency of disadvantages in the socio-economic situation of the latter groups of migrants, it raises three additional questions for future research that are by and large disregarded in present integration-related research in the Netherlands: How do other non-Western migrant communities, other than the major four groups, fare in terms of integration into the Netherlands? How does the group of Western immigrants in the Netherlands fare in terms of integration into Dutch society vis-àvis the documented situation of non-Western migrants? What are potential integration-related differences between the various Western country-of-origin groups? Finally, in light of changing country-of-origin inflows of migrants to the Netherlands in recent years and particularly due to the large increase of asylum seekers and migrants from new EU member states, further research on integration of these new migrant groups becomes ever more relevant. 


\section{Chapter 3: Segregation in neighbourhoods and labour market outcomes of immigrants ${ }^{12}$}

\section{1 - Introduction}

How important is the integration of immigrants in society for labour market outcomes? Many Western countries are faced with large flows of people from developing countries. Commonly, this population group is particularly disadvantaged in the labour market. Participation rates are low and there is a substantial earnings gap between natives and immigrants originating from Western countries. Furthermore, these non-Western immigrants tend to live together in neighbourhoods with people of a similar background, which raises the question whether immigrants benefit from living in these migrant neighbourhoods or if residential integration with the native population would be a better stimulus for success.

In this chapter we examine the effect of residential segregation in neighbourhoods of non-Western migrants on labour market outcomes, exploiting the random assignment of asylum seekers to municipalities in the Netherlands. The combination of various administrative sources enables us to track the labour market experiences of nearly 92,000 of these immigrants over the six year period from 1999-2004. Furthermore, the large number of instruments we have in our data and the wide ranges of effects of these instruments make it possible to (1) break down the overall findings into subgroups, (2) investigate nonlinearities in the link between immigrant concentration and outcomes, and (3) take a look at possible selection effects related to unobserved characteristics. While OLS estimates suggest that residential segregation of non-Western migrants has a strong negative effect on labour market outcomes (employment and wages), it turns out that these effects dwindle in the linear IV estimation when using initial placement as an instrument for later place of residence. Neighbourhood concentration for both outcome variables is close to zero and insignificant. Further, as we take other neighbourhood characteristics (employment rate and mean wage level) into account, concentration has a positive effect on outcomes, especially for high concentration neighbourhoods. Immigrants who move to high concentration neighbourhoods tend to benefit much from such concentrated environments. This implies that the correlation observed in the OLS specification results from selection

12 This chapter is based on the paper: Beckers, P. \& Borghans, L. (2007), "Segregation in neighbourhoods and labour market outcomes of immigrants - Evidence from random assignment in the Netherlands", Conference paper at the Annual Conference of the Society of Labor Economists, Chicago, May 2007. 
effects and that the measured effects are biased downwards due to the correlation between non-Western concentration and other less favourable neighbourhood characteristics.

A crucial feature of our empirical approach is the random allocation of asylum seekers by the Dutch government. The vast majority of asylum seekers enter the Netherlands at Schiphol, the airport of Amsterdam. Upon arrival to the Netherlands, individual asylum seekers and families are assigned to housing centres spread all over the country, where they are to reside until they are officially granted asylum status. This allocation process only depends on the availability of accommodation in the centres. This process results in regional variation of the first place of residence which is uncorrelated to immigrant origin and characteristics or family background. Thus, on average the groups of asylum seekers of each centre are expected to possess similar characteristics, which give them equal chances on the labour market. It takes, in most cases, $12-36$ months to get a residence permit that allows the asylum seekers to work. Although asylum seekers are free to move once in possession of a residence permit, initial placement turns out to be an important determinant of the later place of living. This allows us to identify the effect of non-Western neighbourhood concentration on labour market outcomes for these asylum seekers.

The data we use are based on the joint administration of all municipalities in the Netherlands for the period 1995-2004. These data sets provide information about all consecutive places of residence of all asylum seekers at the level of four digit postal codes and the population in each postal code area by country of origin. A four digit postal code represents a neighbourhood of on average 1500 inhabitants. Combined administrative data from the fiscal and social security authorities gives us information about the labour market position and income of all employed and self-employed workers from 1999-2004. Matching of these sources enables us to investigate the labour market outcomes of the asylum seekers for a period of six years. In the period of investigation, annually between 23,000 and 44,000 asylum seekers entered the country. Large fractions came from Iraq, Afghanistan, Somalia and Sudan. After a phase of inquiry - during which employment of asylum seekers is restricted - about 40 per cent of them receive a residence permit. In total, we analyse the labour market outcomes of nearly 92,000 of these immigrants. Depending on the place of first residence, later non-Western neighbourhood concentrations vary considerably from near zero to above 90 per cent.

This chapter is related to a long line of predominantly US-based research as well as more recent studies from the Netherlands that explore the relationship between residential concentration of ethnic minority population and its socio-economic 
outcomes. The prior US-based research generally finds that higher levels of minority concentration reduce employment chances and income levels of migrants (Blalock 1957, Brown \& Fuguitt 1972, Wilcox \& Roof 1978, Tienda \& Lii 1987, Fossett and Seibert 1997). Recent studies from the Netherlands, however, question the applicability of these findings to the Dutch context. This is explained by the fact that Dutch ethnic minority concentrated neighbourhoods are greatly more diverse in terms of ethnic mix and income levels, which is the likely result of a long tradition of national and local government welfare policy, the extended social security system in the country and neighbourhood-based support networks (Musterd 1996, Uunk 2002, Van der Laan Bouma-Doff 2005, Pinkster 2008, Dagevos 2009). In the case of the Netherlands, neighbourhood concentration effects on migrant economic outcomes ought not necessarily to be negative; two opposing views on concentration effects coexist. The first and most popular view sees these neighbourhoods as 'ghettos', which implies social isolation of migrants from mainstream society coincided with socio-economic disadvantage (Wilson 1987, Crane 1991, Anderson 1991, Bertrand, Luttmer and Mullainathan 2000), the second one sees these neighbourhoods as 'springboards' helping newcomers to establish a living in receiving societies that also function as 'safe havens' from discrimination in mainstream society (Portes \& Rumbaut 1990, Tesser et al. 1995, Van der Laan Bouma-Doff 2005). Concentration neighbourhoods may also be beneficial to the development of ethnic entrepreneurship and the establishment of ethnic labour market niches as described by Waldinger (1996) and Kloosterman \& Van der Leun (1999). Other researchers stress that ethnic minority concentrated neighbourhoods may function as a social safety net for newcomers providing individuals with social capital in the form of informal support from the family and the co-ethnic community (Snel \& Burgers 2000). In conclusion, while for the American setting ethnic minority concentration effects on economic outcomes of migrants appear to be consistently negative, in the setting of the Netherlands the issue remains subject of scientific debate. Our study contributes to this debate by providing a case where concentration may have positive implications for labour market outcomes of migrants once controlling for self-selection effects, especially for recent arrivers.

Edin et al. (2003) and Piil Damm (2009) use the assignment of immigrants to municipalities as a quasi-experiment to investigate the causal effects of ethnic concentration on immigrant labour market outcomes. Effects of segregation on outcomes are most likely mainly affected by the direct neighbourhood people live in. Variation in neighbourhood concentration is much higher than variation in ethnic concentration between municipalities. Using a very large data set with precise information on where people live, this chapter contributes by identifying neighbourhood rather than municipality effects of segregation and by identifying non-linearities and heterogeneity in the effects of concentration on outcomes. 
The chapter is structured in six parts. Following the general introduction, Section 3.2 provides a review of background literature on immigrant residential concentration and labour market performance. Section 3.3 explains the endogeneity issue relating to neighbourhood concentration and presents key information on asylum seekers in the Netherlands together with required background information on Dutch asylum policy to set the stage for later analysis. Section 3.4 introduces the data and methodology of this study while Section 3.5 and Section 3.6 contain the prime findings and concluding remarks respectively.

\section{2 - Literature review}

\section{Theoretical background}

Empirical evidence shows that there is a strong tendency for migrants to reside in neighbourhoods with high concentrations of ethnic minority population that are particularly located in larger cities (Borjas 1999), which may have implications for immigrant cultural as well as socio-economic integration (Chiswick and Miller 1995, Uunk 2002, Van der Laan Bouma-Doff 2005).

The above assertion is based on the idea that the local living environment or residential neighbourhood shapes (in part) the personal development of individuals, which may reflect in concrete behaviour but also in more subtle social norms and values. The residential neighbourhood influences, for instance, whom we meet on the street, where our children go to school or how we perceive the world (Pinkster 2008). There may be reasons to doubt the existence of these neighbourhood effects, as peoples' geographic mobility and social contacts are generally not restricted to these neighbourhoods (Van Kempen 2000, Ostendorf en Musterd 2005). However, a long-standing body of predominantly US-based scientific literature documents that neighbourhood effects are important for the development of individuals on a wide range of individual characteristics including labour market outcomes (Lewis 1966, Wilson 1987, Massey \& Denton 1993, Musterd \& Andersson 2006). Inspired by the living conditions in urban ghettos in large American cities, a prime concern of this literature is whether and how geographic concentration of ethnic minority groups affects labour market outcomes of migrants (Blalock 1957, Brown \& Fuguitt 1972, Wilcox \& Roof 1978, Tienda \& Lii 1987, Fossett and Seibert 1997, Tesser et al. 1999).

The discussion on the issue is dominated by two competing views. The first and most popular view sees these neighbourhoods as 'ghettos' that implies social isolation of migrants from mainstream society coincided with socio-economic disadvantage (Wilson 1987, Crane 1991, Anderson 1991, Bertrand, Luttmer and 
Mullainathan 2000). The second one sees these neighbourhoods as 'springboards' helping newcomers to establish a living in receiving societies that also function as 'safe havens' from discrimination in mainstream society (Portes \& Rumbaut 1990, Tesser et al.1995, Van der Laan Bouma-Doff 2005).

From the ghetto-perspective, literature provides several arguments why living in highly concentrated migrant neighbourhoods may affect labour market outcomes of individuals. First, labour market disadvantages may result from stigmatization effects that often go hand-in-hand with concentration of socio-economic deprivation. Negative neighbourhood images or reputations may be harmful for employment opportunities of residents as redlining practices are often based on them. Redlining implies that certain neighbourhoods are seen as 'risky to recruit people from' as they accumulate residents with low socio-economic profiles and are lacking social order. Thus, redlining practices might further reinforce labour market disadvantages of residents as employers may refrain from hiring workers from these stigmatized areas (Wacquant 1993, White 1998, Musterd \& Andersson 2006).

A second explanation why living in high concentration neighbourhoods may affect labour market outcomes of individuals is found in the social isolation hypothesis. It stresses that the accumulation of disadvantageous living circumstances in high concentration neighbourhoods further reinforces the unfortunate socio-economic position of migrants in society. The argument is built on the idea that living in a neighbourhood with deprived people limits the usefulness of local social networks to get ahead in the labour market. As locals tend to be less educated and commonly hold unfavourable positions in the labour market, social networks fail to provide essential information as well as social support to individuals seeking employment opportunities (Wilson 1987, Crane 1991, Anderson 1991, Tigges, Brown \& Green 1998, Bertrand, Luttmer and Mullainathan 2000, Topa 2001, Ioannides \& Datcher-Loury 2004).

A third explanation is the belief that immigrant concentration reduces the acquisition of host-country specific human capital, e.g. language skills (Chiswick 1991, Chiswick and Miller 1995, Lazear 1999). As residential concentration reduces the frequency of social interactions of migrants with the native population, this reduces migrant incentives to acquire host-country specific human capital and in turn drives up the costs of doing so in the future. This reduces migrant labour market flexibility and, thus, prospects for economic mobility. This argument underlies the newcomer dispersion policy implemented in many Western countries. 
Fourth, another argument relates to the access to and quality of local services, such as child care facilities, preschool services and after-school programmes, as well as employment opportunities, which commonly puts individuals in migrant neighbourhoods at a disadvantage (Musterd \& Andersson 2006). Kain (1968) and Ihlanfeldt and Sjoquist (1998) introduce the argument of spatial mismatch, which states that residential segregation of migrants depresses their labour market prospects as immigrant communities tend to be located at a distance from available jobs. Due to high commuting costs and time used between place of residence and work, migrant incentives to search for available and suitable jobs are reduced, which lowers job matching effectiveness and, thus, labour market prospects. While spatial mismatch may be less relevant to explain migrant labour market disadvantages in the Dutch context than in the North American setting, due to better collective urban transportation systems and lower commuting times, it is nonetheless likely to be of significance here (Kain 1968, Musterd \& Andersson 2006).

Other theoretical contributions explaining why increased spatial concentration of immigrants may positively affect the group's labour market outcomes focus on spatial concentration effects of ethnic groups in migrant neighbourhoods. First, it has been argued that increased spatial concentration of migrants raises the relative contacts between people of common ethnicity living in geographic proximity of each other (ethnic networks) (Bertrand, Luttmer, Mullainathan 2000). This increased density of ethnic networks is further hypothesized to have implications for labour market outcomes of immigrants (Loury 1977, Piil Damm 2009, Edin et al. 2003). Ethnic social networks impact individual behaviour of members of the migrant community in two ways, namely through information channels and norms as noted by Bertrand, Luttmer and Mullainathan (2000) and Akerlof (1980). Ethnic networks render an important information source to newcomers and, thereby, facilitate their acquisition of essential host country insights, which positively impacts their economic prospects. This would include information about the labour market in general, potential job openings, required labour market skills and qualifications as well as potential opportunities for business start-up (Lazear 1999). Next to offering orientation support for participation in the mainstream economy, local ethnic networks are believed to also provide information on employment and own business opportunities in the co-ethnic economy. For many newcomers, these latter means imply first stepping stones towards establishing new livings in the receiving countries (Portes 1998, Light and Bonacich 1988, Waldinger 1996). Over time, this has resulted in immigrant concentration in particular occupations in the labour market and in clustering of business activities in certain sectors. These established ethnic niches may provide a kind of refuge for immigrants discriminated in the primary labour market (Li 1998). While immigrants in these 
sheltered ethnic economies - also called enclaves - may achieve higher returns to their human capital, naturally, immigrant entrepreneurs may benefit greatly also through reduced risk and costs of hiring (Bailey \& Waldinger 1991, Newman 1999, Portes \& Bach 1985, Wang 2004). At the same time, ethnic networks may also negatively impact immigrant economic outcomes. Information exchange between equally disadvantaged immigrants may result in low job seeking success as actors are poorly informed about labour market opportunities but, nonetheless, are likely to consult their co-ethnic acquaintances rather than consulting other sources of information regarding vacancies (Phelps 1972). Additionally, ethnic social networks may also play a role in dissemination of welfare eligibility (Bertrand, Luttmer, Mullainathan 2000).

Next to their function in the exchange of information, ethnic networks shape the norms of individual co-ethnic members, which also affect their labour market outcomes through, for instance, peer group pressure (Granovetter 1985). We distinguish between direct and indirect effects. Norms directly affect economic outcomes through work ethics, intra-household gender role distributions, as well as traditions of self-employment and attitudes of receiving welfare benefits. They indirectly impact through cultural perceptions regarding education, early marriage and fertility as noted, among others, by Coleman et al. (1966), Lewis (1968), Wilson (1987), Case and Katz (1991), Massey \& Denton (1993), Borjas (1995), Glaeser, Sacerdote and Scheinkman (1996), and Piil Damm (2009).

Second, it has also been argued that the effects of co-ethnic social networks on labour market outcomes of migrants depend on the nature of human capital externalities or quality (human capital stock) of the co-ethnic community as well as the skill level of the individual. In this case the relative benefit of living in the coethnic community would increase with the share of high skilled members in the group as this enhances its resourcefulness. Benefits of living among the co-ethnic community are particularly high for low skilled individuals as their gains from coethnic interactions and exchanges tend to be greatest (Borjas 1998, Kahanec 2006, Cutler and Glaeser 1997, Edin et al. 2003, Piil Damm 2009).

Third, Chiswick and Miller (1995) explain earnings differentials between high and low concentration regions through the existence of ethnic goods, which are consumption goods and services fulfilling unique migrant needs that are different from those of natives or those of other migrant groups. Examples of these are traditional food products from the home country, or places to socialize with coethnic members or carry out religious practices. Moreover, the authors argue that migrants are willing to accept lower wages in exchange for availability of ethnic goods, which become increasingly available in higher concentrated areas. Thus, 
this may yet be another explanation why migrant wages are lower in areas of higher co-ethnic concentration.

\section{Prior empirical findings}

Although it may seem intuitive that the local living environment shapes individuals, the existence of neighbourhood effects and specifically of ethnic concentration effects on labour market outcomes remain subject to scientific debate in the Netherlands for two reasons. First, the body of literature studying minority concentration effects on labour market outcomes is by and large inspired by circumstances of hyper segregation found in large North American cities, the findings of which are however believed to translate poorly to the Dutch situation. This is explained by the fact that Dutch neighbourhoods with high concentrations of non-Western immigrants are greatly more diverse in terms of ethnic mix and income levels, which is the likely result of a long tradition of national and local government welfare policy, the extended social security system in the country and neighbourhood-based support networks (Musterd 1996, Kloosterman \& Van der Leun 1999, Pinkster 2008, Dagevos 2009). Thus, before turning to the predominantly US-based literature, which traditionally documents negative concentration effects on employment chances and income levels of migrants (Blalock 1957, Brown \& Fuguitt 1972, Wilcox \& Roof 1978, Tienda \& Lii 1987, Fossett and Seibert 1997), we need to stress that these effects are likely to be less significant for the case of the Netherlands as shown by the exploratory studies by Uunk (2002) and Van der Laan Bouma-Doff (2005). These authors study neighbourhood ethnic concentration effects on socio-economic outcomes of the four major groups of non-Western migrants (Turkish, Moroccan, Surinamese, Dutch Antillean) to find selective small negative, but mostly insignificant, effects on employment chances and income levels of these groups.

Second, the effects are generally not clearly measurable as they are empirically difficult to distinguish from self-selection effects into neighbourhoods as will be explained in more depth in Section 3.3. As a consequence, the great bulk of empirical research treats ethnic residential concentration as an exogenous factor in estimations, the findings of which document a negative effect of concentration on labour market outcomes (Kahanec 2006, Chiswick \& Miller 2005, Borjas 1987). More recent studies, however, assert that ethnic concentrations ought to be treated as an endogenous factor instead, as residential location is subject to individual choices of migrants that are likely influenced by their characteristics (Borjas 1995, Edin et al. 2003). This research underlines that conclusions drawn from earlier studies may be premature, which is triggering a renewed interest in the topic by academics and policy makers alike. 
A good overview of the traditional body of research on the topic, treating concentration as an exogenous variable, is provided in a recent study by Kahanec (2006). These studies conducted since the 1950's predominantly document a negative relation between immigrant group concentration and economic performance. Some of the earlier empirical studies from the US are carried out by Blalock (1956, 1957) and Heer (1959), with the latter one finding a significant negative correlation of -0.71 between the percentage of the Black population and the group median per capita income. Later studies by Brown and Fuguitt (1972) and Frisbie and Neidert (1977) support these findings with Frisbie and Neidert pointing out a correlation in the range of 0.19 and 0.70 between majority-minority income differentials and minority percentage in the population. In 1987, Tienda and Lii find that increasing labour market concentration of minorities further enforces own group labour market disadvantages while actually benefiting the majority. Studies by Borjas (1987) and Chiswick \& Miller (2005) furthermore verify prior findings in that immigrant earnings decrease with higher concentration of same ethnic or linguistic group populations. Borjas (1987) finds that an immigrant increase of 10 per cent reduces immigrant earnings by 10 per cent, an impressive finding stressing the high substitutability of immigrant labour. Finally, Chiswick \& Miller (2005) outline that for consolidating across all immigrants, an increase in concentration level from a 0 concentration area to the mean level of 7.8 per cent, reduces earnings by approximately 4.4 per cent.

Several recent studies explicitly address the endogeneity issue. First, Borjas (1995) uses parental neighbourhood choices under the assumption that these are exogenous in determining their children's outcomes. Second, studies by Bertrand, Luttmer, and Mullainanthan (2000), Cutler and Glaeser (1997), Dustmann and Preston (1998), and Gabriel and Rosenthal (1999) use the variation across metropolitan areas stressing that sorting is less of an issue at that level. Third, Edin et al. (2003) and Piil Damm (2009) make use of natural experiments in Sweden and Denmark respectively to identify the effect of concentration in municipalities on outcomes, whereby asylum seekers are randomly allocated to initial housing centres across the country. As these natural experiments result in initial housing locations being independent of unobservable migrant characteristics, initial concentrations can be used as instruments for later concentrations allowing causal analysis of concentration on outcomes. Edin et al. document immigrant earning gains associated with a standard deviation increase in ethnic concentration in a municipality amounting to 13 per cent. Piil Damm (2009) finds that a standard deviation increase in local ethnic group size in a municipality on average increases earnings by 18 per cent while the effect on employment chances are positive (insignificant) for low-educated individuals but negative for the high-educated. 
Although the use of random assignment to identify municipality or neighbourhood effects is attractive, both studies are troubled by a number of shortcomings. First, neither of the studies manages to clearly identify the asylum population given missing information on residency status. As a consequence the studies rely on country of origin information and define asylum seekers as all individuals originating from the main asylum sending countries, a choice that naturally leaves a large margin of error as it necessarily includes many non-asylum migrants. Second, the studies only observe the municipality of the immigrants and not the neighbourhood they live in. Literature suggests that the effects of concentration on outcomes result mainly from neighbours in the direct environment of a person. Concentration at the municipality level is, therefore, only a rough approximation for neighbourhood concentration. Third, as both studies are situated in small European countries and the asylum identification procedures further reduces the population size, the resulting samples of the studies are rather small considering the methodological approach chosen. As a consequence, the smaller samples of Edin et al. (2003) and Piil Damm (2009) do not allow the analyses of non-linearities and heterogeneity in the relationship between neighbourhood concentration and labour market outcomes. It is however unlikely, that all migrants are affected equally or that the true relationship between concentration and labour market outcomes is linear. Benefits of concentration are expected to rise with the level of concentration due to increasing economic opportunities related to ethnic economies (Portes \& Bach 1985).

\section{3 - Random allocations of asylum seekers in the Netherlands}

Theory suggests that that neighbourhood concentration is an endogenous variable as unobserved individual characteristics determine residential choices of migrants. This, in turn, complicates causal analysis of the effect of concentration on labour market outcomes. In the following section we will allude to this problem and explain our methodological approach chosen to tackle it, namely by exploiting a natural experiment - the random allocation of asylum seekers to initial housing centres in the Netherlands.

\subsection{1 - Natural experiments and endogeneity}

To illustrate the problem related to neighbourhood sorting, we consider the following model to estimate labour market outcomes (i.e. wages or employment status) of individual $i$ expressed by

$Y_{i}=e_{i} \alpha+A_{1 i} \beta_{1}+\varepsilon_{i}$ 
where $Y_{i}$ represents labour market outcomes of individual $i_{,} e_{i}$ is a scalar variable measuring residential ethnic concentration of individual $i, A_{1 i}$ is a matrix including observed and unobserved individual, ethnic group, and local neighbourhood characteristics, and $\varepsilon_{i}$ is a random error term. Our key variable of interest is $\alpha$, which measures the average impact of ethnic concentration on labour market outcomes.

In our model, the effect of ethnic concentration on labour market outcomes can be clearly identified as long as concentration is an exogenous variable to the model. This is, however, unlikely since housing decisions are based on costs and benefits given personal circumstances, as was pointed out by various earlier studies (Cutler and Glaeser 1997, Bertrand, Luttmer and Mullainathan 2000, Edin et al. 2000). Neighbourhood choices and thus concentration tend to themselves be affected by unobserved individual, ethnic group, and/or local neighbourhood characteristics. These omitted variables in turn introduce unexplained variation to the model, which biases the concentration coefficient. To adequately address these endogeneity issues, our study exploits a natural experiment, namely the random allocation of asylum seekers to initial housing centres in the Netherlands.

\subsection{2 - Asylum inflows in the Netherlands and the role of COA}

\section{Asylum claims in the Netherlands}

In the period from 1995 to 2004, annually between 9,600 and 45,000 asylum claims were made in the Netherlands as shown in Figure 3.1 below. Asylum claims strongly fluctuated increasing towards a peak in the end 1990's at the time of the Kosovo crisis and decreasing thereafter as a result of, among others, stricter asylum regulations from 2001 onwards. While asylum claimants have originated from a great number of origin countries, which were changing over time, many asylum seekers have come from the countries of Ethiopia, Somalia, Sudan, Liberia, Sierra Leone, Iran, Iraq, Afghanistan, Sri Lanka, Turkey, and the former Yugoslavia.

Despite the large number of asylum claims in the country, it is self-evident that the actual number of asylum inflows is far lower than this. First, due to repeat claims, the number of asylum claims is overstating the actual population of asylum seekers. Second, only a fraction of asylum claims is actually recognized enabling residency. As asylum procedures may take several years, it is difficult to estimate the success rate of asylum claims for recent cohorts. However, according to the Dutch Immigration and Naturalization Service (IND hereafter), this fraction was 40 per cent, 43 per cent and 47 per cent for the 1995 to 1997 cohorts respectively. 
Figure 3.1: Annual asylum claims and recognized claims in the Netherlands 19952004

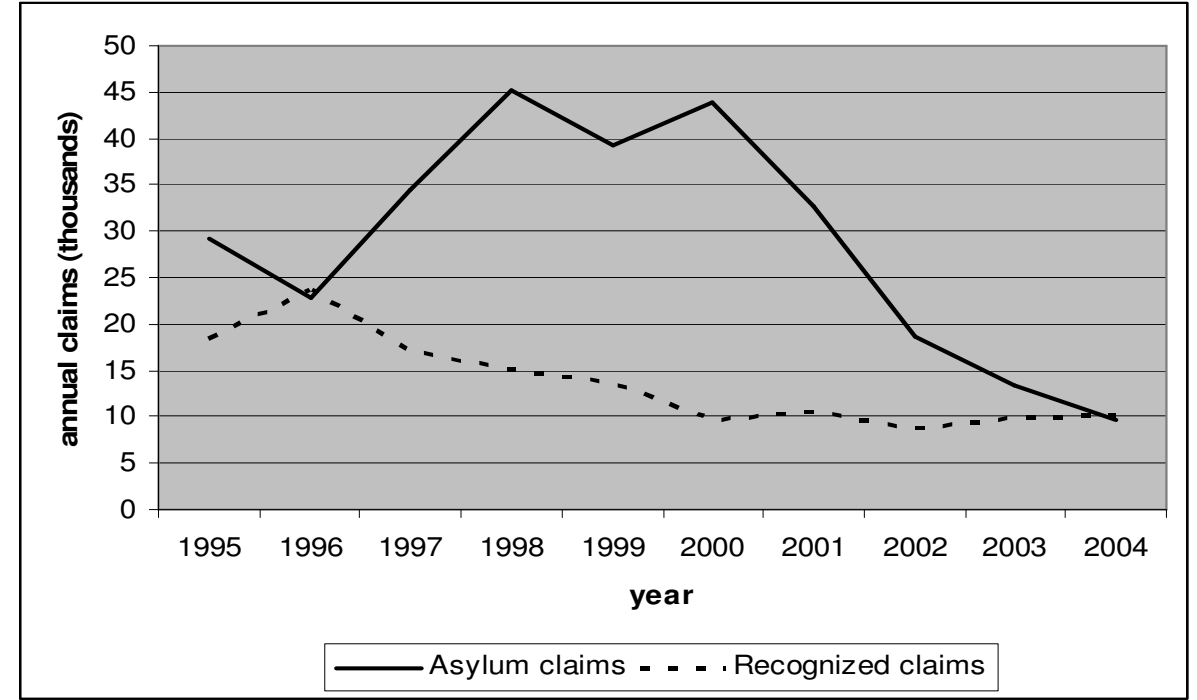

Sources: Netherlands Bureau of Statistics Statline 2007, IND (Vluchtelingen in getallen 2004)

Figure 3.1 further illustrates the temporal divide between launched claims and recognitions, which at that time commonly measured one to three years. During the waiting time in procedure, asylum seekers, with few exceptions, are centrally allocated to asylum centres, which are coordinated by the independent governmental body 'Centraal Orgaan opvang Asielzoekers' (COA hereafter). In the coming section we will discuss the details of the allocation procedure and provide information on the asylum centres to illustrate random allocation.

\section{Asylum procedure}

Asylum seekers have to claim asylum immediately upon entrance to the Netherlands. This can be done at any of four registration centres at Zevenaar, Rijsbergen, Ter Apel or at Schiphol Airport. At these locations personal belongings are checked and IND staff carries out interviews to gather information on identity, nationality, reason for seeking asylum and travel route of the asylum seekers. On basis of the acquired information, the IND then decides as to whether the asylum claim is to be processed in the registration centre within the fast procedure generally within 48 hours - or as to whether more time for research is required and the procedure is transferred to another IND office. While asylum seekers in the fast procedure are residing in IND provided housing nearby the registration centres, all other individuals are put under custody of COA, which then allocates the newcomers to asylum centres throughout the country. According to information from the IND, around 40 per cent of asylum claims are completely processed 
within the fast procedure, the great majority of which being rejected (IND, De procedure in het aanmeldcentrum 2006; VluchtelingenWerk Nederland, Vluchtelingen in getallen 2004). Figure 3.2, below, provides an overview of the asylum procedure in the Netherlands including parties responsible for central housing provisions.

Figure 3.2: Asylum procedure in the Netherlands and parties responsible for central housing provisions

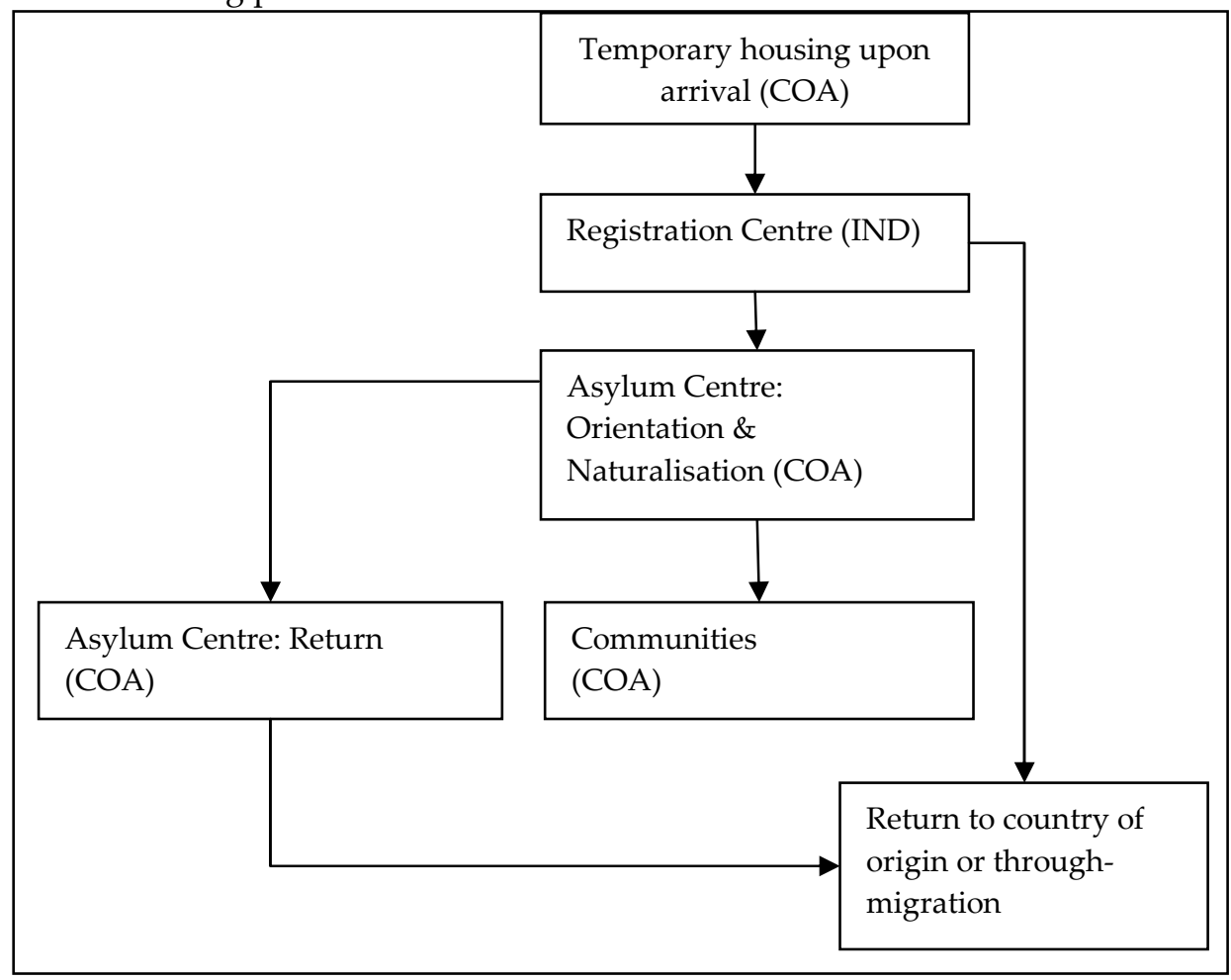

Source: COA 2007

As shown in Figure 3.2 above, COA assumes all central housing responsibilities apart from asylum seekers remaining at the IND registration centres, and until 1996, individuals directly residing in communities while awaiting the outcome of the asylum procedure. As relatively few individuals receive residency permits during the fast or so-called 48 hour procedure and are then free to reside as they wish, nearly all individuals are centrally allocated to COA housing centres without having own choices regarding locations. According to COA information, the direct inflows to communities in the years 1995 and 1996 were 10,650 and 580 respectively. These direct placements were spread across the country with particularly larger inflows to the cities of Rotterdam, Den Haag, Amsterdam, Eindhoven, Zaanstad, Apeldoorn, Groningen, Emmen, Arnhem and Enschede as 
shown in Table 3.1 below. From 1996 onwards, all asylum seekers were obligated to reside in COA asylum centres upon entrance to the country, and thus direct community placement was no longer allowed.

Table 3.1: Main communities with direct asylum inflows in the years 1995-1996

\begin{tabular}{llll}
\hline \hline & years & & \\
Community & 1995 & 1996 & Total \\
\hline Rotterdam & 823 & 53 & 876 \\
Den Haag & 457 & 37 & 494 \\
Amsterdam & 221 & 14 & 235 \\
Eindhoven & 197 & 10 & 207 \\
Zaanstad & 157 & 15 & 172 \\
Apeldoorn & 165 & 5 & 170 \\
Groningen & 148 & 10 & 158 \\
Emmen & 147 & 3 & 150 \\
Arnhem & 141 & 8 & 149 \\
Enschede & 141 & 5 & 146 \\
\hline \hline
\end{tabular}

Source: COA 1995-2004

According to official figures from COA, asylum seekers in 2005 resided on average 47 months in asylum centres before being free to reside elsewhere upon hearing the verdict of their asylum claim (IND 2004). 70 per cent of all asylum seekers of the respective year stayed in the centres for longer than three years, without actually knowing as to whether they would be allowed to remain in the country thereafter (Vluchtelingenwerk, Integratiebarometer 2006). ${ }^{13}$

\section{COA Asylum centres}

According to official COA information, initial placement of asylum seekers is essentially random with exceptions only necessitated by medical conditions or reunification of the first grade family. ${ }^{14}$ Centre locations are furthermore chosen to optimize immigrant prospects for socio-economic integration in local communities. Important criteria are labour market possibilities, availability of educational institutions as well as the favourability of local reception conditions (COA 1995-

\footnotetext{
${ }^{13}$ For the prior years the asylum procedures took relatively less time, nonetheless leaving thousands of asylum seekers to reside in centres for more than three years. For the years 2000 to 2004, the numbers and percentages of asylum seekers remaining with COA for longer than three years are 6,800 (11\%), $9,000(12 \%), 18,800(25 \%), 25,300(44 \%)$, and $29,200(55 \%)$ respectively.

${ }^{14}$ First grade family are siblings, parents and their children. At later stage, asylum seekers may be relocated upon request in case of a job opportunity or special education needs. Under exceptional local circumstances COA may also have to consider additional factors such as nationality, religion and gender composition.
} 
2004). While - given these criteria - it is unrealistic to assume that all communities of the Netherlands are equally likely to host asylum seekers, randomness of centre locations is not necessary as long as they remain uncorrelated to asylum seeker characteristics.

In the period 1995-2004 COA operated a total of 436 asylum centres throughout the country, which were organized in 12 provincial clusters as can be seen in Table 3.2 below (please refer to Figure 3.A1 in the Appendix for a map of the 12 Dutch provinces). In absolute numbers, many asylum seekers were hosted by the provinces of Noord-Brabant $(71,230)$ and Gelderland $(63,436)$, followed by Friesland $(48,806)$ and Zuid-Holland $(48,680)$. Few asylum seekers were placed in the provinces of Zeeland $(14,882)$, Utrecht $(20,459)$ and Flevoland $(25,217)$. However, when accounting for general population differences between provinces a different picture emerges. The shares of asylum seekers per total population are notably higher in provinces with low population density (i.e. Drenthe, Friesland, Groningen, Flevoland, and Zeeland) than in those with high population density (i.e. Noord and Zuid-Holland, Utrecht). In other words, asylum seekers are more likely to be placed in less urbanized regions of the country, which may be explained by the more favourable local reception conditions there (i.e. less distressed) as compared to the ones around the larger cities. This overall allocation pattern is furthermore consistent throughout the years 1995-2004. ${ }^{15}$

Table 3.2: Asylum centres per province (1995-2004)

\begin{tabular}{llll}
\hline \hline province & centres & people & asylum share* \\
\hline Drenthe & 43 & 38,911 & $0.73 \%$ \\
Friesland & 42 & 48,806 & $0.69 \%$ \\
Groningen & 41 & 42,822 & $0.68 \%$ \\
Flevoland & 6 & 25,217 & $0.64 \%$ \\
Zeeland & 19 & 14,882 & $0.36 \%$ \\
Overijssel & 37 & 42,100 & $0.35 \%$ \\
Gelderland & 49 & 63,436 & $0.29 \%$ \\
Noord-Brabant & 45 & 71,230 & $0.27 \%$ \\
Limburg & 36 & 32,012 & $0.25 \%$ \\
Utrecht & 14 & 20,459 & $0.16 \%$ \\
Noord-Holland & 65 & 37,220 & $0.13 \%$ \\
Zuid-Holland & 39 & 48,680 & $0.13 \%$ \\
Total & 436 & 48,5775 & \\
\hline \hline
\end{tabular}

* Average annual number of asylum seekers per province (1995-2004) divided by total population of province as of 1 January 2000.

${ }^{15}$ Refer to Table 3.A1 in the Appendix for further details. 
Source: COA 1995-2004, Netherlands Bureau of Statistics SSB 1995-2004

The equal distribution of asylum centres and seekers throughout the country is, however, not paramount for the validity of our research approach as long as individual characteristics of asylum seekers do not systematically differ between centre locations. To recap, according to official COA policy this is unlikely the case, as the policy states that initial placement of asylum seekers is essentially random with exceptions only necessitated by medical conditions or reunification of first grade family. While our data does not contain information on medical circumstances nor on family ties, it does provide us with details on country of origin, gender and age group compositions at the centre level. We compare these compositions and indeed find little variation across centres; specifically, we find that the distribution of the centre shares of females, minors and individuals aged 18 to 64 resembles normality averaging $38,8 \%, 33,9 \%$ and $65,4 \%$ respectively. ${ }^{16} \mathrm{We}$ furthermore aggregate these compositions to the province level to perform cross province comparisons. Across all provinces, the countries of Afghanistan and Iraq are the most common countries of origin contributing more than 10 per cent each of total asylum seekers per province (Refer to Table 3.A2 in the Appendix). Next to Afghanistan and Iraq, the countries of Angola, Azerbaijan, Armenia, Iran, Somalia, Sierra Leone, Sudan and the former Yugoslavia are also prime origin countries across the panel. When summed together, these top 10 origin countries account for the majority of all asylum seekers hosted by each of the provinces. We further contrast gender and age group compositions across the 12 provinces, which in both cases reveal little variation (refer to Table 3.A3 in the Appendix). On average women constitute 38 per cent of the national asylum population and all of the provincial averages fall within a 2 per cent range from this. In a similar fashion, age group compositions across provinces are remarkably similar. About 33 per cent of the provincial asylum populations are under age 18, 66 per cent of working age (i.e. 18-64 years), and 1 per cent in the age group above 65 . In conclusion, based on our comprehensive review of all available official COA documentation and data sources, we have sufficient reason to believe that allocation of asylum seekers to centres is near random, which suggests that initial housing locations are a valid instrument for later residential concentrations.

3.4 - Data and methodology

The analysis of this chapter is based on administrative data for the period 19952004 collected by Statistics Netherlands. This data contains information on all 16

16 Temporary locations (i.e. hotels, youth hostels) accomodating less than 10 asylum seekers are excluded from the analysis as they were only used at times of humanitarian crises when the supply of housing in asylum centres was insufficient for the large inflow of people. Standard deviations are $6,8 \%$, $8,9 \%$ and $8,9 \%$ respectively. 
million people residing in the country in the respective period including information on the working population of about 8 million individuals. This data is part of the SSB (Social Statistical Database), which includes a number of connected administrative registers with demographic and socio-economic information that are complemented by surveys providing additional insight. ${ }^{17}$ For the purposes of our study, we match two data sets of the SSB, which we briefly explain hereafter, namely the GBA (Gemeentelijke Basisadministratie) and the SSB Banenbestand (Social Statistical Database of Jobs).

\section{The GBA (Gemeentelijke Basisadministratie)}

The GBA contains information on demographics, household compositions, and geographical locations of all 16 million individuals residing in the Netherlands. We use the records for the 10-year period 1995-2004, which are kept by local communities according to a unified national recording system assuring compatibility of records throughout the country. Moreover, the data set is a panel as individuals can be tracked across time by means of a personal identifier (the socalled RIN number). Changes in personal records such as address changes, changes in marital status etc. become visible, as a new record is created for each change containing a coding for the type of change that occurs.

\section{The Social Statistical Database of Jobs (SSB Banenbestand)}

The SSB Database of Jobs contains information on all employment relationships in the Netherlands (about 10 million records in 2004), whereby individuals may have several jobs at a given time. Availability of both firm as well as personal identifiers allows evaluation of individuals' and firm performance over time. Self-employed workers are not included in the data set. The data originates predominantly from employee insurance records and is complemented with information from the employee tax records. We use data for the six-year period 1999-2004. ${ }^{18}$

\section{Matching}

Our data set combines information from the GBA (1995-2004) and the SSB Database of Jobs (1999-2004). Through the matching of the two data sources on basis of personal identifiers (RIN numbers) a great amount of information becomes available on demographics, household compositions, geographical locations, jobs

\footnotetext{
${ }_{17}$ Next to the core databases, also a number of so-called satellite databases exist. These databases can be linked by means of personal identifiers (RIN numbers), Firm identifiers or address identifiers (RIN addresses). They contain additional information, for instance on migration motives, housing characteristics, the Geographic Base Register of the National Post to contain full details on addresses and neighbourhoods of residency, the $1 \%$ of Workforce Survey (rotating panel) (EBB) available from 1999 onwards to include info on educational background, travel distance and time to/from work, current job dynamics such as stress and conflict levels.

${ }^{18}$ For further specifics on the data set, please refer to Borghans and Kriechel, 2007.
} 
and social security benefits of individuals. As the resulting data set is a panel, this furthermore allows tracking of people over the 10-year period 1995-2004. With employment data available from 1999 onwards, it is thus possible to exactly follow individuals across periods of unemployment and employment for six years. Finally, as these records contain specifics on individuals' residence statuses, countries of origin and places of residence at the geographical precision of postal code areas, the data lends itself favourably to the analysis of neighbourhood characteristics and immigrant labour market outcomes.

\section{Variable descriptions}

In this study we investigate labour market performance on the basis of two outcome variables, namely employment status and annual wages. ${ }^{19}$ Employment status is a binomial variable taking the value 0 for people who are not employed and 1 for employed respectively. The annual wages variable is the annual aggregate of all fiscal, gross salaries (excluding fringe benefits) that individuals earn in employment relationships. Finally, as many individuals have worked part time over the respective period, we chose to analyse wages only of the employed having worked at least twenty days with minimum annual wages of $€ 100$ in the respective year. Individuals not meeting these criteria are regarded as unemployed.

The study makes use of various geographical units of aggregation, which require a brief explanation. The country of the Netherlands measures 41,500 square kilometres and comprises twelve provinces and 467 municipalities in 2005. ${ }^{20}$ Each municipality is further subdivided into suburbs and neighbourhoods, the latter of which form the smallest geographical unit. In 2005 the 467 municipalities counted 2,491 suburbs and 11,286 neighbourhoods of varying population numbers. The division into suburbs and neighbourhoods is done centrally by the Netherlands Bureau of Statistics, whereby neighbourhoods are grouped according to homogeneous building structures and/or common socio-economic composition. Suburbs are generally grouped according to common area use, i.e. industrial terrain, high rise housing zone, low rise housing zone. Finally, the country is divided into 40 so-called COROP areas, which are equivalent with Eurostat classification NUTS 3 (i.e. Nomenclature of "Territorial Units for Statistics"). This classification was developed to reflect socio-economic differences across regions of the country with each region generally including a core socio-economic centre and its surrounding area.

${ }^{19}$ Compares to methodology of prior studies (i.e. Chiswick \& Miller, 2002; Bauer et al., 1998).

${ }^{20}$ Please refer to Figure 3.A1 in the Appendix for a map of the country. 
We include a number of local controls in our analysis, namely the degree of urbanization of the municipality, neighbourhood mean employment ratio and neighbourhood mean wage. First, the degree of municipal urbanization is defined as the average number of addresses per square kilometre. As this indicator is rather constant over time we decide to use fixed levels as of 1 January 2003 for the analyses of all years. ${ }^{21}$ Second, neighbourhood mean employment ratio is defined as the percentage of employed people per total neighbourhood population of working age (i.e.18-64). People are considered employed if they have worked at least twenty days with minimum annual wages of $€ 100$ per year. Individuals not meeting these criteria are regarded as unemployed. Third, neighbourhood mean wage is defined as the average wage of the employed population per neighbourhood for each year.

We define non-Western concentration $\left(e_{i j}\right)$ as the share of non-Western population per total population residing in a given neighbourhood. We define the nonWestern population on basis of country of origin information in line with the socioeconomic typology of Statistics Netherlands (Netherlands Bureau of Statistics, Statline, 2007).22 The population includes all individuals originating from countries not part of the European Union $15^{23}$ or other Western Countries ${ }^{24}$. As individual behaviour is shaped by social networks with people sharing common cultural values, beliefs, and language, we further divide the population of non-Westerners into six socio-geographic groups of origin regions to analyse these dynamics. These regional groups are Latin America \& the Caribbean, Eastern Europe \& Commonwealth of Independent States, the Arab Region, Non-Arab Africa, NonArab Asia, and Turkey. ${ }^{25}$ We base our grouping on common linguistic, cultural and historic backgrounds of the origin countries of non-Western immigrants in the Netherlands. While it is clear that this classification is somewhat subjective, it nonetheless allows more in depth analysis of non-Western immigrant groups sharing similar characteristics.

\footnotetext{
${ }^{21}$ The indicator counts all addresses in a $1 \mathrm{~km}$ radius of each $500 \times 500 \mathrm{~m}$ square of land. According to this measure, Amsterdam had the highest population density with around 6,000 addresses per square kilometre, followed by The Hague (4,700), Rotterdam and other municipalities in the Randstad region. 22 Our classification differs slightly from the one of Statistics Netherlands in that we include immigrants from Indonesia and Japan in the group of non-Westerners as we believe their values, beliefs and language to be closer to the ones of other Asian immigrants than to those of natives. They are thus more likely to engage in social interactions with the former group.

${ }^{23}$ The EU 15 includes the United Kingdom, Ireland, Sweden, Finland, Denmark, Germany, Belgium, The Netherlands, Luxemburg, France, Spain, Portugal, Italy, Austria, and Greece.

${ }^{24}$ Western Countries include EU15, Norway, Switzerland, Liechtenstein, Andorra, Monaco, Vatican City, San Marino, Cyprus, Malta, Israel, United States of America, Canada, Australia, New Zealand, and South Africa.

${ }_{25}$ Please refer to Table 3.A4 in the Appendix for an exhaustive list of countries per geographical regions.
} 
The data permits accurate measurement of immigrants' experience in the country. Experience can be calculated on basis of day-month-year information on entry into the country. Moreover, as the data contains precise day-month-year figures also on exit of immigrants, it is possible to calculate experience accurately even for individuals having left and re-entered the country. We measure experience in full year equivalents. ${ }^{26}$

\section{Identification of Asylum Centres and Population}

Thanks to the support of COA, we have detailed information on all Dutch asylum centres in operation over the period 1995-2004. This includes centre characteristics such as capacities, opening and closing dates, exact locations at postal code level, but also centre occupancy statistics on gender, age and country of origin compositions. When matching this dataset with administrative data, it enables us to identify the exact neighbourhoods of the asylum centres. Given average neighbourhood size of about 1,500 people, this implies a good starting point for accurate identification of the asylum population. As we know the official asylum centre neighbourhoods from the COA list ${ }^{27}$, we further follow a three step approach towards identification of asylum seekers in our administrative data. First, as the administrative data contains an address identifier, we identify potential asylum centres as clusters of twenty individuals or more, who reside at the same address, and the address lies in a neighbourhood where an official COA asylum centre is located. ${ }^{28}$ Second, we compare these clusters from step one with the official COA list to exclude several unlikely locations where: a - clusters have more than 3 times the maximum capacity as stated in the official COA list; $b$ - the number of clusters per neighbourhood in the list from step one exceeds the number of asylum centres from the official COA list largely; ${ }^{29} \mathrm{c}-$ clusters have less

${ }^{26}$ From the identified 93,474 asylum seekers residing in the Netherlands in the 1995-2004 time period, 5,449 individuals have entered the country in or before 1995 and remained throughout the entire period. 87,642 individuals have stayed in the country with no interruptions. 383 individuals have resided in the Netherlands more than one continuous time periods, which represents a share of $0.4 \%$ of the whole asylum population. As this share is considerably low, for convenience we decide to calculate experience as the time period between immigration year and year of analysis.

${ }^{27}$ We exclude temporary residences such as the registration centres at Schiphol, Ter Apel, Zevenaar (open until 2004) and Rijsbergen (open until 2004) from the COA list as asylum seekers only reside there for several days.

${ }^{28}$ These potential asylum centres match to $90 \%$ with the postal codes of the official COA centre list. This does not mean that they are good matches within the neighbourhood. The $10 \%$ of official centres we cannot match are likely to be mostly smaller asylum housing units of COA, which are also part of the official COA list but that are not clusters of 20 people or more.

${ }^{29}$ In several cases this was not done when field research had shown that an asylum centre from the COA list had several addresses and this number of addresses corresponded with the number of clusters found in the administrative data. 
than 80 per cent of residents originating from non-Western countries. ${ }^{30}$ We apply this very conservative procedure in identifying asylum centres to avoid observations in the sample of people who are not placed by the authorities. This yields a final selection of 318 of the 436 official COA asylum centres spread all over the country. Third, we identify the asylum population as all residents of the 318 asylum centres with country of origin other than the Netherlands, the Dutch Antilles, and Suriname. Through our approach, we identify nearly 92,000 asylum seekers initially residing in one of the COA centres. This inflow of asylum seekers constitutes about one third to one fourth of the actual inflows of asylum seekers over the period of investigation, which is a reasonably large share considering the thorough exclusion process that was followed to ensure data validity.

\section{The Econometric Model}

The primary question of interest of our research is whether the level of ethnic residential concentration affects labour market outcomes of immigrants. This question is generally difficult to assess as residential locations are subject to individual choices. This results in non-random allocation of immigrants across neighbourhoods making neighbourhood concentrations endogenous to the socioeconomic background of individuals. However, the natural experiment of random allocation of asylum seekers to initial housing centres in the Netherlands enables us to overcome these estimation problems. As initial housing locations of asylum seekers can be regarded as exogenous to individual socio-economic characteristics, we can use initial neighbourhood identifiers as instruments for neighbourhood concentrations of later years. This will enable us to evaluate the causal effect of neighbourhood concentration on labour market outcomes of immigrant $i$ at time $t$ residing in neighbourhood $j$ using the following baseline specifications:

$$
\begin{aligned}
& \operatorname{Pr}\left(\text { employed }_{i j t}\right)=\alpha X_{i t}+\beta e_{i j t}+\delta_{t}+\delta_{j}+\varepsilon_{i j t} \\
& \ln \left(\text { wages }_{i j t}\right)=\alpha X_{i t}+\beta e_{i j t}+\delta_{t}+\delta_{j}+\varepsilon_{i j t} \text { s.t. } \operatorname{Pr}\left(\text { employed }_{i j t}\right)>0
\end{aligned}
$$

where $\operatorname{Pr}\left(\right.$ employedijt $\left._{i j}\right)$ is a dummy for employment status, $\ln ($ wagesijt $)$ is the natural logarithm of annual wages, $X_{i t}$ is a set of individual characteristics including gender, age and age-square, $e_{i j t}$ is the percentage of non-Western concentration in the neighbourhood such that $e_{i j t} \in[0,1], \delta_{t}$ represents a set of year fixed effects including year and grouped experience dummies, ${ }^{31} \delta_{j}$ stands for local fixed effects

\footnotetext{
${ }^{30}$ We chose for the $80 \%$ instead of $100 \%$ population of non-Western origin as we only possess annual COA data on centre occupancy; since asylum centres have opened and closed during the year, it is thus possible that for the other part of the year the building was in use for accommodating other population groups. If, for instance, a building was in COA use from June 1995 onwards, our GBA data might include other population residing in the tagged centres during the months January-June 1995.

${ }^{31}$ Experience is grouped into three categories, namely 4 years or less, 5-7 years, more than 8 years.
} 
and includes neighbourhood mean employment rate, neighbourhood mean wages, degree of municipal urbanization as well as a regional (i.e. COROP) dummy, and finally $\varepsilon_{i j t}$ is an error term assumed to be multivariate normal, $\left(\varepsilon_{i j t}\right)=\mathrm{N}(0, \Sigma)$.

To overcome the problem of endogeneity of our neighbourhood concentration variable, we use the full set of initial neighbourhood dummies to instrument actual neighbourhood concentration in the current place of living. The first and second stage equations are found in Equations 4-6 below:

$$
\begin{aligned}
& e_{i j t}^{*}=\chi_{i j} C_{i}+v_{i j t} \\
& \operatorname{Pr}\left(\text { employed }_{i j t}\right)^{I V}=\varphi e^{*}+\alpha X_{i t}+\delta_{t}+\delta_{j}+\varepsilon_{i j t} \\
& \ln \left(\text { wages }_{i j t}\right)^{I V}=\varphi e^{*}{ }_{i j t}+\alpha X_{i t}+\delta_{t}+\delta_{j}+\varepsilon_{i j t}
\end{aligned}
$$

where $C_{i}$ includes $X_{i t}, \delta_{t}, \delta_{j}$, and the instrument, $Z_{i} . v_{i j t}$ is the error term by assumption to be multivariate normal, $\left(v_{i j t}\right)=\mathrm{N}(0, \Sigma)$.

\section{5 - Findings}

\section{First stage}

In Section 3.2 we have demonstrated near random allocation of asylum seekers to initial housing centres, which ensures exogeneity of our instrumental variables. Additionally, for the instruments to be relevant for our analysis, they need to be correlated with annual non-Western neighbourhood concentrations. Figure 3.3 shows the average concentration in the neighbourhood of living (in the period 1995-2004) conditional on the concentration in the neighbourhood of initial placement. The figure documents their strong positive relation. Of course, due to reversal to the mean individuals initially residing in lower and higher concentration neighbourhoods tend to move to mid-range ones. ${ }^{32}$ Concluding, overall our instruments are highly relevant for later neighbourhood concentrations especially for individuals initially residing in low to mid-range concentration neighbourhoods. 
Figure 3.3: Average concentration in the neighbourhood of living (1995-2004) conditional on the concentration in the neighbourhood of initial placement*

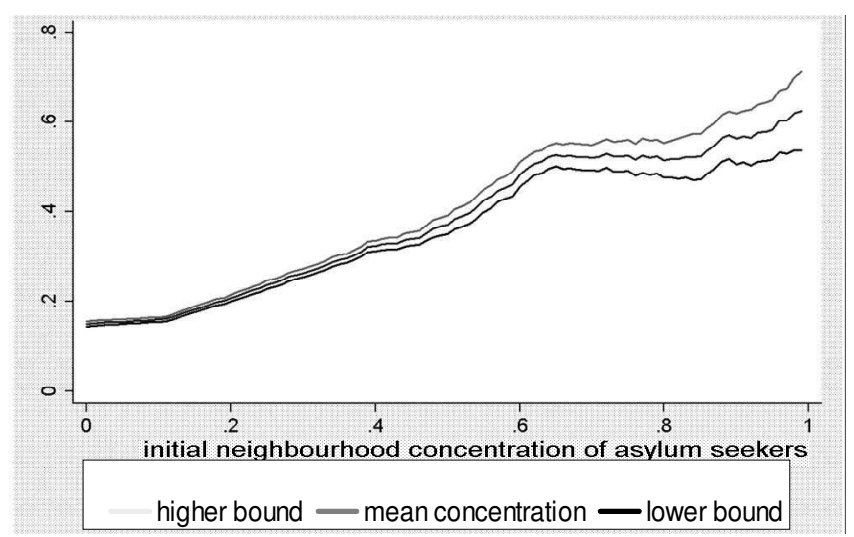

*First stage kernel graph; $\mathrm{x}$-axis - mean initial non-Western neighbourhood concentration; $\mathrm{y}$-axis - mean non-Western neighbourhood concentration, where lower (higher) bound is defined as mean nonWestern neighbourhood concentration less (plus) $1.96^{*}$ standard error. Bandwidth=.1; y=0(.01)1. Source: Netherlands Bureau of Statistics SSB 1995-2004, own calculations

\section{Descriptives}

Our data enables us to track nearly 92,000 asylum seekers who entered the Netherlands in the period 1995-2004 as shown in Table 3.3 below. Our pattern of annual inflows closely resembles the one of actual figures according to COA with numbers strongly increasing towards a peak in 2001 (i.e. introduction of new asylum regulation) and rapidly declining thereafter. Moreover, as shown in the table, with exception of 1998, the female share as well as mean age is relatively constant (40 per cent and 25 years respectively). While a negligible amount of asylum seekers originated from Latin America \& the Caribbean, many asylum seekers originated from the Eastern Europe \& CIS States, Arab, Asia and African regions. In contrast to stable inflows from Turkey, the numbers for the other regions have fluctuated largely reflecting the various economic and political crises that occurred during the 10-year period such as the ones in Kosovo, Iraq, Afghanistan, Somalia, Sudan. ${ }^{33}$

The great majority of asylum seekers accommodated by COA stays in the Netherlands for many years. Table 3.4 shows that, while probabilities to stay have deviated somewhat between cohorts, nearly all asylum seekers remain at least one year, four out of five still reside in the country after five years, and two-thirds even after nine years of first entry to the country.

${ }_{33}$ Please refer also to Table 3.A5 in the Appendix for further specifics on asylum characteristics by year. 
Table 3.3: Characteristics of asylum seekers per cohort

\begin{tabular}{|c|c|c|c|c|c|c|c|c|c|c|c|}
\hline \multirow[b]{4}{*}{ cohort } & \multirow[b]{4}{*}{ count $^{* *}$} & \multirow{4}{*}{$\begin{array}{c}\text { female } \\
\text { share } \\
(\%)\end{array}$} & \multicolumn{7}{|c|}{ shares origin groups $(\%)^{*}$} & \multicolumn{2}{|c|}{ age } \\
\hline & & & & & & & & & unknown & & \\
\hline & & & & & & & & tur- & non- & & \\
\hline & & & lac & eecis & arab & asia & africa & kish & Western & mean & st.dev. \\
\hline 1995 & 5,572 & 39.3 & 0.1 & 21.6 & 13.9 & 4.9 & 8.4 & 1.2 & 49.9 & 25.67 & 15.83 \\
\hline 1996 & 7,345 & 41.1 & 0.1 & 15.5 & 34.2 & 13.8 & 24.1 & 2.1 & 10.2 & 26.45 & 14.62 \\
\hline 1997 & 5.740 & 36.9 & 0.1 & 10.1 & 37.8 & 20.6 & 16.7 & 2.3 & 12.4 & 26.94 & 14.91 \\
\hline 1998 & 5,758 & 29.1 & 0.1 & 8.5 & 46.7 & 14.6 & 11.9 & 3.9 & 14.3 & 27.47 & 14.78 \\
\hline 1999 & 6,799 & 41.0 & 0.3 & 27.7 & 22.6 & 15.8 & 11.4 & 3.2 & 19.0 & 24.22 & 15.73 \\
\hline 2000 & 15.687 & 42.1 & 0.1 & 33.4 & 20.4 & 15.0 & 17.0 & 3.0 & 11.1 & 25.25 & 15.28 \\
\hline 2001 & 19.903 & 40.2 & 0.2 & 23.8 & 18.4 & 17.6 & 25.4 & 3.6 & 11.0 & 24.71 & 14.51 \\
\hline 2002 & 14.592 & 38.6 & 0.1 & 18.0 & 13.3 & 14.9 & 39.4 & 2.8 & 11.4 & 23.57 & 14.19 \\
\hline 2003 & 7,875 & 37.6 & 0.2 & 17.6 & 14.5 & 14.0 & 36.4 & 2.3 & 15.0 & 23.20 & 14.40 \\
\hline 2004 & 2,391 & 39.2 & 1.6 & 14.1 & 19.5 & 9.9 & 33.9 & 2.4 & 18.6 & 22.17 & 14.91 \\
\hline total & 91.662 & & & & & & & & & & \\
\hline
\end{tabular}

* lac (Latin America \& Caribbean), eecis (Eastern European \& CIS region), arab (Arab countries). Table

3.A4 in the Appendix contains further information on the origin grouping.

** Includes all individuals first registered in the GBA in the respective year. GBA registration is typically 6 months after entry.

Source: Netherlands Bureau of Statistics SSB 1995-2004, own calculations

Table 3.4: Probabilities of asylum seekers to stay in the Netherlands (in per cent)

\begin{tabular}{lllllllllll}
\hline \hline & & \multicolumn{10}{c}{ years (\%) } \\
\cline { 3 - 10 } cohort & count & 1996 & 1997 & 1998 & 1999 & 2000 & 2001 & 2002 & 2003 & 2004 \\
\hline 1995 & 5,572 & 95.9 & 85.9 & 80.0 & 78.0 & 76.7 & 74.6 & 72.6 & 70.8 & 67.6 \\
1996 & 7,345 & & 98.2 & 92.4 & 88.5 & 86.9 & 84.7 & 82.2 & 79.2 & 75.2 \\
1997 & 4,740 & & & 97.7 & 93.4 & 90.4 & 87.5 & 85.5 & 82.5 & 78.5 \\
1998 & 5,758 & & & & 98.8 & 93.7 & 88.5 & 85.2 & 80.1 & 74.6 \\
1999 & 6,799 & & & & & 97.6 & 91.7 & 87.7 & 83.0 & 78.7 \\
2000 & 15,687 & & & & & & 99.0 & 94.6 & 88.7 & 82.1 \\
2001 & 19,903 & & & & & & & 99.0 & 92.4 & 84.2 \\
2002 & 14,592 & & & & & & & & 98.1 & 87.3 \\
2003 & 7,875 & & & & & & & & & 96.1 \\
\hline \hline
\end{tabular}

Source: Netherlands Bureau of Statistics SSB 1995-2004, own calculations

Employment probabilities among asylum seekers are generally low, which is in part explained by their unique legal status and the related restrictions to seek employment. ${ }^{34}$ Despite this, asylum seekers with more experience in the country

\footnotetext{
${ }^{34}$ In the period of analysis, the Dutch government changed asylum regulations effective as of 1 April 2001 (i.e. Vreemdelingenwet 2000). This replaced the previous statuses of asylum with new ones as explained in the following. Until April 2001 three statuses were distinguished, namely A-status
} 
are largely more likely to be employed as they have gained country-specific skills such as command of the Dutch language, cultural familiarity, as well as knowledge of the local labour market opportunities and demands. As demonstrated in Table 3.5, overall employment probabilities increase from 14 per cent for individuals with four or less years of country experience to 37 per cent for those with eight years or more experience. ${ }^{35}$ Across the panel, most employment is in low-pay, part time jobs; only 1 per cent of asylum seekers with four years or less of experience is working in jobs paying more than $€ 17,500$ annually, which increases to 15 per cent for individuals with eight years or more experience. Women are considerably less likely to be employed with few working within the first four years after immigration. Even after eight years, labour market participation remains low as around three-quarters of women are not working, and only 7 per cent earn more than $€ 17,500$ per year. Men realize considerable positive economic mobility over time being more than three times as likely to be employed than women in the first four years after immigration and 24 per cent working in jobs making $€ 17,500$ or more annually after eight to ten years. ${ }^{36}$ We detect little variation in employment probabilities and incomes across the country of origin groups. ${ }^{37}$

Table 3.5: Annual wage distributions, per gender and experience groups (in per cent)

\begin{tabular}{llllllllllll}
\hline \hline & & \multicolumn{10}{c}{ wage groups (percentages, wages in $€$ ) } \\
\cline { 3 - 11 } group & experience & 100 & 9,999 & 12,499 & 14,999 & 17,499 & 19,999 & 22,499 & 24,999 & 29,999 & plus \\
\hline overall 1-4years & 86.2 & 11.4 & 0.5 & 0.5 & 0.4 & 0.4 & 0.3 & 0.2 & 0.1 & 0.1 \\
& 5-7years & 72.2 & 15.4 & 1.5 & 1.6 & 1.8 & 2.0 & 1.9 & 1.5 & 1.5 & 0.7 \\
& 8-10years & 62.9 & 15.4 & 1.9 & 1.9 & 2.4 & 2.9 & 2.8 & 2.7 & 4.1 & 3.0 \\
male & 1-4years & 80.5 & 15.8 & 0.8 & 0.7 & 0.6 & 0.6 & 0.5 & 0.3 & 0.2 & 0.1 \\
& 5-7years & 65.3 & 17.5 & 1.8 & 1.9 & 2.3 & 2.8 & 2.8 & 2.3 & 2.3 & 1.0 \\
& 8-10years & 56.2 & 16.2 & 1.9 & 1.9 & 2.5 & 3.4 & 3.8 & 3.9 & 5.8 & 4.5 \\
female & 1-4years & 94.9 & 4.8 & 0.1 & 0.1 & 0.1 & 0.0 & 0.0 & 0.0 & 0.0 & 0.0 \\
& 5-7years & 82.8 & 12.1 & 1.0 & 1.0 & 1.0 & 0.7 & 0.5 & 0.4 & 0.3 & 0.2 \\
& 8-10years & 72.6 & 14.2 & 1.9 & 2.0 & 2.3 & 2.2 & 1.4 & 1.0 & 1.6 & 0.9 \\
\hline \hline
\end{tabular}

Source: Netherlands Bureau of Statistics SSB 1995-2004, own calculations

(Refugee), Vergunning tot verblijf (Vtv-Asylum residence permit), and Voorwaardelijke vergunning tot verblijf (Vvtv-Asylum temporary residence permit). Both A-status as well as Vtv allow work. From April 2001 onwards, the previous statuses were replaced by two new ones, namely Vergunning voor bepaalde tijd (VVA/VVR-bep. - Asylum or regular residence permit for limited time) and Vergunning voor onbepaalde tijd (VVA/VVR-onbep. - Asylum or regular residence permit for unlimited time). While the latter one generally allows work, the former one requires in some regular cases a separate work permit for employment.

${ }^{35}$ Applying our earlier definition of employed as having at least $€ 100$ of income and 20 working days per year.

${ }^{36}$ Please refer to Table 3.A6 in the Appendix for additional information regarding annual working days per experience and gender groups.

${ }^{37}$ Please refer to Table 3.A7 in the Appendix for further information. 
As shown in Figure 3.4, non-Western neighbourhood concentrations at the first places of residence of asylum seekers range from near 0 per cent to near 100 per cent. This shows the importance of using data about neighbourhoods in comparison to municipalities. Approximately two-thirds of the distribution of initial neighbourhood concentrations is below the level of 20 per cent and oneseventh above 60 per cent. Furthermore, Table 3.6 presents summary statistics of the distributions of annual neighbourhood concentrations of non-Western immigrants. It shows that mean concentration levels have increased considerably over the 10-year period, from 13 per cent in 1995 to 25 per cent in 2004, as a consequence of rising numbers of non-Western immigrants over the period.

Figure 3.4: Initial non-Western neighbourhood concentrations

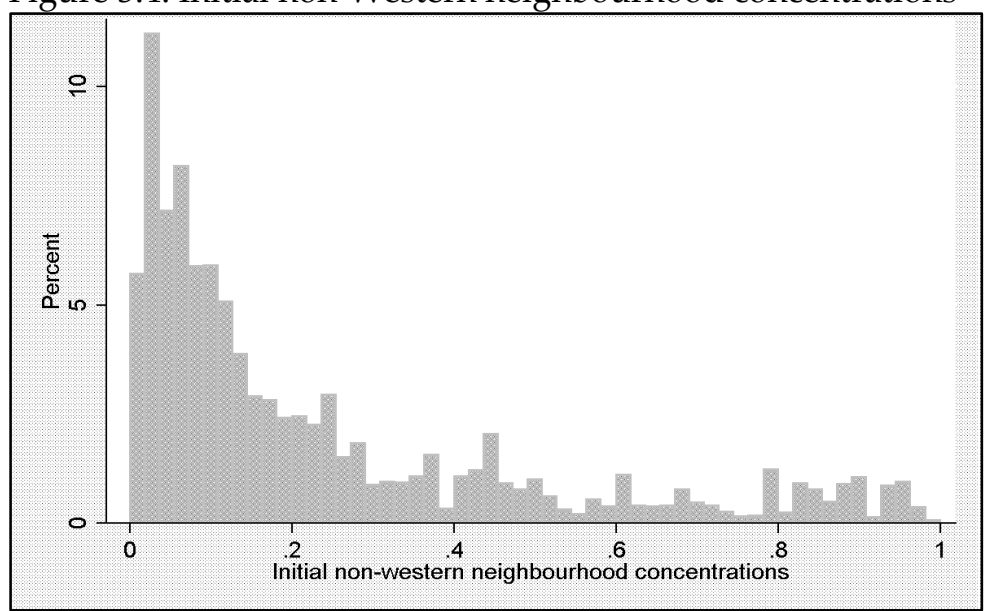

Source: Netherlands Bureau of Statistics SSB 1995-2004, own calculations

Table 3.6: Annual non-Western neighbourhood concentrations (in per cent)

\begin{tabular}{lllllllllllll}
\hline \hline \multirow{2}{*}{$\begin{array}{l}\text { concen- } \\
\text { tration }\end{array}$} & 1995 & 1996 & 1997 & 1998 & 1999 & 2000 & 2001 & 2002 & 2003 & 2004 & overall* $^{*}$ \\
\cline { 2 - 11 } & 12.96 & 20.42 & 21.83 & 18.17 & 18.16 & 19.91 & 24.00 & 25.53 & 26.00 & 24.92 & 23.60 \\
mean & st. dev. & 15.74 & 24.34 & 25.70 & 20.96 & 20.62 & 21.14 & 23.32 & 24.04 & 23.86 & 22.92 & 23.27 \\
\hline
\end{tabular}

* average over the period 1995-2004.

Source: Netherlands Bureau of Statistics SSB 1995-2004, own calculations

\section{Findings}

In Table 3.7 we present the main results. The findings are based on the complete sample of 306,200 pooled observations to estimate the employment status equation and 57,357 pooled observations to estimate the annual wages equation over the 1999-2004 period. All regression models control for individual characteristics, year fixed effects and local fixed effects through the inclusion of the variables gender, 
age, age-square, year, experience in the country, degree of urbanization, region within the Netherlands. As Table 3.7 shows, the controls are significant across the panel. As expected, age has positive, bell-shaped effects on employment chances and wages increasing to maxima at age 33 and 37 respectively and decreasing thereafter. Women are less likely to be employed and earn less than men. Moreover, employment probabilities and earnings tend to be higher for individuals residing in more urbanized regions of the Netherlands.

According to the basic OLS models shown in columns (1) and (5), non-Western neighbourhood concentration is negatively related to labour market outcomes. Immigrants residing in high concentration neighbourhoods are 8 per cent less likely to be employed and have 28 per cent lower annual wages than individuals residing in low concentration neighbourhoods. However, the corresponding IV results in columns (2) and (6) respectively show quite a different picture as the effect of neighbourhood concentration on labour market outcomes becomes insignificant at the 10 per cent significance level. This suggests the presence of negative residential selection effects where immigrants with lower labour market qualifications tend to self-select into poor immigrant neighbourhoods.

Immigrants tend to live in neighbourhoods that are characterized by less favourable circumstances in general. To investigate this issue we include neighbourhood characteristics, namely the neighbourhood mean employment rate and neighbourhood mean wage of the working age population. Using the large number of instruments available in our data both ethnic concentration and the neighbourhood characteristics are instrumented since also these characteristics of a neighbourhood are subject to choice. ${ }^{38}$ Column (3), (4), (7) and (8) show that local neighbourhood dynamics greatly affect labour market outcomes of asylum seekers. Both the OLS findings in columns (3) and (7) as well as the IV findings in columns (4) and (8) demonstrate a highly significant positive effect of concentration on labour market outcomes. As was the case in the regressions without neighbourhood characteristics, the IV estimates show a stronger positive effect of concentration on labour market outcomes, which is consistent with our prior presumption regarding the presence of negative selection affects into neighbourhoods. The OLS (IV) findings suggest that individuals residing in high concentration neighbourhoods are 7 per cent ( 29 per cent) more likely to be employed and have 47 per cent (161 per cent) higher annual wages than people residing in low concentration neighbourhoods. We perform a number of robustness checks varying our employment definition, which further support these findings. ${ }^{39}$

${ }^{38}$ This reduces the sample as employment characteristics are lacking for some neighbourhoods.

${ }^{39}$ Please refer to Table 3.A8 in the Appendix for further details. 
Table 3.7: The relationship between migrant concentration and employment and income (linear specification)

\begin{tabular}{|c|c|c|c|c|c|c|c|c|}
\hline & \multicolumn{4}{|c|}{$\begin{array}{c}\text { dependent variable: probability } \\
\text { of employment }\end{array}$} & \multicolumn{4}{|c|}{$\begin{array}{l}\text { dependent variable: annual gross } \\
\text { wages }\end{array}$} \\
\hline & $(1)$ & (2) & (3) & (4) & (5) & (6) & (7) & $(8)$ \\
\hline & OLS & IV & OLS & IV & OLS & IV & OLS & IV \\
\hline \multirow[t]{2}{*}{ concentration } & -.077 & .011 & .067 & .290 & -.282 & .083 & .472 & 1.61 \\
\hline & $(.004)^{* * *}$ & $(.011)$ & $(.014)^{* * *}$ & $*(.034)^{* * *}$ & $*(.035)^{* * *}$ & $(.098)$ & $(.089)^{* * *}$ & $(.311)^{* * *}$ \\
\hline \multirow[t]{2}{*}{ female } & -.125 & -.124 & -.132 & -.130 & -.443 & -.437 & -.430 & -.427 \\
\hline & $(.002)^{* * *}$ & $(.002)^{* * *}$ & $*(.003)^{* * *}$ & $*(.003)^{* * *}$ & $(.018)^{* * *}$ & $(.018)^{* * *}$ & $(.021)^{* * *}$ & $(.021)^{* * *}$ \\
\hline \multirow[t]{2}{*}{ age } & .019 & .019 & .020 & .020 & .217 & .216 & .229 & .226 \\
\hline & $(.001)^{* * *}$ & $(.001)^{* * *}$ & $*(.001)^{* * *}$ & $*(.001)^{* * *}$ & $(.006)^{* * *}$ & $(.006)^{* * *}$ & $(.007)^{* * *}$ & $(.007)^{* * *}$ \\
\hline \multirow[t]{2}{*}{ age-square } & -.0003 & -.0003 & -.0003 & -.0003 & -.003 & -.003 & -.003 & -.003 \\
\hline & $(.001)^{* * *}$ & $(.000)^{* * *}$ & $*(.000)^{* * *}$ & $*(.000)^{* * *}$ & $(.000)^{* * *}$ & $(.000)^{* * *}$ & $(.000)^{* * *}$ & $(.000)^{* * *}$ \\
\hline \multirow[t]{2}{*}{ urbanisation } & .016 & .013 & .006 & -.003 & .116 & .100 & .074 & .050 \\
\hline & $(.002)^{* * *}$ & $(.002)^{* * *}$ & $*(.002)^{* * *}$ & $*(.002)$ & $(.012)^{* * *}$ & $(.013)^{* * *}$ & $(.014)^{* * *}$ & $(.017)^{* * *}$ \\
\hline \multirow[t]{2}{*}{ employment_nbh } & & & .315 & .407 & & & 1.27 & 1.46 \\
\hline & & & $(.016)^{* * *}$ & $*(.040)^{* * *}$ & & & $(.124)^{* * *}$ & $(.460)^{* * *}$ \\
\hline \multirow[t]{2}{*}{ meanwage_nbh } & & & -.001 & -.001 & & & .001 & .001 \\
\hline & & & $(.000)^{* * *}$ & $*(.000)^{* * * *}$ & & & $(.000)^{* * *}$ & $(.000)^{* * *}$ \\
\hline \multirow[t]{2}{*}{ constant } & -.068 & -.079 & -.127 & -.164 & 3.27 & 3.30 & 2.37 & 1.82 \\
\hline & $(.012)$ & $(.012)^{* * *}$ & $*(.020)^{* * *}$ & $*(.036)^{* * *}$ & $(.150)^{* * *}$ & $(.150)^{* * *}$ & $(.211)^{* * *}$ & $(.389)^{* * *}$ \\
\hline experience & yes & yes & yes & yes & yes & yes & yes & yes \\
\hline year & yes & yes & yes & yes & yes & yes & yes & yes \\
\hline corop & yes & yes & yes & yes & yes & yes & yes & yes \\
\hline observations & 306,200 & 306,200 & 176,296 & 176,296 & 57,357 & 57,357 & 36,511 & 36,511 \\
\hline r-square & .159 & & .169 & & .283 & & .291 & \\
\hline
\end{tabular}

a. Table represents estimation outcomes using OLS and IV techniques with dependent variables probability of employment and annual gross wages, where employment is defined as min. annual wages of $€ 100$ and 20 working days.

b. urbanisation is the natural logarithm of the degree of urbanization of neighbourhoods, which is measured as the number of addresses per $1 \mathrm{~km}$ radius of the neighbourhood.

c. heteroskedasticity-consistent standard errors are in parentheses. They are corrected to account for multiple observations of individuals over time. Asterisks indicate significance level: ${ }^{*}$ at $10 \%$, ** at $5 \%$, *** at $1 \%$ respectively.

d. In the IV regressions, initial neighbourhood concentrations are used as instruments for annual neighbourhood concentrations.

e. All regressions include dummies for level of experience (levels: 1-4 years, 5-7 years, 8-10 years), year (1999-2004), corop (40 areas). Regressions (3), (4), (7) and (8) moreover include neighbourhood fixed effects where employment_nbh is mean employment rate among the population aged 18-64 in the neighbourhood and meanwage_nbh is mean wage of the population 18-64 working of the neighbourhood. In the latter regressions the sample is reduced as employment characteristics are lacking for many neighbourhoods.

Source: Netherlands Bureau of Statistics SSB 1995-2004, own calculations 


\section{Non-linearity}

An important question is whether the effect of neighbourhood concentration on labour market outcomes is linear across all levels of concentration. We therefore incorporate non-linearities in the model. As a first look, Figures 3.5 and 3.6 show the nonparametric relationships between mean initial non-Western neighbourhood concentration, which we use as exogenous instrumental variables in the regressions, and the outcome variables, namely mean annual probability to work and mean annual wages respectively. Mean annual probability to work and wages are calculated for each population group originating from the same initial housing centre using annual information of the years 1999-2004. While the middle lines in the two figures represent the mean probability to work and mean annual wages, the top and bottom lines mark the 95 per cent confidence intervals for the indicators. Both figures clearly suggest inherent non-linearity in the underlying relationships. Figure 3.5 suggests a U-shaped relationship between concentration and mean probability to work. The function is decreasing to a global low at around 60 per cent concentration and increasing thereafter with local disturbances of the overall trend at around 20 per cent and 30 per cent and a somewhat unclear pattern after 90 per cent concentration.

Figure 3.5: Employment chances of initial asylum clusters per neighbourhood concentration (kernel regression)

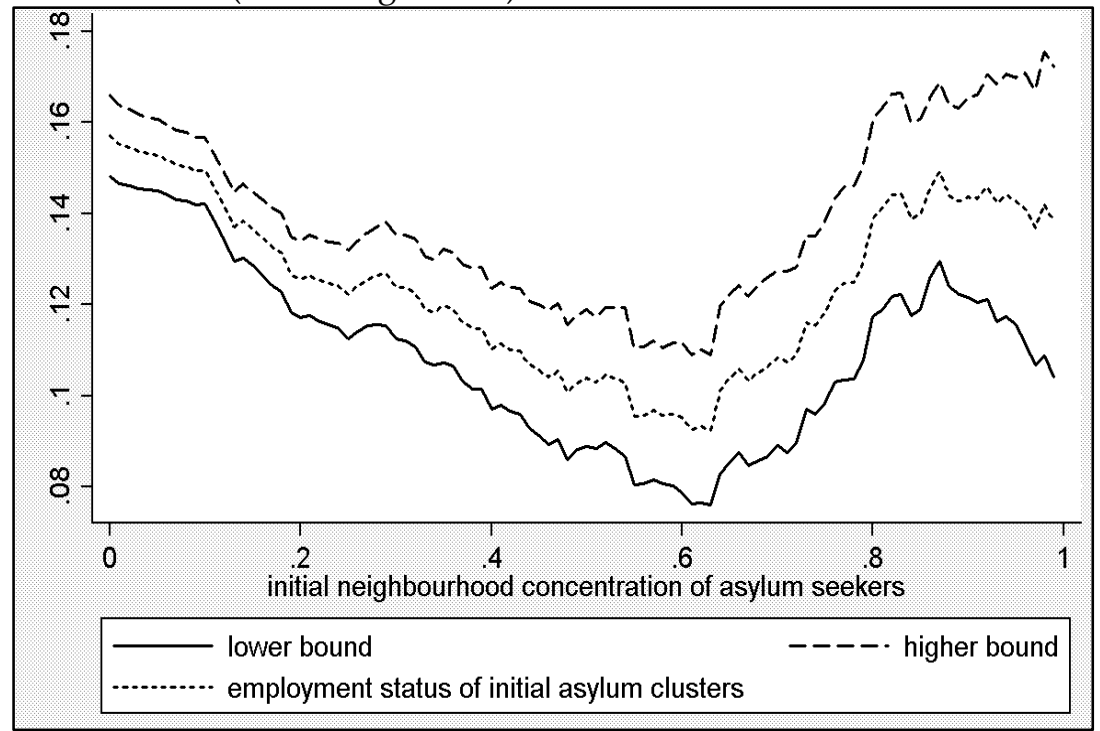

Notes: $\mathrm{x}$-axis - mean initial non-Western neighbourhood concentration; $\mathrm{y}$-axis - mean annual probability to work, where lower (higher) bound is defined as mean annual probability to work less (plus) $1.96^{*}$ standard error.

Source: Netherlands Bureau of Statistics SSB 1995-2004, own calculations 
Figure 3.6 shows a similar pattern for concentration and mean annual wages than was portrayed before. The figure also suggests a U-shaped parabolic relationship between concentration and mean annual wages. The function is decreasing to a global minimum at about 60 per cent of concentration with disturbances to the overall trend around 35 per cent and 45 per cent and, as in Figure 3.5, a somewhat unclear pattern after 90 per cent concentration. The unclear trend for concentration levels above 90 per cent is likely a consequence of lack of sufficient data at the high end of the concentration continuum.

Figure 3.6: Mean annual log wages of initial asylum clusters per neighbourhood concentration (kernel regression)

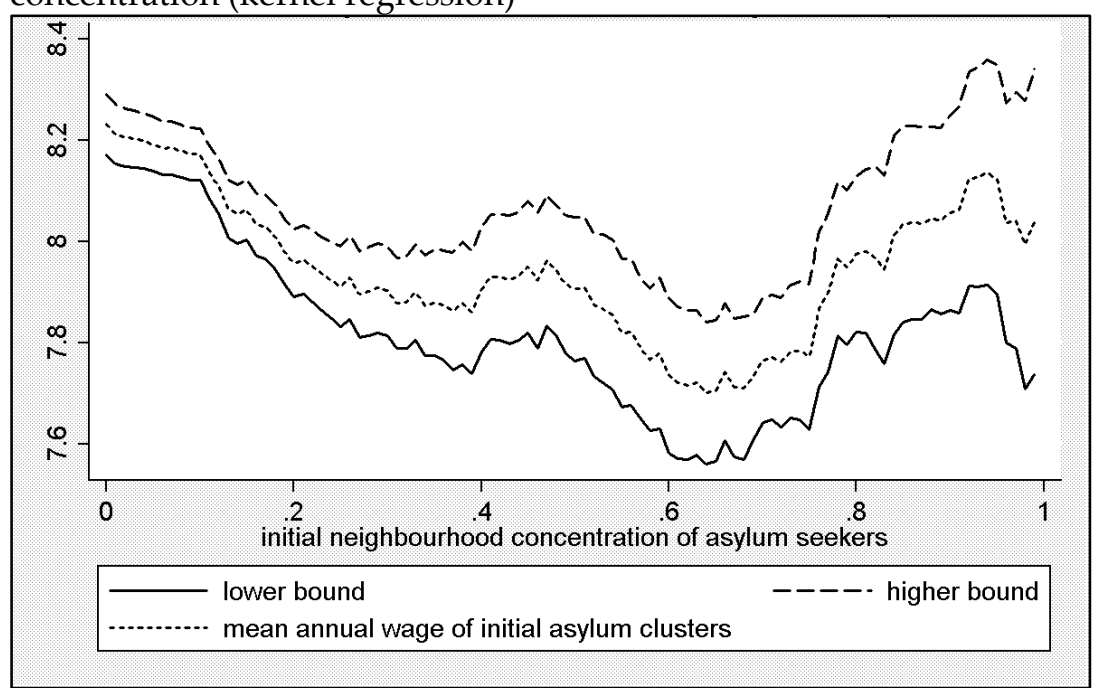

Notes: x-axis - mean initial non-Western neighbourhood concentration; y-axis - natural log of mean annual wages, where lower (higher) bound is defined as natural log of mean annual wages less (plus) $1.96^{*}$ standard error.

Source: Netherlands Bureau of Statistics SSB 1995-2004, own calculations

To investigate this issue we augment the linear models with extra terms capturing non-linearity. For robustness reasons we use several non-linear specifications, which are perhaps somewhat arbitrary, but inspired by the findings from the above kernel regression analyses under consideration of the sample distribution. This yields the following models: a - Square Model including a squared term of neighbourhood concentration; $b-1$ Spline Model including a spline or kink at 60 per cent neighbourhood concentration for both the probability of employment and the annual wages regressions; c - 2 Spline Model including two splines at 30 and 60 per cent concentration for the probability of employment regression and at 45 and 65 per cent concentration for the annual wages regression; $d-3$ Spline Model including three splines at 20,30 and 60 per cent concentration for the probability of 
employment regression and at 35, 45 and 65 per cent concentration for the annual wages regression. ${ }^{40}$

Tables 3.8 and 3.9 below present the IV regression outputs of the linear and nonlinear model specifications for the two outcome variables employment probabilities and annual wages respectively. We additionally investigate the impact of neighbourhood quality (mean employment rate and wage level) on labour market outcomes and thus carry out estimations both without as well as with neighbourhood controls. All models control for individual characteristics, year fixed effects, and local fixed effects through the inclusion of the variables gender, age, age-square, year, experience in the country, degree of urbanization, region of the country, neighbourhood mean employment rate and neighbourhood mean wages.

Table 3.8 presents the IV regression findings of the various models for the outcome variable employment chances both with and without neighbourhood controls. As Table 3.8 shows, with the exception of degree of urbanization, all controls are significant across the panel. As expected, age has a positive, bell-shaped effect on employment chances increasing to a maximum at age 33 and decreasing thereafter, while women are less likely to be employed then men. Moreover, employment probabilities tend to be slightly higher for individuals residing in more urbanized regions of the Netherlands, a trend that is driven predominantly by neighbourhood characteristics as seen in columns 5-10 where the significance of the urbanization variable generally vanishes. Neighbourhood quality greatly impacts on immigrants' labour market outcomes with migrants residing in neighbourhoods with low unemployment having considerably better chances to be employed. Owing to our large sample size, most neighbourhood concentration coefficients are significant at the 10 per cent significance level, which enables us to stress a number of interesting findings. First, the findings of the various models consistently demonstrate that the effect of non-Western neighbourhood concentration on employment chances is not negative but rather positive when controlling adequately for neighbourhood quality. The findings without neighbourhood controls show a pattern that is similar to Figures 3.5 and 3.6. Initially - at low levels of concentration - neighbourhood concentration has a negative impact on outcomes, but at higher levels of concentration the impact becomes positive. Second, the findings suggest that the effect of concentration on employment chances is non-linear in nature and benefits on employment chances are increasing at an increasing rate. This is clearly shown by the concentration coefficients as well as the results of the F-tests included in Table 3.8, the latter

40 The splines do not always coincide with the trend-breaks observed in Figures 3.5 and 3.6 given our aim of similar distributions in the various ranges of concentration. 
comparing the goodness of fit of the non-linear with the linear specifications. All of the Square, 1Spline and 2Spline Models fit the data better than the linear ones. Benefits thus tend to be especially great at high levels of concentration, which may demonstrate the supportive 'springboard' function that migrant neighbourhoods hold in the establishment of newcomers in society. It could furthermore be explained by the rise of local ethnic economies offering improved labour market prospects to co-ethnic members, and it is also likely that with increasing ethnic group size information about labour market opportunities and requirements becomes increasingly available resulting in greater success on the labour market.

Table 3.9 presents the IV regression findings of the various models for the outcome variable annual wages both without and with neighbourhood controls. The findings share many commonalities with those presented in Table 3.8. The control variables are significant across the panel suggesting that women earn less than men. Furthermore, earnings increase with age towards a maximum at age 37 and decrease thereafter; also, they are higher in more urbanized regions of the country. Once again, the latter trend is driven predominantly by neighbourhood characteristics as seen in columns 5-10 in that the urbanization coefficient decreases when controlling for neighbourhood characteristics. As was the case in the employment chances regressions, neighbourhood quality greatly impacts on immigrants' labour market outcomes with migrants residing in neighbourhoods with high employment rates and wage levels having considerably higher wages. After controlling adequately for neighbourhood quality, most neighbourhood concentration coefficients are significant at the 10 per cent significance level (with the exception of the 3Spline model), which enables us to stress a number of interesting findings. Comparable to the findings for employment chances, our findings consistently suggest a positive, non-linear effect of concentration on migrant wages with benefits rising at an increasing rate with the level of concentration. This reflects in the trends captured by the concentration coefficients in Table 3.9 and is also supported by the F-test results of the 1 Spline Model. The model fit of the other non-linear specifications is not clearly better than the fit of the linear ones, which indicates that patterns of non-linearity are most in line with the trends suggested by the 1Spline Model. These findings are again in line with the 'springboard' function that migrant neighbourhoods hold in the establishment of newcomers in society. Also, it supports that larger ethnic group size leads to increasing presence of ethnic economies and rising efficiency of intra-group information exchange. Although it is beyond our reach to claim the true, non-linear relationship between concentration and migrant labour market outcomes, in the remainder of this chapter we set out a first exploration of this non-linearity while acknowledging that our models yield perhaps somewhat rough approximations of these effects. 
Table 3.8: The relationship between migrant concentration and employment (linear and non-linear IV specifications)

\begin{tabular}{|c|c|c|c|c|c|c|c|c|c|c|}
\hline & \multicolumn{10}{|c|}{ " dependent variable: probability of employment } \\
\hline & \multicolumn{5}{|c|}{ no neighbourhood controls } & \multicolumn{5}{|c|}{ neighbourhood controls } \\
\hline & $\begin{array}{l}\text { Linear } \\
(1)\end{array}$ & $\begin{array}{l}\text { Square } \\
\text { (2) }\end{array}$ & $\begin{array}{l}\text { 1Spline } \\
\text { (3) }\end{array}$ & $\begin{array}{l}\text { 2Splines } \\
(4)\end{array}$ & $\begin{array}{l}\text { 3Splines } \\
\text { (5) }\end{array}$ & $\begin{array}{l}\text { Linear } \\
\text { (6) }\end{array}$ & $\begin{array}{l}\text { Square } \\
\text { (7) }\end{array}$ & $\begin{array}{l}\text { 1Spline } \\
(8)\end{array}$ & $\begin{array}{l}\text { 2Splines } \\
\text { (9) }\end{array}$ & $\begin{array}{l}\text { 3Splines } \\
\text { (10) }\end{array}$ \\
\hline \multirow[t]{2}{*}{ concentration } & .011 & -.084 & -.012 & -.058 & -.251 & .290 & .122 & .270 & .193 & -.044 \\
\hline & $(.011)$ & $(.042)^{*}$ & $(.017)$ & $(.040)$ & $(.077)^{* * *}$ & $(.034)^{* * *}$ & $(.076)^{* * *}$ & $(.041)^{* * *}$ & $(.058)^{* * *}$ & $(.090)$ \\
\hline \multirow[t]{2}{*}{ conc.-square } & - & .110 & - & - & - & - & .228 & - & - & - \\
\hline & - & $(.047)^{* *}$ & - & - & - & - & $(.089)^{* * *}$ & - & - & - \\
\hline \multirow[t]{2}{*}{ conc.-spline1 } & - & - & .103 & .088 & .580 & - & - & .127 & .205 & .849 \\
\hline & - & - & $(.057)^{*}$ & $(.069)$ & $(.198)^{* * *}$ & - & - & $(.141)$ & $(.100)^{* *}$ & $(.242)^{* * *}$ \\
\hline \multirow[t]{2}{*}{ conc.-spline2 } & - & - & - & .036 & -.372 & - & - & - & -.130 & -.571 \\
\hline & - & - & - & $(.076)$ & $(.171)^{* *}$ & - & - & - & (.185) & $(.242)^{* *}$ \\
\hline \multirow[t]{2}{*}{ conc.-spline3 } & - & - & - & - & .133 & - & - & - & - & .126 \\
\hline & - & - & - & - & $(.082)^{*}$ & - & - & - & - & (.197) \\
\hline \multirow[t]{2}{*}{ female } & -.124 & -.124 & -.124 & -.130 & -.124 & -.130 & -.131 & -.130 & -.131 & -.131 \\
\hline & $(.002)^{* * *}$ & $(.002)^{* * * *}$ & $(.002)^{* * *}$ & $(.002)^{* * *}$ & $(.002)^{* * *}$ & $(.003)^{* * *}$ & $(.003)^{* * *}$ & $(.003)^{* * *}$ & $(.003)^{* * *}$ & $(.003)^{* * *}$ \\
\hline \multirow[t]{2}{*}{ age } & .019 & .018 & .019 & .019 & .020 & .020 & .020 & .020 & .020 & .020 \\
\hline & $(.001)^{* * *}$ & $(.001)^{* * *}$ & $(.000)^{* * *}$ & $(.001)^{* * *}$ & $(.000)^{* * *}$ & $(.001)^{* * *}$ & $(.000)^{* * *}$ & $(.000)^{* * *}$ & $(.000)^{* * *}$ & $(.000)^{* * *}$ \\
\hline \multirow[t]{2}{*}{ age-square } & -.0003 & -.0003 & -.0003 & -.0003 & -.0003 & -.0003 & -.0003 & -.0003 & -.0003 & -.0003 \\
\hline & $(.000)^{* * *}$ & $(.000)^{* * *}$ & $(.000)^{* * *}$ & $(.000)^{* * *}$ & $(.000)^{* * *}$ & $(.000)^{* * *}$ & $(.000)^{* * *}$ & $(.000)^{* * *}$ & $(.000)^{* * *}$ & $(.000)^{* * *}$ \\
\hline \multirow[t]{2}{*}{ urbanisation } & .013 & .016 & .014 & .016 & .019 & -.003 & .002 & -.002 & .002 & .005 \\
\hline & $(.002)^{* * *}$ & $(.002)^{* * *}$ & $(.002)^{* * *}$ & $(.002)^{* * *}$ & $(.002)^{* * *}$ & $(.002)$ & $(.003)$ & $(.003)$ & $(.003)^{* * *}$ & $(.003)$ \\
\hline \multirow{2}{*}{\multicolumn{2}{|c|}{ employment_nbh }} & & & & & .407 & .386 & .400 & .401 & .407 \\
\hline & & & & & & $(.040)^{* * *}$ & $(.041)^{* * *}$ & $(.042)^{* * *}$ & $(.041)^{* * *}$ & $(.042)^{* * *}$ \\
\hline \multirow[t]{2}{*}{ meanwage_nbh } & & & & & & -.001 & -.001 & -.001 & -.001 & -.001 \\
\hline & & & & & & $(.000)^{* * *}$ & $(.000)^{* * *}$ & $(.000)^{* * *}$ & $(.000)^{* * *}$ & $(.000)^{* * *}$ \\
\hline \multirow[t]{2}{*}{ constant } & -.079 & -.086 & -.082 & -.087 & -.089 & -.164 & -.180 & -.166 & -.182 & -.189 \\
\hline & $(.012)^{* * *}$ & $(.012)^{* * *}$ & $(.012)^{* * *}$ & $(.013)^{* * *}$ & $(.013)^{* * *}$ & $(.036)^{* * *}$ & $(.036)^{* * *}$ & $(.036)^{* * *}$ & $(.037)^{* * *}$ & $(.037)^{* * *}$ \\
\hline experience & yes & yes & yes & yes & yes & yes & yes & yes & yes & yes \\
\hline year & yes & yes & yes & yes & yes & yes & yes & yes & yes & yes \\
\hline corop & yes & yes & yes & yes & yes & yes & yes & yes & yes & yes \\
\hline p-value(F-test) & base & $<.001$ & $<.001$ & $<.001$ & $<.001$ & base & $<.001$ & $<.001$ & $<.001$ & 1 \\
\hline observations & 306200 & 306200 & 306200 & 306200 & 306200 & 176296 & 176296 & 176296 & 176296 & 176296 \\
\hline
\end{tabular}

a. Table represents estimation outcomes using IV techniques with dependent variable probability of employment, where employment is defined as min. annual wages of $€ 100$ and 20 working days.

b. Models are composed as follows: (1) and (6) are the linear specifications equivalent to the ones found in Table 3.9; (2) and (7) contain a square term of neighbourhood concentration; (3) and (8) contain a spline at $60 \%$ neighbourhood concentration; (4) has splines at 30 and 60\%; (9) has splines at 45 and 65\%; (5) has splines at 20, 30, 60\%; (10) has splines at $35,45,65 \%$ concentration.

c. Urbanisation is the natural logarithm of the degree of urbanisation of neighbourhoods, which is measured as the number of addresses per $1 \mathrm{~km}$ radius of the neighbourhood.

d. Heteroskedasticity-consistent standard errors are in parentheses. They are corrected to account for multiple observations of individuals over time. Asterisks indicate significance level: * at $10 \%,{ }^{* *}$ at $5 \%,{ }^{* * *}$ at $1 \%$ respectively.

e. In the IV regressions, initial neighbourhood concentrations are used as instruments for annual neighbourhood concentrations.

f. All regressions include dummies for level of experience (levels: 1-4 years, 5-7 years, 8-10 years), year (1999-2004), corop (40 areas). Regressions (6) - (10) moreover include neighbourhood fixed effects where employment_nbh is mean employment rate among the population aged 18-64 in the neighbourhood and meanwage_nbh is mean wage of the population 18-64 working of the neighbourhood. In the latter regressions the sample is reduced as employment characteristics are lacking for many neighbourhoods.

g. P-values capture significance levels of F-test assuming model goodness of fit equals between non-linear and linear specifications. Small levels of significance indicate that non-linear specifications offer better fit than linear ones.

Source: Netherlands Bureau of Statistics SSB 1995-2004, own calculations 
Table 3.9: The relationship between migrant concentration and income (linear and non-linear IV specifications)

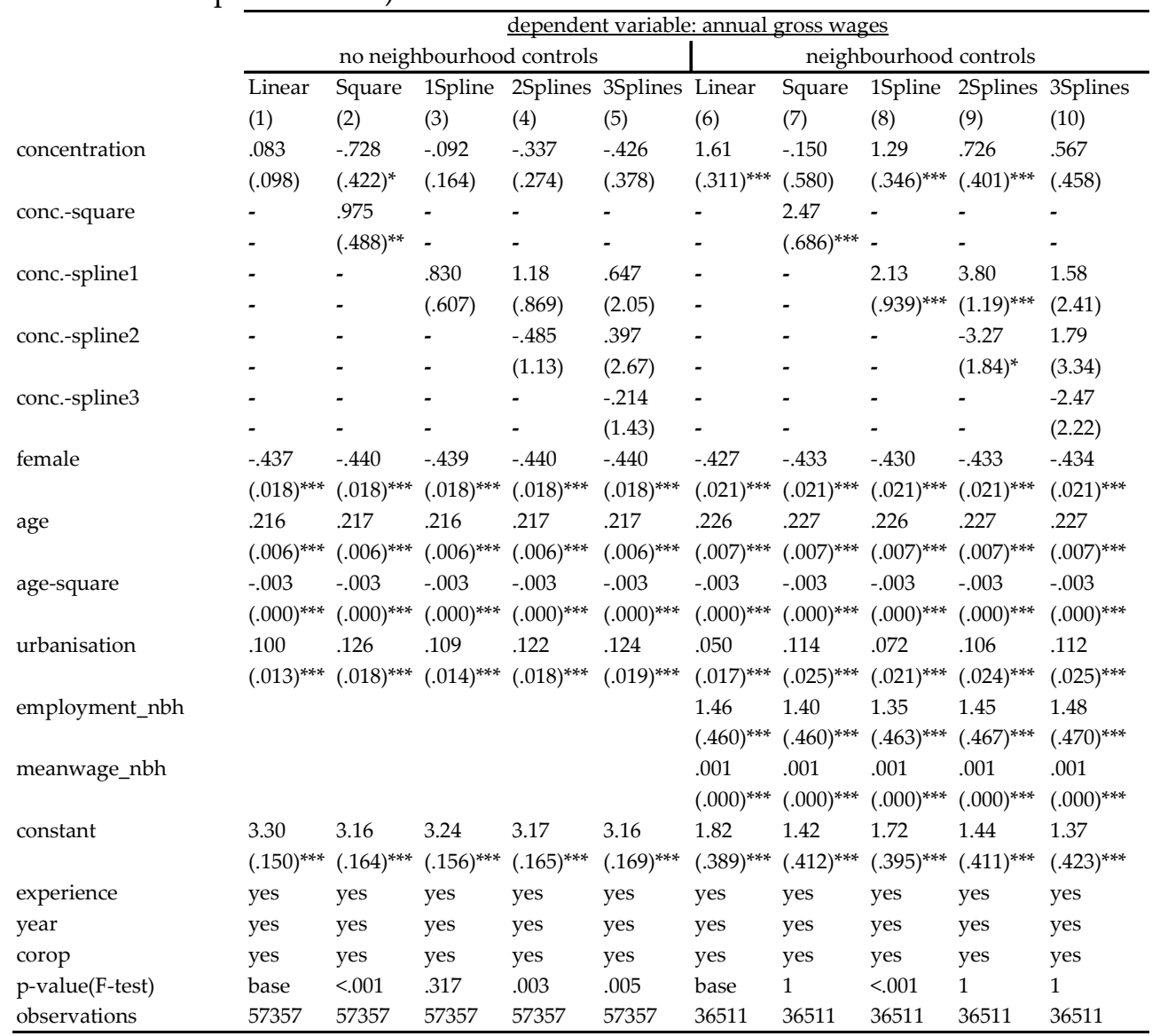

a. Table represents estimation outcomes using IV techniques with dependent variable annual gross wages, where employment is defined as min. annual wages of $€ 100$ and 20 working days.

b. Models are composed as follows: (1) and (6) are the linear specifications equivalent to the ones found in Table 3.9; (2) and (7) contain a square term of neighbourhood concentration; (3) and (8) contain a spline at $60 \%$ neighbourhood concentration; (4) has splines at 30 and 60\%; (9) has splines at 45 and 65\%; (5) has splines at 20,30,60\%; (10) has splines at $35,45,65 \%$ concentration.

c. Urbanisation is the natural logarithm of the degree of urbanisation of neighbourhoods, which is measured as the number of addresses per $1 \mathrm{~km}$ radius of the neighbourhood.

d. Heteroskedasticity-consistent standard errors are in parentheses. They are corrected to account for multiple observations of individuals over time. Asterisks indicate significance level: ${ }^{*}$ at $10 \%,{ }^{* *}$ at $5 \%,{ }^{* * *}$ at $1 \%$ respectively.

e. In the IV regressions, initial neighbourhood concentrations are used as instruments for annual neighbourhood concentrations.

f. All regressions include dummies for level of experience (levels: 1-4 years, 5-7 years, 8-10 years), year (1999-2004), corop (40 areas). Regressions (6) - (10) moreover include neighbourhood fixed effects where employment_nbh is mean employment rate among the population aged 18-64 in the neighbourhood and meanwage nbh is mean wage of the population 18-64 working of the neighbourhood. In the latter regressions the sample is reduced as employment characteristics are lacking for many neighbourhoods.

g. P-values capture significance levels of F-test assuming model goodness of fit equals between non-linear and linear specifications. Small levels of significance indicate that non-linear specifications offer better fit than linear ones.

Source: Netherlands Bureau of Statistics SSB 1995-2004, own calculations 
The findings outlined in Tables 3.8 and 3.9 are further presented graphically in Figures 3.7a and 3.7b below, which combine the various effects of each model into a single line. The resulting lines, moreover, enable global as well as local analysis for different levels of non-Western concentration as the slope of the line captures the local effect of concentration on the outcome variables. This allows convenient comparison of the regression outcomes of the various models at different levels of concentration. ${ }^{41}$ The figures graphically show the following points. First, they clearly demonstrate the positive effects of concentration on employment chances and annual wages of migrants. Second, on average, individuals residing in high concentration neighbourhoods tend to be 30-35 per cent more likely to be employed and tend to have considerably higher wages than migrants living in low concentration neighbourhoods (i.e. 150-200 per cent higher). Third, non-linear models tend to suggest that benefits of concentration are increasing at an increasing rate with benefits being particularly low for migrants residing in low concentration neighbourhoods and especially high for individuals living in high concentration neighbourhoods.

Figure 3.7a: Employment chances by level of concentration, various models

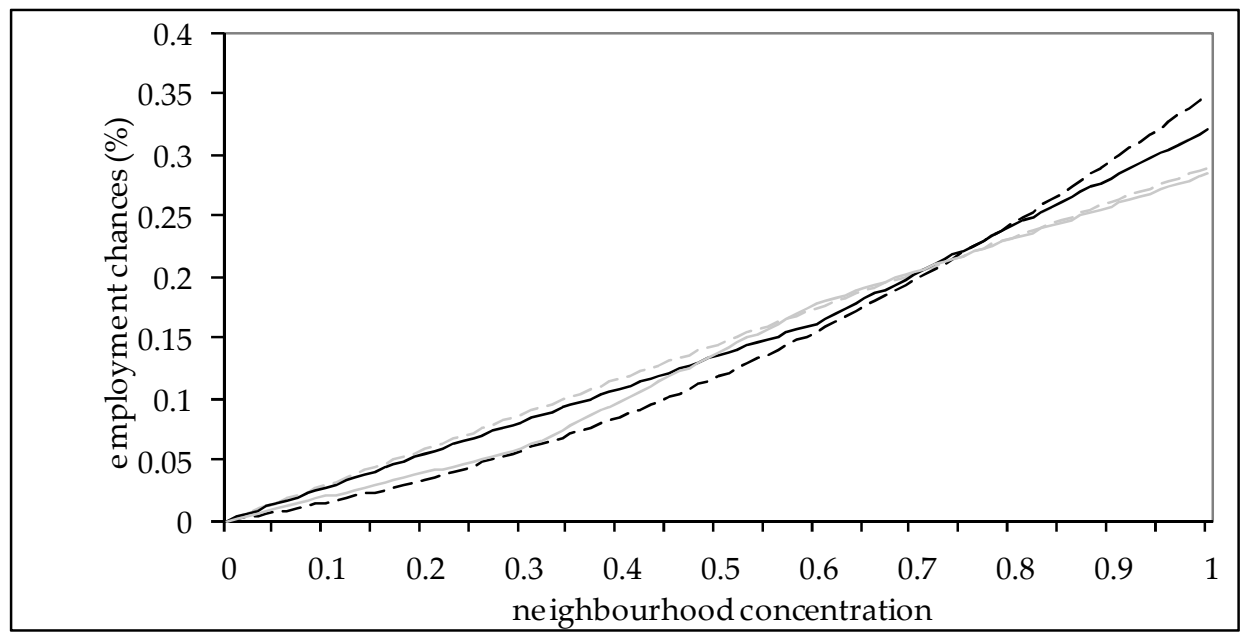

${ }^{41}$ The figures do not include the results from the 3Spline specifications to reduce display complexity and as the latter models fit the data no better than the linear models (i.e. p-value of model comparison F-test >.1). 
Figure 3.7b: Annual wages by level of concentration, various models

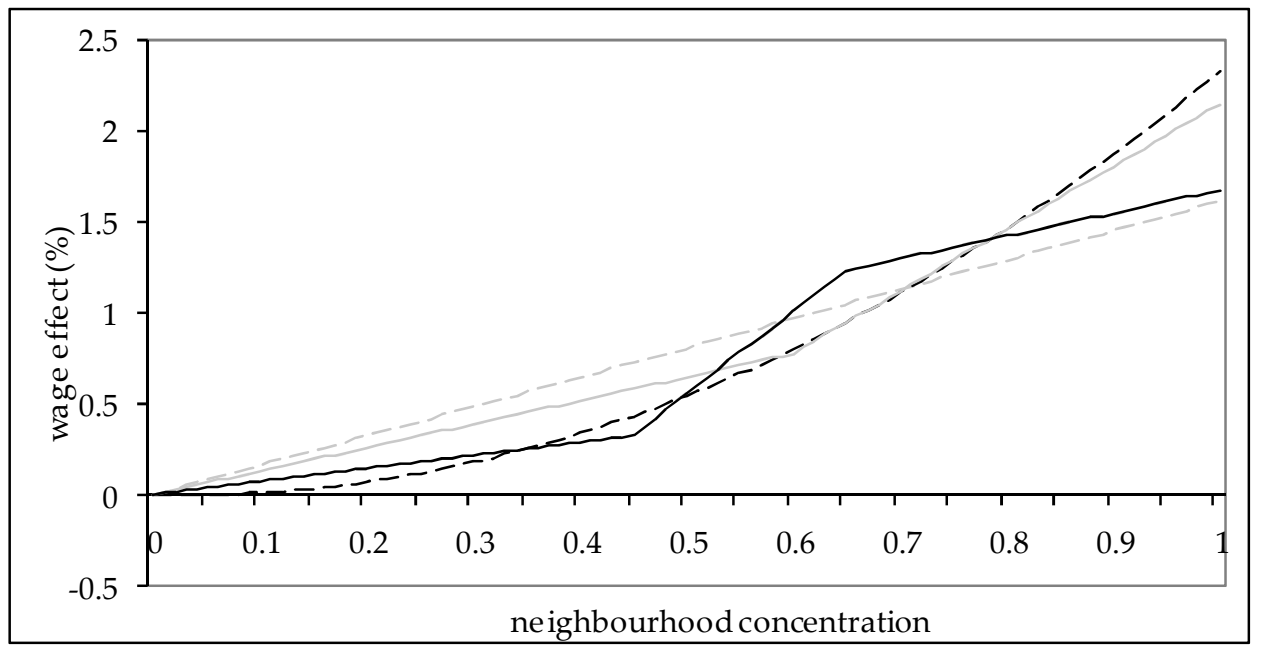

* Graphs plot the regression outputs of the IV estimations including neighbourhood controls for the dependent variables employment chances and annual gross wages with non-Western neighbourhood concentrations on the horizontal axis and the dependent variables on the vertical axis.

Source: Netherlands Bureau of Statistics SSB 1995-2004, own calculations

Next to the IV regression findings of the complete sample of pooled observations, we performed separate analyses for subgroups defined by gender and experience in the country for the period 1999-2004. Figures 3.8a and 3.8b present the IV regression findings from the gender analyses of the various model specifications for the dependent variables employment chances and annual wages respectively. To safeguard display clarity, the figures only show regression outcomes of the nonlinear model specifications if they offer better data fit than linear models. ${ }^{42}$ The findings across model specifications per gender subgroup are rather similar for both outcome variables. Men tend to be largely more likely to be employed than women at all levels of concentration, while concentration effects on wages of men and women tend to be similar. On average, employment chances of women and men residing in high concentration neighbourhoods are 25 and 35 per cent higher than those of individuals residing in low concentration neighbourhoods respectively. Furthermore, concentration benefits to employment chances tend to increase at an increasing rate for both genders, although for men this overall increase is less pronounced as the effect reverses for high levels of concentration. This means that female (and to a lesser extent male) employment chances benefit particularly little at low levels of concentration and especially much at high levels.

${ }^{42}$ Models with p-value of F-test $<.05$, whereby F-test compares data fit of non-linear to linear model specifications. If linear specification displayed, concentration effects are quasi-linear for respective subgroup (i.e. none of non-linear specifications having better data fit than linear one). 
This pattern is also observable in Figure $3.8 b$, which documents positive and increasing concentration effects on female wages and positive quasi-linear effects for men. Overall, it is thus striking that employment benefits from concentration of women are notably low for concentration levels below 60 per cent and strongly increasing for higher concentration levels. A possible explanation for this pattern may be related to the rising local presence of ethnic economies going alongside with increasing migrant residential concentration, which are an important source of employment creation especially for women, who are not able or allowed to find employment elsewhere (Waldinger 1996, Kloosterman \& Van der Leun 1999).

Figure 3.8a: Employment chances by level of concentration, male and female, various models

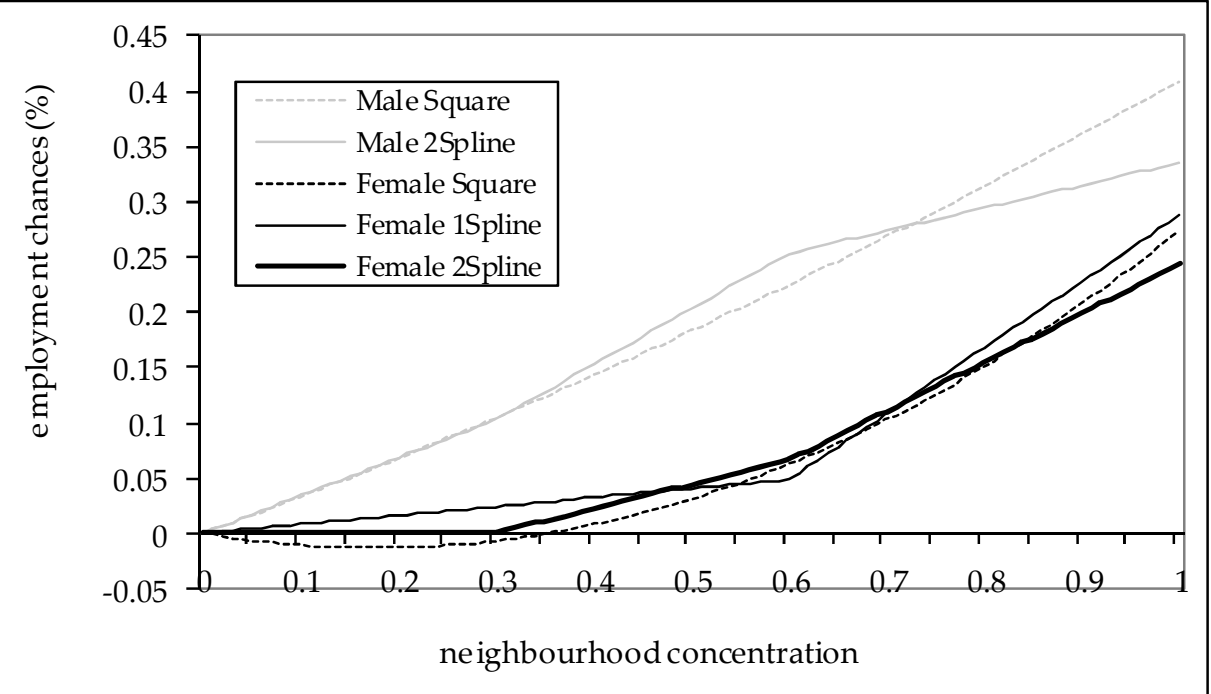


Figure 3.8b: Annual wages by level of concentration, male and female, various models

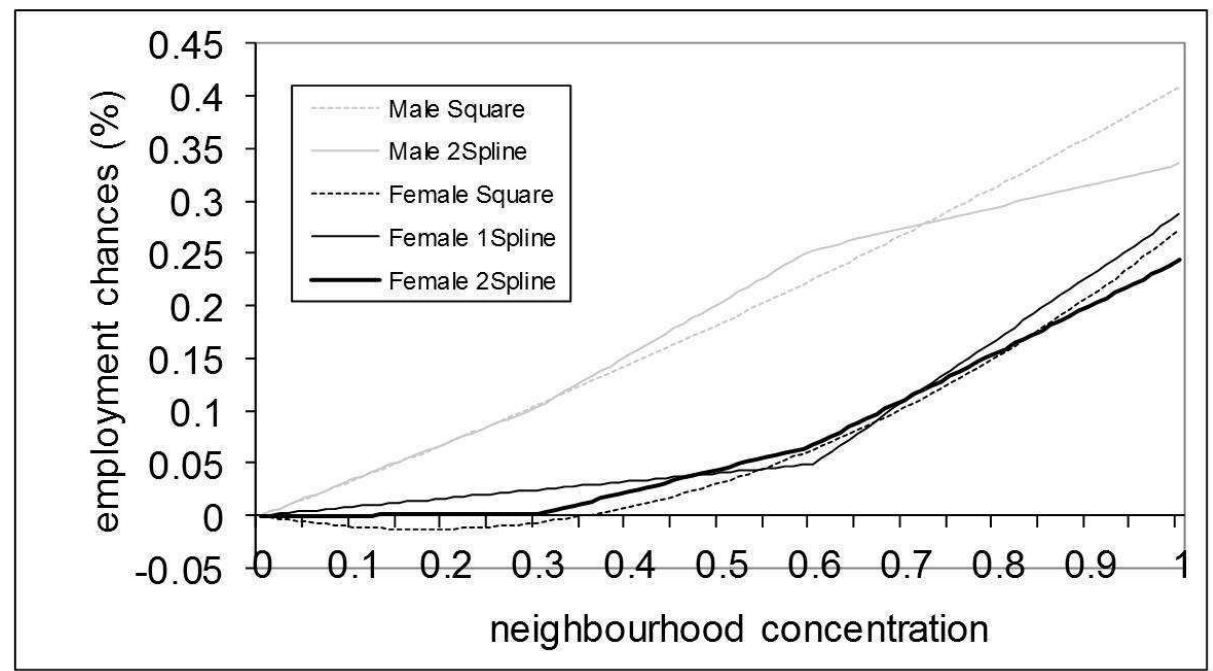

Notes: Graphs plot the regression outputs of the IV estimations including neighbourhood controls for the dependent variables employment chances and annual gross wages with non-Western neighbourhood concentrations on the horizontal axis and the dependent variables on the vertical axis. Figures display non-linear models with better data fit than linear specification per subgroup (i.e. $p$ value of F-test < .05). If linear specification displayed, concentration effects are quasi-linear for respective subgroup (i.e. none of non-linear specifications having better data fit than linear one).

Source: Netherlands Bureau of Statistics SSB 1995-2004, own calculations

We also perform separate analyses by the level of experience in the country expecting particularly newcomers to benefit from concentration through the availability of co-ethnic social networks facilitating knowledge spill overs and thus fostering the acculturation process. We define three groups, namely: a - Experience of four years or less; $b$ - Experience of five to seven years; $c$ - Experience of eight years or more. Our findings of concentration effects by experience group on employment chances and annual wages are displayed in Figures 3.9a and $9 \mathrm{~b}$ respectively. As can be seen in Figure 3.9a, concentration effects on employment chances are positive for migrant groups of 1-4 years and 5-7 years of experience, but negative for migrants with 8-10 years of experience. Moreover, benefits of migrants with 5-7 years of experience are higher than for the group with 1-4 years of experience, which can be explained by the fact that some asylum seekers in the latter group still face legal employment restrictions as was explained in Section 3.3. The concentration effects on migrant wages by experience group are shown in Figure $3.9 \mathrm{~b}$, which further underline the findings from the employment chance regressions. Again, concentration effects are positive for migrants with 1-4 years and 5-7 years of experience and negative for the group with 8-10 years of experience. While concentration benefits to migrants of 5-7 years of experience are 
quasi-linear, benefits to the 1-4 years of experience group tend to increase at an increasing rate generally, though this rate decreases for concentration levels higher than $65 \%$. The concentration penalty on migrant wages of the 8-10 years of experience group increases at a decreasing rate, reaching its maximum around the $70 \%$ concentration level and diminishing thereafter. Concluding, as expected, benefits of concentration to migrant labour market outcomes are highest for recent arrives and tend to decrease with duration of stay in the country. Thus, the findings from Figures $3.9 \mathrm{a}$ and $3.9 \mathrm{~b}$ provide supportive evidence for the 'springboard' function of migrant neighbourhoods facilitating the establishment of newcomers in the receiving society as suggested by Portes \& Rumbaut (1990), Tesser et al. (1995) and Van der Laan Bouma-Doff (2005). Furthermore, the wage regression findings for the 1-4 years of experience group show that concentration is especially beneficial in high migrant concentration neighbourhoods, which may offer unique opportunities to newcomers in ethnic economies and ethnic entrepreneurship as stated by Waldinger (1996) and Kloosterman \& Van der Leun (1999). Notably, concentration effects actually become negative for migrants with 8-10 years of experience, which may suggest that these migrants 'get stuck' in migrant neighbourhoods. A possible explanation for these negative effects may be found with the spatial mismatch hypothesis, which argues that the cause of these negative employment outcomes is the large spatial separation of migrant neighbourhoods to job opportunities. Alternatively, these individuals may also have become self-employed and actually derive far greater benefits from living in migrant neighbourhoods, which are not accounted for in the employment data.

Figure 3.9a: Employment chances by level of concentration, experience groups, various models

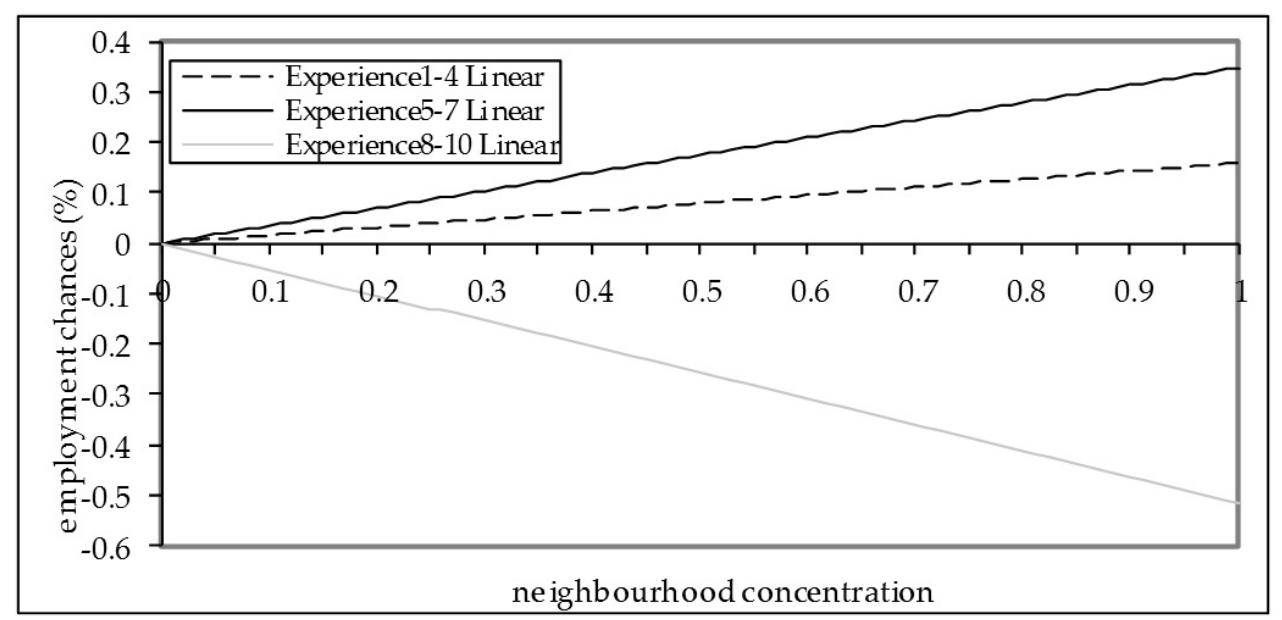


Figure 3.9b: Annual wages by level of concentration, experience groups, various models

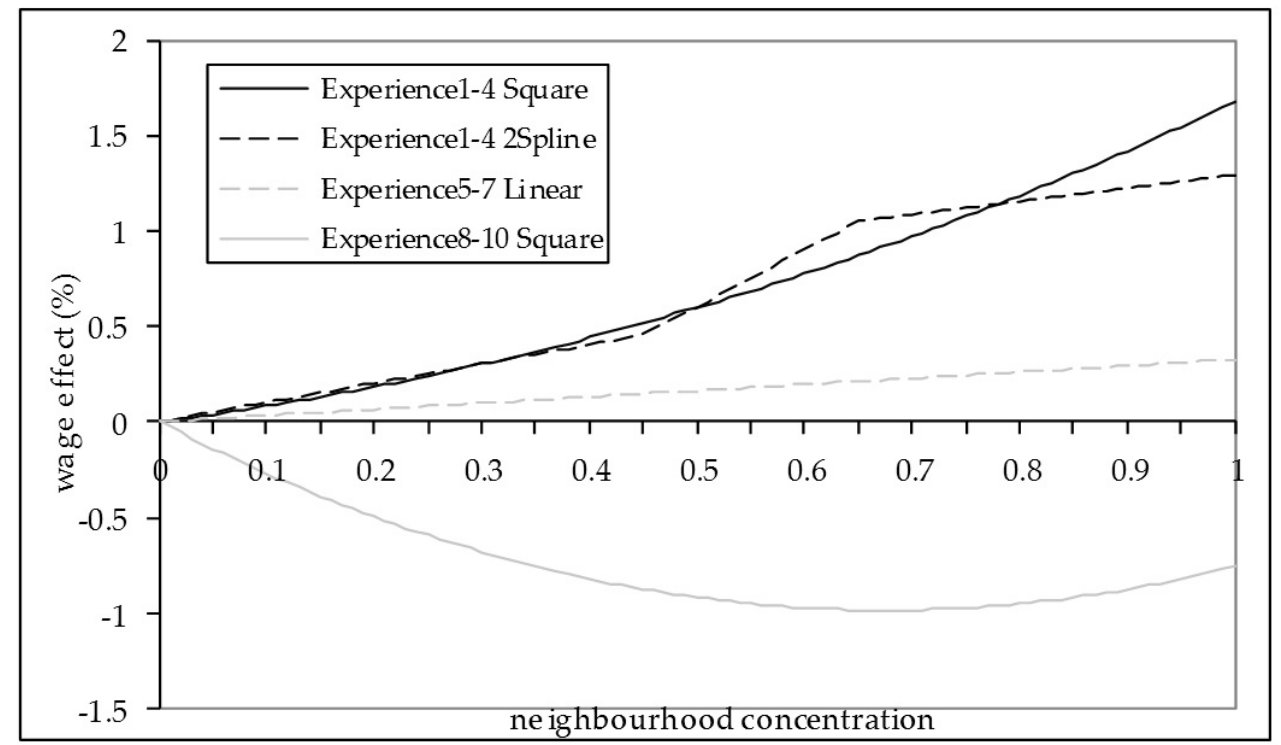

* Graphs plot the regression outputs of the IV estimations including neighbourhood controls for the dependent variables employment chances and annual gross wages with non-Western neighbourhood concentrations on the horizontal axis and the dependent variables on the vertical axis. Figures display non-linear models with better data fit than linear specification per subgroup (i.e. p-value of F-test <.05). If linear specification displayed, concentration effects are quasi-linear for respective subgroup (i.e. none of non-linear specifications having better data fit than linear one). In case of 1-4 years of experience subgroup in wage regressions (Figure9b), all non-linear models offer better fit than linear one but cannot all be included. Please refer to Figure 3.A2 in Appendix for complete display.

Source: Netherlands Bureau of Statistics SSB 1995-2004, own calculations

\section{Heterogeneity of concentration effects}

The effect of concentration on outcomes might be different between immigrants. To investigate this heterogeneity of the concentration effects we explore the information about movements of migrants across the country. The idea behind this is that if migrants who differ in their concentration effect parameter make different decisions concerning the choice of neighbourhood, this information reveals patterns of heterogeneity. Table 3.10 reports mobility in four categories, namely: non-movers, movers within the same municipality, movers within the same corop region ${ }^{43}$ and movers between corop regions. We find that mobility of migrants is substantial. Nearly one third of the asylum population $(28,190$ people or 30.8 per cent) does not move from the initial place of residence, while nearly half of the population remains in the same corop region of the country $(44,400$ people or 47.4 per cent).

${ }^{43}$ As described in depth in section 3.4, the country is divided into 40 corop regions. 
Table 3.10 relates mobility patterns of individuals to their levels of initial and 10year (1995-2004) mean annual concentration levels. Moreover, for convenient display, migrants are sorted into three groups based on their levels of initial and 10-year mean annual concentration levels for the left hand and right hand sections of the table respectively. This creates two sets of three equal-size groups including migrants with high, medium and low initial and 10-year mean concentration levels respectively. The findings in the left hand part of the table show that individuals initially residing at higher concentrations tend to move less than those initially residing at lower levels of neighbourhood concentration. In the right hand part, the table shows that asylum seekers residing on average in higher concentration neighbourhoods over the 10-year period (1995-2004) also tend to move less than individuals residing in lower concentration neighbourhoods. Overall, this evidence clearly suggests a clustering trend of non-Western migrants over the 10-year period.

Table 3.10: Mobility (\%) by migrant level of initial and 10-year mean neighbourhood concentration

\begin{tabular}{|c|c|c|c|c|c|c|}
\hline \multirow[t]{2}{*}{ 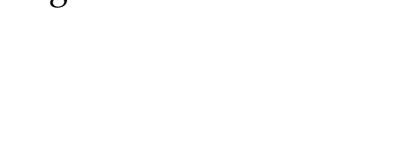 } & \multicolumn{3}{|c|}{ initial concentration level ${ }^{*}$} & \multicolumn{3}{|c|}{$\begin{array}{l}\text { 10-year mean } \\
\text { concentration level }^{* *}\end{array}$} \\
\hline & high & medium & low & high & medium & low \\
\hline non-movers & 36.36 & 33.47 & 22.43 & 27.68 & 18.82 & 8.83 \\
\hline mover within municipality & 5.22 & 7.91 & 6.68 & 5.44 & 8.65 & 8.57 \\
\hline mover within corop area & 12.38 & 9.96 & 10.89 & 10.82 & 11.57 & 14.16 \\
\hline mover between corop area & 46.04 & 48.65 & 60 & 56.07 & 60.95 & 68.44 \\
\hline
\end{tabular}

* migrant level of non-Western neighbourhood concentration at first point of residence in country

** 10-year (1995-2004) mean of individual annual levels of non-Western neighbourhood concentration

Source: Netherlands Bureau of Statistics SSB 1995-2004, own calculations

To measure heterogeneity in concentration effects we split the sample in three subgroups according to their mobility patterns. Assuming that from all people who start in one specific asylum centre those who prefer to live in a high concentration neighbourhood will actually move to the more concentrated neighbourhoods compared to others, we sort individuals per initial housing location and year on their later choices of neighbourhood residential concentrations $^{44}$ and create three equal-size groups of people for each of these yearinitial housing combinations. We call these groups 'low preference', 'medium preference' and 'high preference', which reflect different residential preferences as people starting at the same initial level of neighbourhood concentration choose to reallocate to neighbourhoods of different levels of concentration over time in line

${ }^{44}$ Individual mean level of all later annual neighbourhood concentrations. 
with their individually derived benefits. Furthermore, as we perform this grouping separately for each initial housing location the three resulting preference groups are independent on the initial level of concentration and are expected to reflect differences in underlying personal preferences to reside in the non-Western migrant community. Members of the low preference group have the lowest preference to reside in the migrant community, while members of the high preference group the highest. ${ }^{45}$ For each group we performed the analyses of the effect of concentration on outcomes separately. Figures 3.10a and 3.10b show the outcomes. As can be seen in Figure 3.10a, concentration benefits to employment chances are highest for individuals in the low concentration preference group up to concentration levels of just below 70 per cent. For high neighbourhood concentrations the benefits to the high preference group become larger than those to the prior group. Concentration gains to migrants with medium concentration preferences are considerably lower than to either of the other two groups at all levels of concentration. So people with the highest tendency to move to high concentration areas profit most from very high levels of concentration while those who tend to move to low concentration areas profit more from low levels of concentration. The middle group is an exception to this pattern. Considering concentration effects on migrant wages, as displayed in Figure $3.10 \mathrm{~b}$, a similar picture emerges. We find that migrants with high concentration preferences tend to derive the greatest gains from concentration in terms of wages, followed by the medium preferences group and finally the low preferences group. Overall, the findings of the heterogeneity analysis suggest - with the exception of the middle group in the analyses of employment probability - that people who tend to move to high concentration areas profit more from high concentration than others.

\footnotetext{
${ }^{45}$ This approach is based on the assumption that people are acting to equal extent on their preferences at different levels of initial concentration (i.e. costs of moving are comparable). While this is perhaps somewhat unrealistic, outcomes of mobility analysis remain valid as long as potential differences in sensitivity to move between individuals do not alter ranking of three groups. We are confident that this is not the case as monetary costs of moving are not substantial in the Netherlands given the small size of the country, and thus cost differences between individuals are expected to be relatively small.
} 
Figure 3.10a: Employment chances by level of concentration, residential preference groups

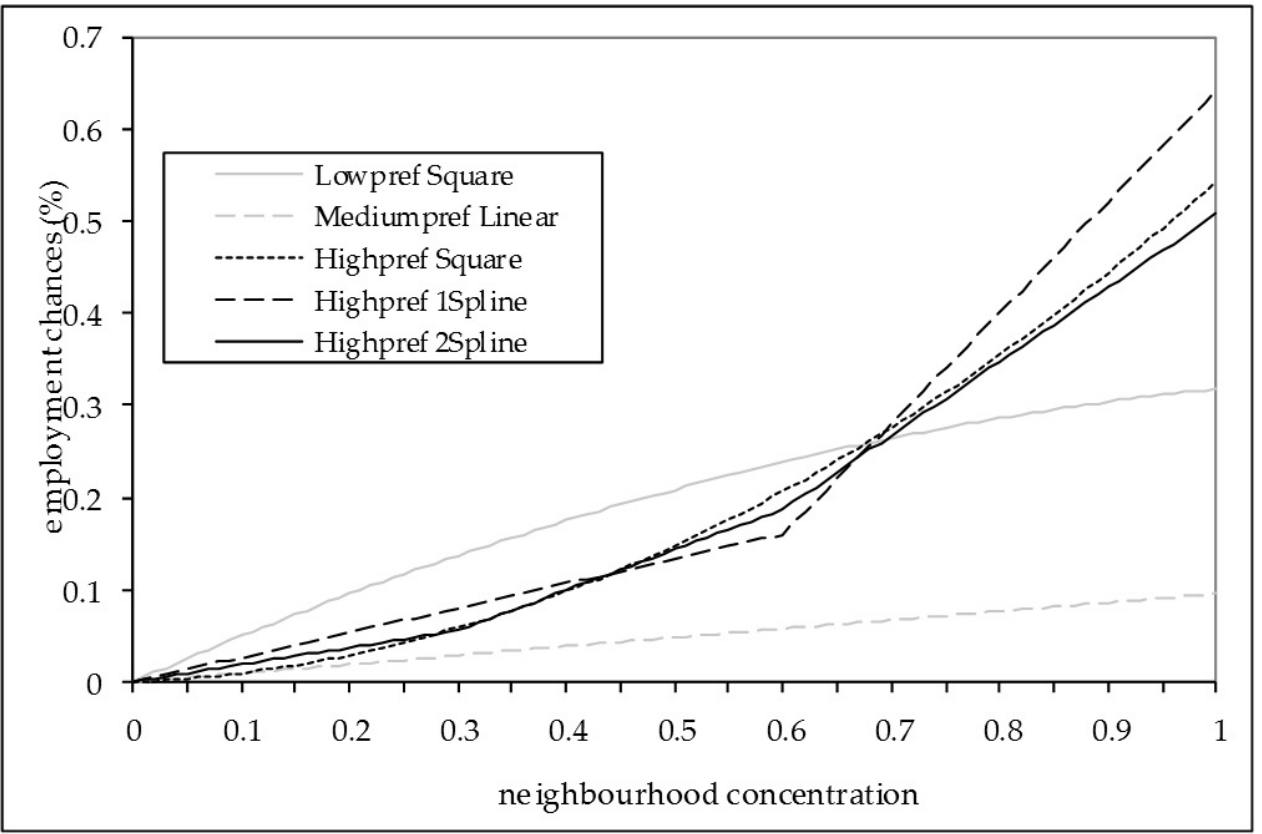


Figure 3.10b: Annual wages by level of concentration, residential preference groups

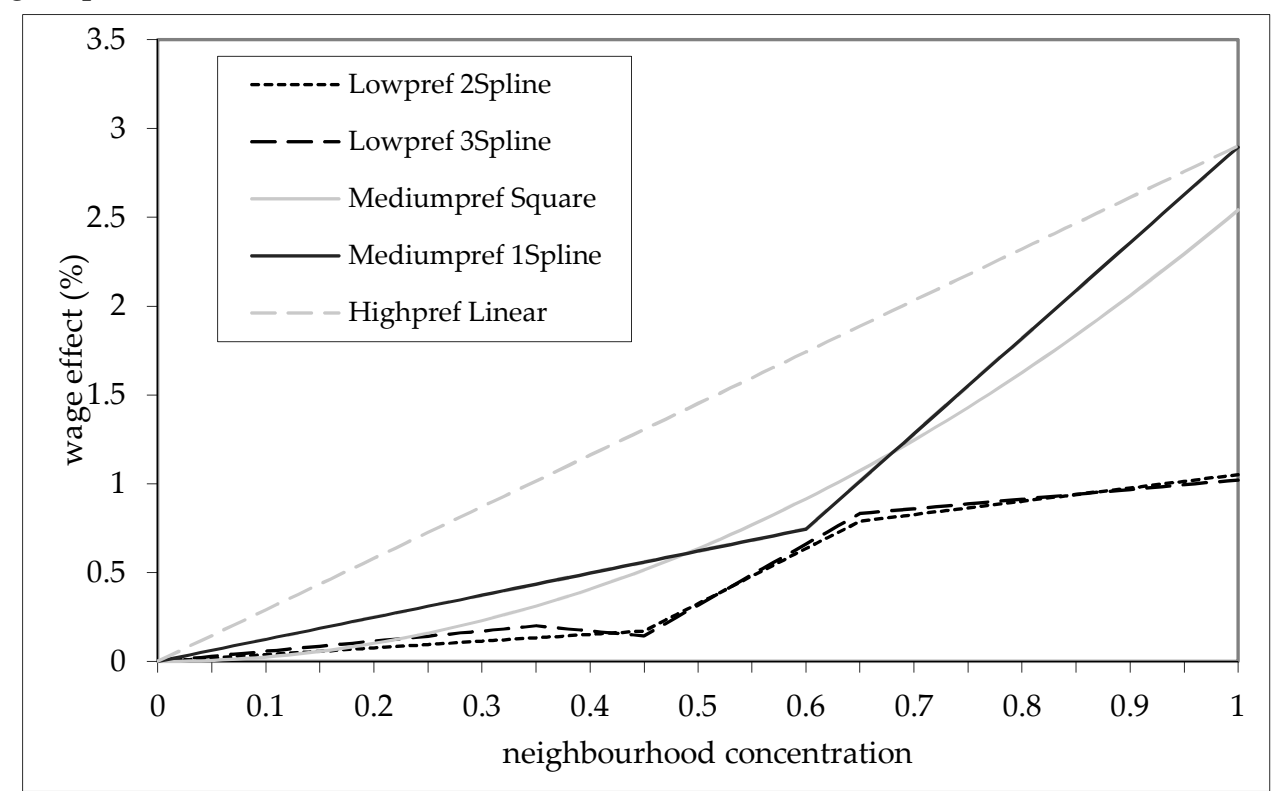

* Graphs plot the regression outputs of the IV estimations including neighbourhood controls for the dependent variables employment chances and annual gross wages with non-Western neighbourhood concentrations on the horizontal axis and the dependent variables on the vertical axis. Figures display non-linear models with better data fit than linear specification per subgroup (i.e. p-value of F-test $<.05$ ). If linear specification displayed, concentration effects are quasi-linear for respective subgroup (i.e. none of non-linear specifications having better data fit than linear one).

Source: Netherlands Bureau of Statistics SSB 1995-2004, own calculations

\section{6 - Concluding remarks}

The main aim of this study was to estimate the causal effect of residential segregation of non-Western migrants on their labour market outcomes. In other words, does living in high concentration non-Western migrant neighbourhoods benefit or harm immigrant labour market performance? To address this question, our study made use of a unique natural experiment, namely the random allocation of asylum seekers to initial housing locations in the Netherlands. This natural experiment enabled us to use exogenous initial housing locations as instruments for endogenous later neighbourhood concentrations, which in turn made causal estimation of the effect of neighbourhood concentration on immigrant labour market performance possible. While most prior studies disregarding endogeneity issues have documented a negative effect of concentration on labour market outcomes, by accounting for endogeneity, our study suggests that the true causal effect on labour market outcomes is likely to be positive instead. The key findings of our study are the following: First, we find evidence for residential sorting, which 
introduces a downward bias to concentration estimates of regressions not accounting for endogeneity. Second, the residential neighbourhood quality is very important for labour market performance of migrants as migrants residing in lowunemployment neighbourhoods tend to be more successful in the labour market than migrants residing elsewhere. Third, using exogenous initial housing locations as instruments and controlling for individual characteristics, year fixed effects, local fixed effects and neighbourhood fixed effects, our findings suggest that, on average, individuals residing in high concentration neighbourhoods are 29 per cent more likely to be employed and have 161 per cent higher annual wages than people residing in low concentration neighbourhoods. These findings are comparable but much stronger than findings at the level of the municipality by Edin et al. (2003) and Piil Damm (2009), who find that earning gains associated with a standard deviation increase in ethnic concentration (Edin et al.) and local ethnic group size (Piil Damm) amount to 13 and 18 per cent respectively. Fourth, the positive effects of concentration on outcomes are especially strong during the first years after migration. With more experience in the Netherlands the effects reduce. Fifth, we find heterogeneity in the effects of concentration on outcomes. Migrants who tend to go to high concentration neighbourhoods benefit most from living in concentrated areas.

Inspired by the above findings, we conclude with a number of final remarks on the theoretical contributions, policy implications, limitations and suggestions for future research of this chapter. The study's findings contribute to the academic debate on the existence of residential neighbourhood effects in the case of the Netherlands as well as the international debate on residential concentration effects on socio-economic integration of non-Western ethnic minorities. First, while there may be reasons to doubt the existence of neighbourhood effects in the Netherlands, as peoples' geographic mobility and social contacts are generally not restricted to these neighbourhoods, our study's findings clearly indicate that the Dutch neighbourhood does play a role in the development of individuals, as is also generally concluded in the predominantly US-based literature on the subject. Second, while the international academic literature is dominated by the view that high residential concentrations of ethnic minorities lead to 'ghetto-like' circumstances, characterized by migrant social isolation from mainstream society and socio-economic deprivation, our study provides a case where concentration actually has positive implications for migrant labour market outcomes. More specifically, it documents a significant positive causal effect of non-Western migrant neighbourhood concentration on migrant labour market outcomes, especially so for recent arrives, which provides strong evidence in support of the 'springboard' function of high concentration migrant neighbourhoods for the case of the Netherlands. The argument states that migrant neighbourhoods foster 
newcomers' acculturation process in receiving societies as they, for instance, provide 'safe havens' from discrimination in mainstream society, or they offer economic opportunities through employment in ethnic economies or by means of ethnic entrepreneurship. The latter two arguments, relating to the establishment of ethnic economies and ethnic entrepreneurship opportunities in high migrant concentration neighbourhoods, might also be reflected in our findings that migrant labour market gains from concentration are especially high at high levels of concentration. However, this does not directly follow from our findings as we have analysed the labour market effects of non-Western concentration rather than the effects of co-ethnic, or own-group, concentration. The interpretation rests on the assumption that in areas with high non-Western concentration also the level of coethnic group concentration is high, which is not always the case. Nonetheless, given the financial limitations of most asylum seekers (see Table 3.5), it is likely that many asylum seekers end up living in migrant neighbourhoods, and thus, coethnic concentrations for asylum seekers in these areas can also be expected to be higher. Interestingly, the gains at the high end range of non-Western neighbourhood concentrations are relatively more pronounced for women, which might suggest that ethnic economies are an especially important source of employment creation for ethnic minority women, who are not able or allowed to find employment elsewhere. Next to this, our findings seem to provide empirical evidence in support of the importance of local social networks for migrants' labour market outcomes. Although, our analysis does not enable the disentanglement of different social network effects (i.e. information exchange, peer group pressure), it does suggest that the gains derived from local social networks, i.e. by means of information availability about labour market regulations or available jobs, likely exceed the negative effects these networks can have on individuals, i.e. through information provision about welfare eligibility. Finally, despite the generally positive concentration effects on migrant labour market outcomes, our evidence also suggests that these effects decrease over time and actually become negative for migrants with 8-10 years of experience in the country. Thus, this may be an indication that migrants 'get stuck' in migrant neighbourhoods, which may reduce their labour market outcomes as migrant neighbourhoods are not located where the job opportunities are, in line with the spatial mismatch hypothesis. Alternatively, these individuals may also have become self-employed and actually derive far greater benefits from living in these neighbourhoods, which are however not accounted for in the employment data.

The chapter relates to the on-going discussion in many Western countries as to whether residential segregation of non-Western migrants affects their socioeconomic integration into receiving societies. This political and societal debate has been dominated by the view that residential concentration is harmful for migrant 
integration as it stalls the acquisition of host-country specific skills, e.g. language skills. Furthermore, this negative view on concentration effects has been an important justification for the implementation of settlement policies for asylum seekers, which have the aim to allocate individuals to regions with low migrant concentration and thus to reduce immigrant concentration in larger cities (implemented by national governments in e.g. UK, Germany, Denmark, Sweden and the Netherlands). Our research provides strong evidence in support of positive effects of non-Western migrant residential concentration on migrant labour market outcomes; this undermines the economic meaningfulness of settlement programs for migrants - especially those who recently arrived - actually are economically better off while residing in migrant neighbourhoods than elsewhere.

Our study has a number of limitations, which may provide fruitful grounds for future research. First, our study focuses on the identification of the causal effect of concentration on migrant labour market outcomes but lacks to clearly explain why and how concentration affects these outcomes. Thus, further research is required to explore this 'black box' and uncover the underlying mechanisms explaining this causal relationship. This research could, for instance, explore why various population subgroups benefit to a different extent from residing in high concentration migrant neighbourhoods. Also, the analysis of co-ethnic concentration effects on labour market outcomes would add valuable insight to the findings of our study. Future research should test the validity of our proposition that increased co-ethnic concentration in migrant neighbourhoods increases employment outcomes of asylum seekers due to the establishment of ethnic economies and ethnic entrepreneurship. Second, although we show that the true effect of concentration on migrant labour market outcomes is most likely nonlinear, we acknowledge that the non-linear model specifications used offer rather rough approximations of this true effect as no prior literature was available to guide our model building process. Given the growing societal relevance of the discussion on residential segregation effects on migrant socio-economic integration, future research may make an important contribution to this debate by further improving the modelling precision of concentration effects following in the footsteps of this study. Third, our analysis is limited to migrant economic outcomes in the regular labour market, which leaves out two important alternative channels that migrants use for income generation, namely employment in the irregular labour market and self-employment. We expect that these three channels are closely intertwined as family and co-ethnic networks play an important role in economic activities of migrants. Moreover, while irregular labour market activities are clearly difficult to study, future research would gain a more holistic picture of the impact of concentration on economic performance of migrants by including 
self-employment outcomes in the analysis. This would also enable exploration of transitions between the labour market and self-employment. 
3.7 - Appendix to chapter three

Figure 3.A1: Map of the Netherlands and its provinces

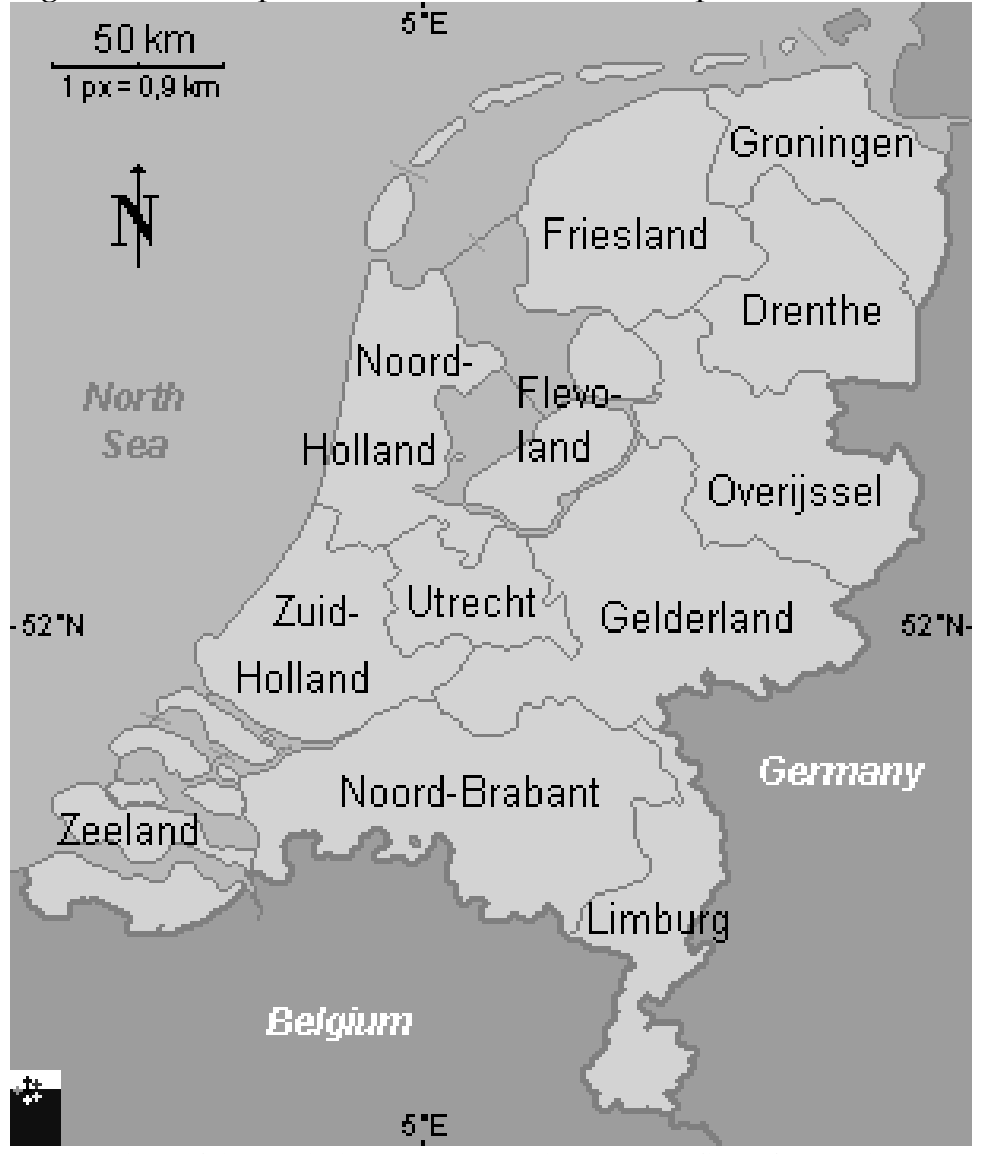

Source: Flags of the world homepage 2009: http://www.flagsoftheworld.com 
Table 3.A1: Annual asylum seekers per province

\begin{tabular}{lllllllllllll}
\hline \hline & & & & \multicolumn{1}{c}{ years } & & & & \\
province & 1995 & 1996 & 1997 & 1998 & 1999 & 2000 & 2001 & 2002 & 2003 & 2004 & 2005 & total \\
\hline Drenthe & 1389 & 1857 & 2004 & 3582 & 4302 & 4923 & 6383 & 6006 & 3993 & 3034 & 1438 & 38911 \\
Flevoland & 1575 & 1670 & 1910 & 1845 & 2323 & 2719 & 3571 & 3169 & 2259 & 2145 & 2031 & 25217 \\
Friesland & 1009 & 1556 & 3115 & 3927 & 6147 & 5937 & 6540 & 7061 & 5407 & 4487 & 3620 & 48806 \\
Gelderland & 2758 & 3674 & 3091 & 3606 & 5653 & 6522 & 8470 & 9321 & 8413 & 6757 & 5171 & 63436 \\
Groningen & 567 & 882 & 1250 & 2538 & 3642 & 4309 & 6143 & 8629 & 6730 & 4594 & 3538 & 42822 \\
Limburg & 1251 & 2639 & 2269 & 2448 & 3394 & 3879 & 4244 & 4339 & 3052 & 2300 & 2197 & 32012 \\
Noord-Brabant & 3053 & 4352 & 4822 & 6093 & 8948 & 9652 & 9874 & 9076 & 6340 & 5380 & 3640 & 71230 \\
Noord-Holland & 1846 & 3037 & 2330 & 2296 & 3016 & 3583 & 4118 & 5012 & 4565 & 4105 & 3312 & 37220 \\
Overijssel & 2006 & 2665 & 2875 & 3214 & 3905 & 5253 & 6146 & 5635 & 5115 & 2904 & 2382 & 42100 \\
Utrecht & 1354 & 1736 & 1449 & 1516 & 2265 & 2341 & 2911 & 2288 & 1509 & 1439 & 1651 & 20459 \\
Zeeland & 1027 & 1207 & 978 & 1060 & 1277 & 1771 & 2060 & 2043 & 1672 & 978 & 809 & 14882 \\
Zuid-Holland & 2406 & 3755 & 3355 & 3908 & 5538 & 6160 & 7277 & 7129 & 4382 & 2909 & 1861 & 48680 \\
Total & 20241 & 29030 & 29448 & 36033 & 50410 & 57049 & 67737 & 69708 & 53437 & 41032 & 31650 & 485775 \\
\hline \hline
\end{tabular}

Source: COA 1995-2005 
Table 3.A2: Top 10 nationalities of asylum seekers per province (1995- 2005)

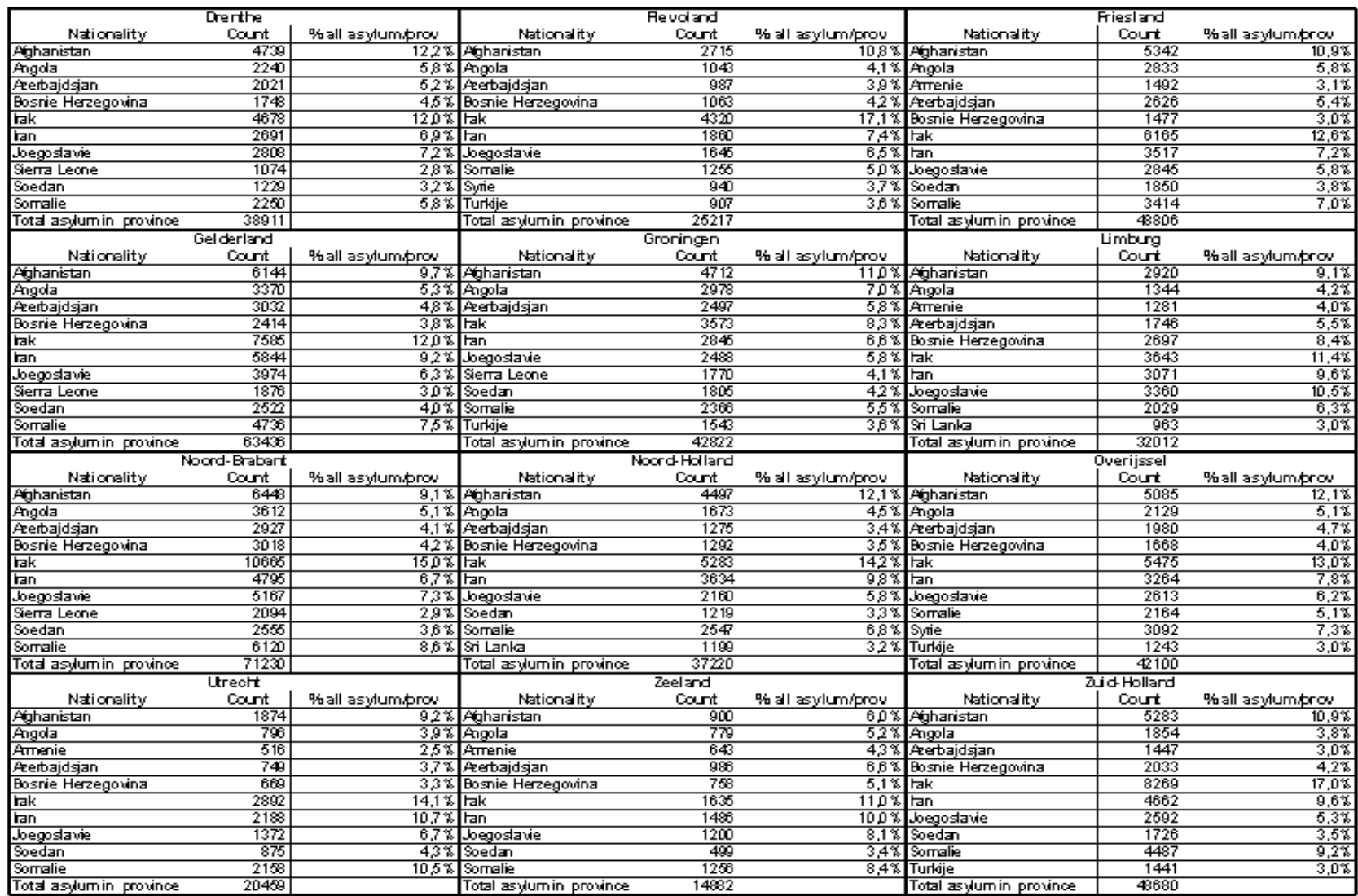

Notes: Table displays top 10 nationalities of asylum seekers for each province of the Netherlands in absolute terms and as share of total asvlum seekers of province. Source: COA 1995-2005. 
Table 3.A3: Characteristics of asylum seekers per province (1995-2005)

\begin{tabular}{lcccc}
\hline \hline & share & \multicolumn{3}{c}{ share age groups } \\
\cline { 3 - 5 } province & female & below18 & $18-64$ & $65 p l u s$ \\
\hline Zuid-Holland & $38.11 \%$ & $31.15 \%$ & $67.56 \%$ & $1.29 \%$ \\
Noord-Holland & $38.61 \%$ & $32.37 \%$ & $66.62 \%$ & $1.02 \%$ \\
Noord-Brabant & $36.13 \%$ & $32.79 \%$ & $66.38 \%$ & $0.84 \%$ \\
Gelderland & $37.24 \%$ & $31.30 \%$ & $67.80 \%$ & $0.89 \%$ \\
Utrecht & $39.06 \%$ & $31.96 \%$ & $66.75 \%$ & $1.29 \%$ \\
Limburg & $38.94 \%$ & $34.53 \%$ & $64.69 \%$ & $0.78 \%$ \\
Overijssel & $38.76 \%$ & $34.41 \%$ & $64.24 \%$ & $1.35 \%$ \\
Friesland & $37.03 \%$ & $34.88 \%$ & $64.38 \%$ & $0.75 \%$ \\
Groningen & $37.97 \%$ & $33.89 \%$ & $65.24 \%$ & $0.87 \%$ \\
Drenthe & $39.06 \%$ & $36.37 \%$ & $62.85 \%$ & $0.79 \%$ \\
Zeeland & $37.91 \%$ & $33.97 \%$ & $65.44 \%$ & $0.59 \%$ \\
Flevoland & $36.01 \%$ & $31.84 \%$ & $67.28 \%$ & $0.88 \%$ \\
\hline \hline
\end{tabular}

Source: COA 1995-2005 
Table 3.A4: List of countries per regions of origin

\begin{tabular}{|c|c|c|c|c|}
\hline \multicolumn{5}{|c|}{\begin{tabular}{|l|l|l|l|l} 
Eastern European\& CIS & Araion \\
\end{tabular}} \\
\hline 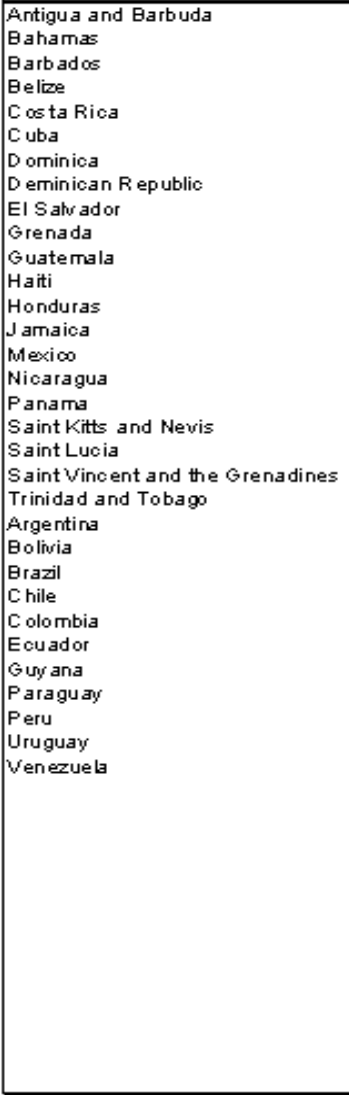 & 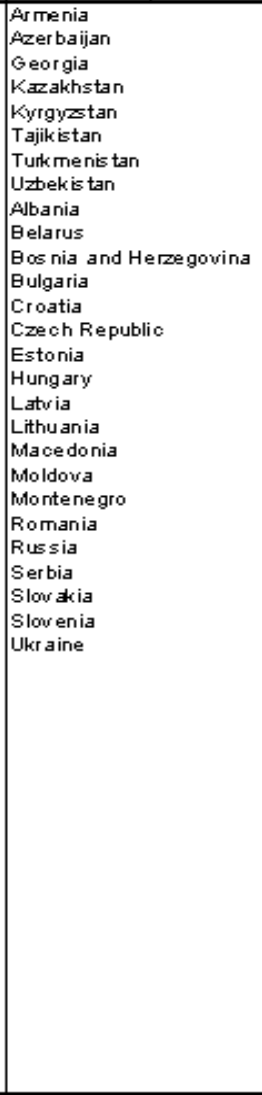 & 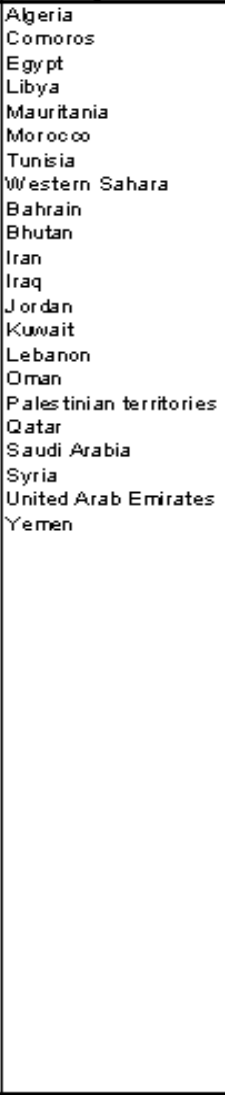 & 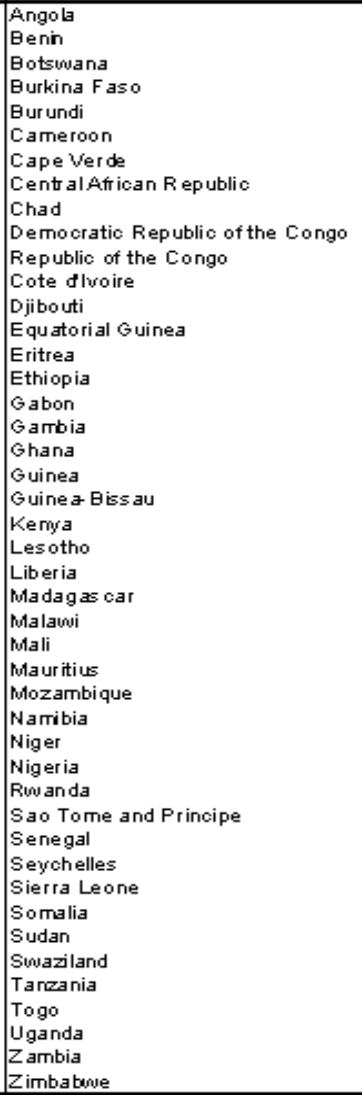 & 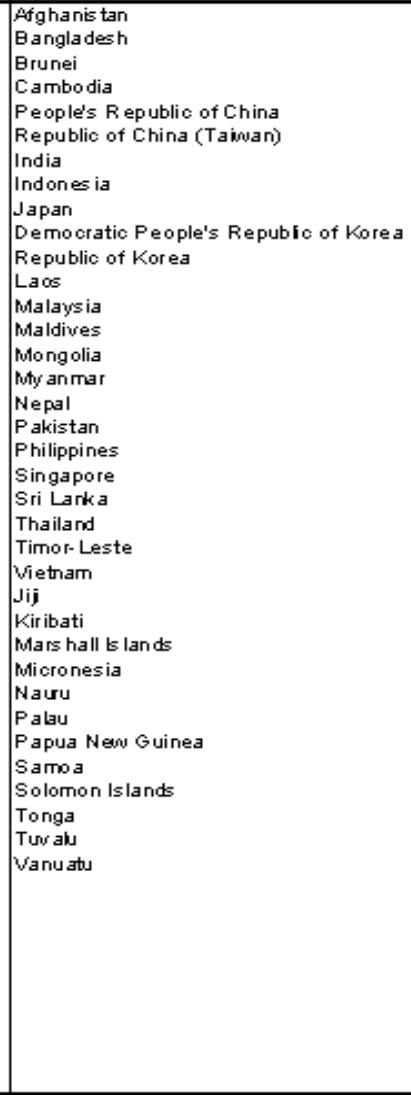 \\
\hline
\end{tabular}

Source: Netherlands Bureau of Statistics SSB 1995-2004, own additions 
Table 3.A5: Characteristics of asylum seekers per year

\begin{tabular}{|c|c|c|c|c|c|c|c|c|c|c|c|}
\hline \multirow[b]{2}{*}{ years } & \multirow{2}{*}{\multicolumn{2}{|c|}{$\begin{array}{cc} & \text { share } \\
& \text { female } \\
\text { count }^{* *} & (\%)\end{array}$}} & \multicolumn{7}{|c|}{ origin group $(\%)^{*}$} & \multicolumn{2}{|c|}{ age } \\
\hline & & & lac & eecis & arab & asia & africa & turkish & $\begin{array}{l}\text { un- } \\
\text { known }\end{array}$ & mean & st. dev. \\
\hline 1995 & 2804 & 38.3 & 0.0 & 4.0 & 3.5 & 1.1 & 4.5 & 0.8 & 86.1 & 20.75 & 15.95 \\
\hline 1996 & 8088 & 39.8 & 0.1 & 20.2 & 21.8 & 6.7 & 13.9 & 1.6 & 35.8 & 22.82 & 15.26 \\
\hline 1997 & 14275 & 40.3 & 0.1 & 17.4 & 27.8 & 11.2 & 18.4 & 1.8 & 23.3 & 23.63 & 14.90 \\
\hline 1998 & 18433 & 38.9 & 0.1 & 14.8 & 31.7 & 14.4 & 16.5 & 2.1 & 20.4 & 24.52 & 14.93 \\
\hline 1999 & 24200 & 37.3 & 0.1 & 14.6 & 34.6 & 14.3 & 15.0 & 2.5 & 19.0 & 25.14 & 14.95 \\
\hline 2000 & 33268 & 38.8 & 0.1 & 19.8 & 31.2 & 12.9 & 14.3 & 2.7 & 18.0 & 25.11 & 15.25 \\
\hline 2001 & 52918 & 40.1 & 0.1 & 23.2 & 26.5 & 15.5 & 16.9 & 2.9 & 14.9 & 25.15 & 15.18 \\
\hline 2002 & 68349 & 39.8 & 0.1 & 22.8 & 23.9 & 15.8 & 20.7 & 3.0 & 13.7 & 25.50 & 15.02 \\
\hline 2003 & 76027 & 39.8 & 0.1 & 22.0 & 22.1 & 16.0 & 23.6 & 2.8 & 13.4 & 25.95 & 14.99 \\
\hline 2004 & 75794 & 40.2 & 0.2 & 21.6 & 22.3 & 16.2 & 23.4 & 2.7 & 13.6 & 26.63 & 15.07 \\
\hline
\end{tabular}

* lac (Latin America \& Caribbean), eecis (Eastern European \& CIS region), arab (Arab countries). Table 3.A4 in the Appendix contains further information on the origin grouping.

** Only individuals are reported residing in the country as of 1 July of the each respective year.

Source: Netherlands Bureau of Statistics SSB 1995-2004, own additions

Table 3.A6: Annual working days, by gender and experience group (per cent)

\begin{tabular}{llllll}
\hline \hline \multirow{2}{*}{ group } & experience & $0-59$ & $60-144$ & $145-364$ & 365plus \\
\hline overall & 1-4 years & 90.6 & 3.2 & 3.7 & 2.4 \\
& 5-7 years & 75.9 & 3.8 & 8.4 & 11.9 \\
& 8-10 years & 66.5 & 3.4 & 8.8 & 21.3 \\
male & 1-4 years & 86.6 & 4.5 & 5.4 & 3.6 \\
& 5-7 years & 69.9 & 4.5 & 10.4 & 15.2 \\
& 8-10 years & 60.4 & 3.8 & 10.4 & 25.4 \\
female & 1-4 years & 96.7 & 1.3 & 1.3 & 0.7 \\
& 5-7 years & 85.3 & 2.8 & 5.2 & 6.8 \\
& 8-10 years & 75.3 & 2.8 & 6.5 & 15.4 \\
\hline
\end{tabular}

Source: Netherlands Bureau of Statistics SSB 1995-2004, own additions 
Table 3.A7: Annual wages by country of origin group

\begin{tabular}{llllllllllll}
\hline \hline \multicolumn{1}{l}{ group } & & $100-$ & $10000-$ & $12500-$ & $15000-$ & $17500-$ & $20000-$ & $22500-$ & $25000-30000$ \\
$*$ & $0-99$ & 9999 & 12499 & 14999 & 17499 & 19999 & 22499 & 24999 & 29999 & plus \\
\hline lac & 87.0 & 10.4 & 1.0 & 0.5 & 1.0 & 0.0 & 0.0 & 0.0 & 0.2 & 0.0 \\
eecis & 84.3 & 9.4 & 0.7 & 0.7 & 0.8 & 0.9 & 0.8 & 0.8 & 1.1 & 0.6 \\
arab & 76.8 & 15.8 & 1.2 & 1.1 & 1.1 & 1.1 & 1.0 & 0.7 & 0.8 & 0.5 \\
asia & 77.8 & 15.2 & 0.9 & 1.0 & 1.0 & 1.3 & 1.1 & 0.7 & 0.7 & 0.3 \\
africa & 77.8 & 15.9 & 1.0 & 0.9 & 0.9 & 0.9 & 0.9 & 0.7 & 0.6 & 0.3 \\
turkish 84.0 & 11.1 & 0.7 & 0.7 & 0.8 & 0.6 & 0.8 & 0.5 & 0.4 & 0.2 \\
\hline \hline
\end{tabular}

* lac (Latin America \& Caribbean), eecis (Eastern European \& CIS region), arab (Arab countries). Table 3.A4 in the Appendix contains further information on the origin grouping.

Source: Netherlands Bureau of Statistics SSB 1995-2004, own additions 
Table 3.A8: Robustness check regressions, outputs linear specification

\begin{tabular}{|c|c|c|c|c|c|c|c|c|}
\hline & \multicolumn{4}{|c|}{$\begin{array}{l}\text { Dependent variable: Probability o } \\
\text { employment }\end{array}$} & \multicolumn{4}{|c|}{$\begin{array}{l}\text { Dependent variable: Annual gross } \\
\text { wages }\end{array}$} \\
\hline & (1) & (2) & (3) & (4) & (5) & (6) & (7) & (8) \\
\hline & OLS & IV & OLS & IV & OLS & IV & OLS & IV \\
\hline \multirow[t]{2}{*}{ concentration } & -.073 & .001 & .057 & .242 & -.177 & -.135 & .261 & .399 \\
\hline & $(.004)^{* * *}$ & $(.009)$ & $(.012)^{* * *}$ & $*(.029)^{* * * *}$ & $(.032)^{* * * *}$ & (.109) & $(.072)^{* * * *}$ & $(.290)^{* * * *}$ \\
\hline \multirow[t]{2}{*}{ female } & -.093 & -.093 & -.102 & -.101 & -.357 & -.356 & -.344 & -.343 \\
\hline & $(.002)^{* * *}$ & $(.002)^{* * *}$ & $(.002)^{* * *}$ & $*(.002)^{* * * *}$ & $(.015)^{* * *}$ & $(.015)^{* * * *}$ & $(.016)^{* * *}$ & $(.016)^{* * * *}$ \\
\hline \multirow[t]{2}{*}{ age } & .014 & .014 & .016 & .016 & .171 & .171 & .180 & .179 \\
\hline & $(.001)^{* * *}$ & $(.000)^{* * *}$ & $(.000)^{* * *}$ & $*(.000)^{* * * *}$ & $(.006)^{* * * *}$ & $(.006)^{* * * *}$ & $(.006)^{* * * *}$ & $(.006)^{* * * *}$ \\
\hline \multirow[t]{2}{*}{ age2 } & -.0003 & -.0003 & -.0003 & -.0003 & -.002 & -.002 & -.002 & -.002 \\
\hline & $(.000)^{* * * *}$ & $(.000)^{* * *}$ & $(.000)^{* * *}$ & $*(.000)^{* * * *}$ & $(.000)^{* * *}$ & $(.000)^{* * * *}$ & $(.000)^{* * *}$ & $(.000)^{* * *}$ \\
\hline \multirow[t]{2}{*}{ urbanisation } & .018 & .016 & .010 & .003 & .061 & .059 & .043 & .038 \\
\hline & $(.001)^{* * * *}$ & $(.001)^{* * *}$ & $(.002)^{* * *}$ & (.002) & $(.010)^{* * *}$ & $(.012)^{* * * *}$ & $(.012)^{* * *}$ & $(.016)^{* * *}$ \\
\hline \multirow[t]{2}{*}{ employment_nbh } & & & .264 & .337 & & & .816 & .722 \\
\hline & & & $(.014)^{* * *}$ & $(.034)^{* * * *}$ & & & $(.103)^{* * *}$ & $(.415)^{*}$ \\
\hline \multirow[t]{2}{*}{ meanwage_nbh } & & & -.001 & -.001 & & & .000 & .000 \\
\hline & & & $(.000)^{* * *}$ & $*(.000)^{*}$ & & & $(.000)$ & $(.000)$ \\
\hline \multirow[t]{2}{*}{ constant } & -.106 & -.115 & -.180 & -.214 & 5.11 & 5.11 & 4.56 & 4.54 \\
\hline & $(.010)^{* * * *}$ & $(.011)^{* * *}$ & $(.017)^{* * *}$ & $(.031)^{* * * *}$ & $(.138)^{* * *}$ & $(.138)^{* * * *}$ & $(.183)^{* * *}$ & $(.356)^{* * * *}$ \\
\hline experience & yes & yes & yes & yes & yes & yes & yes & yes \\
\hline year & yes & yes & yes & yes & yes & yes & yes & yes \\
\hline corop & yes & yes & yes & yes & yes & yes & yes & yes \\
\hline observations & 306200 & 306200 & 176296 & 176296 & 41377 & 41377 & 27018 & 27018 \\
\hline r-square & .153 & & .160 & & .291 & & .300 & \\
\hline
\end{tabular}

a. Table represents estimation outcomes using OLS and IV techniques with dependent variables probability of employment and annual gross wages, where employment is defined as min. annual wages of $€ 1000$ and 80 working days.

b. urbanisation is the natural logarithm of the degree of urbanization of neighbourhoods, which is measured as the number of addresses per $1 \mathrm{~km}$ radius of the neighbourhood.

c. heteroskedasticity-consistent standard errors are in parentheses. They are corrected to account for multiple observations of individuals over time. Asterisks indicate significance level: ${ }^{*}$ at $10 \%,{ }^{* *}$ at $5 \%$, $* * *$ at $1 \%$ respectively.

d. In the IV regressions, initial neighbourhood concentrations are used as instruments for annual neighbourhood concentrations.

e. All regressions include dummies for level of experience (levels: 1-4 years, 5-7 years, 8-10 years), year (1999-2004), corop (40 areas). Regressions (3), (4), (7) and (8) moreover include neighbourhood fixed effects where employment_nbh is mean employment rate among the population aged 18-64 in the neighbourhood and meanwage_nbh is mean wage of the population 18-64 working of the neighbourhood.

Source: Netherlands Bureau of Statistics SSB 1995-2004, own additions 
Figure 3.A2: Regression outputs for 1-4 years experience group, non-linear models, annual wages

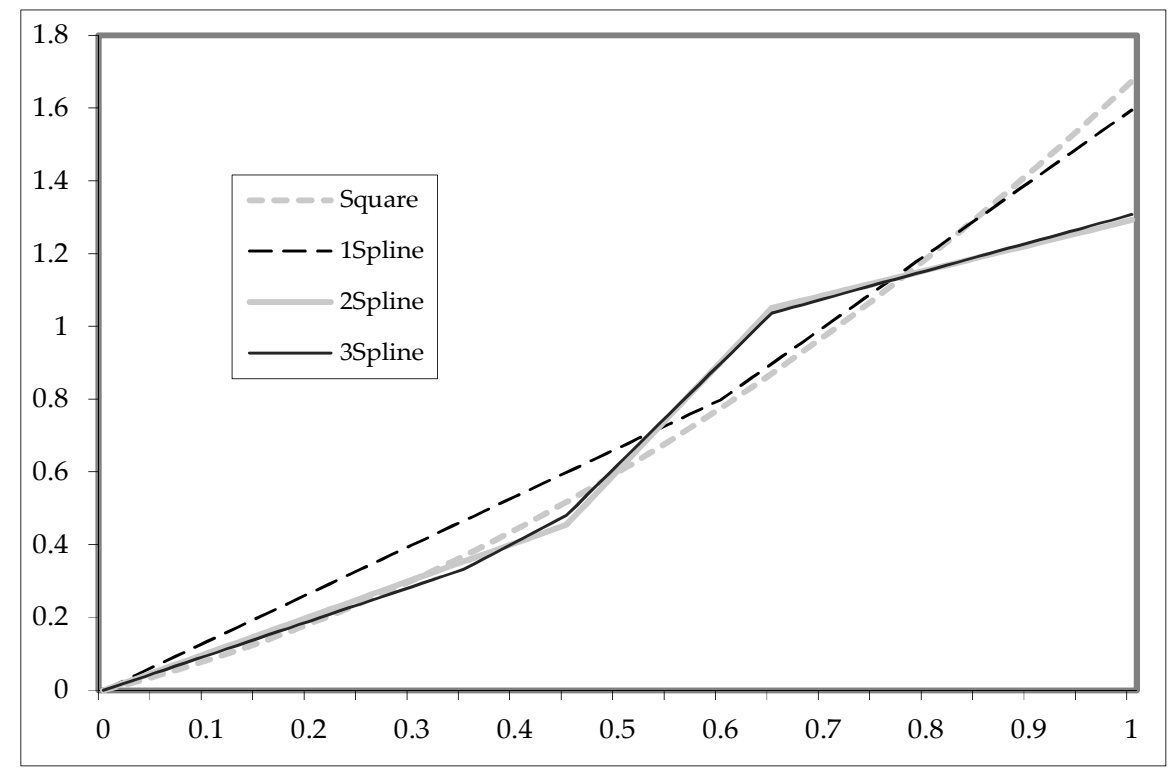

* Graphs plot the regression outputs of the OLS and IV estimations for the dependent variables employment chances and annual gross wages with non-Western neighbourhood concentrations on the horizontal axis and the dependent variables on the vertical axis.

Source: Netherlands Bureau of Statistics SSB 1995-2004, own additions 


\section{Chapter 4: Immigrant entrepreneurship on the move: A longitudinal analysis of first and second generation immigrant entrepreneurship ${ }^{46}$}

\section{1 - Introduction}

Over the past decades, most Western countries, including the Netherlands, have seen a notable increase of immigrant business ownership, especially for migrants from non-Western countries (ITS 2007, CBS Statline 2009). This development seems promising in light of on-going disadvantages of the latter groups in the labour market. Participation rates are low and there is a substantial earnings gap to natives and immigrants from Western countries. While immigrant entrepreneurship can be a promising vehicle for enabling individuals to gain economic mobility and social recognition (Van den Tillaart 2001, Choenni 1997), it is commonly discredited on the grounds of being low value-added, lacking innovation, and marginally profitable (Light \& Rosenstein 1995, Waldinger 1996, Kloosterman, Rath \& Van der Leun 1997). ${ }^{47}$

Explorative studies by Van den Tillaart (2001), EIM (2004) and Rusinovic (2006), however, suggest that the traditionally gloomy image of migrant entrepreneurship needs to be reassessed as a "new" group of migrant entrepreneurs - namely the children of migrants or the so-called second generation - have started businesses in more promising sectors of the economy. Therefore, the first objective of this chapter is to investigate the claim that second generation migrant entrepreneurs have substantially better economic positions and more promising future prospects than their parent's generation. More specifically, we offer a systematic account of first and second generation migrant entrepreneurs in the Netherlands based on administrative data from different sources. From a theoretical perspective the chapter contributes to the field in two ways. First, while much of the current literature on migrant entrepreneurship has emphasized human and social capital as important determinants for entering self-employment (see, e.g., Fairlie 1999, Clark \& Drinkwater 2000, Ram et al. 2000, Levent et al. 2003, Arenius \& De Clercq 2005, Wilson et al. 2007, Andersson \& Hammarstedt 2010), we focus more on firm

\footnotetext{
${ }^{46}$ This chapter is based on the paper: Beckers, P. \& Blumberg, B. (2010), "Immigrant Entrepreneurship on the move - A longitudinal analysis of first and second generation immigrant entrepreneurship in the Netherlands", Conference paper at the Academy of Management Annual Meeting, Montreal, August 2010.

${ }^{47}$ In this discourse, migrant entrepreneurship refers to businesses operated by migrants originating from non-Western or developing countries.
} 
and firm location characteristics and the relative success of these firms. In our view, business success is an essential but neglected factor, as many self-employed people in general, and migrant self-employed people in particular, operate marginal businesses in fragmented industries. Looking solely at the decision to become self-employed does not capture the heterogeneity of self-employment ranging from those generating incomes barely exceeding welfare benefits to those of wealthy businessmen and community leaders. A second contribution is that we illustrate the heterogeneity across different migrant groups and develop hypotheses relating to the entrepreneurial success of non-Western migrant entrepreneurs in the Netherlands.

The chapter is structured in six parts. Following this introduction, Section 4.2 provides a general overview of migrant entrepreneurship in the Netherlands paying particular attention to recent developments for non-Western migrant groups. Section 4.3 discusses the literature on migrant integration trajectories and entrepreneurship to develop research hypotheses. Sections 4.4 to 4.6 present the research methodology, study findings and their discussion. Section 4.7 contains some conclusions.

\section{2 - Migrant entrepreneurship in the Netherlands}

Table 4.1 depicts the self-employment figures of different population groups in the Netherlands between 1999 and 2004. Overall self-employment has remained relatively constant, while self-employment among non-Western migrants has strongly and consistently increased absolutely from 32,700 to 45,300 and relatively from 4.3 per cent to 5.9 per cent between 1999 and 2004. Similar growth trends of non-Western entrepreneurship are found in many other European countries such as the UK (Thompson et al. 2010, Ram et al. 2006), Germany (Wilpert 2003) or France (Ma Mung \& Lacroix 2003). The non-Western group of entrepreneurs is divided into first-generation and second-generation entrepreneurs to show that the former group still accounts for the lion's share (more than 85 per cent) of business activities as most second-generation migrants are still in compulsory education. Nevertheless, over the 1999-2004 period the second generation has increasingly entered self-employment with annual growth rates averaging over 10 per cent.

As the population of non-Western migrant entrepreneurs is rather heterogeneous, we select the five largest groups, namely those originating from Turkey, Morocco, Suriname, the Dutch Antilles/Aruba and China, which together account for more than half of non-Western entrepreneurship. Among these five groups, the Turkish is by far the largest $(7,700$ to 11,500$)$, followed by the Surinamese $(5,900$ to 7,400$)$, 
Chinese $(3,400$ to 4,700$)$, Moroccan $(2,700$ to 4,700$)$ and finally the Dutch Antillean/Aruban group (1,300 to 2,000).

Table 4.1: Entrepreneurship in the Netherlands 1999-2004*

\begin{tabular}{llll|llll}
\hline Year & All & Native & Western & \multicolumn{3}{|l}{ Non-western } \\
\cline { 2 - 7 } & & & & & & $\%$ & $\%$ \\
& count & $\%$ & $\%$ & count & $\%$ & 1gen. & 2gen. \\
\hline $\mathbf{1 9 9 9}$ & 764,200 & 87.75 & 7.97 & 32,700 & 4.29 & 3.78 & 0.47 \\
$\mathbf{2 0 0 0}$ & 787,300 & 87.41 & 7.95 & 36,500 & 4.64 & 4.14 & 0.55 \\
$\mathbf{2 0 0 1}$ & 803,700 & 86.78 & 8.01 & 41,800 & 5.20 & 4.58 & 0.64 \\
$\mathbf{2 0 0 2}$ & 795,500 & 86.61 & 8.02 & 42,700 & 5.38 & 4.69 & 0.68 \\
$\mathbf{2 0 0 3}$ & 788,700 & 86.16 & 8.08 & 45,400 & 5.76 & 4.96 & 0.75 \\
$\mathbf{2 0 0 4}$ & 768,200 & 86.10 & 8.00 & 45,300 & 5.91 & 5.01 & 0.83 \\
\hline
\end{tabular}

* Entrepreneurs defined as persons reporting income from self-employment ('eigen bedrijfsvoering') (excludes freelancers, directors-main shareholders ('directeur-grootaandeelhouders'). Definitions of Western and non-Western, first and second generation migrants follow those of Netherlands Statistics Bureau, whereby non-Western migrants are individuals who were born, or at least one of whose parents were born, in a non-Western country of Asia (excluding Japan and Indonesia), Africa, Latin America and Turkey. Western migrants are individuals born (or who had at least one of their parents born) in a Western country outside the Netherlands. First-generation migrants were born abroad and second generation migrants are children with at least one parent born abroad.

Source: CBS Statline 2009

Table 4.2 shows the self-employment propensities for different country-of-origin populations for the period 1999-2004 including the five main non-Western groups. Self-employment is still higher among the native population (11.5 per cent) than the non-Western migrants (8.8 per cent for the first generation and 4.5 per cent for the second generation), but the gap is narrowing as the latter has increased by 20 per cent over this six-year period. The figures differ considerably between the five non-Western migrant groups investigated. Self-employment is more common among Turkish and Chinese migrants than among migrants of the other three groups..$^{48}$ Finally, over the six year period, self-employment rates increased for first and second generations of the Turkish, Moroccan, Surinamese and Antillean groups, but decreased for the first generation Chinese and stayed about constant for the second generation Chinese. In summary, over the 1999-2004 period, nonWestern entrepreneurship has increased notably in scale, which can be largely attributed to the developments of five main groups.

${ }^{48}$ The first-generation Chinese population is a unique case as self-employment is more popular than salaried employment. This pattern is explained by the large number of Chinese migrants (mostly from Hong Kong) that entered the Netherlands in the 1960s, many of which opened Chinese restaurants. 
Table 4.2: Self-employment propensities per groups (in per cent)*

\begin{tabular}{|c|c|c|c|c|c|c|c|c|c|c|c|c|c|c|}
\hline \multirow[t]{2}{*}{ Year } & \multirow[t]{2}{*}{$\begin{array}{l}\stackrel{0}{\Xi} \\
\tilde{Z} \\
Z\end{array}$} & \multirow[t]{2}{*}{$\begin{array}{l}5 \\
\stackrel{0}{ \pm} \\
\infty \\
\infty \\
3\end{array}$} & \multicolumn{2}{|c|}{ Non-western } & \multicolumn{2}{|c|}{ Turkish } & \multicolumn{2}{|c|}{ Moroccan } & \multicolumn{2}{|c|}{ Surinamese } & \multicolumn{2}{|c|}{ Antillean } & \multicolumn{2}{|c|}{ Chinese } \\
\hline & & & 1gen. & 2gen. & 1gen. & า. 2 gen. & 1gen. & 1. 2gen. & 1gen. & . 2gen. & 1gen. & 1. 2gen. & 1gen. & 1. 2 gen. \\
\hline 1999 & 11.8 & 10.7 & 7.8 & 4.1 & 9.7 & 3.7 & 4.2 & 1.6 & 4.6 & 4.1 & 2.9 & 4.8 & 61.2 & 11.4 \\
\hline 2000 & 11.9 & 10.7 & 8.2 & 4.3 & 10.5 & 4.2 & 4.7 & 1.9 & 5.0 & 4.3 & 3.0 & 4.8 & 60.5 & 10.7 \\
\hline 2001 & 11.9 & 10.8 & 8.9 & 4.6 & 12.2 & 4.9 & 5.4 & 2.3 & 5.4 & 4.4 & 3.2 & 5.2 & 57.9 & 11.4 \\
\hline 2002 & 11.7 & 10.7 & 8.8 & 4.5 & 12.6 & 5.2 & 5.5 & 2.3 & 5.3 & 4.3 & 3.1 & 5.3 & 53.5 & 10.9 \\
\hline 2003 & 11.6 & 10.8 & 9.4 & 4.8 & 13.1 & 5.8 & 6.2 & 2.5 & 5.4 & 4.5 & 3.4 & 5.4 & 52.4 & 11.1 \\
\hline 2004 & 11.4 & 10.6 & 9.5 & 5.0 & 13.3 & 6.1 & 6.5 & 2.9 & 5.4 & 4.4 & 3.3 & 5.5 & 53.1 & 10.9 \\
\hline
\end{tabular}

* Defined as population aged 15-65 with income from self-employment (excluding freelancers, directors main-shareholders) as share of population with employment income as of the last Friday in September in respective years. Definitions of Western and non-Western as well as first-generation and secondgeneration migrants are, as in Table 4.1, based on those by the Netherlands Statistics Bureau.

Source: CBS Statline 2009

\section{3 - Integration trajectories and immigrant entrepreneurship}

Generational change in migrant entrepreneurship is closely related to migrant integration trajectories in their host societies. Integration trajectories have been studied extensively (Portes and Zhou 1993, Alba and Nee 2004, Portes, FernandezKelly \& Haller 2008, Pels 1991, Vermeulen and Penninx 1994, 2000, Lindo 1996, Crul 2000, Dagevos 2001), but surprisingly, the literature turns a blind eye to selfemployment, even though labour market positions are portrayed as an important outcome of integration. It is expected that integration into the host society will increase the chance of entering self-employment and improve the prospects of the founded firms, since integration enhances migrants' abilities to access vital business information and mobilise necessary resources (see also Constant \& Zimmermann 2006, Evans 1989, Le 2000).

Intergenerational differences in host society integration

In this chapter, we use the definition of integration by Vermeulen and Penninx $(1994,2000)$ which distinguishes between two dimensions of integration, namely the socio-cultural and the structural dimensions. ${ }^{49}$ The socio-cultural dimension reflects interpersonal relations with the native Dutch population and the extent of cultural, attitudinal, and behavioural changes towards the host society (i.e. Dagevos, Gijsberts and Van Praag 2003, Dagevos 2001, Vermeulen and Penninx 2000, Veenman 1995, Rusinovic 2006). Structural integration refers to the

${ }^{49}$ A thorough discussion of varying definitions of migrant integration is beyond the scope of this paper. Please refer to the studies by Dagevos (2001), Portes, Fernandez-Kelly \& Haller (2008) for comprehensive overviews of going definitions. 
participation of immigrants in the core institutions of society and is usually measured by educational attainment, position in the labour market, and residential integration (Dagevos 2001, Rusinovic 2006).

Integration-related aspects of migrants and children of migrants have been widely studied in the Netherlands (see, e.g., Crul and Pásztor 2007, Pels and de Gruyter 2006, Coenen 2001, Crul 2000, Lindo 1996, Klatter-Former 1996, Veraart 1996, v.d. Hoek 1992, Pels 1991). The findings generally support the segmented assimilation model (Portes \& Zhou 1993), which proposes that different ethnic groups follow different assimilation pathways at different paces. Despite occasional concerns of intergenerational downward social mobility of disadvantaged immigrant groups, Alba and Nee (2004) point out that even in the most disadvantaged groups, the dominant trend is still upward social mobility.

Using Vermeulen \& Penninx's $(1994,2000)$ integration terminology, Table 4.3 presents the socio-cultural and structural integration of the five major migrant groups in the Netherlands. In general, the second generation is more integrated along both the socio-cultural and the structural dimensions. The second generation has a better command of the Dutch language, maintains more interpersonal relations with the native Dutch population and possesses more "Dutch" opinions, attitudes and behaviour (Dagevos, Gijsberts and Van Praag 2003, Beekhoven and Dagevos 2005, Rusinovic 2006). With regard to the structural dimension, the second generation generally appears to achieve higher levels of education and holds more favourable positions in the labour market than their parents. Nonetheless, disadvantages as compared to natives persist in educational achievements for some groups and in the labour market for all groups (Vermeulen and Penninx 1994, 2000, Dagevos and Bierings 2005, Zorlu and Traag 2005, Rusinovic 2006). ${ }^{50}$ Residential allocation, which indicates exposure to the host culture, has hardly changed between the first and second generation with the exception of the Dutch Antillean group. In conclusion, the picture regarding integration on the structural dimension is mixed. For the second generation, we observe a higher level of integration regarding education, but not regarding labour market or residential location.

\footnotetext{
${ }^{50}$ It should be noted that the comparison of the first and second generation on educational attainment and labour market position is problematic due to the age difference between the two groups and the fact that many second generation migrants, especially those with better prospects, are still in education. Thus the population segment at the lower end of the education span and labour market is overrepresented.
} 
Table 4.3: Socio-cultural and structural integration for five groups of non-Western migrants in the Netherlands

\begin{tabular}{|c|c|c|c|c|c|c|c|c|c|c|c|}
\hline \multirow{2}{*}{ dimensions of integration } & \multirow[t]{2}{*}{ Natives } & \multicolumn{2}{|c|}{ Turkish } & \multicolumn{2}{|c|}{ Moroccan } & \multicolumn{2}{|c|}{ Surinamese } & \multicolumn{2}{|c|}{ Antillean } & \multicolumn{2}{|c|}{ Chinese } \\
\hline & & $\underset{\dot{\varpi}}{\dot{\Xi}}$ & 䓵 & $\underset{\dot{D}}{\vec{\sigma}}$ & $\begin{array}{l}\text { d. } \\
\text { d. }\end{array}$ & $\underset{\varpi}{\infty}$ & $\begin{array}{l}\text { 苛 } \\
\text { d. }\end{array}$ & 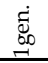 & 离 & $\dot{\varpi ్}$ & 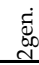 \\
\hline \multicolumn{12}{|l|}{ SOCIO-CULTURAL } \\
\hline Dutch language proficiency (1-low;2-medium;3-high) ${ }^{* * * *}$ & n.a. & 1.7 & 24 & 1.8 & 2.7 & 2.8 & 2.9 & 2.5 & 2.9 & 1.7 & 28 \\
\hline never receives visit by native friends $(\%) * * * *$, & n.a. & 40 & 30 & 50 & 18 & 33 & 14 & 25 & 6 & 33 & 18 \\
\hline often contacts with natives in free time $(\%) * * * *,,, \circ$ & n.a. & 21 & 47 & 29 & 58 & 50 & 70 & 61 & 92 & 12 & 42 \\
\hline identification with own group (\%) $* * * *$ & n.a. & 99 & 93 & 97 & 89 & 90 & 68 & 83 & 31 & no info & \\
\hline \multicolumn{12}{|l|}{$\begin{array}{l}\text { modern values (gender roles, family relations, emancipation, } \\
\text { religious liberalism; 1-least modern; 5-most modern) }{ }^{* * *}\end{array}$} \\
\hline & n.a. & 2.8 & 3.1 & 2.8 & 3 & 3.2 & 3.5 & 3.3 & 3.7 & no info & \\
\hline \multicolumn{12}{|l|}{ STRUCTURAL } \\
\hline \multicolumn{12}{|l|}{ - educational outcomes (highest level of education) ** } \\
\hline only basic education (max.bo) & 22 & 67 & 35 & 78 & 41 & 34 & 17 & 33 & 9 & 58 & 7 \\
\hline some secondary education (vbo/mavo) $* * * * * *$ & 28 & 13 & 37 & 8 & 27 & 31 & 29 & 31 & 18 & 18 & 32 \\
\hline starting qualification (mbo/havo/vwo/hbo/wo) & 50 & 18 & 28 & 14 & 31 & 35 & 54 & 36 & 73 & 25 & 61 \\
\hline $\begin{array}{l}\text { - labour market outcomes/social security } \\
\text { share of working age population working* }\end{array}$ & 66 & 43 & 54 & 43 & 54 & 64 & 57 & 55 & 63 & 31 & 55 \\
\hline share unemployed ${ }^{* *}$ & 4 & 18 & 15 & 19 & 22 & 9 & 11 & 14 & 8 & 11 & (8) \\
\hline share of work age pop. receiving public assistance * & 2 & 14 & 4 & 19 & 5 & 13 & 6 & 21 & 4 & 12 & 2 \\
\hline job functional level - elementary/lower ** & 37 & 78 & 65 & 77 & 72 & 51 & 55 & 51 & 39 & 48 & \\
\hline job function level - medium ** & 32 & 15 & 26 & 17 & 21 & 33 & 26 & 33 & 30 & 38 & \\
\hline $\begin{array}{l}\text { job function level - higher/scientific ** } \\
\text { - residential allocation (across neighbourhood type)* }\end{array}$ & 32 & 7 & 9 & 6 & 7 & 15 & 19 & 16 & 32 & 15 & \\
\hline $0-15 \%$ non-western migrants in neighbourhood & 86 & 29 & 31 & 28 & 29 & 30 & 37 & 37 & 55 & 54 & 58 \\
\hline $15-50 \%$ non-western migrants in neighbourhood & 13 & 48 & 48 & 50 & 49 & 46 & 45 & 47 & 36 & 35 & 33 \\
\hline $50+\%$ non-western migrants in neighbourhood & 1 & 22 & 21 & 23 & 22 & 24 & 18 & 16 & 9 & 10 & 9 \\
\hline
\end{tabular}

Notes: * Source: Netherlands Bureau of Statistics Statline 2009 (means of period 1999-04, working age population defined as age 15-65); ** Sources: SPVA ‘98/CHIN'97, for education indicators only individuals who finished their schooling period are included; *** Sources: SCP, Rapportage minderheden 2003, SPVA ‘02; **** Sources: SCP, Rapportage minderheden 2003, SPVA ‘98/CHIN`97; The National Bureau of Statistics figures define second generation only as individuals born in the Netherlands with at least on migrant parent, while the SPVA also include migrants to the Netherlands before age 6 as second generation. For Chinese, the language proficiency ranking is computed as follows:1-speaks no Dutch/often language difficulties, 2-sometimes difficulties, 3-speaks Dutch well; ***** For the Chinese group, the havo educational qualification is grouped to this lower category although it fits better in the higher one. This was necessary due to the difficult distinction between mavo and havo levels in the Chinese educational system. As a consequence, education levels of the Chinese are somewhat understated when compared to other groups. ${ }^{\circ}$ Chinese data based on responses of household heads, partners and children above 12, other group responses based on information of household heads only. ${ }^{\circ}$ For non-Chinese migrant groups, this indicator is somewhat understated as it indicates the share of migrants with more contacts to natives than their co-ethnic groups.

Table 4.3 also reveals that integration trajectories of the five migrant groups differ as segmented assimilation theory would predict. With regard to socio-cultural aspects, for example, gains in language skills are higher for the Turkish, Moroccan and Chinese than for Surinamese and Dutch Antillean migrants, certainly because Dutch is an official language in the two latter countries. While, consequently, social contacts with natives are also lower for the Turkish, Moroccan and Chinese migrants, a clear intergenerational catching-up trend is visible for these groups. 
Turkish and Moroccan migrants also identify more strongly with their ethnic groups and are more likely to uphold traditional values. This may be explained, next to cultural and linguistic considerations, by the groups' relatively higher levels of self-sufficiency, as the size of their ethnic community is large enough to form a viable sub-cluster within the host society.

With regard to structural integration, a clear convergence trend towards natives is observed in first and second generation migrant educational achievements, whereby the Chinese, Antillean and Surinamese second generations actually surpass the educational levels of the native Dutch. The Turkish, Moroccan and Chinese groups show the largest gains between generations. Despite great intergenerational improvements in educational attainment, labour market prospects of the second generation migrant groups trail consistently behind those of the natives even for those groups that are better educated than the Dutch. Especially, Turkish, Moroccan and to a lesser extent Surinamese migrants are experiencing difficulties in the transition phase from education to the labour market (Dagevos 2001, Crul and Pásztor 2007). In the Antillean and Chinese cases, educational advances of the second generations seem to have become translated into significant labour market improvements (Vogels et al. 1999, Dagevos 2001, Martens 1999). Regarding residential location, the final element of the structural dimension, we observe some differences between the five migrant groups but little change between the first and second generations. While both generations of Turkish, Moroccan and Surinamese migrants reside in areas with a high migrant concentration, second-generation Antilleans have moved on to less concentrated areas. Chinese migrants comprise a special group as both its first generation and, even more so, its second generation are highly dispersed across the country and consequently reside in neighbourhoods with few migrants.

\section{Mixed embeddedness framework and migrant entrepreneurship}

The analysis above revealed that, for all five ethnic groups, the second generation has achieved higher levels of socio-cultural and structural integration in society than their parents' generation. The question still remains how this affects migrant entrepreneurship. The mixed embeddedness framework developed by Kloosterman, van der Leun and Rath (1999) offers a useful theoretical approach. This framework builds upon interaction theory (Aldrich \& Waldinger 1990, Light \& Rosenstein 1995) and considerations regarding social embeddedness (Granovetter 1985). It departs from the notion that immigrant entrepreneurship depends on a multitude of contingencies that determine the interplay of individual characteristics of the entrepreneur on the one side, and the characteristics of the wider social, economic and politico-institutional environment on the other side. The latter context, which Kloosterman et al. (1999) call "opportunity structures", 
describes the setting that creates business opportunities for prospective and established entrepreneurs. Opportunity structures are shaped by economic factors on the supply side (e.g. individual and cultural characteristics of entrepreneurs), and the demand side (e.g. the presence of an accessible customer base). At the same time politico-institutional factors, such as national rules and legislations, institutions and laws, will enable or constrain businesses start-ups and development.

Socio-cultural and structural integration will affect the opportunity structures of prospective and established migrant entrepreneurs as they act as intermediaries between the supply side (products/services offerings) and the demand side (products/services demanded by customers). In other words, integration determines the extent to which migrant entrepreneurs are able to identify and seize business opportunities in main-stream markets. In terms of the mixed embeddedness framework, the integration differences observed for first and second generation migrant entrepreneurs result in a divergence of opportunity structures relating to the socio-cultural and economic (and possibly also politicoinstitutional) dimensions. Generally, we expect that integration in society improves entrepreneurial prospects of migrants as this enlarges the size of potential markets.

\section{Hypothesis development}

Following up on the discussion on the relationship between integration and migrant entrepreneurship, this section presents the research hypotheses of the study. To recap, this study sets out to investigate the difference in success between first and second generation migrant entrepreneurs among the five major nonWestern migrant groups. More specifically, it presents possible explanations on the basis of integration for the observed business performance and the intergenerational differences therein. As mentioned before, across all origin groups, the second generation has achieved higher levels of integration than the first generation, a fact which is expected to enhance business success. Hypothesis 4.1, the main hypothesis of the study, states this more formally:

Hypothesis 4.1: Business prospects of second-generation migrant entrepreneurs are more promising than those of their first-generation counterparts.

For the following hypotheses, variables reflecting the opportunity structures are linked to business performance. In a second step we introduce generation as a moderator and investigate whether the second generation profits more from certain opportunity structures than the first. Business prospects of entrepreneurs are presumed to be better in more prosperous areas with higher employment rates and wage levels, since the customer base in those areas should have more 
purchasing power. While this positive relationship should hold for all groups of entrepreneurs, the second generation entrepreneurs should profit relatively more from these market opportunities because its higher socio-cultural integration would allow it to take better advantage of these opportunities.

Hypothesis 4.2a: Local employment rates and wage levels are positively related to migrant business performance.

Hypothesis 4.2b: Business prospects of migrant entrepreneurs increase with local employment rates and wage levels, and more so for the second generation than for the first.

Although the literature on migrant entrepreneurship stresses that the local presence of a co-ethnic community plays a role in the development of migrant businesses as entrepreneurs are socially embedded in their communities (Light 1979, Light et al. 1985, Portes \& Bach 1985, Raijman \& Tienda 1999, Renzulli, Aldrich \& Moody 2000), the direction of the effect is ambiguous. On the one hand, the presence of the co-ethnic community is portrayed as an asset, which may create specific migrant business opportunities (co-ethnic markets), render a supportive customer base and/or offer business advantages through reduced recruitment and hiring costs. On the other hand, the presence of the co-ethnic community may also affect migrant business prospects negatively since the community places demands on entrepreneurs that conflict with business development or when entrepreneurs operating solely in co-ethnic markets reach growth limits. Irrespective of the direction, it is expected that the presence of the co-ethnic community will have a larger effect on business prospects of first generation migrants as their social and business relations are more centred on their local co-ethnic community. Moreover, as first generation migrant firms tend to cluster in the same industries, the presence of local co-ethnic businesses are likely to have a stronger effect on business prospects of the first generation than on those of the second generation. This yields the following hypotheses, which focus on the local co-ethnic residential concentration and the local concentration of co-ethnic businesses:

Hypothesis 4.3a: Local co-ethnic residential and business concentrations are negatively related to migrant business performance.

Hypothesis 4.3b: The magnitude of the relationships between local co-ethnic concentrations and migrant business prospects is larger for first generation entrepreneurs than for second generation ones.

The lion's share of non-Western migrant business operations in the Netherlands are situated in the four major cities, namely Amsterdam, The Hague, Rotterdam and Utrecht, the economic heartland of the country (EIM 2004). These cities generally offer more favourable business opportunities to migrant entrepreneurs 
than other parts of the country as mainstream and ethnic local markets are more prosperous and entrepreneurs have easier access to the extensive networks of national and international commercial actors. We furthermore argue that the second generation benefits relatively more from these opportunities arising in these urban economies than the first generation as it is better integrated in essential commercial networks, more informed about market developments and possesses higher professional skills.

Hypothesis 4.4a: Business performance of migrant firms in the four major Dutch cities is higher than elsewhere in the country.

Hypothesis 4.4b: The business setting in the four major Dutch cities is relatively more beneficial for business prospects of second generation entrepreneurs than for first generation entrepreneurs.

As mentioned before, first and second generation migrant entrepreneurs tend to operate in different industry sectors. This largely explains the variations in business development patterns between the groups (Van den Tillaart 2001, EIM 2004, Rusinovic 2006). While the first generation is predominantly active in lowmargin trade and hospitality sectors, the business activities of the second generation are more diverse including more lucrative sectors like business services. In addition, market opportunities of first and second generation entrepreneurs will differ according to the on-going evolution from a production to a services-based economy. Second generation entrepreneurs are more frequently found in the more promising services and especially business services sectors, while the share of entrepreneurs operating in the hospitality sector has declined. It is therefore expected that the second generation is more successful in entrepreneurship than the first generation as it is operating in more promising sectors.

Hypothesis 4.5a: Migrant business performance is higher in the more promising sectors (i.e. business services), than in the traditional migrant sectors (i.e. trade and hospitality).

Hypothesis 4.5b: While second generation migrant entrepreneurs operating in promising sectors are more successful than their first generation counterparts in these sectors, those operating in traditional sectors are less successful than their first generation counterparts.

4.4- Methodology

\section{Data sources}

The analysis was performed on administrative data for the six-year period 19992004 collected by Statistics Netherlands and covers all Dutch residents (approximately 16 million people) including 800,000 self-employed. The selfemployment data were taken from the SSB (Social Statistical Database), which 
complements the information from the administrative registers with demographic and socio-economic information. Three datasets were matched in the study: the GBA (Gemeentelijke Basisadministratie - Base administrative register of the municipalities) providing demograhic information as well as place of residence, the SSB Zelfstandigen (Social Statistical Database of Self-employed) providing information on the firms, such as size (number of employees) and location, industry sector, annual profits, deductibles and tax contributions and the SSB Banenbestand (Social Statistical Database of Jobs) containing information on all employment relationships in the Netherlands (about 10 million records in 2004) from social insurance records and is complemented with information from tax records as well as data from a large-scale employer survey (EWL).

These three datasets were merged on basis of personal identifiers (RIN numbers) of the entrepreneurs as well as the municipal location codes of the firms. The resulting panel dataset for the period 1999-2004 makes it possible to track entrepreneurs over time and space and conduct an in-depth business performance analysis of the various origin groups of entrepreneurs. The dataset was reduced to six origin groups of entrepreneurs, namely native (991,308 individuals), Turkish $(19,708$ individuals), Moroccan (7,618 individuals), Surinamese $(12,300$ individuals), Dutch Antillean (3,298 individuals) and Chinese entrepreneurs (8,578 individuals). Furthermore, it is restricted to small and medium-sized firms with up to 100 employees and excludes agricultural firms.

\section{Measurements}

Table 4.4 depicts the variables used in the analyses. Acknowledging that performance is a multi-dimensional concept, three distinct indicators are used to measure it, namely business profit, firm growth (increase in number of employees) and firm survival. The bivariate variable set 'first generation' and 'second generation' indicates the groups to which the entrepreneurs belong. In the later analyses, these variables will reveal the differences between native entrepreneurs and first and second generation migrants. The indicators used to measure the characteristics of entrepreneurs and firms were age, marital status, gender and sector of industry. The demand side of the opportunity structure is captured by various variables describing the environment (municipality) surrounding entrepreneurial operations, namely local employment levels, average wage levels and the concentration of migrants and firms belonging to the same group as the entrepreneurs. 
Table 4.4: Description of variables

\begin{tabular}{|c|c|}
\hline \multicolumn{2}{|l|}{ Dependent variables } \\
\hline Annual profit $(\ln )^{t}$ & $\begin{array}{l}\text { Natural logarithm of sum of all business profits per person } \\
\text { per year. Figures originate from income tax assessments for } \\
\text { the years } 1999 \text { and } 2000 \text { and from the entrepreneurs' tax } \\
\text { declarations the years } 2001 \text { to } 2004 \text {. }\end{array}$ \\
\hline Growingt & $\begin{array}{l}\text { Forward-looking binary variable taking the value } 1 \text { if the firm } \\
\text { moves from one size category to a higher size category } \\
\text { between years. Size categories are: no employees, one } \\
\text { employee, two to four employees and five and more } \\
\text { employees. }\end{array}$ \\
\hline Survival $^{t}$ & $\begin{array}{l}\text { Forward-looking binary variable taking the value } 1 \text { if the firm } \\
\text { is still operating in the following year. }\end{array}$ \\
\hline \multicolumn{2}{|c|}{ Independent variables: personal and firm characteristics } \\
\hline $\begin{array}{l}1 \text {-gen } \\
2 \text {-gen }\end{array}$ & $\begin{array}{l}\text { Set of dummy variables with the reference category 'natives'. } \\
\text { 1-gen dummy takes value } 1 \text { if entrepreneur belongs to the } \\
\text { first generation migrants, i.e. is born outside the Netherlands. } \\
\text { 2-gen dummy takes value } 1 \text { if entrepreneur belongs to the } \\
\text { second generation migrants, i.e. is born in the Netherlands } \\
\text { but at least one parent is born abroad. }\end{array}$ \\
\hline Age & Entrepreneur's age in years \\
\hline Married & Binary variable taking the value 1 if entrepreneur is married \\
\hline Female & Binary variable taking the value 1 if entrepreneur is female \\
\hline $\begin{array}{l}\text { Trade } \\
\text { Hospitality } \\
\text { Transport/Storage/Com. } \\
\text { Business Services } \\
\text { Other Services }\end{array}$ & $\begin{array}{l}\text { Set of dummy variables to capture the firm's sector with the } \\
\text { reference category manufacturing/construction. The variable } \\
\text { of the sector the firm is active in takes the value 1, all other } \\
\text { variables take the value } 0 .\end{array}$ \\
\hline \multicolumn{2}{|c|}{ Independent variables related to demand } \\
\hline Employment ${ }^{t}$ & Employment rate in the municipality \\
\hline Wage level $(\ln )^{t}$ & Natural logarithm of the mean wage level in the municipality \\
\hline Citytop4 & $\begin{array}{l}\text { Binary variable that takes the value } 1 \text { if firm is located in one } \\
\text { of the four major Dutch cities (Amsterdam, The Hague, } \\
\text { Rotterdam or Utrecht). }\end{array}$ \\
\hline Concentration $^{t}$ & $\begin{array}{l}\text { Number of migrants of group investigated divided by total } \\
\text { population in the municipality }\end{array}$ \\
\hline Firm concentration ${ }^{t}$ & $\begin{array}{l}\text { Share of firms owned by the migrant group in a particular } \\
\text { municipality. }\end{array}$ \\
\hline
\end{tabular}

$\mathrm{t}$ indicates time varying variables

\section{5 - Findings}

\section{Descriptive Analysis}

This section presents the study's descriptive findings presented in Table 4.5 and Figure 4.1. To start with, Table 4.5 provides an overview of the variables' per origin 
group and generation. While the study aim is to compare first and second generation groups of entrepreneurs, the inclusion of the native Dutch group as a reference category is essential to enable meaningful interpretation of some of the results. A distinction is made in the table between on the one side entrepreneur and firm-based characteristics, which are defined on the individual level, and on the other side location-based characteristics shared by entrepreneurs within the same business location.

With regard to the entrepreneur and firm-based characteristics, second generation entrepreneurs are, as expected, younger and less likely to be married across all migrant groups. The second generation also includes relatively more female entrepreneurs than the first generation. Migrant entrepreneurship is strongly concentrated in the country's four major cities for both generations. In particular 40 to 50 per cent of the Turkish, Moroccan and Surinamese entrepreneurs locate in these four cities as compared to just 30 per cent for the Dutch Antillean and 19 to 34 per cent for first and second generation Chinese. Furthermore, it is striking to observe that, except for the Surinamese group, the migrant business concentration in the major four cities has not declined from the first to the second generations. This suggests that the four major cities behave as magnets in attracting first and second generation migrant entrepreneurs alike.

Comparing firm-based performance indicators between the generations of the origin groups, three clusters emerge, namely the Turkish/Moroccan, the Surinamese/Dutch Antillean and the Chinese cluster. These clusters reflect important differences in the migration histories of the groups to the Netherlands. Most of the first-generation Turkish and Moroccan migrants entered the country as labour migrants in the 1960s. At this time, the Netherlands - like many other European countries - had introduced policies to attract foreign migrants to address acute labour shortages at home. In contrast, most first-generation Surinamese and Dutch Antillean migrants were repatriating to the Netherlands from former Dutch colonies, arriving in great numbers from the 1970s onwards. Finally, most firstgeneration Chinese migrants originated from Hong Kong and other coastal areas with historical trade relations with the Netherlands, mostly entering the country in the 1960s. A second, much smaller group of Chinese migrants settled in the Netherlands more recently as asylum seekers.

The intergenerational trends of the firm-based performance indicators also differ across the three origin clusters. In the Turkish/Moroccan cluster, the second generation generates lower profits, slower growth and has lower survival rates than its parents' generation. The already considerable performance gap between natives and the first generation has widened even further for this group. This 
suggests that intergenerational advances in the socio-economic position in society have not been translated into better business prospects for Turkish and Moroccan entrepreneurs. In the Surinamese/Dutch Antillean cluster, there is no difference between the two generations, which implies that their performance gap to natives is sustained across generations. Finally, only the Chinese second generation entrepreneurs outperform their parents in profits, but not in terms of growth and survival. In terms of firm profitability they are even on par with natives and the second generation's survival rates come fairly close to natives' survival rates. Of all five origin groups, the Chinese is the only one in which intergenerational advances in the socio-economic position seem to have tentatively translated to higher business performance of the second generation.

Table 4.5: Summary statistics per migrant group, entrepreneur/firm-based and firm location-based characteristics (group means) *

\begin{tabular}{|c|c|c|c|c|c|c|c|c|c|c|c|}
\hline \multirow{3}{*}{1} & \multirow{3}{*}{ Native } & \multirow{2}{*}{\multicolumn{2}{|c|}{ Turkish }} & \multirow{2}{*}{\multicolumn{2}{|c|}{ Moroccan }} & \multirow{2}{*}{\multicolumn{2}{|c|}{ Surinamese }} & \multirow{2}{*}{\multicolumn{2}{|c|}{ Antillean }} & \multirow{2}{*}{\multicolumn{2}{|c|}{ Chinese }} \\
\hline & & & & & & & & & & & \\
\hline & & 1gen. & 2gen. & 1gen. & 2 gen. & 1gen. & 2gen. & 1gen. & 2gen. & 1gen. & 2gen. \\
\hline \multicolumn{12}{|c|}{ Entrepreneur/fim-based characteristics } \\
\hline observations & 547,505 & 40,451 & 6,150 & 16,622 & 2,154 & 26,920 & 6,558 & 5,707 & 2,517 & २2,580 & 1,515 \\
\hline female & $\begin{array}{l}.3192 \\
(.466)\end{array}$ & $\begin{array}{r}.142 \\
(.349)\end{array}$ & $\begin{array}{r}.196 \\
(.397)\end{array}$ & $\begin{array}{r}.099 \\
(.299)\end{array}$ & $\begin{array}{r}.215 \\
(.411)\end{array}$ & $\begin{array}{r}.275 \\
(.446)\end{array}$ & $\begin{array}{r}.314 \\
(.464)\end{array}$ & $\begin{array}{r}.315 \\
(.464)\end{array}$ & $\begin{array}{r}.315 \\
(.464)\end{array}$ & $\begin{array}{r}.397 \\
(.489)\end{array}$ & $\begin{array}{r}.337 \\
(.472)\end{array}$ \\
\hline age & $\begin{array}{r}44.41 \\
(11.08)\end{array}$ & $\begin{array}{l}35.86 \\
(7.66)\end{array}$ & $\begin{array}{l}25.71 \\
(4.98)\end{array}$ & $\begin{array}{l}36.08 \\
(8.77)\end{array}$ & $\begin{array}{l}25.84 \\
(4.53)\end{array}$ & $\begin{array}{l}41.37 \\
(9.21)\end{array}$ & $\begin{array}{l}34.78 \\
(9.78)\end{array}$ & $\begin{array}{l}42.39 \\
(9.65)\end{array}$ & $\begin{array}{l}33.99 \\
(7.49)\end{array}$ & $\begin{array}{l}39.85 \\
(9.42)\end{array}$ & $\begin{array}{r}37.72 \\
(12.43)\end{array}$ \\
\hline married & $\begin{array}{l}.6771 \\
(.467)\end{array}$ & $\begin{array}{r}.782 \\
(.412)\end{array}$ & $\begin{array}{r}.440 \\
(.496)\end{array}$ & $\begin{array}{r}.684 \\
(.464)\end{array}$ & $\begin{array}{r}.265 \\
(.441)\end{array}$ & $\begin{array}{r}.466 \\
(.498)\end{array}$ & $\begin{array}{r}.341 \\
(.474)\end{array}$ & $\begin{array}{r}.463 \\
(.498)\end{array}$ & $\begin{array}{r}.337 \\
(.472)\end{array}$ & $\begin{array}{r}.801 \\
(.399)\end{array}$ & $\begin{array}{r}.466 \\
(.499)\end{array}$ \\
\hline citytop4 & $\begin{array}{r}.107 \\
(.309)\end{array}$ & $\begin{array}{r}.414 \\
(.492)\end{array}$ & $\begin{array}{r}.401 \\
(.490)\end{array}$ & $\begin{array}{r}.503 \\
(.500)\end{array}$ & $\begin{array}{r}.487 \\
(.499)\end{array}$ & $\begin{array}{r}.546 \\
(.497)\end{array}$ & $\begin{array}{r}.428 \\
(.494)\end{array}$ & $\begin{array}{r}.298 \\
(.457)\end{array}$ & $\begin{array}{l}.308 \\
(.462)\end{array}$ & $\begin{array}{r}.187 \\
(.390)\end{array}$ & $\begin{array}{r}.340 \\
(.474)\end{array}$ \\
\hline annual profit & 23,678 & 17,910 & 13,552 & 17,442 & 12,935 & 19,150 & 18,751 & 18,413 & 18,925 & 19,131 & 24,369 \\
\hline & $(36,796)$ & $(32,129)$ & $(29,657)$ & $(34,988)$ & $(22,369)$ & $(33,618)$ & $(38,777)$ & $(37,550)$ & $(30,254)$ & $(22,545)$ & $(39,539)$ \\
\hline growing $^{\star \star}$ & .161 & .158 & .134 & .147 & .103 & .155 & .136 & .147 & .141 & .138 & .121 \\
\hline & $(.368)$ & $(.364)$ & $(.340)$ & $(.354)$ & $(.304)$ & (.362) & $(.343)$ & $(.354)$ & $(.349)$ & $(.345)$ & (.327) \\
\hline survival"** & .905 & .840 & .805 & .852 & .812 & .854 & .842 & .837 & .846 & .928 & .882 \\
\hline & (.291) & (.365) & (.395) & $(.354)$ & $(.390)$ & $(.352)$ & $(.364)$ & $(.369)$ & $(.360)$ & $(.257)$ & $(.321)$ \\
\hline Firm location- & sed charac & teristics * & & & & & & & & & \\
\hline observations & 483 & 370 & 225 & 288 & 152 & 346 & 257 & 285 & 215 & 447 & 156 \\
\hline employment & $\begin{array}{r}.651 \\
(.039)\end{array}$ & $\begin{array}{r}.656 \\
(.037)\end{array}$ & $\begin{array}{r}.661 \\
(.035)\end{array}$ & $\begin{array}{r}.657 \\
(.042)\end{array}$ & $\begin{array}{r}.665 \\
(.035)\end{array}$ & $\begin{array}{r}.656 \\
(.037)\end{array}$ & $\begin{array}{r}.659 \\
(.037)\end{array}$ & $\begin{array}{r}.658 \\
(.037)\end{array}$ & $\begin{array}{r}.660 \\
(.036)\end{array}$ & $\begin{array}{r}.652 \\
(.040)\end{array}$ & $\begin{array}{r}.658 \\
(.036)\end{array}$ \\
\hline wage level & $\begin{array}{l}23,319 \\
(3,260)\end{array}$ & $\begin{array}{l}23,550 \\
(3,515)\end{array}$ & $\begin{array}{l}23,468 \\
(2,765)\end{array}$ & $\begin{array}{l}23,854 \\
(3,525)\end{array}$ & $\begin{array}{l}24,464 \\
(3,674)\end{array}$ & $\begin{array}{l}23,769 \\
(3,440)\end{array}$ & $\begin{array}{l}24,032 \\
(3,634)\end{array}$ & $\begin{array}{l}24,071 \\
(3,477)\end{array}$ & $\begin{array}{l}24,378 \\
(3,499)\end{array}$ & $\begin{array}{l}23,325 \\
(3,172)\end{array}$ & $\begin{array}{l}24,214 \\
(3,804)\end{array}$ \\
\hline concentration & $\begin{array}{r}.008 \\
(.014)\end{array}$ & $\begin{array}{r}.010 \\
(.015)\end{array}$ & $\begin{array}{r}.016 \\
(.017)\end{array}$ & $\begin{array}{r}.010 \\
(.013)\end{array}$ & $\begin{array}{r}.015 \\
(.016)\end{array}$ & $\begin{array}{r}.008 \\
(.012)\end{array}$ & $\begin{array}{r}.009 \\
(.014)\end{array}$ & $\begin{array}{r}.005 \\
(.005)\end{array}$ & $\begin{array}{l}.005 \\
(.005)\end{array}$ & $\begin{array}{r}.002 \\
(.001)\end{array}$ & $\begin{array}{r}.003 \\
(.001)\end{array}$ \\
\hline firm concentration & $\begin{array}{r}.005 \\
(.010) \\
\end{array}$ & $\begin{array}{r}.007 \\
(.011) \\
\end{array}$ & $\begin{array}{r}.011 \\
(.013) \\
\end{array}$ & $\begin{array}{r}.003 \\
(.004) \\
\end{array}$ & $\begin{array}{r}.005 \\
(.006) \\
\end{array}$ & $\begin{array}{r}.005 \\
(.007) \\
\end{array}$ & $\begin{array}{r}.006 \\
(.007) \\
\end{array}$ & $\begin{array}{r}.003 \\
(.002) \\
\end{array}$ & $\begin{array}{r}.003 \\
(.002) \\
\end{array}$ & $\begin{array}{r}.005 \\
(.003) \\
\end{array}$ & $\begin{array}{r}.007 \\
(.003) \\
\end{array}$ \\
\hline
\end{tabular}

* Bold numbers indicate rejected equal means tests of first and second generations per origin group at a $0.1 \%$ significance level. Standard deviations in brackets. First and second generation migrants are defined, as in Table 4.1, according to the definition of Netherlands Statistics Bureau. Variable definitions are found in the appendix.

** These variables are defined in a forward-looking way indicating if an entrepreneur is growing and operating in the coming year respectively. As a consequence these variables have fewer observations than stated since information is missing for 2004 .

*** These statistics are reported at the level of the municipality where firms of the respective groups are located.

Source: Netherlands Bureau of Statistics SSB 1995-2004, own calculations 
The lower panel of Table 4.5 allows for the comparison of a number of firm location-based indicators between the generations of the origin groups (i.e. local employment and wage levels as well as levels of co-ethnic local residential and business concentration). ${ }^{51}$ Although no significant intergenerational changes can be observed with regard to local employment and wage levels, a rather striking intergenerational change is visible for the concentration variables. Not only does the second generation Chinese group, as expected ${ }^{52}$, operate in areas of higher coethnic residential and business concentration than its first generation counterparts, a similar pattern is found for Turkish and Moroccan entrepreneurs. However, no intergenerational changes are observed for the origin cluster of Surinamese and Dutch Antilleans. Leaving the Chinese group aside, we can observe that two origin clusters (Turkish/Moroccan, Surinamese/Dutch Antillean) with no intergenerational business performance improvements are also the ones that operate in environments with high levels of co-ethnic concentration.

In addition to Table 4.5, Figure 4.1 provides an important contribution to the chapter's descriptive analysis as it shows the distributions of business activities of the various origin groups. The clustering of origin groups that was observed before is again prevalent. The Turkish/Moroccan cluster is traditionally more active in the trade and hospitality sectors, although this is less pronounced for the second generation. The Surinamese/Dutch Antillean cluster is more active in services, but also in trade (Surinamese) and manufacturing (Dutch Antillean), and has less intergenerational variation. The first-generation Chinese group is a special case as four-fifths of its business activity is found in the hospitality sector (i.e. the typical Chinese take-out and low-budget restaurants that are found even in the smallest Dutch village). The Chinese second generation has turned away from the hospitality sector and towards business services.

The intergenerational shifts evident in Figure 4.1 demand some further clarification. First, these results document the change in market opportunities that took place from one generation to the next. This is perhaps most convincingly demonstrated by the Chinese case, in which first-generation entrepreneurs exploited the Chinese restaurant niche market to saturation thus forcing many second-generation Chinese entrepreneurs to start up in a different sector or take over the family business. Second, next to the trends that may be expected from market developments, it seems that the second generation groups of the first

\footnotetext{
${ }^{51}$ For natives, levels of local ethnic residential and business concentration are defined as the average levels of local ethnic concentration of the five migrant groups (residential and business concentrations respectively).

${ }^{52}$ As the first generation operates by and large Chinese specialty restaurants spread throughout the country.
} 
cluster (Turkish/Moroccan) seize the new opportunities of the services economy the least of all groups. Instead, these groups tend to keep to the trade sector in a similar fashion as their parents' generation. The underrepresentation of these second-generation groups in the services sectors (as compared to natives and the other migrant groups) could be explained by persisting educational and labour market disadvantages, language and cultural barriers and lack of essential business information.

Figure 4.1: Distribution of native and non-Western migrant entrepreneurs across sectors (\% of group total) for the first and second generation

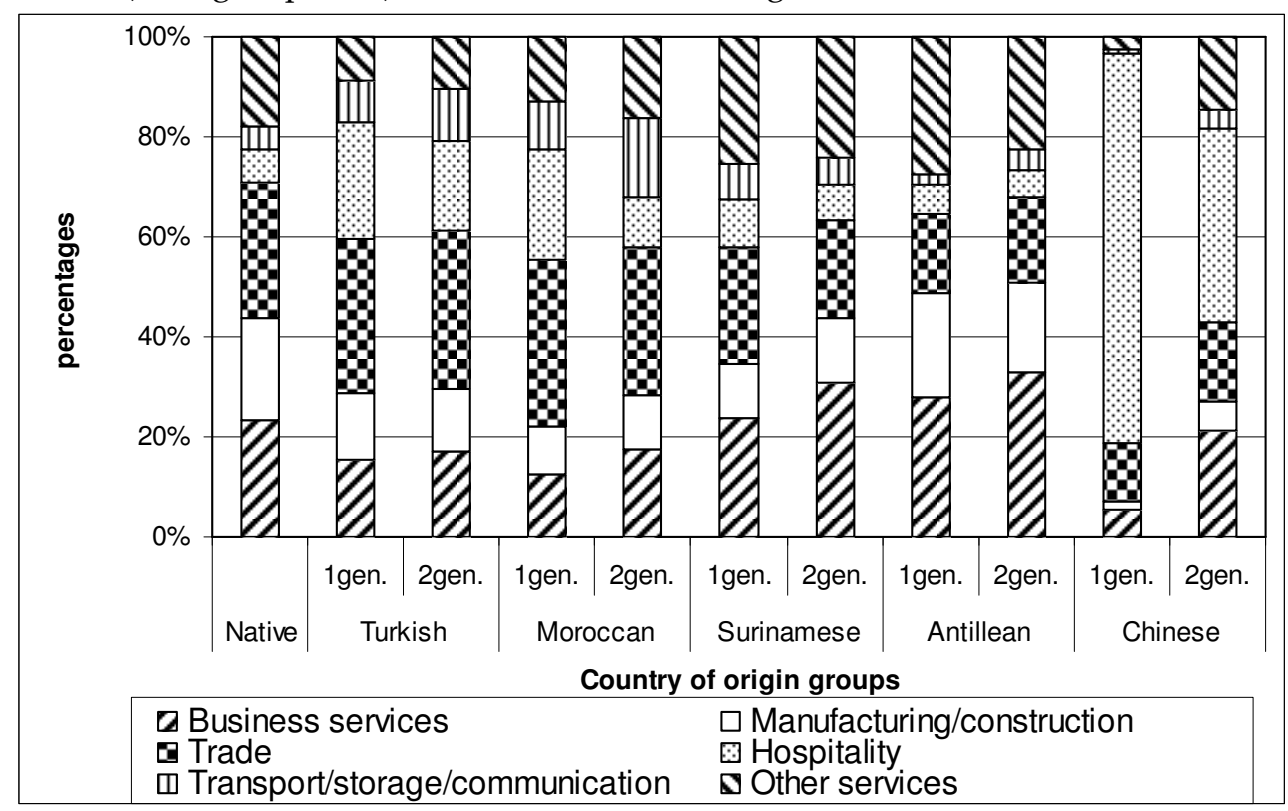

* The agricultural sector was excluded as too few cases exist for some migrant groups and migrant firms in this sector and are not comparable to the enterprises of natives. First and second generation migrants are defined, as in Table 4.1, according to the definition of the Netherlands Statistics Bureau.

Source: Netherlands Bureau of Statistics SSB 1995-2004, own calculations

\section{Testing of hypotheses}

Econometric analyses were carried out to test the hypotheses as follows. For each migrant group we estimated annual profit, growth and survival separately by contrasting the respective migrant group with a random sample of natives taken from the Dutch population. ${ }^{53}$ Each of these estimations is a sequence of three

${ }^{53}$ Missing variable information of entrepreneurs in the dataset was inferred from information available for other years wherever possible, favouring temporal proximity. Nonetheless 3.1 million observations (around $50 \%$ ) of the dataset remained with missing variable information with regard to firm location, size, country of origin information, industry sector and annual profits. Given the relatively random nature of the distribution of missing observations across the relevant subpopulations of this study, and 
models starting with a base model that only includes characteristics of entrepreneurs. The second and third model, base+ and base++ respectively, also include the business and business-location characteristics. The latter two models are identical with the exception of the variables local co-ethnic concentration and co-ethnic business concentration. As these two independent variables are highly correlated $(r>.90)$ we chose not include them in a single model in order to avoid problems of multicollinearity. To test hypotheses two to five, we extended the prior models by first and second generation interaction terms with other relevant variables (citytop4, local co-ethnic residential concentration, local co-ethnic firm concentration, local employment and wage levels, and industry sector dummies) and analysed specific first and second generation effects in line with the formulated hypotheses. Robustness checks found that our results to be stable.

As can be seen from Tables 4.6 to 4.8 , the effects of the entrepreneur's characteristics on firm prospects are consistent across the models and outcome variables. Age has a positive impact on firm performance at a decreasing rate. From this we can conclude that life and professional experience tend to result in more informed business decisions, but older entrepreneurs can also be less quick to capitalize on market opportunities. Married entrepreneurs tend to perform better, which suggests that the support of a spouse either directly (assistance in business operations and/or financing) or indirectly (emotional and/or time-management support) contributes to the firm's success. Finally, female entrepreneurs have a lower business performance than males.

Tables 4.6 to 4.9 depict the findings of the regression analyses testing the research hypotheses. The first three tables show the results of the general random effects regressions, which include the bivariate variables of first and second generation migrants. On the basis of these variables hypothesis 1 can be assessed. The other hypotheses are addressed in Table 4.9, which presents the random effects regression findings of the interaction models. To reduce output complexity, the table only presents first and second generation composite coefficients (base plus interaction coefficients) of the variables relevant for assessing hypotheses 4.2 to 4.5 as well as the corresponding test outcomes. Whenever the stated hypotheses $4.2 \mathrm{a}$, 4.3a, 4.4a, 4.5a are supported by our findings, this is indicated by asterisks behind the composite coefficients. In a similar fashion, asterisks in the 'Welch ( $\mathrm{t})^{\prime}$ ' columns indicate that the stated hypotheses $4.2 \mathrm{~b}, 4.3 \mathrm{~b}, 4.4 \mathrm{~b}$, $4.5 \mathrm{~b}$ are supported by our findings. Finally, since multiple test outcomes need to be considered to assess the validity of the formulated research hypotheses for each origin group, we apply the

given the importance of the variables for further analyses, it was decided to reduce the dataset to the observations with fully available information on all variables. 
general rule that a hypothesis is confirmed by the data whenever at least half of the group's test results are supportive of the stated claim at the $10 \%$ significance level.

Hypothesis 4.1. The findings of the multivariate analyses support the earlier descriptive outcomes, which illustrated a high degree of diversity in intergenerational trends. As we compare the first and second generation coefficients in Tables 4.6 to 4.8 and consider the groups' means comparison test outcomes in the final rows of the tables, we observe that, for annual profits, the coefficients are larger for the second generation entrepreneurs in the Moroccan, Surinamese and Antillean cases, about the same for the Turkish and smaller for the Chinese group. Thus, as far as profits are concerned, three of the five groups are doing better than their parents. Looking at firm growth the picture changes considerably. None of the second generation groups of entrepreneurs had firms that grew more than their parents' generation. Moreover, second-generation Moroccan and Surinamese groups actually tended to grow less. With respect to firm survival, second generation Turkish and Antillean entrepreneurs show higher survival rates than their parents' generation, while intergenerational differences of the Moroccan and Surinamese groups are insignificant at the $10 \%$ level and Chinese second generation even had lower survival rates. Overall, the findings show that the intergenerational developments differ considerably between the origin groups, an outcome which supports the segmented assimilation theory. Reflecting on the prior findings in light of Hypothesis 4.1, we come to the conclusion that the hypothesis, which suggests that the second generation would outperform the first generation, is not generally supported despite some indications of higher profitability and survival rates in the labour migrant (Turkish/Moroccan) and colonial migrant (Surinamese/Antillean) clusters. Interestingly, these regression findings contrast with the prior descriptive findings on business performance (see Table 4.5), which suggested especially promising intergenerational developments for the Chinese group and less promising developments for the labour migrant (Turkish/Moroccan) cluster. On the same note, two observations from the regression findings are particularly noteworthy. First, within the colonial migrant cluster we detected different intergenerational trends for the Antillean and Surinamese groups: second-generation Antillean entrepreneurs tended to outperform their parent's generation, but secondgeneration Surinamese entrepreneurs did not. This difference between the two origin groups may be explained, in part, by the larger difficulties of the second generation Surinamese group in its labour market integration (see Table 4.3). Inauspicious conditions in the regular labour market may lead Surinamese secondgeneration individuals to accept subsistence self-employment, despite these entrepreneurs' generally unfavourable start-up conditions. Second, in contrast with the descriptive findings, the regression findings for the Chinese group clearly 
point towards an intergenerational reduction in business performance. This surprising outcome - given the group's substantial intergenerational advances in education and labour market achievements - may be explained by a negative selection effect into self-employment and/or a change in market opportunities from the first to the second generation. Regarding the first, as the Chinese second generation is much more successful in the labour market than its parent's generation, it is possible that self-employment for the second generation Chinese has become a fall-back strategy, attracting relatively more individuals who do not manage to find a job in the regular labour market. Regarding the second possibility, the second generation faces less promising market conditions than the first generation, which over the past decades has effectively established and maintained a unique competitive edge in the profitable and low-risk Chinese restaurant niche market. However, as this niche was already saturated at the point at which the second generation entered self-employment, this group was obliged to compete in more risky and competitive mainstream markets.

Hypothesis $4.2 a$ and $4.2 b$ argue that economic prosperity of the municipality (indicated by high employment and average wage levels) enhances the chances of success of migrant entrepreneurs and that second generation entrepreneurs are better equipped to seize opportunities in these more prosperous markets. The composite coefficients of first and second generation migrants and their corresponding test outcomes, shown in Table 4.9, reveal that high employment and wage levels generally do have the expected positive effects on firm profitability (except for wage level effects in the Turkish and Surinamese cases), but their effects on firm growth and survival rates are less clear. While higher local wage levels tend to positively impact migrant firm growth, the effects of higher employment rates on growth are not significant. In the firm survival models, higher local employment rates are associated with higher survival rates, but increased wage levels actually tend to reduce migrant firm-survival. From this it appears that the excess money available in prosperous municipalities improves profitability, but not growth and survival and therefore Hypothesis 4.2a is only supported in the profit model. This finding indicates that some non-Western migrant entrepreneurs capitalize on these higher market prospects while others are driven out of business as a result of fiercer competition.

When comparing the first and the second generation composite coefficients in Table 4.9 and considering the corresponding test results in the 'Welch(t)' columns, we come to the conclusion that Hypothesis $4.2 \mathrm{~b}$ can be generally rejected. Despite better education, the second generation is not able to reap the benefits of economic prosperous regions more than their parents' generation did. A rather select number of intergenerational differences appear to support Hypothesis $4.2 \mathrm{~b}$ at the 
$10 \%$ significance level and no clear pattern is observable among these except perhaps for the Moroccan group. In the Moroccan case, the second generation benefits more from higher wage levels in terms of profits and growth rates, but less in terms of survival rates than their first generation counterparts. However, these findings can hardly be interpreted as significant since the intergenerational comparison of the employment rate effects on firm performance yields either insignificant or less beneficial outcomes for the second generation vis-à-vis the first generation.

Hypotheses $4.3 a$ and $4.3 b$ stipulate that local co-ethnic residential and business concentrations negatively affect migrant business performance and that these relationships are stronger in magnitude for first generation entrepreneurs than for second generation ones. As shown in Table 4.9, local co-ethnic residential and business concentration tends to negatively impact firm profitability and survival rates, but, except for the Moroccan group of entrepreneurs, their effects on firm growth are insignificant or even positive. Thus, Hypothesis 4.3a is supported in the profit and survival models, but not in the growth one. This suggests that migrant entrepreneurs may benefit from the presence of the co-ethnic community through facilitated labour recruitment, but also that concentration can exacerbate local business rivalry and/or co-ethnic business claims that hinder business development.

Hypothesis $4.3 b$ stipulates that business prospects of the first generation are more affected by the local presence of the co-ethnic community than those of the second generation as the first are more involved in their local co-ethnic communities. The Welch t-test findings in Table 4.9 however demonstrate that the concentration effects on business prospects of first and second generation migrant entrepreneurs show no significant differences supportive of the hypothesis. Hypothesis $4.3 \mathrm{~b}$ is therefore generally not confirmed by our data. 
Table 4.6: Base random-effects regression estimates for dependent variable annual profits, by origin group* (Source: CBS SSB 1995-2004, own calculations)

\begin{tabular}{|c|c|c|c|c|c|c|c|c|c|c|c|c|c|c|c|}
\hline \multirow[t]{2}{*}{$\begin{array}{c}\text { Dependent variable: } \\
\text { annual profit (In) }\end{array}$} & \multicolumn{3}{|c|}{ Turkish } & \multicolumn{3}{|c|}{ Moroccan } & \multicolumn{3}{|c|}{ Surinamese } & \multicolumn{3}{|c|}{ Antillean } & \multicolumn{3}{|c|}{ Chinese } \\
\hline & base & base + & base++ & base & base+ & base++ & base & base + & base++ & base & base+ & base++ & base & base + & base++ \\
\hline constant & .992 & -4.34 & -4.53 & .584 & -5.52 & -5.71 & .540 & -4.94 & -5.43 & .524 & -5.13 & -5.44 & .494 & -4.56 & -4.42 \\
\hline & $(.183)^{*+*+}$ & $(1.34)^{\star \star * *}$ & $(1.33)^{\star * \star}$ & $(.189)^{\star * *}$ & $(1.36)^{\star * *}$ & $(1.36)^{* \star *}$ & $\begin{array}{l}(.187)^{* * *} \\
111)^{2}\end{array}$ & $(1.35)^{* * *}$ & $(1.36)^{* * *}$ & $(.191)^{\star * \star}$ & $(1.35)^{\star * *}$ & $(1.38)^{* \star \star}$ & $(.187)^{\star * *}$ & $(1.33)^{\star \star *}$ & $(1.34)^{* * *}$ \\
\hline 1 gen. & -.864 & -845 & -.825 & -1.04 & -1.01 & -.986 & -1.12 & -1.14 & -1.12 & -1.44 & -1.53 & -1.55 & 1.07 & .892 & .892 \\
\hline & $(.065)^{\star \star \star}$ & $(.068)^{\star \star \star *}$ & $(.068)^{\star \star \star *}$ & $(.097)^{\star \star \star}$ & $(.099)^{\star \star \star *}$ & $(.099)^{\star \star \star \star}$ & $(.078)^{\star \star \star}$ & $(.081)^{\star \star \star \star}$ & $(.081)^{\star \star \star \star}$ & $(.161)^{\star \star \star \star}$ & $(.159)^{\star \star \star \star}$ & $(.159)^{\star \star \star *}$ & $(.072)^{\star \star \star}$ & $(.085)^{\star \star \star \star}$ & $(.085)^{\star \star \star}$ \\
\hline 2gen. & $\begin{array}{l}-.902 \\
(.156)^{\star \star *}\end{array}$ & $\begin{array}{l}-.827 \\
(.155)^{\star \star \star}\end{array}$ & $\begin{array}{l}-.809 \\
(.155)^{\star \star \star *}\end{array}$ & $\begin{array}{l}-.670 \\
(.245)^{\star \star \star *}\end{array}$ & $\begin{array}{l}-.635 \\
(.243)^{\star \star \star}\end{array}$ & $\begin{array}{l}-.608 \\
(.244)^{\star \star}\end{array}$ & $\begin{array}{l}-.900 \\
(.153)^{\star \star \star *}\end{array}$ & $\begin{array}{l}-.892 \\
(.152)^{\star \star \star}\end{array}$ & $\begin{array}{l}-.879 \\
(.152)^{\star \star \star}\end{array}$ & $\begin{array}{l}-.864 \\
(.237)^{\star \star \star}\end{array}$ & $\begin{array}{l}-.872 \\
(.234)^{\star \star \star *}\end{array}$ & $\begin{array}{l}-.879 \\
(.234)^{\star \star \star}\end{array}$ & $\begin{array}{l}-.351 \\
(.314)\end{array}$ & $\begin{array}{l}-.394 \\
(.310)\end{array}$ & $\begin{array}{l}-.400 \\
(.310)\end{array}$ \\
\hline age & $\begin{array}{l}.269 \\
(.008)^{\star * *}\end{array}$ & $\begin{array}{l}.268 \\
(.008)^{\star \star \star}\end{array}$ & $\begin{array}{l}.268 \\
(.008)^{\star \star \star}\end{array}$ & $\begin{array}{l}.286 \\
(.008)^{\star \star \star}\end{array}$ & $\begin{array}{l}.287 \\
(.008)^{\star \star \star *}\end{array}$ & $\begin{array}{l}.287 \\
(.008)^{\star \star \star \star}\end{array}$ & $\begin{array}{l}.288 \\
(.008)^{\star \star \star}\end{array}$ & $\begin{array}{l}.288 \\
(.008)^{\star \star *}\end{array}$ & $\begin{array}{l}.288 \\
(.008)^{\star \star \star *}\end{array}$ & $\begin{array}{l}.289 \\
(.008)^{\star \star \star}\end{array}$ & $\begin{array}{l}.289 \\
(.008)^{\star \star \star}\end{array}$ & $\begin{array}{l}.289 \\
(.008)^{\star \star \star}\end{array}$ & $\begin{array}{l}.289 \\
(.008)^{\star \star \star \star}\end{array}$ & $\begin{array}{l}.288 \\
(.008)^{\star \star \star *}\end{array}$ & $\begin{array}{l}.288 \\
(.008)^{\star \star \star}\end{array}$ \\
\hline age-square/100 & -.301 & -.295 & -.295 & -.319 & -.314 & -.315 & -.321 & -.316 & -.316 & -.322 & -.317 & -.317 & $\begin{array}{l}-.322 \\
-.31\end{array}$ & -.317 & -.316 \\
\hline & $(.009)^{\star \star \star}$ & $(.009)^{\star \star \star}$ & $(.009)^{\star \star \star}$ & $(.009)^{\star \star \star}$ & $(.009)^{\star \star \star}$ & $(.009)^{\star \star \star}$ & $(.009)^{\star \star \star}$ & $(.009)^{\star \star \star}$ & $(.009)^{\star \star \star}$ & $(.009)^{\star \star \star}$ & $(.009)^{\star \star \star}$ & $(.009)^{\star \star \star}$ & $(.009)^{\star \star \star}$ & $(.009)^{\star \star \star}$ & $(.009)^{\star * *}$ \\
\hline married & .374 & & .384 & .367 & & & .379 & .382 & & .388 & & .389 & .403 & .398 & .401 \\
\hline & $(.029)^{\star \star *}$ & $(.029)^{\star \star \star}$ & $(.029)^{\star \star \star}$ & $(.030)^{\star \star \star}$ & $(.030)^{\star \star \star}$ & $(.030)^{\star \star \star}$ & $(.030)^{\star \star \star}$ & $(.030)^{\star \star \star}$ & $(.030)^{\star \star \star}$ & $(.030)^{\star \star \star}$ & $(.031)^{\star \star \star}$ & $(.031)^{\star \star \star}$ & $(.030)^{\star \star \star}$ & $(.030)^{\star \star \star}$ & $(.030)^{\star \star \star}$ \\
\hline female & $\begin{array}{l}-.671 \\
-(033 * * *\end{array}$ & $\begin{array}{l}-.492 \\
-034 * * *\end{array}$ & $\begin{array}{l}-.493 \\
-034 * \star *\end{array}$ & $\begin{array}{l}-.674 \\
.034)^{* \star *}\end{array}$ & $\begin{array}{l}-.496 \\
-0355 * * *\end{array}$ & $\begin{array}{l}-.497 \\
-0355^{* * *}\end{array}$ & $\begin{array}{l}-.693 \\
-.032 * \star * *\end{array}$ & $\begin{array}{l}-.519 \\
-034)^{* \star *}\end{array}$ & $\begin{array}{l}-.520 \\
-(034 * * *\end{array}$ & $\begin{array}{l}-.678 \\
.034 * * *\end{array}$ & $\begin{array}{l}-.496 \\
-035 * * *\end{array}$ & $\begin{array}{l}-.495 \\
-0355^{* * *}\end{array}$ & $\begin{array}{l}-.653 \\
-032 * * *\end{array}$ & $\begin{array}{l}-.492 \\
-034 * * *\end{array}$ & $\begin{array}{l}-.491 \\
-(024) * * *\end{array}$ \\
\hline & $(.033)^{\star \star \star}$ & $(.034)^{\star \star \star}$ & $(.034)^{\star \star \star}$ & $(.034)^{\star \star \star}$ & $(.035)^{\star \star \star *}$ & $(.035)^{\star \star \star}$ & $(.033)^{\star \star \star}$ & $(.034)^{\star \star \star}$ & $(.034)^{\star * \star}$ & $(.034)^{\star \star \star *}$ & $(.035)^{\star \star \star}$ & $(.035)^{\star \star \star}$ & $(.033)^{\star \star \star}$ & $(.034)^{\star \star \star \star}$ & $(.034)^{\star * *}$ \\
\hline employment & & $\begin{array}{l}3.62 \\
(.401)^{\star \star * *}\end{array}$ & $\begin{array}{l}3.54 \\
(.400)^{* \star *}\end{array}$ & & $\begin{array}{l}3.38 \\
(.412)^{* \star *}\end{array}$ & $\begin{array}{l}3.34 \\
(.406)^{\star \star \star *}\end{array}$ & & $\begin{array}{l}3.52 \\
(.406)^{\star \star \star *}\end{array}$ & $\begin{array}{l}3.65 \\
(.407)^{\star \star *}\end{array}$ & & $\begin{array}{l}3.54 \\
(.410)^{* \star *}\end{array}$ & $\begin{array}{l}3.50 \\
(.412)^{* \star *}\end{array}$ & & $\begin{array}{l}3.30 \\
(.399)^{* \star *}\end{array}$ & $\begin{array}{l}3.26 \\
(.399)^{\star * \star *}\end{array}$ \\
\hline wage level (In) & & .398 & .422 & & .488 & .510 & & .418 & .460 & & .434 & .467 & & .391 & .379 \\
\hline & & $(.138)^{\star \star \star}$ & $(.136)^{\star \star *}$ & & $(.139)^{\star \star \star}$ & $(.139)^{\star \star \star}$ & & $(.138)^{\star \star \star}$ & $(.139)^{\star \star \star}$ & & $(.139)^{\star * *}$ & $(.140)^{\star \star *}$ & & $(.137)^{\star \star \star}$ & $(.137)^{\star \star \star}$ \\
\hline concentration & & -2.18 & & & -1.42 & & & -2.20 & & & -6.74 & & & -18.3 & \\
\hline firm concentration & & $(.859)^{\star \star \star}$ & & & (1.15) & & & $(1.00)^{\star *}$ & & & $(2.26)^{\star \star \star}$ & & & $(7.52)^{\star *}$ & \\
\hline firm concentration & & & $\begin{array}{l}-3.83 \\
(.954)^{\star \star \star}\end{array}$ & & & $\begin{array}{l}-9 . / 0 \\
(2.50)^{\star \star \star *}\end{array}$ & & & $\begin{array}{l}-6.11 \\
(1.80)^{\star \star \star *}\end{array}$ & & & $\begin{array}{l}-8.47 \\
(5.57)\end{array}$ & & & $\begin{array}{l}-6.31 \\
(3.61)^{*}\end{array}$ \\
\hline citytop4 & & $\begin{array}{l}.585 \\
.058)^{\star \star * *}\end{array}$ & $\begin{array}{l}.637 \\
.058)^{* * *}\end{array}$ & & $\begin{array}{l}.504 \\
(.083)^{* * *}\end{array}$ & $\begin{array}{l}.596 \\
.066)^{* \star *}\end{array}$ & & $\begin{array}{l}.579 \\
(.088)^{* * *}\end{array}$ & $\begin{array}{l}.645 \\
.078)^{* * *}\end{array}$ & & $\begin{array}{l}.523 \\
(.060)^{\star \star * \star}\end{array}$ & $\begin{array}{l}.457 \\
.055)^{* * *}\end{array}$ & & $\begin{array}{l}.434 \\
.063)^{\star \star * *}\end{array}$ & $\begin{array}{l}.363 \\
.0511^{* * *}\end{array}$ \\
\hline trade & & -1.67 & -1.67 & & $\begin{array}{l}-1.58 \\
-1.5\end{array}$ & $\begin{array}{l}-1.58 \\
-1.08\end{array}$ & & $\begin{array}{l}-1.59 \\
-1.09\end{array}$ & $\begin{array}{l}-1.58 \\
-1.58\end{array}$ & & $\begin{array}{l}-1.56 \\
-1.56\end{array}$ & $\begin{array}{l}. .050) \\
-1.56\end{array}$ & & $\begin{array}{l}.003) \\
-1.55\end{array}$ & $\begin{array}{l}.051) \\
-1.55\end{array}$ \\
\hline & & $(.039)^{\star * \star *}$ & $(.039)^{\star \star \star *}$ & & $(.040)^{\star \star *}$ & $(.040)^{\star \star * *}$ & & $(.040)^{* \star *}$ & $(.040)^{* * \star}$ & & $(.041)^{* \star \star *}$ & $(.041)^{* \star \star *}$ & & $(.041)^{\star * \star}$ & $(.041)^{\star \star \star \star}$ \\
\hline hospitality & & -.952 & -.952 & & -.950 & -.950 & & -1.01 & -1.02 & & -.976 & -.976 & & -.725 & -.724 \\
\hline & & $(.060)^{\star \star \star}$ & $(.060)^{\star \star *}$ & & $(.064)^{\star \star \star *}$ & $(.064)^{\star \star \star}$ & & $(.065)^{\star \star \star}$ & $(.065)^{\star \star \star}$ & & $(.067)^{\star \star \star}$ & $(.067)^{\star \star *}$ & & $(.063)^{\star \star \star}$ & $(.063)^{* * *}$ \\
\hline transport/storage/ & & -.919 & -.922 & & -916 & $\begin{array}{l}-.916 \\
.071 * * *\end{array}$ & & -.885 & -.884 & & -.881 & -.883 & & -.872 & -873 \\
\hline $\begin{array}{l}\text { communication } \\
\text { business services }\end{array}$ & & $\begin{array}{l}(.069) \\
-1.44\end{array}$ & $\begin{array}{l}(.069)^{2 \times x \times} \\
-1.44\end{array}$ & & $\begin{array}{l}(.071)^{* \times *} \\
-1.47\end{array}$ & $\begin{array}{l}.071) \\
-1.47\end{array}$ & & $\begin{array}{l}.070) \\
-1.48\end{array}$ & -1.48 & & $\begin{array}{l}(.02) \\
-1.48\end{array}$ & $\begin{array}{l}.0278 \\
-1.48\end{array}$ & & $\begin{array}{l}(.072) \\
-1.47\end{array}$ & $\begin{array}{l}(.0 / 2) \\
-1.47\end{array}$ \\
\hline Dusiness services & & $\begin{array}{l}-1.44 \\
(.039)^{\star * *}\end{array}$ & $\begin{array}{l}-1.44 \\
(.039)^{* * *}\end{array}$ & & $(.040)^{* \star *}$ & $(.040)^{* * *}$ & & $(.040)^{* \star *}$ & $(.040)^{* \star *}$ & & $(.040)^{* \star *}$ & $(.040)^{* \star *}$ & & $(.041)^{\star \star \star \star}$ & $(.041)^{\star * \star}$ \\
\hline other services & & $\begin{array}{l}-1.16 \\
(.043)^{\star \star *}\end{array}$ & $\begin{array}{l}-1.16 \\
(.043)^{\star * *}\end{array}$ & & $\begin{array}{l}-1.17 \\
(.044)^{\star * *}\end{array}$ & $\begin{array}{l}-1.17 \\
(.044)^{* * *}\end{array}$ & & $\begin{array}{l}-1.14 \\
(.043)^{\star \star *}\end{array}$ & $\begin{array}{l}-1.14 \\
(.043)^{\star \star *}\end{array}$ & & $\begin{array}{l}-1.18 \\
(.044)^{\star \star *}\end{array}$ & $\begin{array}{l}-1.18 \\
(.044)^{\star \star \star}\end{array}$ & & $\begin{array}{l}-1.14 \\
(.044)^{* * *}\end{array}$ & $\begin{array}{l}-1.15 \\
(.044)^{\star \star *}\end{array}$ \\
\hline observations & 594,106 & 594,106 & 594,106 & 566.281 & 566.281 & 566.281 & 580,983 & 580,983 & 580,983 & 555,729 & 555,729 & 555,729 & 571,600 & 571,600 & 571,600 \\
\hline $\begin{array}{l}\text { individuals } \\
\text { Hypothesis } 1\end{array}$ & 141,231 & 141,231 & 141,231 & 132,873 & 132,873 & 132,873 & 136,401 & 136,401 & 136,401 & 129,618 & 129,618 & 129,618 & 132,747 & 132,747 & 132,747 \\
\hline$z$-value $(\mathrm{H} 0: 2$ gen $<=1$ gen $)$ & .22 & .1 & .1 & $1.41^{*}$ & $1.48^{*}$ & $1.46^{*}$ & $1.3^{*}$ & $1.49^{*}$ & $1.44^{*}$ & $2.04^{* *}$ & $2.36^{* * *}$ & $2.33^{* * * *}$ & 4.44 & 4.03 & 4.06 \\
\hline
\end{tabular}


Table 4.7: Base random-effects logistic regression estimates for dependent variable growth, by origin group * (Source: CBS SSB 1995-2004, own calculations)

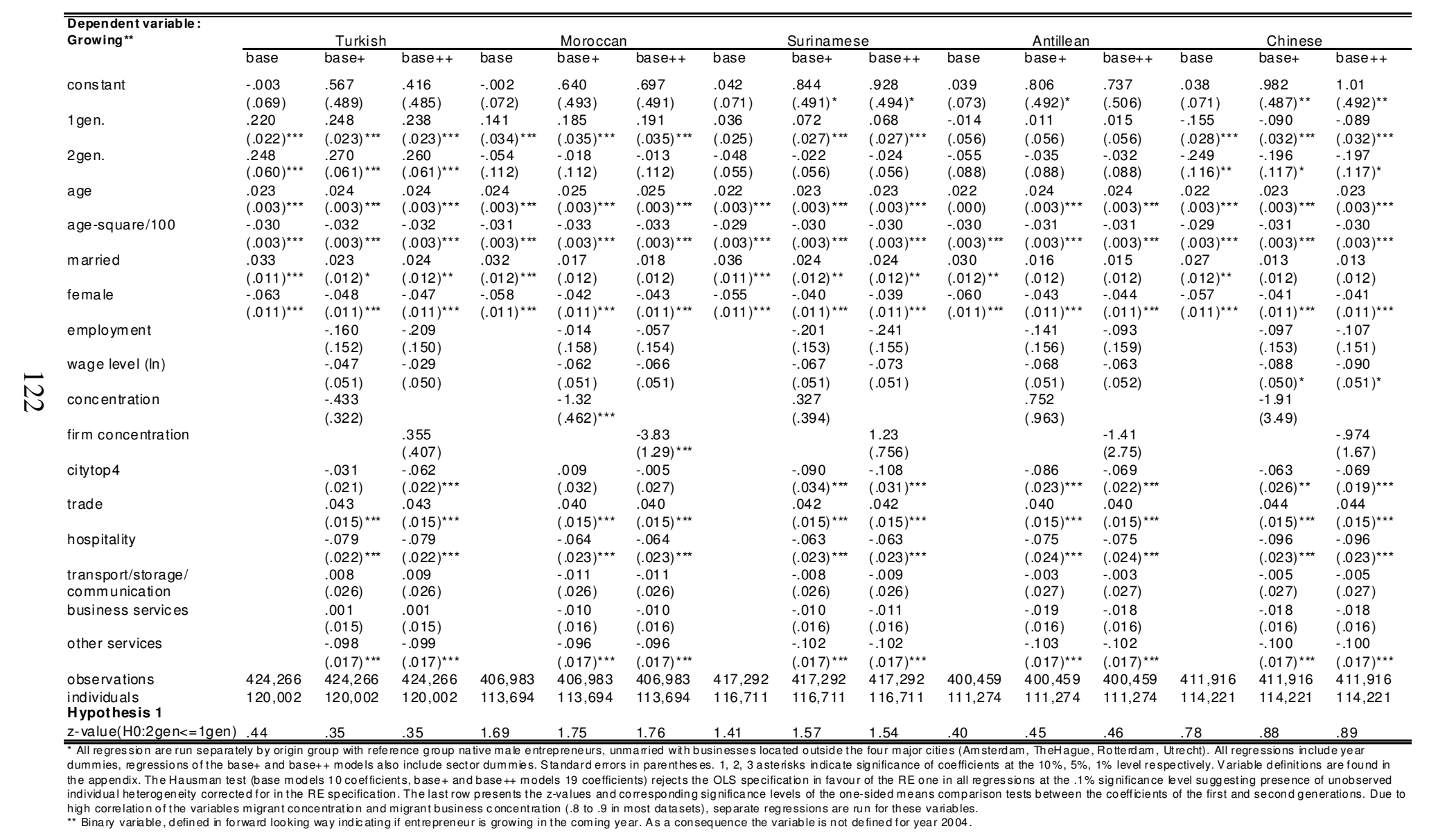


Table 4.8: Base random-effects logistic regression estimates for dependent variable survival, by origin group *

(Source: CBS SSB 1995-2004, own calculations)

\begin{tabular}{|c|c|c|c|c|c|c|c|c|c|c|c|c|c|c|c|}
\hline \multirow{2}{*}{$\begin{array}{l}\text { De pendent variable: } \\
\text { Survival to next period }\end{array}$} & \multicolumn{3}{|c|}{$\begin{array}{l}\text { Turkish } \\
\end{array}$} & \multicolumn{3}{|c|}{$\begin{array}{l}\text { Moroccan } \\
\end{array}$} & \multicolumn{3}{|c|}{$\begin{array}{l}\text { Surinamese } \\
\end{array}$} & \multicolumn{3}{|c|}{$\begin{array}{l}\text { Antillean } \\
\end{array}$} & \multicolumn{3}{|c|}{ Chinese } \\
\hline & base & base+ & base++ & base & base+ & base++ & base & base+ & base++ & base & base+ & base++ & base & base+ & base++ \\
\hline constant & $\begin{array}{l}.360 \\
(.072)^{* *+*}\end{array}$ & $\begin{array}{l}2.78 \\
(.584)^{\star \star \star}\end{array}$ & $\begin{array}{l}2.26 \\
(.578)^{\star * *}\end{array}$ & $\begin{array}{l}.284 \\
.075)^{* \star *}\end{array}$ & $\begin{array}{l}1.36 \\
(.591)^{\star \star}\end{array}$ & $\begin{array}{l}1.44 \\
(.590)^{\star *}\end{array}$ & $\begin{array}{l}.238 \\
(.074)^{\star \star * *}\end{array}$ & $\begin{array}{l}.886 \\
(.588)\end{array}$ & $\begin{array}{l}.503 \\
(.591)\end{array}$ & $\begin{array}{l}.251 \\
(.076)^{\star \star * *}\end{array}$ & $\begin{array}{l}1.63 \\
(.588)^{\star \star \star *}\end{array}$ & $\begin{array}{l}.200 \\
(.604)\end{array}$ & $\begin{array}{l}.364 \\
(.075)^{\star * *}\end{array}$ & $\begin{array}{l}2.32 \\
(.586)^{* * *}\end{array}$ & $\begin{array}{l}2.83 \\
(.593)^{* * *}\end{array}$ \\
\hline 1 gen. & $\begin{array}{l}-812 \\
.822)^{* * *}\end{array}$ & $\begin{array}{l}-.721 \\
.024)^{\star \star *}\end{array}$ & $\begin{array}{l}.715 \\
.024)^{* * *}\end{array}$ & $\begin{array}{l}-.658 \\
.034)^{\star \star \star}\end{array}$ & $\begin{array}{l}-610 \\
-6035)^{\star * *}\end{array}$ & $\begin{array}{l}-.585 \\
.035)^{\star \star *}\end{array}$ & 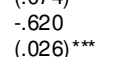 & $\begin{array}{l}-.553 \\
.028)^{\star \star *}\end{array}$ & $\begin{array}{l}-.535 \\
.028)^{\star * * *}\end{array}$ & $\begin{array}{l}-.768 \\
.054)^{\star \star *}\end{array}$ & $\begin{array}{l}-.707 \\
.054)^{\star * *}\end{array}$ & $\begin{array}{l}-.715 \\
.054)^{\star \star *}\end{array}$ & $\begin{array}{l}.327 \\
(.036)^{* * *}\end{array}$ & $\begin{array}{l}.375 \\
.040)^{* * *}\end{array}$ & $\begin{array}{l}.382 \\
(.040)^{* * *}\end{array}$ \\
\hline 2gen. & $\begin{array}{l}-.664 \\
(.052)^{* \star *}\end{array}$ & $\begin{array}{l}-.577 \\
(.052)^{\star \star *}\end{array}$ & $\begin{array}{l}-.576 \\
(.053)^{\star \star *}\end{array}$ & $\begin{array}{l}-.550 \\
(.087)^{\star \star \star}\end{array}$ & $\begin{array}{l}-.510 \\
(.088)^{\star \star \star *}\end{array}$ & $\begin{array}{l}-.491 \\
(.088)^{\star \star \star *}\end{array}$ & $\begin{array}{l}-.572 \\
(.052)^{\star \star \star \star}\end{array}$ & $\begin{array}{l}-.493 \\
(.052)^{\star \star *}\end{array}$ & $\begin{array}{l}-.486 \\
(.052)^{\star \star *}\end{array}$ & $\begin{array}{l}-.575 \\
(.084)^{\star \star \star}\end{array}$ & $\begin{array}{l}-.505 \\
(.084)^{\star \star \star}\end{array}$ & $\begin{array}{l}-.497 \\
(.084)^{\star \star *}\end{array}$ & $\begin{array}{l}-.133 \\
-(.118)\end{array}$ & $\begin{array}{l}-.062 \\
(.118)\end{array}$ & $\begin{array}{l}-.071 \\
(.118)\end{array}$ \\
\hline age & $\begin{array}{l}.125 \\
(.003)^{* *+*}\end{array}$ & $\begin{array}{l}.125 \\
(.003)^{\star \star \star}\end{array}$ & $\begin{array}{l}.125 \\
(.003)^{* * *}\end{array}$ & $\begin{array}{l}.129 \\
(.003)^{\star \star \star *}\end{array}$ & $\begin{array}{l}.131 \\
(.003)^{* * *}\end{array}$ & $\begin{array}{l}.131 \\
(.003)^{* \star *}\end{array}$ & $\begin{array}{l}.131 \\
(.003)^{* * *}\end{array}$ & $\begin{array}{l}.132 \\
(.003)^{* \star *}\end{array}$ & $\begin{array}{l}.132 \\
(.003)^{* * *+1}\end{array}$ & $\begin{array}{l}.131 \\
(.003)^{* * *}\end{array}$ & $\begin{array}{l}.133 \\
(.003)^{\star *+*}\end{array}$ & $\begin{array}{l}.133 \\
(.003)^{* \star *}\end{array}$ & $\begin{array}{l}.126 \\
(.003)^{* *+*}\end{array}$ & $\begin{array}{l}.127 \\
(.003)^{* * *}\end{array}$ & $\begin{array}{l}.127 \\
(.003)^{* * *}\end{array}$ \\
\hline age-square/100 & $\begin{array}{l}-150 \\
.1003)^{* * *}\end{array}$ & $\begin{array}{l}-.149 \\
(.003)^{* \star *}\end{array}$ & $\begin{array}{l}-.149 \\
(.003)^{\star * * *}\end{array}$ & $\begin{array}{l}-.155 \\
(.003)^{\star * *}\end{array}$ & $\begin{array}{l}-155 \\
-.003)^{\star * *}\end{array}$ & $\begin{array}{l}-.155 \\
.003)^{* * *}\end{array}$ & 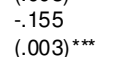 & $\begin{array}{l}-.156 \\
.003)^{\star \star *}\end{array}$ & $\begin{array}{l}-155 \\
.1003)^{\star * *}\end{array}$ & $\begin{array}{l}-.156 \\
(.003)^{* * *}\end{array}$ & $\begin{array}{l}-.157 \\
(.003)^{\star * *}\end{array}$ & $\begin{array}{l}-.157 \\
(.003)^{* * *}\end{array}$ & $\begin{array}{l}-.151 \\
(.003)^{* * *}\end{array}$ & $\begin{array}{l}-.152 \\
(.003)^{* * *}\end{array}$ & $\begin{array}{l}-.151 \\
.003)^{* * *}\end{array}$ \\
\hline married & $\begin{array}{l}.210 \\
(.013)^{\star * *}\end{array}$ & $\begin{array}{l}.186 \\
(.013)^{\star \star *}\end{array}$ & $\begin{array}{l}.189 \\
(.013)^{\star \star \star *}\end{array}$ & $\begin{array}{l}.204 \\
. .014)^{\star \star \star *}\end{array}$ & $\begin{array}{l}.182 \\
(.014)^{\star \star \star *}\end{array}$ & $\begin{array}{l}.181 \\
(.014)^{\star \star \star}\end{array}$ & $\begin{array}{l}.217 \\
(.014)^{\star \star \star *}\end{array}$ & $\begin{array}{l}.196 \\
(.014)^{\star \star \star}\end{array}$ & $\begin{array}{l}.197 \\
(.014)^{\star \star \star}\end{array}$ & $\begin{array}{l}.209 \\
.014)^{\star \star \star}\end{array}$ & $\begin{array}{l}.180 \\
(.014)^{\star \star * *}\end{array}$ & $\begin{array}{l}.182 \\
(.017)^{\star \star \star}\end{array}$ & $\begin{array}{l}.228 \\
(.014)^{\star \star \star \star}\end{array}$ & $\begin{array}{l}.197 \\
(.014)^{\star \star \star}\end{array}$ & $\begin{array}{l}.204 \\
(.014)^{\star \star \star}\end{array}$ \\
\hline female & $\begin{array}{l}-.211 \\
(.013)^{\star * * *}\end{array}$ & $\begin{array}{l}-.216 \\
(.013)^{\star \star *}\end{array}$ & $\begin{array}{l}-.217 \\
(.013)^{* *+*}\end{array}$ & $\begin{array}{l}-.224 \\
(.013)^{\star \star *}\end{array}$ & $\begin{array}{l}-.224 \\
(.014)^{* * *}\end{array}$ & $\begin{array}{l}-225 \\
(.014)^{\star \star *}\end{array}$ & $\begin{array}{l}-.209 \\
(.013)^{* * *}\end{array}$ & $\begin{array}{l}-.211 \\
(.013)^{* \star *}\end{array}$ & $\begin{array}{l}-.212 \\
(.013)^{* * * *}\end{array}$ & $\begin{array}{l}-.217 \\
.013)^{\star \star \star}\end{array}$ & $\begin{array}{l}-.218 \\
(.014)^{* * * *}\end{array}$ & $\begin{array}{l}-.217 \\
(.014)^{\star \star *}\end{array}$ & $\begin{array}{l}-.210 \\
(.013)^{* * *}\end{array}$ & $\begin{array}{l}-212 \\
(.014)^{* \star *}\end{array}$ & $\begin{array}{l}-.210 \\
.014)^{* * *}\end{array}$ \\
\hline employment & & $\begin{array}{l}.013) \\
-.239 \\
(185)\end{array}$ & $\begin{array}{l}-.348 \\
(184)^{\star}\end{array}$ & & $\begin{array}{l}.014) \\
-.288 \\
(193)\end{array}$ & $\begin{array}{l}-.321 \\
(.189)^{*}\end{array}$ & & $\begin{array}{l}-.03 \\
-.303 \\
(.188)\end{array}$ & $\begin{array}{l}(.03) \\
-.105 \\
(.190)\end{array}$ & & $\begin{array}{l}(.014) \\
-.221 \\
(.192)\end{array}$ & $\begin{array}{l}(.04) \\
-.139 \\
(.194)\end{array}$ & & $\begin{array}{l}-.398 \\
(.189)^{\star *}\end{array}$ & $\begin{array}{l}-.046 \\
-.646 \\
(187)^{\star \star \star \star}\end{array}$ \\
\hline wage level (In) & & -.203 & -.145 & & -.067 & -.074 & & -.022 & .003 & & -.099 & .039 & & -.141 & -.174 \\
\hline concentration & & $\begin{array}{l}(.060)^{\star \star \star} \\
-4.50 \\
(.367)^{\star \star \star}\end{array}$ & $(.060)^{\star \star}$ & & $\begin{array}{l}(.061) \\
-3.63 \\
(.524)^{\star \star \star *+}\end{array}$ & $(.061)$ & & $\begin{array}{l}(.060) \\
-4.30 \\
(.440)^{* \star *}\end{array}$ & $(.061)$ & & $\begin{array}{l}(.061) \\
-14.6 \\
(1.04)^{\star \star \star}\end{array}$ & $(.062)$ & & $\begin{array}{l}(.060)^{\star \star} \\
-45.4 \\
(3.86)^{\star \star \star}\end{array}$ & $(.061)^{\star \star \star}$ \\
\hline firm concentration & & & $\begin{array}{l}-5.26 \\
(.425)^{\star * *+*}\end{array}$ & & & $\begin{array}{l}-12.6 \\
(1.32)^{\star \star *}\end{array}$ & & & $\begin{array}{l}-9.64 \\
(.813)^{* \star * * *}\end{array}$ & & & $\begin{array}{l}-33.8 \\
(3.02)^{\star \star *}\end{array}$ & & & $\begin{array}{l}-20.0 \\
(1.93)^{* * *}\end{array}$ \\
\hline citytop4 & & .147 & .165 & & .174 & .192 & & .278 & .294 & & .185 & .105 & & .182 & .020 \\
\hline & & $(.024)^{\star \star \star}$ & $(.025)^{\star \star * *}$ & & $(.037)^{\star \star \star *}$ & $(.032)^{\star \star \star \star}$ & & $(.039)^{\star \star \star}$ & $(.035)^{\star \star \star *}$ & & $(.027)^{\star \star \star *}$ & $(.025)^{\star \star \star}$ & & $(.030)^{\star \star \star}$ & $(.023)$ \\
\hline trade & & -.205 & -.205 & & -.236 & -.235 & & -.232 & -.232 & & -.230 & -.231 & & -.242 & -.242 \\
\hline & & $(.018)^{\star \star \star \star}$ & $(.018)^{\star \star \star \star}$ & & $(.019)^{\star \star \star * t}$ & $(.019)^{\star \star \star}$ & & $(.019)^{\star \star \star}$ & $(.019)^{\star \star * t}$ & & $(.019)^{\star \star \star}$ & $(.019)^{\star \star \star}$ & & $(.020)^{\star \star \star \star}$ & $(.020)^{\star * \star *}$ \\
\hline hospitality & & $\begin{array}{l}-.277 \\
(.026)^{\star \star \star *}\end{array}$ & $\begin{array}{l}-.278 \\
(.026)^{\star \star * \star}\end{array}$ & & $\begin{array}{l}-.292 \\
(.028)^{\star \star \star *}\end{array}$ & $\begin{array}{l}-.292 \\
(.028)^{\star \star \star \star}\end{array}$ & & $\begin{array}{l}-.301 \\
(.028)^{\star \star \star \star}\end{array}$ & $\begin{array}{l}. .302 \\
(.028)^{\star \star \star *}\end{array}$ & & $\begin{array}{l}-.306 \\
(.029)^{\star \star \star}\end{array}$ & $\begin{array}{l}-.304 \\
(.029)^{\star \star \star}\end{array}$ & & $\begin{array}{l}-.233 \\
(.028)^{\star \star \star}\end{array}$ & $\begin{array}{l}.0233 \\
-.028)^{\star \star \star}\end{array}$ \\
\hline transport/storage/ & & -.026 & -.031 & & -.061 & -.061 & & -.091 & -.091 & & -.079 & -.084 & & -.087 & -.090 \\
\hline communication & & $(.032)$ & $(.032)$ & & $(.033)^{\star}$ & $(.033)^{\star}$ & & $(.033)^{\star \star \star}$ & $(.033)^{\star \star \star * t}$ & & $(.034)^{\star *}$ & $(.034)^{\star \star}$ & & $(.034)^{\star \star \star}$ & $(.034)^{\star \star \star *}$ \\
\hline business servic es & & -.486 & -.487 & & -.491 & -.491 & & -.469 & -.467 & & -.479 & -.480 & & -.486 & -.493 \\
\hline & & $(.019)^{\star \star \star}$ & $(.019)^{\star \star \star}$ & & $(.019)^{\star \star \star}$ & $(.019)^{\star \star \star \star}$ & & $(.019)^{\star \star \star}$ & $(.019)^{\star \star \star}$ & & $(.019)^{\star \star \star \star}$ & $(.019)^{\star \star \star *}$ & & $(.020)^{\star \star \star *}$ & $(.020)^{\star \star \star}$ \\
\hline other services & & $\begin{array}{l}-.035 \\
.021)\end{array}$ & $\begin{array}{l}-.037 \\
(021)^{*}\end{array}$ & & $\begin{array}{l}-.062 \\
(022)^{\star * *}\end{array}$ & $\begin{array}{l}-.062 \\
(022)^{\star \star \star}\end{array}$ & & $\begin{array}{l}-.055 \\
.021)^{\star \star}\end{array}$ & $\begin{array}{l}-.053 \\
.021)^{\star *}\end{array}$ & & $\begin{array}{l}-.068 \\
.022)^{* * *}\end{array}$ & $\begin{array}{l}-.069 \\
.022)^{\star * *}\end{array}$ & & $\begin{array}{l}-.081 \\
.022)^{* * *}\end{array}$ & $\begin{array}{l}-.084 \\
.022)^{* * *}\end{array}$ \\
\hline observations & 496,302 & 496,302 & 496,302 & 473,475 & 473,475 & 473,475 & 486,162 & 486,162 & 486,162 & 465,182 & 465,182 & 465,182 & 478,157 & 478,157 & 478,157 \\
\hline $\begin{array}{l}\text { individuals } \\
\text { Hypothesis } 1\end{array}$ & 134,454 & 134,454 & 134,454 & 126,786 & 126,786 & 126,786 & 130,227 & 130,227 & 130,227 & 123,905 & 123,905 & 123,905 & 126,971 & 126,971 & 126,971 \\
\hline$z$-value $(H 0: 2$ gen $<=1$ gen $)$ & $2.70^{\star \star \star \star}$ & $2.63^{\star \star \star}$ & $2.53^{\star \star \star}$ & 1.16 & 1.08 & 1.00 & .84 & 1.04 & .85 & $1.93^{\text {t* }}$ & $2.03^{\star \star}$ & $2.19^{\text {** }}$ & 3.73 & 3.55 & 3.67 \\
\hline
\end{tabular}


Hypotheses $4.4 a$ and $4.4 b$ focus on the effect of location in the four major Dutch cities, Amsterdam, Rotterdam, The Hague and Utrecht. The hypotheses claim that migrant business performance in these four cities should be higher than elsewhere in the country and that these business settings are relatively more beneficial for the second generation vis-à-vis the first. When looking at the migrant composite coefficients as well as their corresponding test results in Table 4.9, migrant firms located in the four major cities do indeed report higher profitability and survival figures than firms located elsewhere, but growth rates are comparable or even less (except for the Turkish first generation). A possible explanation is that while business prospects in these cities seem more promising, entrepreneurs may be reluctant to hire given the general scarcity of suitable business space. The Chinese group is an exceptional case as firms in the four major cities actually show lower profitability and survival rates (the latter only for the first generation) than elsewhere, a trend likely driven by the entrepreneurs in the Chinese restaurant niche, who face fiercer competition in the big cities. Overall, taking the Chinese group aside, Hypothesis 4.4a is supported in the profit and survival models but not in the growth model.

Comparisons between the two generations (see Table 4.9) reveal that intergenerational differences in the effect of the four major cities are not systematic and therefore Hypothesis $4.4 \mathrm{~b}$ is rejected. The only intergenerational finding supportive of the hypothesis is that second generation Chinese firms do show higher survival rates than their parents' generation in the four major cities. This difference can be attributed to the fact that the second generation is less active in the Chinese restaurant niche, which - as just explained - offers relatively lower business prospects in the four major cities.

Hypotheses $4.5 a$ and $4.5 b$ focus on performance implications of the intergenerational differences regarding business activities across industry sectors, as observed in Figure 4.1. The figure suggests that the second generation operates to a greater extent in more promising sectors, such as business services, while the first generation remains in more traditional sectors, such as trade and hospitality. More specifically, Hypothesis 4.5a claims that migrant business prospects in the former industry sectors should be higher than in the latter ones. Hypothesis $4.5 \mathrm{~b}$ in turn stipulates that, while second generation entrepreneurs outperform first generation entrepreneurs in the more promising sectors, the reverse is expected for the traditional sectors. Focusing our analysis on the sectors trade, hospitality and business services, the findings in Table 4.9 suggest different patterns for the three origin clusters in relation with Hypothesis 4.5a. In the labour migrant (Turkish/Moroccan) cluster, Hypothesis $4.5 \mathrm{a}$ is supported for firm profitability and perhaps growth but not in terms of survival. In other words, Turkish and 
Moroccan entrepreneurs operating in the business services sector tend to have higher profits and growth rates but not higher survival rates than those operating in the trade and hospitality sectors. For the colonial migrant (Surinamese/Antillean) cluster the results are mixed. The hypothesis is generally supported in the profit model, but not in the firm growth and survival models. This indicates that firms of the same size (in terms of employees) generate higher financial returns in the business services sector than in traditional migrant sectors, but may also face higher risk of business failure especially during the start-up phase. Finally, in the Chinese case, Hypothesis $4.5 \mathrm{a}$ is not supported as firms in the hospitality sector report higher profits and survival rates than those active in business services and firms in the trade sector show the highest growth rates. Strikingly, for the Chinese group of entrepreneurs the traditional commercial activities centred on restaurants and international trade seem to offer the most favourable business prospects for both generations.

The results depicted in Table 4.9 reveal little systematic evidence that the first generation is doing better in the traditional sectors and the second generation is doing better in the other sectors. Thus Hypothesis $4.5 \mathrm{~b}$ can be generally rejected. Apart from this general trend, a few additional observations can be made on the origin clusters of labour migrant and Chinese entrepreneurs, although these are rather fragmented and hard to interpret. In the case of the labour migrant cluster, the second generation is less profitable in the traditional sectors, and not more profitable in the business services sector than their first generation counterparts. It reports higher survival rates in the business services sector, but not lower ones in the traditional sectors. In the case of the Chinese origin group, the second generation shows lower firm growth rates in traditional sectors, but not higher ones in the business services sector. In addition, it shows higher firm survival rates in the business services sector, but not lower ones in the traditional sectors vis-à-vis the first generation. Overall, we can reiterate that Hypothesis $4.5 \mathrm{~b}$ is clearly rejected. Combining the insight from the regression analyses with our previous, more descriptive, findings enables us to add some further remarks. As the second generation operates businesses in the rising sectors and at least partly turns away from the traditional sectors, this indicates that the second generation has apparently understood that the rising sectors offer more opportunities, but it does not manage to seize them more successfully than its parents' generation. Improvements in the economic status of the second generation are therefore due to pure selection effects - the second generation is more likely to start a business in promising sectors than its parents' generation was - and not due to better capabilities or integration, as we do not observe differences between the generations within a sector. 
Table 4.9: Selected random effects regression outputs from interaction models: migrant composite coefficients per independent variable and test results for hypotheses $2-5$

\begin{tabular}{|c|c|c|c|c|c|c|c|c|c|c|c|c|}
\hline & & & \multicolumn{3}{|c|}{$\overline{\text { DV: ANNUAL PROFIT }}$} & \multicolumn{2}{|c|}{ DV: GROWING } & \multicolumn{4}{|c|}{ "DV: SURVIVAL } \\
\hline & & \multirow{2}{*}{\multicolumn{2}{|c|}{ variable group }} & & & Welch & & & Welch & & & Welch \\
\hline & & & & gen1 & gen2 & $(\mathrm{t})$ & gen1 & gen2 & $(\mathrm{t})$ & gen1 & gen2 & $(\mathrm{t})$ \\
\hline \multirow{10}{*}{\multicolumn{2}{|c|}{ 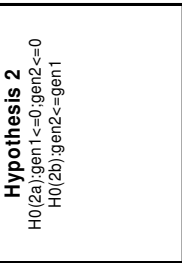 }} & $E$ & Turkish & $4.48^{* *}$ & $5.35 *$ & & -.854 & -2.11 & & $1.25^{* *}$ & $2.58^{\text {** }}$ & \\
\hline & & 㐫 & Moroccan & 2.06 & 5.60 & & -.647 & -3.61 & & 1.48 ** & .927 & \\
\hline & & 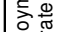 & Surinamese & 4.46 ** & 4.83 * & & -2.18 & 1.89 * & ** & $1.11^{*}$ & 1.52 & \\
\hline & & $\overline{0}^{2}$ & Antillean & $6.60^{* *}$ & 3.94 & & .192 & -.879 & & .544 & 2.76 * & \\
\hline & & & Chinese & 3.39 ** & 12.6 ** & * & .614 & -.421 & & 1.36 * & 1.19 & \\
\hline & & & Turkish & -1.61 & -3.85 & & $2.74^{\star \star}$ & $2.91^{\text {** }}$ & & -.971 & -2.59 & \\
\hline & & $\stackrel{0}{0}$ & Moroccan & .124 & 3.20 ** & ** & .927 ** & 2.70 ** & ** & -.714 & -2.04 & \\
\hline & & $\frac{\omega}{\omega}$ & Surinamese & -1.31 & -1.29 & & .849 ** & $.773^{* *}$ & & -1.19 & -.691 & \\
\hline & & & Antillean & -.340 & 2.05 * & * & -.422 & .247 & & -1.07 & -1.32 & \\
\hline & & & Chinese & 1.54 ** & 1.97 & & .435 ** & .488 & & -.831 & -.063 & \\
\hline \multirow{10}{*}{\multicolumn{2}{|c|}{ 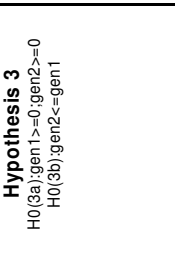 }} & 으 & Turkish & -3.39 & -5.26 & & 2.31 & 4.08 & & -5.20 ** & $-7.20^{* \star}$ & \\
\hline & & 雚 & Moroccan & -.730 & 4.36 & & -.220 & $-5.20 *$ & & -1.09 & -.940 & \\
\hline & & 言 & Surinamese & -1.52 & -6.42 ** & & 1.62 & -1.87 & & -4.20 ** & -7.20 ** & \\
\hline & & 岕 & Antillean & -12.6 & $-37.2 *$ & & -.213 & 5.93 & & -25.9 ** & -11.8 & \\
\hline & & & Chinese & $-117^{* *}$ & -186 ** & & 17.2 & 40.3 & & $-87.7^{* *}$ & -39.3 & \\
\hline & & 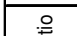 & Turkish & $-3.24^{*}$ & $-9.00 *$ & & 5.70 & 4.56 & & $-5.46^{\star \star}$ & $-8.16^{* *}$ & \\
\hline & & 节 & Moroccan & -19.4 ** & 5.06 & & .940 & -6.99 & & -16.2 ** & -13.9 ** & \\
\hline & & 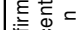 & Surinamese & -8.46 ** & $-18.3^{\text {** }}$ & & 4.47 & -1.96 & & $-11.4^{* *}$ & $-17.7^{* *}$ & \\
\hline & & & Antillean & 48.8 & -45.0 & & 4.14 & 67.4 & & -58.8 ** & -36.5 & \\
\hline & & 8 & Chinese & $-24.7 * *$ & -21.7 & & 23.3 & 41.1 & & -33.2 ** & -14.4 & \\
\hline \multirow{5}{*}{\multicolumn{2}{|c|}{ 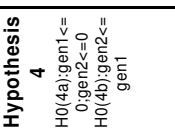 }} & & Turkish & $.917^{\star *}$ & $.699^{* *}$ & & $.103^{\star *}$ & -.010 & & $.120^{* *}$ & $.146^{*}$ & \\
\hline & & i & Moroccan & $.612^{* *}$ & .440 & & .090 & -.139 & & .195 ** & .232 * & \\
\hline & & 문 & Surinamese & $.637^{* *}$ & .252 & & .015 & -.280 & & .264 ** & .108 & \\
\hline & & & Antillean & .595 ** & .221 & & -.156 & -.107 & & .147 & .272 * & \\
\hline & & & Chinese & -.510 & -1.75 & & -.076 & .040 & & -.220 & .167 & * \\
\hline \multirow{14}{*}{ 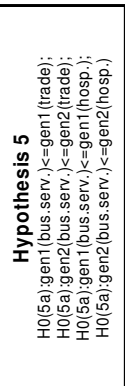 } & \multirow{10}{*}{ 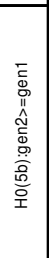 } & & $\begin{array}{l}\text { Turkish } \\
\end{array}$ & -2.82 ** & $-3.98^{* *}$ & ** & $.105^{* *}$ & .178 & & .064 & .100 & \\
\hline & & & Moroccan & -3.27 ** & -3.44 & & .230 * & .799 & & -.179 & .331 & \\
\hline & & $\frac{\pi}{\pi}$ & Surinamese & -2.83 ** & -2.73 & & .183 & .066 & & -.079 & .256 & \\
\hline & & & Antillean & $-4.83^{* *}$ & -3.12 * & & .104 & .040 & & -.240 * & .146 & \\
\hline & & & Chinese & -1.28 & -2.45 & & .619 & -.444 & ** & -.966 & .353 & \\
\hline & & & Turkish & $-1.11^{* *}$ & -1.97 & ** & $-.018^{* *}$ & .122 & & -.032 & .017 & \\
\hline & & $\frac{3}{a}$ & Moroccan & -1.44 & -3.64 & ** & .301 & .923 & & .010 & .117 & \\
\hline & & $\frac{\pi}{2}$ & Surinamese & $-2.17^{*}$ & -1.23 & & .268 & -.024 & & -.081 & .325 & \\
\hline & & 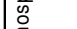 & Antillean & -1.93 & -2.16 & & .269 & -.233 & & -.049 & -.256 & \\
\hline & & & Chinese & 1.20 & .979 & & .174 & -.640 & ** & -.205 & 1.10 & \\
\hline & v & & Turkish & - - & $-1.94--$ & & .398 --- & $.394 \quad--$ & & - & - -383--- & \\
\hline & $\stackrel{v}{\tilde{\Sigma}}_{-}$ & $\mathscr{\infty}$ & Moroccan & $-1.08--$ & $-2.50--$ & & .524 --- & 1.10 & & $-.433--$ & .326 --- & ** \\
\hline & 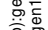 & $\stackrel{ \pm}{\frac{c}{0}} \cdot \frac{0}{2}$ & Surinamese & -1.72 --- & $-2.19--$ & & .248 --- & .116 --- & & .018 --- & - & \\
\hline & 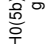 & 疍㐫 & Antillean & $-2.29--$ & $-1.92---$ & & $123---$ & $-.083--$ & & .050 --- & $-.415--$ & *** \\
\hline
\end{tabular}

Notes: The table displays the composite coefficients (base plus interaction coefficients) of first and second generation migrants for each independent variable relevant for hypothesis testing. All regressions include the variables of the base+ models with the exception of the regressions for migrant business concentration, which include the variables of the base++ models. The interaction regressions were run separately for each of the following variable groups: citytop4, concentration, firm concentration, employment and wage level (ln), sector dummies. The Hausman test rejects the OLS specifications in favour of the RE ones in all regressions at the.1\% significance level suggesting the presence of unobserved individual heterogeneity corrected for in the RE specification. Welch unpaired means comparison test scores identify intergenerational differences in coefficients for each origin group. One and two asterisks behind composite coefficients indicate rejection of stated $\mathrm{H} 0$ for hypotheses $2 \mathrm{a}$, $3 a, 4 a, 5 a$ at $10 \%$ and $5 \%$ significance levels respectively. One and two asterisks in Welch-t columns indicate rejection of stated $\mathrm{H} 0$ for hypotheses $2 \mathrm{~b}, 3 \mathrm{~b}, 4 \mathrm{~b}, 5 \mathrm{~b}$ at the $10 \%$ and $5 \%$ significance levels respectively. Sensitivity checks carried out by running means comparison tests with assumption of equal group variances supported stated findings. Variable definitions are found in the appendix. Source: Netherlands Bureau of Statistics SSB 1995-2004, own calculations 
From the 1960s onwards, many Western European countries changed from emigration countries to immigration countries. Today, migrants form a substantial part of their populations. In the case of the Netherlands, nearly one out of five residents has a migrant background, of which the so-called second generation is rapidly increasing in size and economic importance. The presence of this latter group is increasingly visible in the self-employment landscape, but these new entrepreneurs are largely neglected by the literature. As a consequence, while migrant entrepreneurship in general has already been studied extensively (Light 1979, Light et al. 1985, Portes \& Bach 1985, Raijman \& Tienda 1999, Renzulli, Aldrich \& Moody 2000, Kloosterman et. al. 1999), little is known about its intergenerational dynamics. In particular, studies based on representative longitudinal samples are missing. This study takes a first step in the direction of closing this gap in the migrant entrepreneurship literature.

\section{Intergroup differences}

One of our most striking findings is that the five migrant origin groups investigated roughly divide into three clusters according to their history of migration to the Netherlands. The clusters identified in this chapter were coined 'labour migrant entrepreneurs' originating from Turkey and Morocco, 'colonial migrant entrepreneurs' originating from the former Dutch colonies of Suriname and the Dutch Antilles and Chinese entrepreneurs, who came from China and Southeast Asia to the Netherlands to escape economic hardship and political persecution.

The differences between the clusters manifest themselves in the nature of the business start-ups (see also Rusinovic 2006, Van den Tillaart 2001, EIM 2004) as well as business success. Notably, labour-migrant entrepreneurs are underrepresented in more promising business sectors and are generally less successful than colonial migrant and Chinese entrepreneurs. But what could explain these differences between the clusters?

Over the past few decades, the Dutch economy has evolved further in its development towards a fully-fledged service economy. Changing market demands have compelled new and established entrepreneurs to adopt a new business orientation in order to seize business opportunities in the promising services sectors and remain competitive. In order to capitalize on these new business opportunities, entrepreneurs need to possess higher levels of human capital and business-specific and country-specific cultural skills than were required in the traditional migrant sectors. In this regard, social integration becomes essential for providing the link between supply and demand, explaining why some groups of 
migrants characterized by lower integration levels (i.e. labour migrants), are less represented in the services sectors than other groups (i.e. colonial and Chinese migrants), and also appear less successful in business.

More specifically, a number of notable integration-related differences were observed between the migrant origin clusters. Integration was defined in terms of (1) the degree of cultural distance to the receiving society, (2) the degree of coethnic group identification, orientation and self-sufficiency, and (3) the mean educational and labour market outcomes. Regarding the first, the origin groups differ in their degree of cultural distance to the receiving society, which affects the ability of entrepreneurs to access and service mainstream markets. Among the origin groups, the cultural distance to the receiving society is larger for the clusters of labour and Chinese migrants than for colonial ones. Migrants of the latter group were already exposed to the Dutch culture and language, which was one of the official languages in their countries of origin. Suriname was ruled by the Dutch from 1667 to 1975 and the Dutch Antilles are still attached to the Kingdom of the Netherlands but partially independent. Although the Surinamese and Dutch Antillean cultures differ from the Dutch one, in the course of a long joint history the Dutch culture has put its stamp on the former colonies and the Dutch have learned to understand and appreciate the cultures of its colonies; this has resulted in notable proximity between the Dutch, Surinamese and Dutch Antillean cultures today.

Regarding the second factor, the origin clusters differ in their degree of co-ethnic group identification, orientation and self-sufficiency. The labour migrant cluster is known for its high level of group identification and orientation, reinforced by shared religious norms. Moreover, as labour immigrants, members of these groups usually maintain strong bonds with family and friends remaining in the home country, and many of them spend time in their home countries every year. Furthermore, as the close-knit Turkish and Moroccan communities are rather large and centred around the major cities, they have acquired a higher level of local selfsufficiency than the other origin groups. This is reflected in the large number of Turkish and Moroccan cultural associations, but also in the local business landscapes of urban migrant neighbourhoods, which accommodate many firms serving specific needs of these co-ethnic communities. The firms of labour migrant entrepreneurs tend to be located in areas of higher local co-ethnic concentration than is the case for the other origin clusters; this may have negative implications for firm development prospects, as our findings on Hypothesis 4.3a have indicated that increased local presence of the co-ethnic community negatively affects firm profitability and survival rates of migrant businesses. The Chinese community is also known for its strong group identification and orientation, but is less selfsufficient due to its smaller group size and greater residential diffusion. Also, the 
own-group orientation has notably decreased from the first to the second generation as the latter possesses near-native language skills and maintains intensive social relations with the Dutch. Finally, in the case of colonial migrants, the co-ethnic group identification and orientation is rather low compared to the other origin groups. This can be explained by the groups' cultural and linguistic proximity to natives, which facilitates social interactions and results in a blurring of inter-group boundaries.

Regarding the third factor, the three clusters also differ with respect to their mean educational achievements and labour market outcomes. The labour migrant cluster, which experiences the largest educational and labour market disadvantages vis-à-vis natives, also turns out to be generally least successful in business and most confined to traditional low-skill migrant sectors. In the case of the colonial origin cluster, migrants' educational achievements are similar to the ones of natives, but despite this, the groups' labour market disadvantages persevere and, likewise, the business success of entrepreneurs is lower. Thus, the findings for both origin clusters indicate that self-employment is not a better route for upward social mobility than the paid labour market. Finally, the Chinese migrants are an exceptional case. When the first generation came to the Netherlands, most of its members became self-employed (see Table 4.2) and their children did exceptionally well in the educational system (see also Vogels et al. 1999). The second generation even surpasses natives' educational and labour market success and has business success on par with natives. Strikingly, business success for Chinese entrepreneurs in the group's traditional commercial activities (specialty restaurants, international trade) remains higher than in the generally more promising services sectors. This indicates that the group is effectively maintaining its competitive edge in its well-established and highly profitable niche markets. At the same time, many members of the second generation successfully start-up businesses in the services sectors, enabled by their high levels of education and training.

\section{First and second generation differences}

Given that the second generation is overall much better integrated in the host society, we do not find clear evidence that this generation has translated this advantage into business success. This chapter rather suggests the existence of quite different paths of intergenerational evolution in line with the segmented assimilation theory that seem promising for the Chinese and possibly colonial migrant groups, but less so for the labour-migrant groups. The standard neoclassical assumption that higher levels of human capital lead to higher earnings does thus not hold across the board, nor are higher levels of socio-cultural and structural integration a proven success factor for achieving greater economic success for immigrant entrepreneurs. 
The literature on self-employment determinants of migrants might provide a possible explanation for this puzzling finding. Clark \& Drinkwater (2010) found a negative correlation between educational attainment and self-employment propensities of migrants in the UK, which suggests that for higher-educated groups of migrants, self-employment has become less attractive as compared to salaried employment, whereby the former becomes a fall-back strategy attracting more individuals who do not manage to find suitable jobs. This group compositional difference between first and second generation migrant entrepreneurs might explain why, despite higher levels of human capital and hostcountry specific skills, the second generation is not more successful in business than the first generation. At the same time, some migrant groups as for instance the Chinese, are known for their entrepreneurial acumen, which seems to be handed down through the generations. Given this, it is plausible that the secondgeneration Chinese group of entrepreneurs includes relatively many highly educated people, who have chosen to become entrepreneurs to seize business opportunities in promising markets in line with the argumentation by Wilson et al. (2007) and Arenius \& De Clercq (2005).

One promising intergenerational trend is clearly visible, namely that the second generation generally tends to operate in more promising industry sectors. However, these sectors are also more dynamic, exposing entrepreneurs to higher vulnerability for business failure, especially those possessing lower levels of business and cultural skills. The divergent intergenerational trends between the origin clusters are best illustrated by the stark contrast between the groups of labour migrant and Chinese entrepreneurs. The second generation labour migrants - more so than other second generation groups - follow in the footsteps of their parents, establishing businesses in the same industries and in the same areas. Their higher integration enabled them to set up businesses with better survival prospects, but not to achieve higher growth or profitability. This suggests that in practise, entrepreneurship turns out to be a minimum income generation or unemployment avoidance strategy rather than a path towards socio-economic mobility. In contrast, the integration achievement of second-generation Chinese migrants allowed them to go beyond their parents' careers as owners of small and low-budget Chinese restaurants (see also Van den Tillaart 2001, EIM 2004). Many second-generation Chinese entrepreneurs have managed to set up businesses in other sectors including business services and seem to have done so successfully. Given the fact that the Chinese second generation is younger than its counterparts from other ethnicities and many of its members pursue university education, we might have even underestimated their entrepreneurial success. 
A somewhat puzzling finding of this study is that, against our expectations, the second generation groups of entrepreneurs show lower rates of firm growth than the first generations. However, after further reflection, it seems that this may be the outcome of more formalised recruitment practises of the second generation groups of entrepreneurs (see Rusinovic 2006). This increases costs and complexity of hiring procedures and thus reduces incentives of entrepreneurs to take on more staff.

The question remaining is why, given their better integration, the second generation is not universally more successful than the first generation. Two possibilities are firm age and selection effects. Our sample covers the years 1999 to 2004. Thus most of the firms from first generation migrants are probably larger and more well-established firms, while the second generation firms include relatively more start-ups. Unfortunately, we could not include a control variable for firm age as such a variable correlates in a panel model highly with the entrepreneur's age.

Another reason can be found in the large differences in education. While Chinese migrants often obtain a university degree, Turkish and Moroccan migrants are more commonly among the early school-leavers. Accordingly, second-generation Chinese entrepreneurs have much better start-up conditions (educational qualifications) than their Turkish and Moroccan counterparts, who began selfemployment at younger age and with less education.

Yet another reason explaining the many insignificant intergenerational findings relates to the large variation of entrepreneurial outcomes within the second generation groups of entrepreneurs, which is substantially larger than for the first generation. It is likely that the large diversity among the former groups is caused by integration-related factors at the entrepreneur level, which could not be captured in this study. Future research should aim to further explore this intragroup variation by identifying relevant integration-related (or other) aspects causing this trend and conducting thorough comparisons between resulting subgroups of entrepreneurs.

Finally, differences in entrepreneur motivations may also explain the small differences between the first and the second generation. Performance indicators may not adequately measure entrepreneurship across the generations as secondgeneration entrepreneurs are likely to have a more long-term business orientation while first generation ones are more short-term-profit oriented. This can be explained by the groups' age differences and their position in the business cycle. Since first generation entrepreneurs are considerably older, they tend to be less inclined to invest in the sustainability of their firms. In contrast, for second generation entrepreneurs the payoffs of long-term investments would be greater. However, in the second group's case, the sacrificing of short-term profits in 
exchange for long-term benefits cannot be captured adequately in the outcome figures due to the relative young age of the firms.

\section{Limitations}

Before we continue with the concluding discussion in Section 4.7, we would like to mention some of the study's limitations. First, despite the many advantages of the government data used for our analysis, naturally it also has its limitations. To obtain the base dataset for our analyses, several administrative records were merged, which resulted in the loss of many observations as individuals are no longer found across all data sources. In this context, particularly the selfemployment data source contains much missing variable information as regards the variables firm location, size, industry sector and annual profits. While this missing information was inferred from records of other years whenever possible, unfortunately it still resulted in the exclusion of almost 50 per cent of the observations. Fortunately, given the relatively random nature of the distribution of missing observations across the relevant subpopulations of this study, reducing the dataset to the observations with fully available information on all variables did not reduce the representativeness of the data.

Another issue of concern relates to the face validity of the variables. The variables describing the environment (i.e. average wage, migrant concentration) were defined at the municipal level. It is, however, questionable whether the whole city is the relevant social environment. Especially for larger cities the relevant social environment is probably the district. Given that districts within larger cities are rather heterogeneous, the variables at the municipal level provide rough indications of the local business environments at best. With respect to our dependent variable, the three selected performance indicators are a widely used set of indicators, but they focus on financial aspects of performance and neglect nonfinancial aspects such as motivation and satisfaction. Thus, dissimilarities between first and second generation entrepreneurship could also be caused by different priorities of older and younger entrepreneurs. It is possible that the second generation may strive for a divergent set of business targets than the first generation, being - as some evidence has suggested - for instance more long-term oriented and thus willing to sacrifice current profits for future growth prospects.

Finally, in our analysis we were also unable to open the black box between integration and business success, which was greatly a consequence of data unavailability with regard to integration-related variables incorporable in our analyses. We tried to remedy this shortcoming as best as we could by collecting relevant integration information on the first and second generations of the five origin groups. As no information was available specifically for migrant entrepreneurs from these groups, we had to rely on general integration information that was known for the groups from prior research (as is presented in 
Table 4.3). Moreover, in the interpretations of our findings, we used this information by making the implicit assumption that integration characteristics of the groups of the self-employed are comparable to the characteristics of the corresponding migrant populations as a whole. This is perhaps somewhat unrealistic as it is likely that the self-employed are more resourceful than other members of society to be able to actually take the step towards self-employment. More data on integration characteristics of the self-employed and further analysis is needed to gain a more thorough understanding of the underlying processes and conditionality mediating the relationship between integration and economic business success.

\section{7 - Conclusion}

This study investigated the relative importance of integration for successful migrant entrepreneurship. The results show that entrepreneurship is not an independent route towards gaining socio-economic mobility bypassing formal requirements of the regular labour market: opportunities in the salaried labour market are important determinants not only of self-employment decisions (i.e. Barrett et al. 1996, Clark \& Drinkwater 2000, Constant \& Zimmermann 2006, Thompson et al. 2010) but also of business success of migrants. While for some migrants, self-employment may be a strategy to avoid unemployment, discrimination and/or blocked mobility in the regular labour market, for others it is a lucrative way to capitalize on unique human and/or social capital endowments. Thus, integration has an essential moderating role in matching supply and demand within the opportunity structure of entrepreneurs, as suggested by the mixed embeddedness framework. Moreover, it seems that integration facilitates entrepreneurial success only once a minimum threshold of integration is surpassed. This threshold also tends to increase over time in line with higher demands regarding occupational qualifications in the labour market. In this respect, (relative) migrant-to-native differences appear more important than (absolute) first to second generational changes indicating the presence of a marketdriven mechanism.

While integration - within the context of the mixed embeddedness framework - is an important determinant of migrant business success, it also is highly path dependent as integration varies greatly among migrant groups. There seems to be a clear connection between the migration motives and entrepreneurial success for three distinct migrant business profiles, which we coined 'labour migrant entrepreneurs', 'colonial migrant entrepreneurs', and Chinese entrepreneurs. These profiles reflect the heterogeneity across different migrant groups and may provide fertile grounds for future research aimed at better understanding the phenomenon of migrant entrepreneurship. 


\section{Chapter 5: Between entrepreneurs and business opportunities. The impact of the local built environment and zoning regulations on small businesses in the Netherlands ${ }^{54}$}

\section{1 - Neighbourhoods and opportunities for migrant businesses}

In his Magnum Opus, Postwar Europe; A History of Europe Since 1945, Tony Judt (2005) describes the emergence of a new social stratification in European cities after 1970. There is, of course, an upper class of highly paid professional workers in producer services and related industries, then there is a second tier of protected and privileged workers in the remaining manufacturing and in public services, and there is a fourth tier consisting of a growing underclass. Squeezed in between the second and the fourth tier is a third one consisting of '... small businesses and services-corner-store keepers, travel agents, tailors, electronics repairmen and the like - more often than not owned and staffed by immigrant communities or their descendants (Arabs in France, Turks or Kurds in Germany, South Asians in Britain) (Judt 2005: 738). Immigrant businesses illustrate the ever more visible footprints migrants are leaving in most Western societies giving a face to rising multiculturalism over the past decades (Kloosterman and Rath 2003). The rise of migrant entrepreneurship in many European cities encompasses many important issues; for instance to what extent entrepreneurship may contribute to upward social mobility or to the local economy. Exploring migrant entrepreneurship has become an important field of study itself covering a wide array of issues (Kloosterman and Rath 2003).

Below, we want to look at the hitherto rather neglected issue of the role of neighbourhood characteristics in determining the presence and survival rates of small businesses. Even if, on the one hand, aspiring entrepreneurs with suitable skills are there, and, on the other, a sufficient demand is also present (for instance due to a critical mass of co-ethnics in the neighbourhood), business start-ups may still be thwarted by the lack of appropriate business spaces. Without a sufficient supply of cheap and accessible business spaces neighbourhoods cannot function as incubators for small businesses. In our view, then, the availability of suitable

\footnotetext{
54 This chapter is based on the paper: Beckers, P. \& Kloosterman, R.C. (2010), “Between entrepreneurs and business opportunities. The impact of the local built environment and zoning regulations on small businesses in the Netherlands", Conference paper at the Annual Conference of the European Regional Science Association, Jönköping, August 2010.
} 
business spaces should be seen as an intervening variable between the supply side (the entrepreneurs and the resources that they bring with them) and the demand side or opportunity structure (Kloosterman 2010). Assessing the role of this availability thus generates further insights in how migrant entrepreneurship may contribute to upward social mobility of newcomers from less-developed countries (here also referred to as non-Western migrants). As these migrants are typically lacking in financial means, they are dependent on cheap and accessible business spaces. These spaces, moreover, should be located in or near residential areas given the predominant consumer orientation of many migrant businesses such as smallscale retail and restaurants and cafés.

Neither business spaces nor migrants are equally distributed across cities. Below, we will empirically test to what extent neighbourhood characteristics related to the built environment and the prevailing local regulations matter in determining the possibilities for small businesses. We hypothesise that these particular characteristics of neighbourhoods intrude in the matching processes between (aspiring) entrepreneurs and business opportunities (Ram and Jones 1998, Kloosterman and Van der Leun 1999, Burgess 1968, Fong et al. 2005). We expect that the physical spatial neighbourhood structures in combination with the local regulatory frameworks at least partly determine the availability of business spaces suitable for nascent (migrant) entrepreneurs who tend to lack financial resources.

To test this proposition, we compare two types of neighbourhoods in the Netherlands which may serve as contrast cases. On the one hand, we focus on older, pre-WWII neighbourhoods with relatively little functional separation between residential and commercial purposes (also called mixed neighbourhoods), and, on the other, on predominantly mono-functional, residential neighbourhoods built after WWII. We assume that mixed neighbourhoods offer more promising business prospects for businesses operating in the retail, small-scale wholesale, restaurants and catering industries combining good access locations with relatively cheap commercial prices (Jacobs 1961). As Ray Pahl (1984) stated, pre-WWII neighbourhoods have a greater 'getting-by potential' than post-WWII neighbourhoods, which are more suitable for independent professionals (Kloosterman and Van der Leun 1999).

The contrast between the two Dutch neighbourhood types provides a promising starting point to find out how the local spatial environment and its regulations may impact on local business prospects, especially those of migrant entrepreneurs. Addressing this question clearly transcends the Dutch case as in many other cities elsewhere neighbourhoods differ with respect to built environment and zoning regulations. Below, we will use both quantitative and qualitative methods to investigate the following research questions: 
1) What are the differences in terms of built environment and regulations between pre- and post-WWII migrant neighbourhoods?

2) Do pre-WWII neighbourhoods provide better conditions for local businesses than post-WWII neighbourhoods due to differences regarding spatial environment and regulations?

We start with a brief discussion of the relevant literature (Section 5.2). We then (Section 5.3) present the research methodology providing information on the neighbourhood selection procedure as well as on the collection and use of qualitative data. After that, we provide a succinct overview of the morphologies and the prevailing zoning regulations of the selected pre- and post-WWII migrant neighbourhoods (Section 5.4). This gives us the foundation to explore differences in business success of local firms in pre- and post-WWII migrant neighbourhoods and assesses research question two (Section 5.5). Finally, we highlight our main findings and dwell on their implications (Section 5.6).

\section{2 - Built environment and zoning: a neglected issue}

Many studies in the field of migrant entrepreneurship have focused on the 'supply side' factors explaining entrepreneurship by means of individual and ethnic group characteristics as well as social embeddedness of entrepreneurs (Light and Bonacich 1988, Portes and Sensenbrenner 1993). More recent studies added the demand side perspective investigating how going market conditions create opportunity structures and how migrant entrepreneurs have been able to exploit these opportunities (Waldinger et al. 1986, 1990). Kloosterman et al. (1999) extended the analytical scope further by incorporating the socio-institutional embeddedness of the national and local opportunity structures thus providing a framework for (inter)national comparative research (Kloosterman 2010). This study especially builds on the latter contribution by Kloosterman et al., the so-called mixed embeddedness framework, by investigating what role the local spatial environment and its regulations play in enabling or hampering small businesses in migrant neighbourhoods.

While researchers tend to become more interested in contextualizing their findings on migrant entrepreneurs thereby acknowledging how entrepreneurship is shaped by its environment, this quest has remained typically space less in the sense that migrant entrepreneurs are more or less "superimposed" on (urban) space instead of embedded therein (Ram et al. 2002). This is rather surprising, as local processes of restructuring of the urban economy in the closing decades of the $20^{\text {th }}$ century have impacted significantly on the opportunity structures creating new sets of openings for small businesses. 
Rekers and van Kempen (2000) identified key dimensions along which urban neighbourhoods may differ regarding opportunities for migrant entrepreneurs: First, the demographic characteristics of neighbourhoods which partly shape both the potential supply of migrant entrepreneurs as well as the demand for their products. Second, in more indirect way, neighbourhoods may influence businesses through their built environment. Third, differences in local policies, rules, business regulations, support regimes, and, very important, zoning regulations pertaining may affect migrant entrepreneurs on a neighbourhood level (Ram et al. 2002). Here, we will focus on the built environment and the zoning regulations as we see these two as crucial intervening variables in the matching process between entrepreneurs and opportunities (cf. Rekers and van Kempen 2000).

Residential neighbourhoods, including migrant neighbourhoods, have become important incubation zones for small-scale businesses (Weterings et al. 2008, Schutjens et al. 2007). This is primarily the result of the steady increase of the local numbers of self-employed without employees, who have chosen to start and operate their firms from the entrepreneurs' homes (Schutjens \& Stam 2003, Stam 2009). Increased outsourcing of business activities by large firms, the economic shift towards business services and ICT, the rise of internet commerce, and growing flexibility of labour contracts have made home-based business a viable business model (Wennekers et al. 2008). As operations of these entrepreneurs often require little more than a desk and a computer, operations from home imply significant savings on accommodation costs (Schutjens et al. 2007, PBL 2010). The importance of neighbourhoods as incubation zones also holds for migrant entrepreneurs who are usually dependent on cheap business spaces nearby in their own neighbourhoods. As migrants are clustered in particular neighbourhoods, the characteristics of the built environment and the zoning regulations of "migrant neighbourhoods" are thus worthwhile to investigate.

The migrant neighbourhood affects business prospects (commonly measured in terms of firm growth or firm survival) of small-scale firms as it forms the local production environment. The term production environment conceptualizes the large number of firm-external factors impacting on business functioning (Buit 1965, Lambooy 1997). While acknowledging that local business dynamics depend greatly on firm-specific characteristics (Garnsey 1998, Bridge et al. 2003, Tamasy 2006) as well as urban and regional characteristics (Porter 1998, Stuart \& Sorenson 2003, Audretsch \& Dohse 2007), the neighbourhood as local production environment does affect local business dynamics, namely business behaviour and development prospects as well as firm mobility as was concluded in a recent study by the Netherlands Environmental Assessment Agency (PBL 2010). 
The PBL (2010) study outlines a number of location factors that affect business functioning at the neighbourhood level in theory and empirically tests the effects of a number of related characteristics. It identifies the following relevant local dimensions based on existing literature: accessibility and parking (Hagens et al. 2009), local market prosperity - especially important for consumer services businesses catering largely to local needs (Bulterman et al. 2007, Ouwehand \& Van Meijeren 2006), local liveability (Wilson 1987), the presence of certain local amenities and other economic activities (McCann \& Folta 2008, Florida 2002, Weterings et al. 2009) and last but not least the availability, quality, size and representativeness of local business spaces (Aalders et al. 2008).

Although business dynamics are by and large determined by internal firm factors, such as the skills and the resources of the entrepreneurs, neighbourhood characteristics do also play a minor role. They are found to affect survival chances, especially for businesses in consumer services and non-services, but seem to have no notable impact on firm growth. Neighbourhood liveability characteristics matter - as, for instance, a high incidence of crime -may reduce firm survival chances as customers stay away and costs rise. This is especially the case for businesses operating in consumer services, but negative liveability factors as decay of the built environment, vandalism, and dirty public spaces, may also negatively affect business services firms for whom a good neighbourhood image is important (See also Aalders et al. 2008).

Dantuma (2007) concludes that the lack of cheap commercial floor space is one of the main bottlenecks for growth of small and medium enterprises (SMEs) in the Netherlands. According to a survey among 1,700 SMEs, those entrepreneurs who are not satisfied with their business space also consistently score worse on sickleave, personnel turnover and customer base growth. In this study, useful suggestions to tackle these problems are put forward, such as the promotion of functional mixing of residential and commercial building spaces in residential neighbourhoods as well as more business friendly local zoning regulations. The present regulatory local regimes are, according to this study, often too restrictive regarding the use of spaces for commercial purposes and, in addition, typically involve lengthy procedures. Moreover, municipalities can use local spatial regulations to ban less desired commercial activities and apply strict conditions for granting construction- and environmental permits (Dantuma 2007).

An additional aspect of the local production environment that is well explored in the migrant entrepreneurship literature but little in the more general entrepreneurship literature is the local social embeddedness of entrepreneurs (Light and Bonacich 1988, Portes and Sensenbrenner 1993, Rusinovic 2006). While prior studies discuss the relevance of migrant entrepreneurs' social embeddedness 
in co-ethnic networks for business success, little is known as to whether the local social context in general (i.e. neighbourhood professional and private relations with residents, businesses, local government etc.) matters. The literature in the field of urban sociology provides useful guidance in this regard. It established that certain neighbourhood characteristics like population homogeneity and the presence of amenities may positively affect social cohesion, which in turn likely impacts on neighbourhood social and physical order (Sampson et al. 1997, Voelker et al. 2007, Musterd \& Andersson 2006). Thus, the local social context is also relevant to shape local business success of firms (See also Aalders et al. 2008).

\section{3 - Methodology}

To investigate how the neighbourhood spatial environment and its regulations shape development prospects of local firms in pre- and post-war migrant neighbourhoods, the study follows an exploratory research approach combining quantitative and qualitative methods. The study compares two contrasting types of migrant neighbourhoods, namely pre-WWII and post-WWII neighbourhoods, with rather different spatial morphologies. Pre-WWII neighbourhoods were built as mixed residential and commercial purposes, while post-WWII neighbourhoods were primarily designed for residential purposes thereby adhering to the then dominant modernist view of spatially separating living and work environments. We expect that these differences are likely to manifest themselves also in the local zoning regimes, which in turn partly shape local business prospects of native and migrant entrepreneurs alike. To explore potential differences between these neighbourhood types further, we have selected five pre-war and post-war migrant neighbourhoods.

\subsection{1 - Neighbourhood selection}

The neighbourhood selection procedure, as outlined in this section, adheres to a number of methodological and practical considerations, which ensure that the study is methodological valid as well as implementable in practise. First, from all Dutch neighbourhoods we select those that are most relevant to answer our research question. For this purpose we used the following neighbourhood selection criteria: ${ }^{55}$

\footnotetext{
55 The neighbourhood selection is based on data available by CBS on all neighbourhoods in the Netherlands. The neighbourhood does not correspond perfectly with the geographical units used in our study and originating from the Chamber of Commerce business register (i.e. 5 digit postal code areas), but this is the best information source that is available to us and the approximation is fairly accurate.
} 
1. As we aim to study non-Western migrant entrepreneurs and as they are strongly concentrated in the four largest Dutch cities (Amsterdam, Rotterdam, The Hague, Utrecht), we focused on neighbourhoods located in these four cities.

2. As we are specifically interested in residential neighbourhoods, we tried to exclude non-residential (commercial) neighbourhoods. These are as follows:

a. Neighbourhoods need to have a minimum of 10 private households per hectare built-up area.

b. The number of private households needs to be at least five times larger than the number of firms.

3. We only look at neighbourhoods with high shares of non-Western migrant population by sorting all neighbourhoods in the four largest cities on their shares of non-Western population and then select the top one-third of the distribution. We define these neighbourhoods with high non-Western residential concentrations as migrant neighbourhoods.

4. Finally, to reach our interview targets with native and non-Western entrepreneurs, we need to dispose over a sufficiently large population of potential interview candidates in the neighbourhoods. To achieve this goal and due to financial constraints, we are pushed to focus our study on neighbourhoods with a minimum of 50 firms $^{56}$.

The above selection procedure yielded 93 migrant urban neighbourhoods that are favourably suited for our analysis. As this study opts for a matched-pairs case study design comparing pre- and post-war migrant urban neighbourhoods, next, we need to ensure the methodological validity of the research. We have to find a number of pre- and post-war neighbourhoods (at least one for each group) that can be seen as 'typical' representatives of the remaining 93 migrant urban neighbourhoods. This means that these neighbourhoods are required to have characteristics that are about average of the characteristics of the 93 migrant urban neighbourhoods. To identify such 'typical' neighbourhoods, we conduct a neighbourhood comparison for these 93 neighbourhoods on basis of relevant characteristics available from the Dutch National Bureau of Statistics. These characteristics are as follows:

1. Socio-economic population composition (variables 1-9):

a. Share of residents per age groups (age groups 0-15, 15-25, 25-45, 45-65, $65+)$

b. Household size (number of persons per household)

c. Share of non-Western population

${ }^{56}$ Acknowledging that this is likely a limitation of our study, the financial resources available for our study largely restrict the number of neighbourhoods to be investigated. 
d. Share of population aged 15-64 working or self-employed

e. Mean income per resident (in Euros)

2. Neighbourhood dynamics (variable 10):

a. Movers per 1,000 residents

3. Commercial characteristics (variables 11-14):

a. Distribution of firms per sector (\% in industry, $\%$ in business services, $\%$ in personal services)

b. Mean value of housing (in Euros)

The comparison of the 93 migrant neighbourhoods yielded five 'typical' neighbourhoods which can be seen as representative of the population in terms of socio-economic population composition, neighbourhood dynamics, and commercial characteristics. For all of the 14 observed variables listed above, the mean scores of the five selected neighbourhoods fall within one standard deviation of the overall population mean of the 93 neighbourhoods (Please refer to Figure 5.A1 in the Appendix for further details). ${ }^{57}$ We have, hence, according to these findings based on available neighbourhood information, selected neighbourhoods which can be seen as representative of our target group of migrant urban neighbourhoods. These selected neighbourhoods include three pre-war type neighbourhoods and two post-war type ones, namely:

1. Overvecht-Neckardreef (Post-war neighbourhood).

2. Moerwijk-West (Post-war neighbourhood).

3. Indische Buurt-Oost (Pre-war neighbourhood).

4. Regentesse-/Valkenboskwartier-Zuid (Pre-war neighbourhood).

5. Oosterparkbuurt (Pre-war neighbourhood).

\subsection{2 - Data collection and use}

We have opted for a combination of quantitative and qualitative methods. First, we quantitatively compare the local business structures and dynamics (total firms, neighbourhood movers, and firm failures per sectors) across the pre- and post-war neighbourhood clusters for the period 2005-2007. This comparison is conducted on data compiled by the local chambers of commerce for their trade register. These data are available on a 5-digit postal code level ${ }^{58}$. While these data have their limitations, as they are not collected for scientific purposes, prior research (Suyver \& Kwie, 1998, Van den Tillaart, 2001) has shown that they are fairly reliable as more than $90 \%$ of immigrant businesses are registered with the regional chambers

57 This was not the case for any of the other 93 neighbourhoods.

585 digit postal code areas vary in size depending on population density, but generally are of dimension 200x200 metres. 
of commerce. ${ }^{59}$ This high coverage results from the legal obligation of business owners in the Netherlands to register with the chambers of commerce within two weeks of business start-up as well as with the annual income-reporting requirement. These quantitative findings furnish a robust foundation for further qualitative analysis of the local business settings in the neighbourhoods.

Second, we review the zoning regulations of the neighbourhoods as stated in the neighbourhood development plans ('bestemmingsplan'). These documents provide a rich source of information including the regulatory aspects determining spatial use in these neighbourhoods.

Third, we draw on qualitative primary data collected in eight focus group discussions with neighbourhood experts as well as 40 interviews with local native and non-Western entrepreneurs. These data were collected in the period from April 2008 - March 2009 and provide us with in-depth descriptions of the local spatial environments and business settings, local institutional arrangements and levels of social cohesion, as well as the perceptions and experiences of the entrepreneurs. The eight focus group discussions were held with four to six experts per session. From a total of eight sessions, we conducted five focus groups with local experts of the selected neighbourhoods and, in addition, three general focus groups with experts on immigrant entrepreneurship/local economy who are not directly related to a specific neighbourhood. Discussions focus on the local neighbourhood economy in general and local migrant entrepreneurship in particular, opportunities and challenges thereof and local initiatives to foster entrepreneurship. To ensure that our group interviews would generate wellinformed discussions on the subject, we invited local experts from a variety of professional backgrounds, such as local administrations, community centres, cultural organisations, business consultancies, police stations, housing associations, financial institutions, and academia. To actually obtain the targeted number of suitable experts, we posted questionnaires to 700 experts to screen their relevant experience for our research purposes and decide upon their potential participation in the focus group discussions.

Next to the focus group sessions, we conduct 40 face-to-face interviews with local entrepreneurs ${ }^{60}$, eight in each of the five neighbourhoods. In order to be able to examine possible differences between native and non-Western entrepreneurs, we engage four native and four migrant entrepreneurs per neighbourhood, half of which operate firms that were relocated to other neighbourhoods and half of

\footnotetext{
59 Please refer to Van den Tillaart (2001) for a more in depth discussion of this data.

${ }^{60}$ Entrepreneurs who live in or nearby the neighbourhood where their firms are located or were living there at the point when the firm started in the neighbourhood.
} 
which operate firms that remain in the neighbourhood. ${ }^{61}$ The latter division is made to tackle the problem of positive selection bias in our neighbourhood evaluations, as firm stayers tend to overstate the positive aspects of their local production environment.

5.4 - The built environment and zoning regulations in pre- and post-war migrant neighbourhoods

\subsection{1 - Building history and general characteristics of neighbourhoods}

\section{Pre-war neighbourhoods}

The three selected pre-war neighbourhoods, Regentesse-/Valkenboskwartier-Zuid (The Hague), Indische Buurt-Oost and Oosterparkbuurt (both Amsterdam) were built in the period 1880-1920 and belong to the set of older urban neighbourhoods on the periphery of the city centres. They were designed for mixed residential and commercial purposes whereby the former was prioritized over the latter. This is reflected in the built environment of the neighbourhoods, which are mostly suitable for housing but also allow for (small-scale) businesses in dedicated spaces. The dwellings are characterized by overall uniform height of around 10-15 metres (3-5 floors) in most parts of the neighbourhoods giving the areas a clearly residential appearance. Several buildings were constructed specifically for nonresidential purposes (i.e. corner stores) offering higher ceilings, larger windows and/or separate entrances. The neighbourhoods have seen similar phases of population growth and decline. In the period between the two World Wars, they attracted mainly working-calls families. After the post-war reconstruction period, the neighbourhoods witnessed a population decline with the rise of mass carownership in the 1960s and the shifts in housing preferences towards newly built (suburban) neighbourhoods with more open spaces.

This population decline was reversed from the late 1980s onward by the inflow of migrants from less-developed countries - "guest-workers" who were looking for larger housing to accommodate their families who had come to the Netherlands as part of the family reunion schemes, migrants from former Dutch colonies, political refugees and asylum seekers. These migrants filled many of the vacancies in the local housing markets and transformed the face of the neighbourhoods from predominantly white working-class neighbourhoods to their current multi-cultural character.

\footnotetext{
${ }^{61}$ As geographical information on business locations originates from the KvK Handelsregister, where locations are recorded by postal codes, we define neighbourhood movers as businesses that relocated to another postal code ( 5 digit level) in the period 1 January 2005 to present.
} 
Today, these neighbourhoods are part of the so-called 'problem neighbourhoods', a group of urban neighbourhoods characterised by high levels of poverty and crime and low level of labour market participation and social cohesion, singled out by the Dutch government for integral neighbourhood improvement schemes. Urban renewal efforts, which were launched in the early 1970s, improved the quality and attractiveness of the built environment by constructing new housing and renovating existing dwellings as well as by the restyling of public spaces. Also, part of these urban renewal schemes was the refurbishing of spaces for commercial activities by means of ground floor building expansions and alterations, and the establishment of designated shopping streets and commercial zones.

\section{Post-war neighbourhoods}

The two selected post-war neighbourhoods Moerwijk-West (The Hague) and Overvecht-Neckardreef (Utrecht) were built in the period 1950-1970 and are situated at some distance (3-4 kilometres) from the city centre. They were built to meet the strong demand for sub-urban housing with generous provisions of open spaces. Only a minimum of commercial spaces was realised, reserved for local firms meeting residents' everyday needs. Furthermore, a clear spatial separation between residential and commercial spaces was implemented to ensure that business activities did not negatively affect the living environment. These spaces are almost exclusively located along the major roads on the edges of the neighbourhoods. The area design of these neighbourhoods stands out for its rightangled major roads, and relatively complex structures of middle to high-rise buildings (latter especially found in Neckardreef) separated by wide green strips. Initially, the neighbourhoods accommodated a predominantly native population, which - given the post-war housing shortage - was happy to find a house in the first place.

In the past two decades, these neighbourhoods had lost much of their appeal among the first residents and many of them left. As in pre-war neighbourhoods, a strong increase in the population originating from non-Western countries took place, a change that coincided with a decrease of the quality of housing and public space. Currently, these rather recent neighbourhoods are also part of the so-called 'problem neighbourhoods'. Urban renewal is now aimed at renovating and replacing a considerable share of the rather monotonous housing blocks in these areas. Renewal initiatives have, however, placed little emphasis on the creation of commercial spaces, which, hence, remain rather thin on the ground. 


\subsection{2 - Pre- and post-war neighbourhoods compared}

Salient differences can be found between the built environments and regulations of pre- and those of post-war neighbourhoods. How can these differences impact on businesses in these neighbourhoods?

With regard to the spatial environment, several notable differences between the two neighbourhood types are visible. First, while pre-war neighbourhoods were designed for mixed residential and commercial purposes, post-war ones were designed purely for residential purposes. This basic functional divide explains why on the one hand pre-war neighbourhoods dispose over numerous buildings especially constructed for small-scale business activities (i.e. offering higher ceilings, larger windows and/or separate entrances) while on the other hand in post-war neighbourhoods quality business spaces are scarce. A second clear difference is visible with regard to the spatial allocation of residential and commercial functions within the neighbourhoods. Although in both pre- and postwar neighbourhoods commercial activities are concentrated along the major roads, in the latter neighbourhoods the spatial separation between residential and commercial functions is far more salient. 'Visible' firms are with few exceptions located on the edges of the neighbourhoods with wide plantation strips keeping firms and residences apart. A third distinguishing feature between the two neighbourhood types relates to the local urban renewal initiatives carried out in recent years. While in pre-war neighbourhoods their focus has in part been on the creation and refurbishment of business spaces (i.e. ground floor expansions and alterations) and on attracting new firms to designated commercial zones, in postwar neighbourhoods the emphasis was rather on the renovation and replacement of monotonous housing blocks. Based on the above differences, it can be expected that firms in post-war neighbourhoods would be put at a disadvantage in terms of the quality and suitability of their local business spaces and would also encounter more difficulties to find adequate local business space to match their changing spatial needs. This might have negative implications for the firms' development prospects as their spatial use is likely suboptimal and could also result in higher firm mobility out of post-war neighbourhoods vis-à-vis pre-war ones.

Also the spatial regulations in pre- and post-war neighbourhoods differ considerably. In general, while regulations in pre-war neighbourhoods are rather supportive of commercial activities, the ones in post-war neighbourhoods do not appear so, especially not to non-neighbourhood oriented firms (not catering to the needs of local residents). First, in pre-war neighbourhoods local policy aims at combining residential and small-scale commercial purposes and permits homebased firm establishment throughout the neighbourhood. On the contrary, in postwar neighbourhoods local regulations are clearly directed at safeguarding the 
residential function of the areas leaving little space for firms and superimposing far-reaching restrictions on them. This also shows in the rigid distinction between residential and commercial purpose spaces, whereby the former may in principle be used exclusively for housing and not for home-based firms. A second significant divide relates to the scope of support for commercial activities. In pre-war neighbourhoods this scope is rather broad encompassing any small-scale business activities not harming the local living environment (by means of excessive noise, pollution, traffic). The policy aim is to safeguard local business spaces and stimulate business start-up activities. This is particularly visible in commercial concentration areas or shopping streets where planned multi-purpose spaces along major roads offer many business spaces on the ground floor level, spatial regulations are especially 'business-friendly' and firms are eligible for government subsidies. Spatial regulations in post-war neighbourhoods clearly have a more narrow scope of support for commercial activities as existing and new building spaces can in principle only be used by neighbourhood oriented firms. Moreover, business spaces in established shopping streets are reserved exclusively for neighbourhood oriented firms in the retail, hospitality and personal services sectors with minor exceptions in Moerwijk. A last point of distinction concerns the procedures for alterations in spatial regulations. In pre-war neighbourhoods appear to be relatively liberal, which entails that convertibility of spaces from residential to commercial purposes and between different commercial purposes can occur without much difficulty and in a timely fashion. In post-war neighbourhoods exemption procedures from spatial regulations appear stricter as exemptions are made on individual basis to allow non-neighbourhood oriented firms as well as partial use of residential spaces for home-based firms. Based on the above differences in spatial regulations, we expect that firms in post-war neighbourhoods experience the regulatory environment as more restrictive. Local government support is limited and entrepreneurs are likely disadvantaged whenever conflicts occur between the local residential and commercial functions as local policy clearly prioritizes the former over the latter. This in turn may have negative implications for firm development prospects, which may show up in less business success and/or higher firm mobility out of post-war neighbourhoods as compared to pre-war ones.

\section{5 - Business success of firms in pre- and post-war migrant neighbourhoods}

Above we have uncovered differences in local spatial environments and regulations between pre- and post-war neighbourhoods, we now this section investigates as to whether there is a connection between these observed neighbourhood differences and local business success of firms. Here we explore how the built environment and the zoning regime in pre- and post-war migrant neighbourhoods impact on local business success. We address this research 
question by combining the insights generated through the analysis of the data of the chamber of commerce trade register with the primary data collected in the focus groups and interviews. We then relate this evidence with the observations made above on the local built environments and zoning regimes. The findings of this section are presented in four parts. We start off with a short description of local commercial activities in pre- and post-war neighbourhoods followed by a discussion on firm survival rates. After that we examine the role of key firm location factors in determining business success. Finally, we dwell on other relevant aspects of the local production environment that may affect business success of firms in pre- and post-war neighbourhoods.

5.5.1 - A snapshot of local business landscapes in pre- and post-war neighbourhoods

The data of the chamber of commerce trade register provide a useful overview of neighbourhood business structures on a 5-digit postal code level ${ }^{12}$ as it contains details on total firms per sector of commercial activity and postal code area. It conveys information on whether and how business structures differ across the preand post-war clusters of neighbourhoods and enables us to draw first connections between potential differences therein and the underlying dissimilarities between the neighbourhoods' spatial environment and regulations.

Table 5.1 displays the commercial activities in the pre- and post-war clusters of neighbourhoods, which reveals striking inter-group variation. After controlling for size inequalities in building areas, it is clearly visible that pre-war neighbourhoods are home to more businesses than post-war neighbourhoods (55.4 vs. 30.7 firms per 10 hectare built-up area respectively). This is a first clear indication of the spatial use differences of the built environment between the two sets of neighbourhoods. On the one hand, post-war neighbourhoods are designed by and large for residential purposes and that leaves limited space for businesses. Pre-war neighbourhoods, on the other hand, were designed to combine both residential and commercial purposes and thus boast a considerably higher number of entrepreneurs.

Commercial activities are not only unevenly spread between the two sets of neighbourhoods, they are also unevenly distributed across sectors. In general, the differences between pre-war and post-war neighbourhoods are relatively lower for neighbourhood oriented sectors (including catering and hospitality, personal services and retail and repair) than for non-neighbourhood oriented ones (respectively 20.3 vs. 14.6 , and 35.1 vs. 16.1 firms per 10 hectare building area

\footnotetext{
62 See footnote 58 .
} 
respectively). We actually expected to observe an even clearer divide between the neighbourhood oriented and non-neighbourhood oriented figures as we expected far less non-neighbourhood oriented businesses in post-war neighbourhoods, since their neighbourhood development plans state that in principle the latter business activities are disallowed there, Apparently, local regulations of these areas are thus less restrictive to non-neighbourhood oriented firms than was assumed from the local development plans. The general picture of pre- and post-war neighbourhoods, then, is fairly clear: pre-war neighbourhoods are accommodating more businesses in general, and especially with respect to non-neighbourhood oriented ones. This is in part a consequence of the observed differences in the neighbourhoods' spatial environments and regulations.

Table 5.1: Total firms, sector and neighbourhood cluster distributions***

\begin{tabular}{|c|c|c|c|c|}
\hline total 2006 & \multicolumn{4}{|c|}{ pre- and post-WWII clusters } \\
\hline & \multicolumn{2}{|r|}{ pre } & \multicolumn{2}{|r|}{ post } \\
\hline business sector classification & total & $\begin{array}{l}\text { total per } 10 \mathrm{ha} \\
\text { building area** }\end{array}$ & total & $\begin{array}{l}\text { total per } 10 \mathrm{ha} \\
\text { building area }\end{array}$ \\
\hline neighbourhood oriented* & 350 & 20.3 & 124 & 14.6 \\
\hline$\%$ of neighbourhood total & \multicolumn{2}{|r|}{$37 \%$} & \multicolumn{2}{|r|}{$48 \%$} \\
\hline non-neighbourhood oriented & 603 & 35.1 & 137 & 16.1 \\
\hline$\%$ of neighbourhood total & \multicolumn{2}{|r|}{$63 \%$} & \multicolumn{2}{|r|}{$52 \%$} \\
\hline OVERALL & 953 & 55.4 & 261 & 30.7 \\
\hline
\end{tabular}

* Neighbourhood oriented firms operate in the sectors hotel \& catering, personal services, retail \& repair. All other firms are non-neighbourhood oriented.

** includes residential and commercial spaces as well as cultural and public facilities; data of neighbourhood built area stems from Netherlands Bureau of Statistics, Statline, 2009.

*** The agricultural sector is excluded from the display as entrepreneurial activities in this sector are very low to non-existing.

Source: Chambers of commerce trade register 2006, own calculations

\subsection{2 - Firm survival rates in pre- and post-war neighbourhoods}

Table 5.2 shows the shares of failed firms per total firms in the pre- and post-war clusters. We distinguish between neighbourhood oriented and non-neighbourhood oriented commercial activities. The figures are based on annual sector shares per neighbourhoods of multiple years as indicated in the table. Overall, the annual rates of failed businesses seem to be somewhat higher in post-war neighbourhoods than in pre-war ones ( 9.9 vs. 7.5 per cent of total firms respectively), a finding that is shared between both neighbourhood oriented and non-neighbourhood oriented sectors, but is greatly more pronounced in the latter sectors ( 9.2 vs. 8.5 per cent for neighbourhood oriented sectors and 10.2 vs. 7.1 per cent for non-neighbourhood 
oriented sectors respectively). These findings however ought to be interpreted with caution as the observed differences between the groupings are insignificant at the 10 per cent level due to the relatively small sample and considerable cross-sector variation within both neighbourhood clusters (the latter is related particularly to the sectors personal services and transport/storage/communication).

While we shall investigate differences between pre- and post-war neighbourhoods in more depth in the next section, we can here add quotes from pre- and post-war neighbourhood experts which point towards possible explanations of the observed differences in survival rates. The descriptions of these experts tend to be in line with the overall finding of the table that generally pre-war neighbourhoods offer better business prospects than post-war ones. As possible explanations experts name differences in the spatial design and regulations of the neighbourhoods putting firms in pre-war neighbourhoods at an advantage over those in post-war neighbourhoods on the grounds of higher vitality attracting customers and business-friendlier local regulations:

[pre-war neighbourhood expert] '[The neighbourhood] with its nice stores can be an incubation area for medium and small business... the firm growth of the Indische Buurt has not yet been proportional to the growth ... of the retail sector in general, and so the Indische Buurt is a sort pearl...'

[post-war neighbourhood expert] 'And you say cold redevelopment, but I say a municipality without policy... at the moment you see that a neighbourhood falls behind. But the neighbourhood can never fall behind by itself, ... because there are policy makers with a vision of what has to happen. But if you have no vision of what has to happen in the coming ten years then you have a problem. And economics, look at the municipalities, economics is a deserted department [of municipalities].'

The finding that pre- and post-war differences in survival rates are relatively smaller for commercial activities in the neighbourhood oriented sectors is somewhat puzzling at first sight. It is, however, a likely consequence of special market advantages of established firms in post-war neighbourhoods, namely low competition, which is the outcome of highly restrictive local regulations that can effectively cap the number of neighbourhood oriented firms to be accommodated in the area. This may boost local survival rates vis-à-vis those in pre-war neighbourhoods, where competition in the neighbourhood oriented sectors is fiercer according to a pre-war neighbourhood expert:

'There are many comparable stores, many greengrocery businesses, many butchers, many hair stylists... and I think that a great number simply has difficulties to survive.' 
Table 5.2: Mean ceased firms per total firms, per sector and neighbourhood cluster

\begin{tabular}{|c|c|c|c|c|c|c|}
\hline & (\% per total firms 2006) *** & \multicolumn{5}{|c|}{ pre- and post-war clusters** } \\
\hline & \multirow[b]{2}{*}{ business sector classification } & \multicolumn{2}{|c|}{ pre } & \multicolumn{2}{|c|}{ post } & \multirow{2}{*}{$\begin{array}{l}p \text {-value } \\
\text { (Welch } t)\end{array}$} \\
\hline & & mean & obs. & mean & obs. & \\
\hline \multirow{3}{*}{$\begin{array}{l}\text { annual ceased } \\
\text { (avg. years 2006-2007) }\end{array}$} & neighbourhood oriented & 8.5 & 18 & 9.2 & 12 & $>.1$ \\
\hline & non-neighbourhood oriented & 7.1 & 48 & 10.2 & 32 & $>.1$ \\
\hline & all sectors & 7.5 & 66 & 9.9 & 44 & $>1$ \\
\hline
\end{tabular}

* Neighbourhood oriented firms operate in the sectors hotel \& catering, personal services, retail \& repair. All other firms are non-neighbourhood oriented.

** P-values indicate significance levels of Welch's t-tests (assuming unequal variances and sample sizes) comparing means between pre- and post-war neighbourhood clusters.

*** The agricultural sector is excluded from the display as entrepreneurial activities in this sector are very low to non-existing.

Source: Chambers of commerce trade register 2006-2007, own calculations

5.5.3 - Firm location factors and business success in pre- and post-war neighbourhoods

In Section 5.5.2, we have identified a number of key location factors that likely affect business operations of firms in migrant neighbourhoods. We have grouped these factors in five blocks, namely local social embeddedness, cost saving potential, convenience, market potential, and firm spatial needs. Moreover, we have asked forty local entrepreneurs in pre- and post-war neighbourhoods to state how these firm location factors affect their businesses. Entrepreneurs were asked to rate the items' relative importance for business success and indicate how their business location in pre- and post-war neighbourhoods scores on each of these items. The responses of the entrepreneurs for the two questions are shown in Figures $5.1 \mathrm{a}$ and $5.1 \mathrm{~b}$ below. The combined presentation enables us not only to identify the relative importance of the various firm location factors, but also to see which factors are considered as business location advantages and which ones as disadvantages. This in turn can provide vital information on how these factors affect firm success.

Before contrasting pre- and post-war neighbourhoods, we would like to emphasise a number of general features of the selected migrant neighbourhoods as production environments. First, entrepreneurs rate all of the firm location factors except the neighbourhood ethnic population mix and the spatial expansion possibilities for the firm are seen as important for their business success, which underlines the relevancy of the chosen items. Factors relating to the neighbourhoods' market potential (neighbourhood cleanliness and safety, firm accessibility/available parking space) appear to be most important for firm success, but also the cost-saving potential (cheap business spaces) and convenience (firm proximity to the entrepreneur's home) are essential factors affecting success. 
Contacts with local residents are generally appreciated but seem to have little bearing upon business performance.

Figure 5.1a: Firm location factors and success: Entrepreneurs in pre-war neighbourhoods

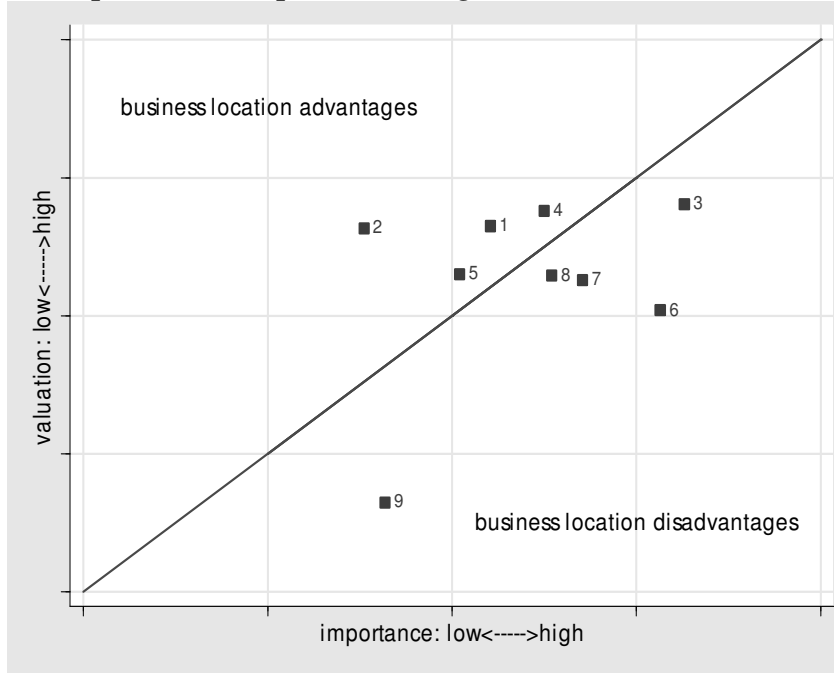

Firm location factors and success Local social embeddedness

1. Contacts with local residents

2. Ethnic population mix Cost saving potential

3. Low cost business space Convenience

4. Firm closeness to entrepreneur's home Market potential

5. Closeness customers

6. Neighbourhood cleanliness

7. Neighbourhood safety

8. Firm accessibility/available parking space Firm spatial needs

9. Firm spatial expansion possibilities

Figure 5.1b: Firm location factors and success:

Entrepreneurs in post-war neighbourhoods

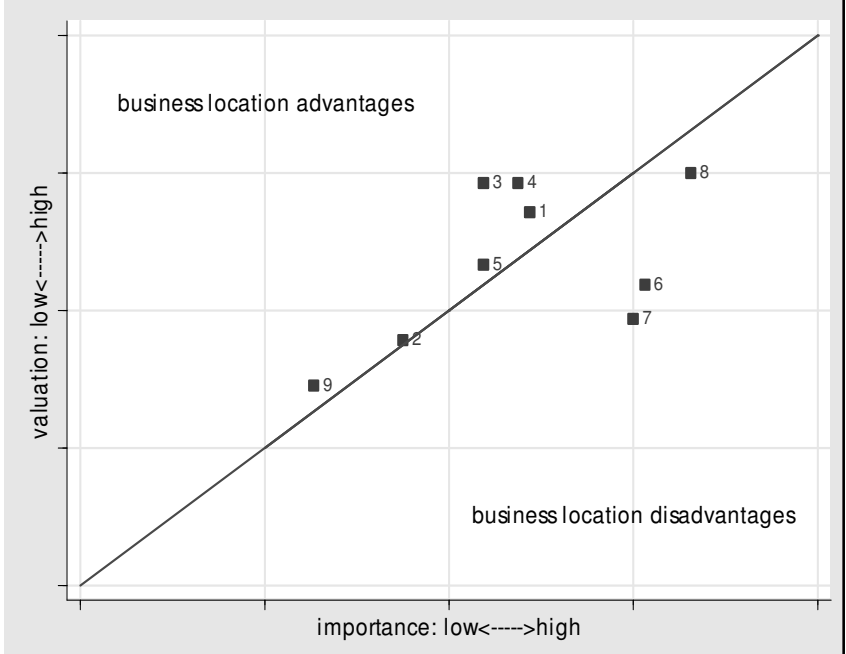

Firm location factors and success Local social embeddedness

1. Contacts with local residents

2. Ethnic population mix ${ }^{* *}$ Cost saving potential

3. Low cost business space Convenience

4. Firm closeness to entrepreneur's home

Market potential

5. Closeness customers

6. Neighbourhood cleanliness

7. Neighbourhood safety

8. Firm accessibility/available parking space

Firm spatial needs

9. Firm spatial expansion possibilities

Notes: ${ }^{*}, * * * * *$ indicate differences in means of business location advantages between pre- and post-war neighbourhoods significant at the $10 \%, 5 \%$ and $1 \%$ level respectively. A scale from 1 to 5 is used for both importance and valuation, whereby 1 is the lowest and 5 the highest score.

Source: Own interviews with 40 entrepreneurs 2008-2009 
It is not surprising that entrepreneurs consider factors relating to the neighbourhoods' market potential as most important for firm success as the neighbourhood image, cleanliness, and security situation affect the decisions of (potential) customers to visit these areas. The value of an attractive physical neighbourhood environment for business success is further demonstrated by the following quotes of migrant neighbourhood experts:

'But not qua appearance, the appearance is not good and pulls it [the neighbourhood] down.'

'... the physical environment has to improve, by means of flowers, flags, flower baskets, you name it... So if you aim at improving this type of neighbourhoods then you ... we have way too few regulations to enhance the quality [of the physical environment].'

'...I think that something has to happen with the physical [environment], with the public spaces along the road, but also with the business spaces themselves, they do not have much appear... But in general, what is a great virtue of the Betjewolfstraat is that there are few vacancies [of commercial spaces]'

A likely explanation for the low importance scores of the item neighbourhood ethnic population mix is provided by the following response of a local entrepreneur in the ICT \& media production sector:

'I find it good, I find it fine ... Look, the ethnic composition of the neighbourhood is nice but what is not nice is the social composition. You have too many poor people. Where they come from is irrelevant. What it has to do with [is] having income.'

While it seems somewhat surprising that firm spatial expansion possibilities are not considered as important to firm success, this is a likely consequence of the fact that migrant neighbourhoods function predominantly as start-up areas, where a great share of entrepreneurs has not yet reached the point in their growth phase that firm space becomes an issue (Weterings et al. 2009, Schutjens et al. 2007). Also, many entrepreneurs are operating from the entrepreneurs' home (Schutjens \& Stam 2003, Stam 2009) requiring little more than a computer and a desk as illustrated by the following quote of an entrepreneur in the business services sector:

'I have thought about that [renting business space], but I do not see much of an advantage to have an office for a broker, because as I look at my firm activities, they are mostly elsewhere. You are actually very little in office and when you are, then you make phone calls. Or you work on your computer, well, I can do that here [in his home-based office] as well. The extra revenues from having a physically separated office space are slim.' 
All selected migrant neighbourhoods share a number of business location advantages and disadvantages. Interestingly, their advantages seems to relate especially to the 'soft aspects' among the location factors, namely to local social embeddedness aspects (contacts with local residents, ethnic population mix) and convenience (firm proximity to the entrepreneur's home). Combining this finding with our prior observation that migrant neighbourhoods accommodate high shares of local entrepreneurs (who also live in the neighbourhood), this indicates that local entrepreneurs are generally satisfied with their choices to operate their firms from home or close to it, which may be convenient for combining their working and private lives. They also seem to value their social embeddedness within the local community. Notably the market potential of the neighbourhoods (cleanliness, safety, firm accessibility/availability of parking space), except for closeness to customers, is seen as a location disadvantage. This supports our contention that migrant neighbourhoods function by and large as start-up locations for its residents, but are apart from their relatively central location little attractive as markets for local entrepreneurs.

When comparing business location advantages and disadvantages between preand post-war neighbourhoods, a number of differences are visible relating to the aspects cost saving potential (cheap business space), local embeddedness (ethnic population mix), market potential (firm accessibility/availability of parking space) and firm spatial needs (firm spatial expansion possibilities), whereby only the first two are significant at the $10 \%$ level. First, low costs of business spaces are seen as a location advantage in post-war neighbourhoods but not in pre-war ones. This seems to indicate that, considering local market prospects, firm spaces in the postwar neighbourhoods are priced more attractively than the ones in the pre-war neighbourhoods. ${ }^{63}$ The competitive advantage on the grounds of low cost business spaces was also confirmed in our discussions with experts:

'... the attractive locations as ... are too expensive for starting entrepreneurs, who have a very restricted budget... Next to that they think that people do not come here, not the people you are looking for [customers]. So for that you go and search in another neighbourhood.'

'I actually notice among my clients originating from this area that when they need firm space, they do not look in their own neighbourhood... They rather go in the direction of ... of course, but that is too expensive...'

A second divide in business location advantages and disadvantages between preand post-war neighbourhoods is that the ethnic population mix is considered as a

63 In absolute terms, there should be no price differences between the chosen pre- and post-war neighbourhoods as we controlled for this in our neighbourhood selection based on data of the Netherlands Bureau of Statistics. 
business location advantage in pre-war neighbourhoods but not in post-war ones. This may be explained by the neighbourhoods' difference in social dynamics as a result of the distinct spatial design of the areas as was pointed out in Section 5.5.1 above. On the one hand, the spatial design of post-war neighbourhoods with clearly separated residential and commercial spaces was intended to generate attractive settings for living but not to stimulate local social interactions in the streets as demonstrated by the following quote of a post-war neighbourhood expert:

'And that [vitality] you miss here, simply, customers do not come here. It is a residential neighbourhood with no reason to be here. You live here, you sleep here but apart from that...'

By contrast, pre-war neighbourhoods aim at the integration of housing and commercial functions. They have a far greater number of storefront commercial activities, which creates a neighbourhood vitality of 'buzzling' shops, cafes and restaurants. This vitality invites more social interactions between individuals and groups of people, which in turn is likely to increase interpersonal understanding and valuation of cultural diversity as reflects in the following quotes of pre-war neighbourhood experts:

'In comparison with other shopping streets, I find the Weimarstraat ... nice, because you see a nice mix of us [migrants] and natives. And actually I find that an entrepreneur is an entrepreneur...'

'... when I still lived here I always found it very pleasant to walk through the Javastraat, to shop there, because it simply has a nice atmosphere...'

An interesting difference between pre- and post-war neighbourhoods relates to firm spatial expansion possibilities, which entrepreneurs in the former neighbourhoods identify as a location disadvantage but not the ones in the latter neighbourhoods. This is due to higher valuations of firm spatial expansion possibilities by entrepreneurs in post-war neighbourhoods. Given that local spatial regulations in post-war neighbourhoods are generally more restrictive to firm spatial expansions, this finding is somewhat surprising. It is expected that the finding actually has less to do with local regulations, but rather with the characteristics of local businesses in pre- and post-war neighbourhoods. As local markets in pre-war neighbourhoods appear more attractive than in post-war ones, the former neighbourhoods are likely to accommodate relatively higher shares of firms in the growth phase of their business life cycle that are looking for more space. Also, given the more attractive local markets in pre-war neighbourhoods, it seems that the local markets for commercial spaces are somewhat more competitive and spatial regulations are perceived as more restrictive to business 
development. This is voiced by the following quotes by pre-war neighbourhood experts:

'Many entrepreneurs want to start in hospitality, but no more hospitality firms are allowed [in the commercial zone], so this is only possible on a business space where an existing hospitality firm leaves.'

'If the urban district council had been faster with for example the granting of the required permit and the changes of the local spatial regulations, then the Albert Heijn supermarket had long been there.'

While the business location factor firm accessibility/availability of parking space is considered a location disadvantage by entrepreneurs in both pre- and post-war neighbourhoods, it is interesting to see that the aspect appears to be more important to firm success in post-war neighbourhoods. This seems to suggest that, in light of low local market attractiveness, entrepreneurs in post-war neighbourhoods need to lure customers from elsewhere on convenience grounds such as availability of free parking. Thus, the competitive edge of post-war neighbourhoods to sustain business has to reside in the cost-saving potential (low cost business space), firm accessibility and availability of parking space. The importance of good accessibility and availability of parking space for firm success and the competitive edge of post-war neighbourhoods in this regard is illustrated by the following quotes of pre- and post-war neighbourhood experts respectively:

'Saturday is one of the better [business] days, ...local residents want to park their cars, but Saturday is the day that I really have to get my sales. You have a car issue there... there are entrepreneurs, so that is three signatures against [the introduction of paid parking]... and then they go along all residents. And then in one sweep there are 40 residents in favour because they want to park their cars. They also want parking spaces. Even paid ones ... ok, but not on Saturday, ...but that you cannot bring across to them.'

'And there is free parking, which is of course also a [business] advantage.'

Finally, entrepreneurs operating in neighbourhood oriented sectors (retail, personal services and hospitality) tend to find business spaces and location aspects (i.e. costs of firm space, closeness to customers, good accessibility \& parking, local security and cleanliness) and contacts with local residents more important for firm success than those operating in non-neighbourhood oriented sectors. These findings are not very surprising as neighbourhood oriented firms generally require proper business spaces while non-neighbourhood oriented commercial activities often take place from the entrepreneurs' home. Moreover, contacts with local residents as (potential) customers are more relevant for business success of neighbourhood oriented firms than for others. The relative importance of firm 
location factors on firm success does not systematically differ between migrant and native entrepreneurs.

5.5.4 - Other aspects affecting local business success in pre- and post-war neighbourhoods

The distinguishing aspects between pre- and post-war neighbourhoods relate namely to entrepreneurs perceptions of social interactions and disturbance in the neighbourhoods, local policy and firm relations with local authorities, and the level of local amenities. Figure 5.2 illustrates the important stated differences between pre- and post-war neighbourhoods that likely affect firm success. It displays entrepreneurs' perceptions of a number of neighbourhood-related characteristics as well as the entrepreneurs' relation with the neighbourhood. Overall, it appears that entrepreneurs have a rather positive perception of and relation with their local neighbourhoods, which was also our finding with regard to the so-called 'soft' business location factors in the prior section. Entrepreneurs generally indicate that they feel safe in their neighbourhoods, feel a sense of attachment and belonging to it and get along well with the local residents.

Looking at differences in entrepreneurs' perceptions of neighbourhood-related characteristics between the two types of neighbourhoods (top panel of the figure), it appears that the intensity of social interactions are perceived to be lower and the degree of disturbance higher in post-war neighbourhoods vis-à-vis pre-war ones. These findings are likely the outcome of the spatial use differences in pre- and post-war neighbourhoods rendering the former neighbourhoods with more vitality, as was already illustrated in Sections 5.5.1 and 5.5.3, which implies more social interactions in public spaces but also more disturbances (i.e. noise, traffic).

A second pre- and post-war neighbourhood divide is that entrepreneurs in postwar neighbourhoods tend to express lower valuations of contacts with municipality and police and higher ones for contacts with housing corporations/property owners (though neither are significant at the $10 \%$ level). The higher valuations of contacts with housing corporations/property owners in postwar neighbourhoods are likely explained by the more relaxed commercial property markets there given lower local market prosperity as described in Section 5.5.3 above. On the contrary, the lower valuations of entrepreneurs' contacts with local authorities (municipalities, police officers) in post-war neighbourhoods seem to be the outcome of less business-friendly local spatial regulations and (business) policies. While entrepreneurs in general express that their relations with local authorities are not always easy, entrepreneurs' difficulties with the existing local regulations and policies as well as with government communication in post-war neighbourhoods are certainly graver. These difficulties relate to various aspects 
ranging from development and coordination of public works projects to lack of service orientation and bureaucratic processes of authorities. The higher level of entrepreneurs' difficulties with authorities in post-war neighbourhoods is a likely consequence of the fact that, as these neighbourhoods are not prioritizing commercial activities; business owners need to spend more effort on solving day to day issues, which hampers their business success. The following quotes of local experts (of pre- and post-war neighbourhoods respectively) and an entrepreneur provide illustrations of how firm-government relations and entrepreneurs' perceptions of local policies in pre- and post-war neighbourhoods differ respectively.

'... there is a foundation managed by the community with currently 25,000 Euro, and the aim is to increase it to 50,000 Euro, and the foundation is for the stimulation of entrepreneurship in Zeeburg. And that means that many of the ideas to do with the improvement of stores, houses [can be realized].'

'In such a neighbourhood...in the neighbourhood action plan of Overvecht a great deal is missing in the area of local economy and entrepreneurship. The word economy that is one of the pillars in all of the neighbourhood action plans, is of course still a very thin pillar... because in post-war neighbourhoods the [business] infrastructure is lacking.'

(Quote of entrepreneur in post-war neighbourhood in consumer services)

'And I called four times [with the municipality], they would send someone, someone should still come now and they do not listen to anything... But now they stopped 100 metres from Elbedreef and now they have to continue... and now the busses can still not pass. So shortly we are simply three weeks without busses... And then they break open the road ... and so the road is closed for three weeks ...It cost the supermarket a mega turnover....'

A third aspect that differs between pre- and post-war neighbourhoods, the local presence of amenities, has already been mentioned in prior sections but should be highlighted again as it helps explain the divide in local business success between the neighbourhoods. As illustrated by the following quotes of pre- and post-war neighbourhood experts, certain amenities, such as a quality supermarket, street cafes, cultural and athletic facilities, can stimulate other local businesses as they draw visitors to the neighbourhood and may increase the neighbourhood image. This is especially relevant for firms operating in neighbourhood oriented sectors, but may also be beneficial for other firms for which neighbourhood image and quality of life are important:

'When I look at the local economy, from my function [as shopping street manager], and especially at the stores, well then I shall raise a flag at the moment that an Albert Heijn [supermarket] comes. Because... then it also becomes interesting for other parties to 
establish business there. Better entrepreneurs than currently. Or entrepreneurs, or stores that are not currently there, that do not yet see potential...but they would come once Albert Heijn is there. So, from this perspective... better [to have the supermarket] today than tomorrow.'

(Two quotes from post-war neighbourhood experts)

'... for instance hospitality. It lacks completely there [in the neighbourhood]. Simply that you think...I just go to eat something nice in Overvecht, nice terraces, nice eateries.'

'A good location where you can hold events. Where festivities can be organized. Where something with theatre, with sport...that is also missing [in the neighbourhood]. That is, on the note of amenity provisions.

Figure 5.2: Entrepreneurs' perceptions of and relations with their neighbourhoods, and valuations of contacts with local organizations

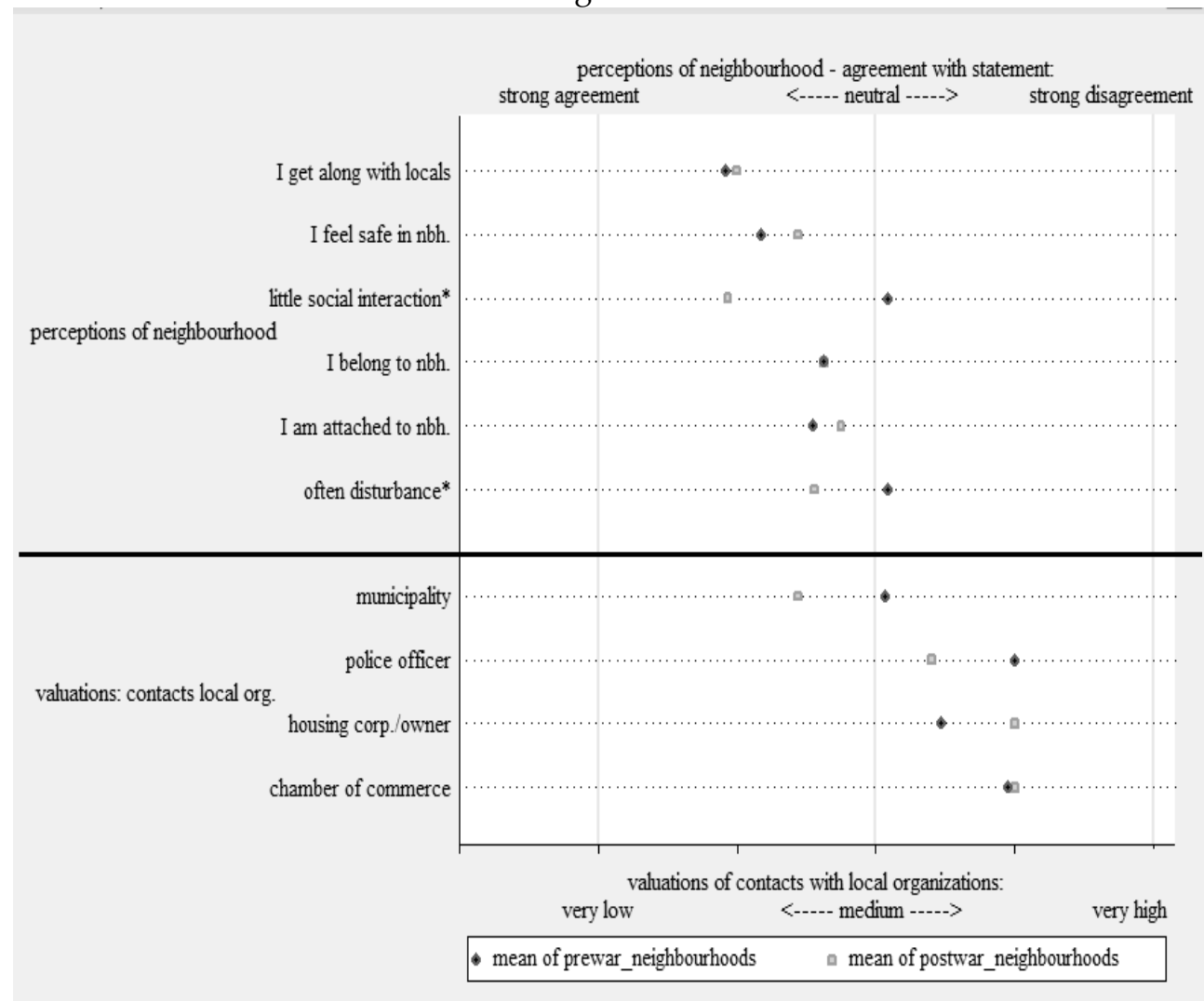

Notes: A scale from 1 to 5 is used for both higher and lower panels of the figure. For the higher panel it reads as follows: 1-absolutely not important, 2-little important, 3-somewhat important, 4-important, 5-very important. For the lower panel it reads as follows: 1-very low, 2-low, 3-medium, 4-high, 5-very high. The vertical lines mark levels 1,3 and 5 . The symbol ${ }^{*}$ indicates significant inter-group differences in means between entrepreneurs' responses from pre- and post-war neighbourhoods at the $10 \%$ level.

Source: Own interviews with 40 entrepreneurs 2008-2009 
We finally briefly touch on essential migrant-specific aspects that are likely affect business success of this group. A striking up-front observation in this regard is that, although most migrant entrepreneurs seem to value good relationships with their co-ethnic community as they appreciate common roots and norms that render a feeling of belonging, these relationships are generally viewed as strictly for private purposes. This also shows as few migrant entrepreneurs do benefit notably from their co-ethnic community ties to draw customers or employees. For the great majority of migrant firms, the commercial dependency on their co-ethnic communities appears limited accounting on average for less than one third $(28 \%)$ of total customers. Furthermore, most of the co-ethnic customers do not originate from neighbourhoods where the firms are situated. A number of other migrantspecific business aspects were voiced extensively throughout our discussions both in pre- and post-war neighbourhoods - that deserve further mention as they may explain why migrant entrepreneurs tend to be less successful in business than native entrepreneurs. These aspects are namely, low levels of education and business-related skills, language and communication problems, information deficiencies regarding (local) rules and regulations, and finally the tendency of migrant entrepreneurs to run similar type of businesses often active in low growth markets. While a thorough discussion of the mentioned aspects is beyond the scope of this chapter, the following quotes of neighbourhood experts provide some lively descriptions of the stated observations:

'But it is certainly a recognized problem of not knowing the way, and ... not knowing the rules... Yes, that is simply a general problem.'

'We are together with the chamber of commerce busy to simply organize meetings where migrants and natives [entrepreneurs] do something together. But the migrants actually do not want that, they have their own meetings with Turks and Moroccans [entrepreneurs]. These are their networks and beyond that they do not look.'

'I think that they [migrant entrepreneurs] generally have to look at their [business] surrounding to see what their market is, because often it is simply copying behaviour of migrant entrepreneurship. That is just such a prominent feature [of migrant entrepreneurship], all these greengrocery businesses, it is just copying behaviour.'

'But there are also rules of the market...there were 40,000 Muslims and 23 Islamic butchers. Well, that can never be a success, that is just not possible. You need 8,000 households per butcher, that is a simple fact.'

\section{6 - Conclusions}

To start a business, entrepreneurs - migrants and natives alike - have to both see and seize opportunities. They have to identify a market, which they, with their particular set of resources, could, in principle, cater to (Kloosterman 2010). This process of matching between, on the one hand, supply (entrepreneurs) and, on the 
other, opportunities (demand) typically has a spatial dimension. Markets are in most cases spatially delineated and (aspiring) entrepreneurs tend to be attached to places through housing, social ties, and knowledge of a particular area. Given the fact that many businesses need spaces to function, the match between entrepreneurs and opportunities is also dependent on the availability of affordable business spaces. This availability in its turn is the result of the interplay between the built environment and the zoning regulations pertaining to a particular area or neighbourhood. If the built environment does not offer suitable business spaces (in terms of rent, size, location, accessibility, or outside appearance) and if the zoning regulations do not allow the construction of new or the transformation of existing spaces into suitable business spaces then, although both aspiring entrepreneurs and market opportunities exist, the match will not take place- at least not in that particular neighbourhood. This intervening spatial variable of the built environment with its set of rules tends to be neglected in much research on (migrant) entrepreneurship.

Above, we have looked at to what extent the built environment and the zoning in migrant neighbourhoods impact on business prospects of local entrepreneurship by comparing two different types of neighbourhoods. The first type of neighbourhood is the mixed-use, pre-WWII neighbourhood and the second type is the much more mono-functional, residential post-WWII neighbourhood, which was mainly built during the post-war reconstruction under the aegis of modernist urban planning with its strong emphasis on the spatial separation of functions. The two types of neighbourhoods differed not only in types of dwellings, street plans and diversity of the buildings, but also with respect to the zoning plans. The prewar neighbourhoods are characterised by relatively low (up to four stories) and small blocks, with finely-grained street plans, relatively diverse housing and business spaces, and comparatively tolerant zoning plans. The post-war neighbourhoods, in contrast, have higher and larger housing blocks, are connected to major thoroughfares, tend to be more monotonous and have stricter zoning plans.

We have used both a quantitative data set supplied by the chambers of commerce and we have drawn on interviews and focus groups with entrepreneurs and neighbourhood experts to tease out the different impacts of these spatial and regulatory contexts on business prospects of (migrant) entrepreneurs. The observed differences between the two types of neighbourhoods are rather salient.

A first conclusion is that pre-war neighbourhoods tend to be more supportive of entrepreneurship in general. These neighbourhoods not only have less restrictive spatial regulations and more available commercial spaces, but there are also less 
conflicts with municipalities and policymakers resulting in better business prospects (except in neighbourhood oriented sectors).

A second conclusion, related to the first, is that pre-war neighbourhoods have more to use Ray Pahl's (1984) term getting-by potential for neighbourhood oriented firms than post-war neighbourhoods, the latter of which attracts entrepreneurs merely on basis of low costs of business space and convenience grounds, for instance due to free of charge abundance of parking spaces. Firms in relying on these advantages appear to be much more vulnerable for shifts in demand.

Third, business prospects differ considerably between neighbourhood oriented and non-neighbourhood oriented commercial activities. The latter seem to be faring relatively worse in post-war neighbourhoods as compared to pre-war neighbourhoods. The reason for this seems to be the relatively restrictive local regulations, which aim at confining local commercial activities to those serving the needs of the local residents. The more restrictive zoning in post-war neighbourhoods has another effect on firms located there. By capping the numbers and type of firms allowed in the neighbourhood, the competition for firms in the neighbourhood oriented sectors is severely limited thus creating protected local markets for the already established firms.

Finally, the success of business activities of ethnic entrepreneurs does not seem to be overly dependent upon the support of their co-ethnic communities. The communities seem to play only a minor role as sources for labour and as (captive) markets. Notwithstanding this, ethnic entrepreneurs do tend to attach significant importance to their co-ethnic groups but this is more on a private level than from a business point of view.

Concluding, this study showed that the spatial environment and its regulations differ greatly between pre- and post-war neighbourhoods. As the spatial environment and its regulations do play a significant role in shaping the local business prospects of firms, the before differences result in a divergence in business prospects across these two neighbourhood types putting firms in pre-war neighbourhoods at an advantage. Restrictive zoning in mono-functional, residential environments seem to hamper the matching of aspiring entrepreneurs and opportunities and, moreover, thwart the expansion of already successful businesses. Jane Jacobs' (1961) view of diverse, mixed-use urban neighbourhoods as vibrant and resilient formulated almost half a century ago seems to be vindicated again. 


\section{7 - Appendix to chapter five}

Figure 5.A1: Neighbourhood comparison of relevant characteristics, positioning of selected 5 neighbourhoods within distribution of 93 neighbourhoods (per characteristic)

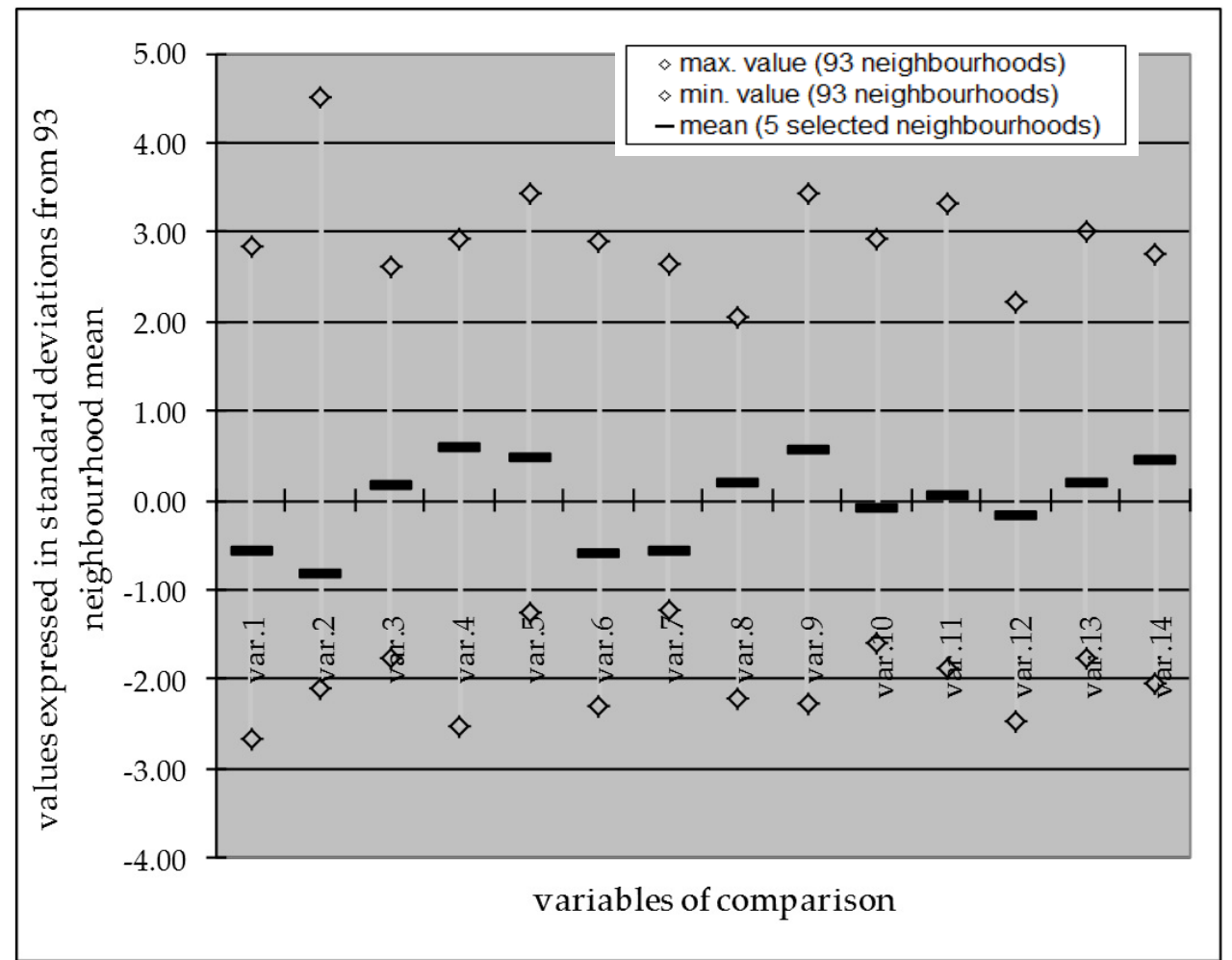

Notes: The figure displays the mean of the five selected neighbourhoods in terms of standard deviations from the mean of the 93 neighbourhoods for each of the 14 indicators described in section 5.3.1. The figure also shows the minimum and maximum values of the 93 neighbourhoods for each of the 14 indicators.

Source: Netherlands Bureau of Statistics Statline 2008: http://statline.cbs.nl, own calculations 


\section{Chapter 6: Conclusions}

This dissertation has combined a number of thematic, complementary research projects based in the Netherlands to investigate potential implications of the local spatial environment on economic success of non-Western immigrants in the labour market and in self-employment. In this section I discuss selective results of this dissertation in light of the basic research question, stress the research limitations of the dissertation and make suggestions for future research and conclude with formulating policy implications.

\section{1 - Discussion of key findings}

In this section, I refrain from reiterating the main findings from the above chapters; instead I discuss some selective results in light of the basic research question that was formulated as follows: Does the spatial location of non-Western immigrants in the Netherlands matter for their economic success in the labour market and in selfemployment? Taking a glimpse at the above findings, the short answer to this question is YES, the location of non-Western immigrants in the Netherlands matters for their economic success both in the labour market as well as in selfemployment. Given this, naturally, the next and more challenging question is: In what way does it matter?

6.1.1 - Implications of regional and municipal differences for immigrant economic success

First, non-Western migrants are unequally spread across the country; regions and municipalities differ with regard to both their labour market and self-employment opportunities, depending on industry structures and economic prosperity of these areas. These opportunities are also subject to competition for labour, and on markets for specific goods and services in these areas. Both labour competition and markets are in turn partially contingent on the local presence of other non-Western migrants, who tend to compete with each other at the low ends of the labour market and in business (i.e. local vegetable grocers or snack bars). The findings of this dissertation have illustrated the relevance of regional and municipal differences for economic success of non-Western immigrants in the labour market (chapter 3) and in self-employment (chapter 4). In chapter three the level of urbanisation is positively related to labour market outcomes of asylum seekers and the regional control variables (40 Corop regions) are highly significant for labour market outcomes as well. With regard to business performance (chapter 4), I showed that the excess money available in prosperous municipalities improves 
profitability, but not growth and survival. This finding likely indicates that some non-Western migrant entrepreneurs capitalize on these higher market prospects while others are driven out of business as a result of fiercer competition. Furthermore, apart from the Chinese group (as explained below), in the four major cities (Amsterdam, Rotterdam, The Hague, and Utrecht) business prospects of nonWestern entrepreneurs seem more promising with regard to profit and survival but not in the growth model, which may be the consequence of greater scarcity of affordable and suitable business spaces there. The spatially delineated goods and services markets in which immigrant entrepreneurs are functioning are of course essential in determining their business success. While market opportunities and prospects are generally higher in the more promising industry sectors (i.e. business services), these markets are also more competitive and dynamic, which exposes entrepreneurs to higher risk for business failure, especially those possessing lower levels of business and country-specific cultural and language skills. An interesting demonstration of the importance of the industry sector choice for firm success is provided by the first generation Chinese case, wherein one ethnic group manages to effectively sustain its competitive edge in the niche market of Chinese specialty restaurants (see chapter 4). This business strategy is however more successful in areas of low concentration of Chinese immigrants; firms of the first generation Chinese in the four major cities (where Chinese concentration is far higher than elsewhere) actually show lower profitability and survival rates than those elsewhere, a trend that is likely driven by the entrepreneurs in the Chinese restaurant niche, who face fiercer levels of competition there than elsewhere in the country.

6.1.2 - The relevance of the local social environment for immigrant economic success

The findings of this dissertation have also demonstrated the importance of the local spatial environment in the area of residence and/or firm location for economic success of non-Western immigrants in the labour market and in self-employment. In this regard, the above findings have underlined in particular the relevance of the local population composition, the built environment and the spatial regulations. To start with, the local population composition in a specific area may affect economic outcomes of non-Western immigrants as, first, the local presence of the co-ethnic community shapes social and economic actions of its members; second, neighbourhoods with high levels of non-Western immigrants (migrant neighbourhoods) have a distinct social setting that impacts on individuals; and third, the general socio-economic population characteristics of an area determine the local levels of prosperity and available social capital that may be decisive for migrant economic success in the labour market and in self-employment. First, although this does not clearly follow from our research, the findings in chapter 3 
seem to indicate that the local presence of the co-ethnic community fosters labour market outcomes of asylum seekers. We found that labour market gains of asylum seekers are particularly large in neighbourhoods with high levels of non-Western concentration where presumably the levels of co-ethnic concentration are also higher than elsewhere. This might suggest that newcomers benefit from the local presence of the co-ethnic community through, for instance, finding employment in ethnic economies. However, we have to be cautious with this interpretation as the analysis in chapter 3 focused on the labour market effects of non-Western concentration rather than the effects of co-ethnic, or own-group, concentration. Thus, the interpretation rests on the assumption that in areas with high nonWestern concentration also the level of co-ethnic group concentration is high, which is not always the case. Nonetheless, given the financial limitations of most asylum seekers (see Table 3.5), it is likely that many asylum seekers end up living in migrant neighbourhoods, and thus, co-ethnic concentrations for asylum seekers in these areas can also be expected to be higher than elsewhere. However, this issue should be investigated more thoroughly. Interestingly, the gains at the high end range of neighbourhood concentrations are relatively more pronounced for women, which, moreover, might suggest that ethnic economies are an especially important source of employment creation for ethnic minority women, who are not able or allowed to find employment elsewhere.

The local presence of the co-ethnic community also shapes immigrant selfemployment prospects as suggested by the findings in chapters four and five. From the results it seems, however, that these effects vary to a large extent between industry sectors and origin groups of entrepreneurs, being relatively more present for labour migrant (Turkish and Moroccan) and Chinese entrepreneurs and less so for colonial migrant (Surinamese, Antillean) entrepreneurs. Overall, my findings in chapter four suggest that local co-ethnic residential and business concentration tend to negatively impact on firm profitability and survival rates of immigrant entrepreneurs, but their effects on firm growth are insignificant to even positive except for the Moroccan group of entrepreneurs. This may indicate that, while on the one hand, migrant entrepreneurs benefit from the local presence of the coethnic community through facilitated labour recruitment, but on the other hand, they lose as concentration triggers local business rivalry and/or co-ethnic business claims that hinder business development. The differences between origin groups may reflect disparities in their degree of co-ethnic group identification, orientation and self-sufficiency. The labour migrant cluster is known for its strong selfidentification and orientation that is partly vested in shared religious norms. Furthermore, as the close-knit Turkish and Moroccan communities are rather large and concentrated in the major cities, they have acquired a higher level of local selfsufficiency than other origin groups. This reflects not only in the great number of Turkish and Moroccan cultural associations, but also in the local business 
landscapes of urban migrant neighbourhoods, which accommodate many firms serving specific needs of these co-ethnic communities. The firms of labour migrant entrepreneurs tend to be located in areas of higher local co-ethnic concentration than is the case for the other origin clusters; this may have negative implications for firm development prospects, as the findings in chapter four have shown that increased local presence of the co-ethnic community negatively affects firm profitability and survival rates of migrant business. Lower firm development prospects are likely the consequence of the fact that labour migrant entrepreneurs tend to compete to a great extent with each other setting up store in similar, lowend industry sectors. Moreover, the finding in chapter five, namely that business success of the interviewed non-Western migrant entrepreneurs is not overly dependent upon the support of their co-ethnic communities, alerts us that migrant entrepreneurs can also target main stream markets instead of, or next to, ethnic markets. Specifically, chapter five concludes that migrant communities seem to play only a minor role as sources for labour and as (captive) markets; however migrant entrepreneurs do tend to attach significant importance to their co-ethnic groups on a more private level rather than from a business point of view.

A second explanation as to why the local population composition in a specific area may affect economic outcomes of non-Western immigrants, as illustrated for labour market outcomes in this dissertation, is that neighbourhoods with high levels of non-Western immigrants (migrant neighbourhoods) have a distinct social setting that impacts on individuals. The above assertion is based on the idea that the local living environment or residential neighbourhood shapes (in part) the personal development of individuals; this may reflect in concrete behaviour but also in more subtle social norms and values. For instance, the residential neighbourhood influences whom immigrants meet on the street, where their children go to school or how they perceive the world (Pinkster 2008). A longstanding body of predominantly US-based scientific literature documents that neighbourhood effects are important for the development of individuals on a wide range of individual characteristics including labour market outcomes (Lewis 1966, Wilson 1987, Massey \& Denton 1993, Musterd \& Andersson 2006, Galster et al. 2008). In this regard, migrant neighbourhoods seem to foster newcomers' acculturation process in receiving societies by for instance providing 'safe havens' from discrimination in mainstream society; this is suggested by the significant positive effect found for non-Western neighbourhood concentration on migrant labour market outcomes, especially so for recent arrives (see chapter 3). Thus, this finding provides strong evidence in support of the 'springboard' function of high concentration migrant neighbourhoods for the case of the Netherlands as explained in chapter three. Although, it is not possible to disentangle different social network effects (i.e. information exchange, peer group pressure), the findings do suggest that the gains derived from migrant local social networks, i.e. 
by means of information availability about labour market regulations or available jobs, likely exceed the negative effects these networks can have on individuals, i.e. through information provision about welfare eligibility. Despite this, labour market benefits of living in areas of high non-Western concentration tend to diminish with the time of stay in the Netherlands and actually become negative after several years (for migrants of 8-10 years of stay in the country). This in turn suggests that immigrants are 'getting stuck' in migrant neighbourhoods, so living in migrant neighbourhoods actually hampers further integration into society after some time. This finding is shared with another recent study from Sweden by Musterd et al. (2008), which finds that own-group neighbourhood concentration is initially beneficial for migrant labour market outcomes, but quickly becomes penalising with stay in the country. A possible explanation for this might be that individuals' social networks remain narrowly centred on the local migrant community which deprives migrants of essential social capital of natives that, for instance, may facilitate access to better jobs.

Third, the general socio-economic population characteristics of an area determine the local levels of prosperity and available social capital that may be decisive for migrant economic success in the labour market and in self-employment. With regard to immigrant labour market outcomes, the 'quality' of the local social environment in general, as captured by population employment and wage levels, are important from a social capital point of view (see the 'neighbourhood effects' argument in the prior paragraph) as migrants living in areas with high employment and wage levels tend to benefit from their social surroundings and have better chances to find suitable jobs (see chapter 3). This argument is underlined by findings of two recent studies from Sweden by Andersson et al. (2007) and Galster et al. (2008), which demonstrate that the neighbourhood income mix is an essential determinant of individuals' earnings. Also, migrant entrepreneurs are affected by the local socio-economic population characteristics as for some firms the neighbourhood forms the captive market for their goods and services. Moreover, local social cohesion, crime, disturbance, but also local social embeddedness of entrepreneurs and conflicts of firm with municipalities and policymakers may affect business functioning as was illustrated in chapter five.

6.1.3 - Implications of the local morphology and spatial regulations for firm economic success

Next to the local population composition, the findings of chapter five of this dissertation also underlined the importance of the local built environment and the spatial regulations in the area of residence and firm location for economic success of non-Western entrepreneurs. This reflected in the salient differences in business prospects of entrepreneurs in pre- and post-WWII neighbourhoods that were the 
result of distinct types of dwellings, street plans, diversity of the buildings, and zoning plans. In this regard, an interesting conclusion of the chapter is that higher local provisions of certain amenities (i.e. cafes, restaurants) may provide neighbourhoods with more 'getting-by potential' that, in turn, positively affects business prospects of other firms, especially the neighbourhood oriented ones. The lack of local amenities may partially explain why some neighbourhoods (i.e. postwar ones) manage to attract entrepreneurs merely on basis of low costs of business space and convenience grounds, for instance through free of charge abundance of parking spaces. Firms in relying on these advantages appear to be much more vulnerable for shifts in demand.

Overall, the chapter showed that restrictive zoning in mono-functional, residential areas seems to hamper the matching of aspiring entrepreneurs and opportunities and, moreover, thwarts the expansion of already successful businesses. The process of matching between, on the one hand, supply (entrepreneurs) and, on the other, demand (market opportunities) typically has a spatial dimension. Markets are in most cases spatially delineated and (aspiring) entrepreneurs tend to be attached to places through housing, social ties, and knowledge of a particular area. Given the fact that many businesses need spaces to function, the match between entrepreneurs and opportunities is also dependent on the availability of affordable business spaces. This availability in turn, is the result of the interplay between the built environment and the zoning regulations pertaining to a particular area or neighbourhood. If the built environment does not offer suitable business spaces (in terms of rent, size, location accessibility, or outside appearance) and if the zoning regulations do not allow the construction of new, or the transformation of existing, spaces into suitable business spaces, then, although both aspiring entrepreneurs and market opportunities exist, the match will not take place- at least not in that particular neighbourhood.

\subsubsection{Other (non-geographic) factors affecting economic performance}

Apart from the above, space-related factors, some more general integration-related aspects were illuminated throughout this dissertation as they have strong bearing on the economic success of non-Western immigrants in the labour market and in self-employment. Although, these integration-related factors have been difficult to pinpoint as they remain conceptually somewhat vague and hard to measure, the above studies have clearly illustrated their relevance both for immigrant labour market and self-employment outcomes. Chapter 3 has shown that labour market outcomes of non-Western immigrants improve with time of stay in the country as immigrants acquire host-country specific cultural and language skills. 
Host-country specific cultural and language skills, or rather the lack thereof, were also identified as an essential problem of immigrant entrepreneurs (see chapter five), who tend to run into problems due to not knowing the rules and regulations and missing vital business information. Chapter four finds that differences in business characteristics and firm success between three clusters of origin groups of non-Western immigrant entrepreneurs seem to reflect important intergroup divergence in education, and receiving country cultural and language skills. ${ }^{64}$ Moreover, this divergence between the three clusters may explain why labour migrant entrepreneurs who tend to have lower levels of education and labour market opportunities are also less represented in more promising business sectors and are generally less successful than colonial migrant and Chinese entrepreneurs. In the last decades the Dutch economy has further developed along its path towards a fully-fledged service economy. The changing market demands have compelled new and established entrepreneurs to adopt a new business orientation in order to seize business opportunities in the promising services sectors so as to remain competitive therein. However, to materialise on these new business chances, entrepreneurs need to possess higher levels of human capital, businessspecific and country-specific cultural skills than were required in the traditional migrant sectors. In this regard, migrant integration in society becomes essential to foster the match between supply and demand; this explains why some groups of migrants characterized by lower integration levels, i.e. the labour migrants, are less represented in the services sectors than other groups, i.e. the colonial and Chinese migrants, and also appear less successful in business. The three clusters also differ in their degree of cultural distance from the receiving society, which affects the ability of entrepreneurs to access and service mainstream markets. This cultural distance is larger for the clusters of labour and (first generation) Chinese migrants than for colonial ones.

The findings of this dissertation in chapter four also stress the connection between the labour market and self-employment, showing that self-employment is not a route for upward social mobility by escaping interdependencies typical for the paid labour market. Moreover, the findings document the importance of integration for successful migrant entrepreneurship: Opportunities in the salaried labour market are important determinants not only of self-employment decisions but also of business success of migrants. While for some migrants, selfemployment may be a strategy to avoid unemployment, discrimination and/or

${ }^{64}$ I would like to add a cautionary note that this interpretation was based on the implicit assumption that integration characteristics of the groups of the self-employed are comparable to the characteristics of the corresponding migrant populations as a whole (as is presented in Table 4.3). This assumption was necessarily made in chapter 4 as no information was available specifically for migrant entrepreneurs from these groups. This is perhaps somewhat unrealistic as it is likely that the self-employed are more resourceful than other members of society to be able to actually take the step towards self-employment. 
blocked mobility in the regular labour market, for others it is a lucrative endeavour to capitalize on unique human and/or social capital endowments. Thus, integration has an essential moderating role in matching the supply and demand side within the opportunity structure of entrepreneurs, as suggested by the mixed embeddedness framework of Kloosterman, Van der Leun and Rath (1999). Moreover, it seems that the required level of integration to facilitate entrepreneurial success tends to increase over time in line with higher demands regarding occupational qualification in the regular labour market. In this respect, migrant-to-native differences become ever more essential indicating the presence of a market-driven mechanism.

\section{2 - Limitations and suggestions for future research}

In this section, I raise a number of limitations of this dissertation and derive suggestions for future research. A first limitation of my dissertation, which is perhaps a classical shortcoming of the literature on immigrant integration in the Netherlands, is that it focuses exclusively on the group of non-Western immigrants. It thereby disregards the group of Western immigrants in the country and contributes to an arguably one-directional line of research that can be criticized for drawing up an artificial, typifying divide between, on the one side, the problematic, difficult to integrate non-Western group of immigrants, and on the other side, the unproblematic, well-integrated Western group of immigrants. Naturally, while this division (implemented some time back by the Netherlands Bureau of Statistics) has resulted in much research on non-Western immigrants, notably on the four major origin groups of Turkish, Moroccan, Surinamese, and Antilleans, it also left many other ethnic groups to the side. As the Netherlands has seen a strong increase of asylum seekers and immigrants from the new EU member states in recent years, some of whom also seem to be facing difficulties in gaining a foothold in the country, these would be particularly relevant groups for future research to focus on. As my dissertation focuses on economic outcomes of nonWestern immigrants, it would be interesting to contrast the above findings with research on (select) Western groups of immigrants for the case of the Netherlands. Besides this, also a cross-country comparison of spatial implications for economic outcomes of non-Western immigrants might prove valuable, as it could indicate whether or not my dissertation findings from the Netherlands also hold for other countries.

A second limitation of this dissertation is that it did not manage to sufficiently explore the 'black box' between concentration and labour market outcomes (chapter 3) and the 'black box' between integration and business success (chapter 4). Further analysis is needed to gain a more thorough understanding of the underlying processes and conditionality mediating the relationship between 
concentration and integration and economic success of non-Western immigrants in the labour market and in self-employment. A step in this direction may be set by future research analysing migrant concentration effects for ethnic subgroups and improving the non-linear modelling of concentration effects on labour market outcomes (chapter 3). Another important step forward towards exploring the mentioned 'black boxes' can be set by including immigrant educational information in the analyses. This was not plausible in my projects due to data unavailability at the time of conducting my research. However, recently some basic information on the educational background of immigrants has become available in the Social Statistical Database of the Netherlands Bureau of Statistics, which might enable research into this direction in the future. An important shortcoming of my dissertation, relating to the unavailability of educational information, is that I cannot control for origin group compositional differences in education, which likely result in selection effects that bias my results. For instance in chapter four, I expect this to lead to an underestimation of business success of the second generation groups of immigrant entrepreneurs, who are young and thus partially still at school. Moreover, these selection effects likely differ between the groups of immigrants as average educational length are relatively higher for Chinese and relatively lower for Turkish and Moroccans. Also, Clark \& Drinkwater (2010) found a negative correlation between educational attainment and self-employment propensities of migrants in the UK, which suggests that for higher educated groups of migrants, self-employment becomes less attractive as compared to salaried employment, whereby the former becomes a fall-back strategy attracting relatively more individuals who do not manage to find suitable jobs. This group compositional difference between first and second generation migrant entrepreneurs might explain why, despite higher levels of human capital and hostcountry specific skills, the second generation is not more successful in business than the first generation in chapter 4 .

Third, in this dissertation I conducted separate analyses for immigrant labour market and self-employment outcomes to study the influence of the local spatial environment thereon. However, as the labour market and self-employment outcomes of non-Western immigrants are highly intertwined, the separate analyses come at the cost of not gaining a full picture of their combined functioning; these investigations thus miss out vital information on, for instance, transitions of nonWestern immigrants between labour market and self-employment. At the time of conducting my research the combined analysis was data wise not an option. Thanks to the recent availability of new data, this has become a viable research opportunity in the future.

A fourth issue of concern about my dissertation involves the face validity of variables used. For instance in the case of chapter four, the variables describing the 
environment (i.e. average wage, migrant concentration) are defined at the municipal level. It is, however, questionable whether, for large municipalities, the whole city is the relevant social environment. Especially for larger cities the relevant social environment is probably more the district. Furthermore, given that districts within larger cities are rather heterogeneous, the used variables at the municipal level provide at best rough indications of the local business environments. With respect to our dependent variable, the three performance indicators chosen are a widely used set of indicators, but they focus on financial aspects of performance and neglect non-financial aspects such as motivation and satisfaction. Future research could follow in the footsteps of this research to investigate as to whether, and how, the inclusion of non-financial aspects might add to the conclusions of this dissertation.

Finally, in this dissertation I discovered that the diversity in business outcomes is much larger among the group of second generation non-Western immigrants than it is among the first generation. This seems rather intuitive as developmental trajectories of members of the second generation in the Netherlands are much more varied: While some second generation non-Western immigrants have excelled in the education system and found high positions in the labour market or have become successful in business, others have been less fortunate and struggle to gain a foothold in Dutch society. This diversity among the second generation has caused some of my results to become insignificant; this in turn made it difficult to address some of my research questions relating to intergenerational developments in self-employment in chapter four. Future research could add to the above findings by conducting subgroup analyses for second generation non-Western immigrants in the attempt to better understand this large intra-group variation in business outcomes and clarify the link between these outcomes and local spatial and integration-related aspects. This research may also benefit the further exploration of the 'springboard' function of migrant neighbourhoods discovered in chapter three. In this regard, a number of questions for future research appear promising, namely: What are the characteristics of immigrants who use migrant neighbourhoods as springboards and what are the characteristics of those who do not? Do successful immigrants (who excel in the labour market and/or in selfemployment) leave migrant neighbourhoods and if so, to where do they move?

\section{3 - Policy implications}

Location is an important determinant of economic success of non-Western immigrants in the Netherlands as regions, municipalities and neighbourhoods within municipalities offer different labour market and self-employment opportunities to migrants. Given this, and knowing that non-Western immigrants are unequally spread across the country and within municipalities, it is therefore 
paramount to study migrant economic outcomes in a spatially decomposed fashion (i.e. distinguishing regions, urban areas etc.) to gain a holistic understanding of their economic situation in society. Moreover, policymakers interested in fostering economic outcomes of non-Western immigrants are therefore well advised to consider the spatial factor in their policy initiatives.

Another central finding of this dissertation is that the local social environment in the area of residence and/or firm location affects economic outcomes of nonWestern immigrants both in the labour market and in self-employment: First, the local presence of the co-ethnic community shapes social and economic actions of its members; second, neighbourhoods with high levels of non-Western immigrants (migrant neighbourhoods) have a distinct social setting that impacts on individuals; and third, the general socio-economic population characteristics of an area determine the local levels of prosperity and available social capital that may be decisive for migrant economic success. An important policy implication of this is that migrant neighbourhoods may actually foster newcomers' acculturation process rather than hampering it, as is demonstrated for the case of asylum seekers, whose labour market success is positively affected by residency in neighbourhoods with high levels of non-Western concentration once controlling for the unfavourable population characteristics of these areas. This somewhat complex finding should be interpreted with caution: it suggests that, while the concentration of people with labour market disadvantages in migrant neighbourhoods reduces labour market outcomes of asylum seekers, the concentration of non-Western immigrants actually improves their job chances and earnings. Thus, policies aimed at improving labour market integration of asylum seekers ought to reduce the spatial clustering of disadvantaged people, but should be less concerned about the concentration of non-Western foreigners. This argument is also formulated in a recent study from Sweden by Andersson et al. (2007), which finds that neighbourhood income mix is more important as a determinant of individuals' earnings than the ethnic neighbourhood composition. Moreover, it argues that, while at present, urban area-based policies are driven partly by the fear of ethnic clustering, they ought to be more centred on neighbourhood income mix. In a similar vein, it seems that the findings of this dissertation undermine the economic meaningfulness of implemented settlement policies for asylum seekers, which have the aim to allocate individuals to regions with low migrant concentration and thus to reduce immigrant concentration in larger cities (implemented by national governments in e.g. UK, Germany, Denmark, Sweden and the Netherlands). As was argued by Andersson et al. (2007) for urban area-based policies, I argue that also settlement policies for asylum 
seekers ought to be more centred on neighbourhood income mix rather than on ethnic clustering. ${ }^{65}$

This dissertation has also shown that, although market opportunities and prospects of entrepreneurs are generally higher in the more promising industry sectors (i.e. business services), these markets are also more competitive and dynamic exposing entrepreneurs to higher vulnerability for business failure, especially those possessing lower levels of business and country-specific cultural and language skills. This implies that migrant entrepreneurship in the more promising industry sectors is not necessarily more successful than entrepreneurship in the more traditional sectors (i.e. retail, hospitality). For policy initiatives aimed at fostering successful non-Western immigrant entrepreneurship this should be read as a cautionary note to emphasize the importance of a good match between, on the one hand, the qualifications of immigrant entrepreneurs (education, professional and country-specific skills) and, on the other hand, market opportunities.

The findings of this dissertation illustrated that the local built environment and spatial regulations shape firm economic prospects in residential neighbourhoods, for migrant and native entrepreneurs alike. In this regard, two striking observations may offer useful guidance for local policymakers interested in fostering entrepreneurship in these areas. First and foremost, restrictive zoning in mono-functional, residential areas seems to hamper the matching of aspiring entrepreneurs and opportunities and to thwart the expansion of already successful businesses. As businesses in most cases need spaces to function, if the local built environment does not offer these spaces (in terms of rent, size, location accessibility, or outside appearance) and if the zoning regulations do not allow the construction of new, or the transformation of existing, spaces into suitable business spaces, then, although both aspiring entrepreneurs and market opportunities exist, the match will not take place in the particular neighbourhood. The second finding that may offer useful guidance for policymakers is that higher local provisions of certain amenities (i.e. cafes, restaurants) may provide neighbourhoods with more 'getting-by potential'. This likely affects business prospects of other local firms positively, especially those of neighbourhood oriented ones. Thus, policymakers interested in fostering entrepreneurship in residential neighbourhoods may want to start their pursuit by reviewing the areas' local built environment and spatial regulations in order to fully understand its spatial functioning and to adopt an integrative plan considering both the interests of residents and firms.

${ }^{65}$ We refrain from generalising our findings from asylum seekers to non-Western migrants in general as it is not clear as to whether the characteristics of the two groups are sufficiently comparable. 
Finally, this dissertation has demonstrated the increasing relevance of non-Western immigrant integration into the Dutch society, both for immigrant labour market and self-employment outcomes. In the last decades, the Dutch economy has evolved further in its development of becoming a fully-fledged service economy, a development that also calls for a more educated and skilled population of workers and entrepreneurs. While this may seem more intuitive for workers than for entrepreneurs, the changing market demands have compelled new and established entrepreneurs to adopt a new business orientation in order to seize opportunities in the promising services sectors and remain competitive therein. To materialise on these new chances, entrepreneurs need to possess higher levels of human capital, and business-specific and country-specific cultural skills than were required in the traditional migrant sectors. This shows that outcomes in the labour market and in self-employment are clearly connected, which demonstrates that self-employment is not a route for upward social mobility by escaping interdependencies typical for the paid labour market. Opportunities in the salaried labour market are important determinants not only of self-employment decisions but also of business success of non-Western immigrants. Policymakers should thus jointly consider the labour market and self-employment situations of non-Western immigrants, while adopting an integrative approach with emphasis on fostering their further integration into society. 


\section{References}

(1995-2004). Central Housing Database, Central Agency for the Reception of Asylum Seekers (COA).

(2006). Integratiemonitor 2006, VluchtelingenWerk Nederland.

(1995-2004). Social Statistical Database (SSB), Netherlands Bureau of Statistics (CBS).

(2007). Statline, Netherlands Bureau of Statistics (CBS).

(2009). Statline online database, Netherlands Bureau of Statistics.

Aalders, R., A. Bakkeren, et al. (2008). De kracht van de wijk. Belang van wijkeconomie voor de leefbaarheid in Amsterdamse krachtwijken. Amsterdam, Rabobank Amsterdam en Omstreken/EZ Amsterdam/MKB Amsterdam.

Akerlof, G. A. (1980). "A theory of social custom of which unemployment may be one consequence." Quarterly Journal of Economics 94(4): 749-775.

Alba, R. and V. Nee (2004). Remaking the American Mainstream - Assimilation and Contemporary Immigration, Harvard University Press.

Aldrich, H., R. Waldinger, et al. (1990). Ethnic Entrepreneurs - Immigrant Business in Industrial Societies. Newbury Park, Sage Publications.

Anderson, E. (1991). Neighborhood effects on teenage pregnancy. The urban underclass. C. Jenck and P. E. Peterson. Washington D.C., The Brookings Institute.

Andersson, R., S. Musterd, et al. (2007). "What mix matters? Exploring the relationships between individuals' incomes and different measures of their neighbourhood context." Housing Studies 22(5): 637-660.

Andersson, L. and M. Hammarstedt (2010). "Intergenerational transmissions in immigrant self-employment: Evidence from three generations." Small Business Economics 34: 261-276.

Arenius, P. and D. De Clercq (2005). "Network-based approach on opportunity recognition." Small Business Economics 24(3): 249-265. 
Audretsch, D. B. and D. Dohse (2007). "Location: A neglected determinant of firm growth." Review of World Economics 143(1): 79-107.

Bailey, T. and R. Waldinger (1991). "Primary, secondary, and enclave labor markets: A training systems approach." American Sociological Review 56(4): 432445 .

Barrett, G. A., T. P. Jones, et al. (1996). "Ethnic minority business: Theoretical discourse in Britain and North America." Urban Studies 33(4-5): 783-809.

Bauer, T., P.T. Pereira, et al. (1998). "Portuguese migrants in the German labor market: Performance and self-selection." IZA Discussion Paper No. 20.

Becker, G. S. (1975). Human capital: A theoretical and empirical analysis, with special reference to education. New York, Columbia University Press.

Beckers, P. and B. Blumberg (2010). "Immigrant entrepreneurship on the move - A longitudinal analysis of first and second generation immigrant entrepreneurship in the Netherlands." Conference paper at the Academy of Management Annual Meeting, Montreal, August 2010.

Beckers, P. and L. Borghans (2007). "Segregation in neighbourhoods and labour market outcomes of immigrants - Evidence from random assignment in the Netherlands." Conference paper at the Annual Conference of the Society of Labor Economists, Chicago, May 2007.

Beckers, P. and R. Kloosterman (2010). "Between entrepreneurs and business opportunities. The impact of the local built environment and zoning regulations on small businesses in the Netherlands " Conference paper at Annual Conference of the European Regional Science Association, Jönköping, August 2010.

Beekhoven, S. and J. Dagevos (2005). Sociaal-culturele integratie. Jaarrapport Integratie 2005. Den Haag/Voorburg, SCP/WODC/CBS: 107-131.

Bertrand, M., E. Luttmer, et al. (2000). "Network effects and welfare cultures." Quarterly Journal of Economics 115: 1019-1055.

Blalock, H. M. (1956). "Economic discrimination and negro increase." American Sociological Review 21(5): 584-588. 
Blalock, H. M. (1957). "Per cent non-white and discrimination in the south." American Sociological Review 22(6): 677-682.

Blokland, T. (2002). "Stand van zaken - Waarom de populariteit van Putnam zorgwekkend is: een bespreking van Robert Putnams benadering van sociaal kapitaal." B en M 29(2): 101-109.

Blundell, R. and A. Duncan (1998). "Kernel regression in empirical microeconomics." Journal of Human Resources 33(1): 62-87.

Borghans, L. and B. Kriechel (2007). "Wage structure and labor mobility in the Netherlands 1999-2003." NBER Working Paper 13210.

Borjas, G. J. (1987). "Immigrants, minorities, and labor market competition." Industrial and Labor Relations Review 40(3): 382-392.

Borjas, G. J. (1995). "Ethnicity, neighborhoods, and human-capital externalities." American Economic Review 85(3): 365-390.

Borjas, G. J. (1998). "To ghetto or not to ghetto: Ethnicity and residential segregation." Journal of Urban Economics 44: 228-253.

Borjas, G. J. (1999). Heaven's Door - Immigration policy and the American economy. Princeton, NJ, Princeton University Press.

Bridge, S., K. O'Neill, et al. (2003). Understanding enterprise, entrepreneurship and small business. Basingstoke/New York, Palgrave Macmillan.

Brouwer, H. J. (1994). Kantorenmarkt en stadsstructuur. Amsterdam, Rodopi.

Brown, D. L. and G. V. Fuguitt (1972). "Per cent nonwhite and racial disparity in nonmetropolitan cities in the south." Social Science Quarterly 53(3): 572-583.

Buit, J. (1965). De structuur van het stadsgewest als productiemilieu. Amsterdam, SISWO.

Bulterman, S., A. v. Klink, et al. (2007). Ondernemers en hun bedrijven in de wijk. Het cement voor de economische pijler. De economische kracht van de stad. J. v. Dijk and V. Schutjens. Assen, Van Gorcum. 
Burgess, E. (1968). The growth of the city: an introduction to a research project. The city. R. E. Park, E. W. Burgess and R. D. McKenzie. Chicago, University of Chicago Press: 47-62.

Case, A. C., and Katz, L.F. (1991). "The company you keep: The effects of family and neighborhood on disadvantaged youths." NBER Working Paper 3705.

Castles, S. and M. J. Miller (2003). The age of migration - International population movements in the modern world - Third edition, Palgrave MacMillan.

Chiswick, B. R. (1991). "Speaking, reading, and earnings among low-skilled immigrants." Journal of Labor Economics 9(2): 149-170.

Chiswick, B. R. and P. W. Miller (1995). "The endogeneity between language and earnings: International analyses." Journal of Labor Economics 13(2): 246-288.

Chiswick, B. R. and P. W. Miller (2002). "Immigrant earnings: Language skills, linguistic concentrations and the business cycle." Journal of Population Economics 15: 31-57.

Chiswick, B. R. and P. W. Miller (2005). "Do enclaves matter in immigrant adjustment?" City and Community 4(1): 5-35.

Choenni, A. (1997). Veelsoortig assortiment: allochtoon ondernemerschap in Amsterdam. Amsterdam, Het Spinhuis.

Clark, K. and S. Drinkwater (2000). "Pushed out or pulled in? Self-employment among ethnic minorities in England and Wales." Labour Economics 7(5): 603-628.

Clark, K. and S. Drinkwater (2010). "Recent trends in minority ethnic entrepreneurship in Britain." International Small Business Journal 28(2): 136-146.

Coenen, L. (2001). Word niet zoals wij. De veranderende betekenis van onderwijs bij Turkse gezinnen in Nederland. Amsterdam, Het Spinhuis.

Coleman, J. S., et al. (1966). Equality of educational opportunity. Washington, DC, US Government Printing Office.

Constant, A. and K. F. Zimmermann (2006). "The Making of Entrepreneurs in Germany: Are Native Men and Immigrants Alike?" Small Business Economics 26(3): 279-300. 
Cooper, A. and K. Artz (1995). "Determinants of satisfaction for entrepreneurs." Journal of Business Venturing 10: 439-457.

Crane, J. (1991). Effects of neighborhoods on dropping out of school and teenage childbearding. The urban underclass. C. Jenck and P. E. Peterson. Washington D.C., The Brookings Institute.

Crul, M. (2000). De sleutel tot succes. Over hulp, keuzes en kansen in de schoolloopbanen van Turkse en Marokkaanse jongeren van de tweede generatie. Amsterdam, Het Spinhuis.

Crul, M. and A. Pasztor (10 October 2007). Patterns of integration. Between group and within group differences in the Dutch context. A contribution to the segmented assimilation debate. 12th International Metropolis conference. Melbourne.

Cutler, D. and E. Glaeser (1997). "Are ghettos good or bad?" Quarterly Journal of Economics 112(3): 827-872.

Dagevos, J. (2001). Perspectief op Integratie: over de sociaal-culturele en structurele integratie van etnische minderheden in Nederland. Den Haag, Wetenschappelijke Raad voor het Regeringsbeleid.

Dagevos, J. (2009). Ruimtelijke concentratie van niet-westerse migranten: achtergronden, gevolgen en aangrijpingspunten voor het beleid. Den Haag, Sociaal en Cultureel Planbureau.

Dagevos, J. and H. Bierings (2005). Arbeid en Inkomen. Jaarrapport Integratie 2005. Den Haag/Voorburg, SCP/WODC/CBS.

Dagevos, J., M. Gijsberts, et al. (2003). Rapportage minderheden 2003: onderwijs, arbeid en sociaal-culturele integratie. Den Haag, SCP.

Dantuma, E. (2008). Bedrijfshuisvesting en groei - MKB Special 2008. Amsterdam, ING Economisch Bureau.

Dijk, J. v. and P. H. Pellenbarg (2000). "Firm relocation decisions in the Netherlands. An ordered logit approach." Papers in Regional Science 79: 191-219.

Dustmann, C. and I. Preston (1998). "Attitudes to ethnic minorities, ethnic context and location decisions." The Economic Journal 111: 353-373. 
Edin, P.-A. and P. Fredriksson. (2000). "LINDA-Longitudinal INdividual DAta for Sweden." Uppsala University Department of Economics Working Paper No. 2000:19.

Edin, P.-A., P. Fredriksson, et al. (2003). "Ethnic enclaves and the economic success of immigrants - evidence from a natural experiment." Quarterly Journal of Economics 118: 329-357.

EIM (2004). Monitor Etnisch Ondernemerschap 2004. Zoetermeer, Ministerie van Economische Zaken.

Engelenburg, R. F. C. and E. Stam (2000). Gazellen in het vizier. Snelgroeiende ondernemingen. Verkenningen van onderzoek en beleid. Den Haag, Raad voor het Zelfstandig Ondernemerschap.

Ersanili, E. (2007). "Netherlands. Focus Migration Country Profile."

Evans, D. S. and B. Jovanovic (1989). "An estimated model of entrepreneurial choice under liquidity constraints." Journal of Political Economy 97: 808-827.

Fairlie, R. W. (1999). "The absence of the African-American owned businesses: An analysis of the dynamics of self-employment." Journal of Labor Economics 17(80108).

Flags of the world homepage 2009: http://www.flagsoftheworld.com

Florida, R. (2002). The rise of the creative class: And how it's transforming work, leisure, cummunity and everyday life. New York, Basis Books.

Fong, E., C. Luk, et al. (2005). "Spatial distribution of suburban ethnic businesses." Social Science Research 34: 215-235.

Fossett, M. A. and T. Seibert (1997). Long time coming: Racial inquality in the nonmetropolitan south, 1940-1990. Boulder, CO, Westview Press.

Frisbie, W. P. and L. Neidert (1977). "Inequality and the relative size of minority populations: A comparative analysis." American Journal of Sociology 82(5): 10071031.

Gabriel, S. and S. Rosenthal (1999). "Location and the effect of demographic traits on earnings." Regional Science and Urban Economics 24: 445-461. 
Galle, M. (forthcoming). Integratie en ruimte - Discoursanalyse van het integratiedebat.

Galster, G., R. Andersson, et al. (2008). “Does neighbourhood income mix affect earnings of adults? New evidence from Sweden." Journal of Urban Economics 63: 858-870.

Garnsey, E. (1998). "A theory of the early growth of the firm." Industrial and Corporate Change 7: 523-555.

Garssen, J., H. Nicolaas, et al. (2005). "Demografie van de allochtonen in Nederland." Bevolkingstrends 53(3): 96-117.

Glaeser, E. L., B. Sacerdote, et al. (1996). "Crime and social interactions." Quarterly Journal of Economics 111: 507-548.

Granovetter, M. (1985). "Economic action and social structures: the problem of embeddedness." American Journal of Sociology 91(3): 481-510.

Granovetter, M. S. (1985). "Economic action and social structure: The problem of embeddedness." American Journal of Sociology 91: 481-510.

Hagens, J., E. v. d. Krabben, et al. (2009). Wijkeconomie: de kleine ondernemer aan het woord. Ondernemerschap in wijk en stad: onderzoek Vastgoed en Ruimtelijke Ordening in het kader van kortlopend STIP-onderzoek 2008. Utrecht/Nijmegen, Bureau Buiten/Radboud Universiteit Nijmegen.

Hayter, R. (1997). The dynamics of industrial location; the factory, the firm and the production system. Chisester, John Wiley \& Sons.

Heckman, J. (1978). "Dummy endogenous variables in a simultaneous equations system." Econometrica 46(4): 931-959.

Heer, D. M. (1959). "The sentiment of white supremacy: An ecological study." American Journal of Sociology: 592-598.

Heijden, P. G. M. et al. (2006). Een schatting van het aantal in Nederland verblijvende illegale vreemdelingen in 2005, IOPS-Utrecht, Utrecht University.

Ihlanfeldt, K. and D. Sjoquist (1998). "The spatial mismatch hypothesis: A review of recent studies and their implications for welfare reform." Housing Policy Debate 9: 849-892. 
IND (2006). De procedure in het aanmeldcentrum, Netherlands Immigration and Naturalization Service (IND).

IND and VluchtelingenWerk Nederland (2004). Vluchtelingen in getallen.

Ioannides, Y. and L. Datcher-Loury (2004). "Job information, networks,

neighborhood effects and inequality." Journal of Economic Literature 17: 1056-1093.

IOM (2000). World Migration Report 2000. Geneva.

ITS (2007). Sociale Zekerheid en Immigratie - Feiten en meningen, Radboud Universiteit Nijmegen.

Jacobs, J. (1961). The Death and Life of Great American Cities. New York, Vintage Books.

Judt, T. (2005). Postwar; A History of Europe Since 1945. New York, Penguin Press.

Kahanec, M. (2006). "Ethnic specialization and earnings inequality: Why being a minority hurts, but being a big minority hurts more." IZA Discussion Paper No. 2050.

Kain, J. F. (1968). "Housing segregation, negro employment, and metropolitan decentralization." Quarterly Journal of Economics 82(2): 175-197.

Kempen, R. v., et al. (2000). Segregatie en concentratie in Nederlandse Steden: mogelijke effecten en mogelijk beleid. Assen, Van Gorcum.

Klatter-Folmer, J. (1996). Turkse kinderen en hun schoolsucces. Een dieptestudie naar de rol van sociaal-culturele orientatie, taalvaardigheid en onderwijskansen. Tilburg, Tilburg University Press.

Kloosterman, R. and J. P. v. d. Leun (1999). "Just for starters: commercial gentrification by immigrant entrepreneurs in Amsterdam and Rotterdam." Housing Studies 14: 659-677.

Kloosterman, R., J. Van der Leun, et al. (1997). Over grenzen. Immigranten en de informele economie, Voorstudie 10. Amsterdam, Het Spinhuis. 
Kloosterman, R., J. Van der Leun, et al. (1999). "Mixed embeddedness: Immigrant Entrepreneurship and Informal Economic Activities." International Journal of Urban and Regional Research 23: 253-267.

Kloosterman, R. C. (2010). "Matching opportunities with resources: A framework for analysing (migrant) entrepreneurship from a mixed embeddedness perspective." Entrepreneurship and Regional Development 22(1): 25-45.

Kloosterman, R. C. and J. Rath, Eds. (2003). Immigrant entrepreneurs; Venturing abroad in the age of globalization. Oxford/New York, Berg.

Kloosterman, R. C. and J. P. Van der Leun (1999). "Just for starters: commercial gentrification by immigrant entrepreneurs in Amsterdam and Rotterdam neighbourhoods." Housing Studies 14(5): 659-677.

Kloosterman, R. C., J. P. Van der Leun, et al. (1999). "Mixed embeddedness: (In)formal economic activities and immigrant businesses in the Netherlands." International Journal of Urban and Regional Research 23(2): 253-267.

Laan Bouma-Doff, W. v. d. (2005). De buurt als belemmering? Assen, Van Gorcum.

Lambooy, J. G. (1990). "Bedrijf en omgeving; een complexe relatie." Geografisch Tijdschrift XXIV(2): 121-129.

Lambooy, J. G. (1995). Regionaal economische dynamiek; een inleiding in de economische geografie. Bussum, Coutinho.

Lambooy, J. G. (1997). "Economische geografie beter gewaardeerd door economen." Geografie 6(maart): 32-35.

Lancee, B. (2010). “The economic returns of immigrants' bonding and bridging social capital. The case of the Netherlands." International Migration Review, 44(1), 202-226.

Dronkers, J. and B. Lancee (2009). “Aandacht voor de Putnam-hypothese is in het geheel niet overdreven. [Research attention for the Putnam-hypothesis is not at all exaggerated]" Migrantenstudies 25(2), 155-162.

Lazear, E. P. (1999). "Culture and language." Journal of Political Economy 107(6): S95-S126. 
Le, A. T. (2000). "The determinants of immigrant self-employment in Australia." International Migration Review 34: 183-214.

Levent, T. B., E. Masurel, et al. (2003). "Diversity in entrepreneurship: Ethnic and female roles in urban economic life." International Journal of Social Economics 30(11): 1131-1161.

Lewis, O. (1966). The culture of poverty. The city reader. R. T. LeGates and F. Stout. London/New York, Routledge: 217-224.

Lewis, O. (1968). The culture of poverty. On understanding poverty: Perspectives from the social sciences. D. P. Monynihan. New York, Basic Books: 187-200.

Li, W. (1998). "Los Angeles' Chinese Ethnoburb: From ethnic service center to global economy outpost." Urban Geography 19(6): 502-517.

Light, I. (1979). "Disadvantaged minorities in self-employment." International Journal of Comparative Sociology 20(1-2): 31-45.

Light, I. (1985). Immigrant entrepreneurs in America: Koreans in Los Angeles. Clamor at the gates: the new American immigration. N. Glazar. San Francisco, ICS Press.

Light, I. and E. Bonacich (1988). Immigrant entrepreneurs. Koreans in Los Angeles, 1965-1982. Berkeley, University of California Press.

Light, I. and E. Bonacich (1988). Immigrant entrepreneurs: Koreans in Los Angeles, 1965-1982. London, University of California Press.

Light, I. and C. Rosenstein (1995). Race, ethnicity, and entrepreneurship in urban America. New York, Aldine de Gruyter.

Lindo, F. (1996). Maakt cultuur verschil? De invloed van groepsspecifieke gedragspatronen op de onderwijsloopbaan van Turkse en Iberische migrantenjongeren. Amsterdam, Het Spinhuis.

Lofland, L. H. (2000). Urbanity, tolerance and public space. Understanding Amsterdam. Essays on economic vitality, city life and urban form. L. Deben, W. Heinemijer and D. Van der Vaart. Amsterdam, Het Spinhuis.

Loury, G. C., Ed. (1977). A dynamic theory of racial income differences. Women, minorities, and employment discrimination. Lexington, MA, Lexington Books. 
Louw, E., B. Needham, et al. (2009). Planning van bedrijventerreinen. Den Haag, Sdu Uitgevers.

Lucassen, L. and R. Penninx (1997). Newcomers. Immigrants and their descendants in the Netherlands 1550-1995. Amsterdam, Het Spinhuis.

Ma Mung, E. and T. Lacroix (2003). France: The narrow path. Immigrant entrepreneurs: Venturing abroad in the age of globalization. R. Kloosterman and J. Rath. Oxford, Berg: 173-193.

Marlet, G. A. and C. M. C. M. v. Woerkens (2008a). "Niet werk in, maar werk voor de wijk." Tijdschrift voor de Volkshuisvesting 3: 49-55.

Marlet, G. A. and C. M. C. M. v. Woerkens (2008b). Werk voor de wijk. Atlas voor gemeenten 2008. Utrecht, Stichting Atlas voor gemeenten.

Martens, E. P. (1995). Minderheden in beeld. Kerncijfers uit de survey Sociale Positie en Voorzieningengebruik Allochtonen 1994 (SPVA-94). Rotterdam, ISEO.

Massey, D. S., J. Arango, et al. (2005). Worlds in motion - understanding international migration at the end of the millennium. Oxford, Clarendon Press.

Massey, D. S. and N. A. Denton (1993). American apartheid - Segregation and the making of the underclass. Cambridge, Harvard University Press.

McCann, B. T. and T. B. Folta (2008). "Location matters. Where we have been and where we might go in agglomeration research." Journal of Management 34: 532565.

Ministry of Internal Affairs (1983). Minderhedennota (Kamerstukken II, 1982-83, 16102, nr.21).

Musterd, S. (1996). Ruimtelijke segregatie en sociale effecten. Assen, Van Gorcum.

Musterd, S. and R. Andersson (2006). "Employment, social mobility and neighbourhood effects: The case of Sweden." International Journal of Urban and Regional Research 30(1): 120-140.

Musterd, S., R. Andersson, et al. (2008). "Are immigrants' earnings influenced by the characteristics of their neighbours?" Environment and Planning A 40: 785-805. 
Netherlands Bureau of Statistics (CBS) (2004). Allochtonen in beeld. Voorburg, The Netherlands.

Netherlands Bureau of Statistics (CBS) (2007). Statline - Labour market statistics.

Netherlands Bureau of Statistics (CBS) (2007). Statline - Population statistics.

Netherlands Second Chamber of the States-General (1970). Nota buitenlandse werknemers [Nota on foreign workers], Kamerstukken II 1969-1970, 10504 nr.1.

Neubourg, C., P. Beckers, et al. (2008). Burning Bridges, Building Ships - Changes in immigration in the Netherlands; trends, policies and incentives, World Bank.

Newman, K. (1999). No shame in my game. New York, Knopf.

Oerlemans, L. A. G., M. T. H. Meeus, et al. (1998). Innovatie en ruimte: theoretische beschouwingen. Innovatie in bedrijf en regio. J. v. Dijk and F. Boekema. Assen, Van Gorcum: 9-27.

Olden, H. (2010). Uit voorraad leverbaar - De overgewaardeerde rol van bouwrijpe grond als vestigingsfactor bij de planning van bedrijventerreinen. Utrecht, Utrecht University. PhD dissertation.

Oort, F. v., R. Ponds, et al. (2007). Verhuizingen van bedrijven en groei van werkgelegenheid. Rotterdam, Ruimtelijk Planbureau/NAi Uitgevers.

Ostendorf, W. and S. Musterd (2005). Segregatie en integratie. Feiten en visies. Gescheiden of gemengd. Een verkenning van etnische concentratie op school en in de wijk. P. Brasse and H. Krijnen. Utrecht, Forum: 77-93.

Ouwehand, A. and M. v. Meijeren (2006). Economische initiatieven in stadswijken. Een verkennend onderzoek. Gouda, Habiforum.

Pahl, R. (1984). Divisions of labour. Oxford, Basil Blackwell.

PBL [Netherlands Environmental Assessment Agency] (2010). Bedrijvigheid en leefbaarheid in stedelijke woonwijken. Den Haag/Bilthoven.

Pellenbarg, P. H. (1996). De actuele struktuur en ontwikkeling van bedrijfsmigratieprocessen in Nederland. Faculteit der Ruimtelijke Wetenschappen. Groningen, Rijksuniversiteit Groningen. 
Pellenbarg, P. H. (2005). Bedrijfsverplaatsingen. Ruimtelijke aspecten van de bedrijvendynamiek in Nederland. P. H. Pellenbarg, P. v. Steen and L. v. Wissen. Assen, Van Gorcum: 101-125.

Pels, T. (1991). Marokkaanse kleuters en hun culturele kapitaal. Opvoeden en leren in het gezin en op school. Amsterdam, Swets \& Zeitlinger.

Pels, T. and M. de Gruyter (2006). Emancipatie van de tweede generatie. Keuzen en kansen in de levensloop van jonge moeders van Marokkaanse en Turkse afkomst. Utrecht, Verwey-Jonker Instituut.

Pen, C. J. (2002). "Wat beweegt bedrijven; besluitvormingsprocessen bij verplaatste bedrijven." Nederlandse Geografische Studies 297.

Phelps, E. S. (1972). "The statistical theory of racism and sexism." American Economic Review 62: 659-661.

Piil Damm, A. (2009). "Ethnic enclaves and immigrant labour market outcomes: Quasi-experimental evidence." Journal of Labor Economics 27(2): 281-314.

Pinkster, F. M. (2008). De sociale betekenis van de buurt - Een onderzoek naar de relatie tussen het wonen in een arme wijk en sociale mobiliteit. Amsterdam, Amsterdam University Press/NICIS Institute.

Porter, M. E. (1998). "Clusters and the New Economics of Competition." Harvard Business Review 76(6): 77.

Portes, A. (1998). "Social capital: Its origins and applications in modern sociology." Annual Review of Sociology 24: 1-24.

Portes, A. and R. Bach (1985). Latin Journey: Cuban and Mexican Immigrants in the United States. Berkeley/Los Angeles, University of California Press.

Portes, A., P. Fernandez-Kelly, et al. (2008). The Adaptation of the Immigrant Second Generation in America: Theoretical Overview and Recent Evidence - CMD Working Paper nr. 08-02.

Portes, A. and R. G. Rumbaut (1990). Immigrant America: A portrait. Berkeley, University California Press. 
Portes, A. and J. Sensenbrenner (1993). "Embeddedness and immigration: notes on the social determinants of economic action." The American Journal of Sociology 98(6): 1320-1350.

Portes, A. and M. Zhou (1993). "The New Second Generation: Segmented Assimilation and Its Variants among Post-1965 Immigrant Youth." The Annals of the American Academy of Political Sciences 530: 74-96.

Raad voor Werk en Inkomen (RWI) [Netherlands Council for Work and Income] (2006). Hogeropgeleide allochtonen op weg naar werk: successen en belemmeringen.

Raijman, R. and M. Tienda (1999). Immigrants' Socioeconomic Progress Post-1965: Forging Mobility or Survival? International Migration and the Remaking of America. C. e. a. Hirschman. New York, Russell Sage Foundation: 239-256.

Ram, M., G. Barrett, et al. (2006). Ethnicity and entrepreneurship. London, Prentice-Hall.

Ram, M. and T. Jones (1998). Ethnic minorities in business, Open University Press, Milton Keynes.

Ram, M., T. Jones, et al. (2002). "Ethnic minority enterprise in its urban context: South Asian restaurants in Birmingham." International Journal of Urban and Regional Research 26(1): 24-40.

Ram, M., B. Sanghera, et al. (2000). "Ethnic minority business in comparative perspective: The case of the independent restaurant sector." Journal of Ethnic and Migration Studies 26(3): 495-510.

Rath, J. and R. C. Kloosterman (2003). The Netherlands: A Dutch treat. Immigrant entrepreneurs - Venturing abroad in the age of globalization. R. C. Kloosterman and J. Rath. Oxford, Berg: 123-145.

Rekers, A. and R. Van Kempen (2000). Location matters: ethnic entrepreneurs and the spatial context. Immigrant businesses - the economic, political and social environment. J. Rath. London, Macmillan Press Ltd.: 54-69.

Renzulli, L. A., H. Aldrich, et al. (2000). "Family Matters: Gender, Networks, and Entrepreneurial Outcomes." Social Forces 79(2): 523-546. 
Roodenburg, H. (2000). Immigratie in Nederland: economische gevolgen. Bevolkingsvraagstukken in Nederland anno 2000 - rapport no. 58. N. Nimwegen and G. Beets. Den Haag, NIDI.

Roodenburg, H., R. Euwals, et al. (2003). Immigration and the Dutch Economy: Facts and Figures, CPB Netherlands Bureau for Economic Policy Analysis.

Rusinovic, K. (2006). Dynamic Entrepreneurship: First and second-generation immigrant entrepreneurs in Dutch cities. Amsterdam, Amsterdam University Press.

Sampson, R. J., S. W. Raudenbush, et al. (1997). "Neighbourhoods and violent crime: A multilevel study of collective efficacy." Science 277(918-924).

Santarelli, E. and M. Vivarelli (2007). "Entrepreneurship and the process of firms' entry, survival and growth." Industrial and Corporate Change 16(3): 455-488.

Schutjens, V., P. Korteweg, et al. (2007). De woning als bedrijfslocatie. Van springplank naar anker. De stadsbuurt. Ontwikkeling en betekenis. R. v. Kempen and S. Musterd. Assen, Van Gorcum.

Schutjens, V. and E. Stam (2003). "The evolution and nature of young firm networks: A longitudinal perspective." Small Business Economics 21: 115-134.

SCP [Social and Cultural Planning Bureau] (2008). Facts and figures of the Netherlands - Social and cultural trends 1995-2006. The Hague.

SCP [Social and Cultural Planning Bureau] and CBS [Netherlands Bureau of Statistics] (2005). Armoedemonitor 2005 [Poverty monitor 2005]. The Hague.

SCP [Social and Cultural Planningbureau] (2007). Jaarrapport integratie 2007 [Annual integration report 2007]. The Hague.

Snel, E. and J. Burgers (2000). "The Comfort of Strangers. Etnische enclaves in de grote steden." Amsterdams Sociologisch Tijdschrift 27(3): 292-313.

Stam, E. (2009). Entrepreneurship, evolution and geography. The handbook of evolutionary economic geography. R. Boschma and R. L. Martin. Cheltenham, Edward Elgar.

Stark, O. (1991). The migration of labour. Oxford, Blackwell. 
Stuart, T. and O. Sorenson (2003). "The geography of opportunity: Spatial heterogeneity in founding rates and the performance of biotechnology firms." Research Policy 32: 229-253.

Suyver, J. F. and J. A. Kwie (1998). Professioneler ondernemen door allochtonen. Zoetermeer, The Netherlands, EIM.

Tamasi, C. (2006). "Determinants of regional entrepreneurship dynamics in contemporary Germany: A conceptual and empirical analysis." Regional Studies 40(4): 365-384.

Tesser, P. T. M., J. G. F. Merens, et al. (1999). Rapportage minderheden 1999. Positie in het onderwijs en op de arbeidsmarkt. Den Haag, Sociaal en Cultureel Planbureau/Elsevier.

Tesser, P. T. M., et al. (1995). Rapportage minderheden 1995. Concentratie en segregatie. Rijswijk/Den Haag, SCP/VUGA.

Thompson, P., D. Jones-Evans, et al. (2010). "Education and entrepreneurial activity: A comparison of white and South Asian Men." International Small Business Journal 28(2): 147-162.

Tienda, M. and D.-T. Lii (1987). "Minority concentration and earnings inequality: Blacks, Hispanics, and Asians compared." American Journal of Sociology 93(1): 141-165.

Tigges, L. M., I. Brown, et al. (1998). "Social isolation of the urban poor. Race, class, and neighborhood effects on social resources." The Sociological Quarterly 39(1): 5377 .

Tillaart, H. v. d. (2007). "Etnische ondernemerschap in Nederland. Ontwikkelingen en perspectieven." Migrantenstudies 23(2): 76-98.

Tillaart, H. v. d. (2001). Monitor Etnisch Ondernemerschap 2000. Zelfstandig ondernemerschap van etnische minderheden in Nederland in de periode 19902000. Nijmegen, Instituut voor Sociale Wetenschappen.

Topa, G. (2001). "Social interactions, spillovers and unemployment." Review of Economic Studies 68: 261-295. 
Uunk, W. (2002). Concentratie en achterstand. Over de samenhang tussen etnische concentratie en de sociaal-economische positie onder allochtonen en autochtonen. Assen, Van Gorcum.

Van de Hoek, J. (1992). Marokkaanse tienermeisjes. Gezinsinvloeden op keuzen en kansen. Utrecht, Jan van Arkel.

Veenman, J. (1995). Onbekend maakt onbemind. Over selectie van allochtonen op de arbeidsmarkt. Assen, Van Gorcum.

Veraart, J. (1996). In vaders voetspoor. Jonge Turken op de arbeidsmarkt. Amsterdam, University of Amsterdam Press.

Vermeulen, H. and R. Penninx (1994). Het democratisch ongeduld. De emancipatie en integratie van zes doelgroepen van het minderhedenbeleid. Amsterdam, Het Spinhuis.

Vermeulen, H. and R. Penninx (2000). Immigrant Integration: the Dutch case. Amsterdam, Het Spinhuis.

Voelker, B., H. Flap, et al. (2007). "When are neighbourhoods communities? Community in Dutch neighbourhoods." European Sociological Review 23(1): 99114 .

Vogels, R., P. Geense, et al. (1999). De maatschappelijke positie van Chinezen in Nederland. Assen, Van Gorcum.

Wacquant, L. (1993). "Urban outcasts: stigma and division in the black American ghetto and the French urban periphery." International Journal of Urban and Regional Research 17(3): 366-383.

Waldinger, R. (1986). Through the eye of the needle. Immigrants and enterprise in New York's garment trades. New York, New York University Press.

Waldinger, R. (1996). Still the promised city: African-Americans and new immigrants in post-industrial New York. Cambridge, MA, Harvard University Press.

Waldinger, R., R. Aldrich, et al. (1990). Ethnic entrepreneurs. Immigrant business in industrial societies. Newbury Park CA, Sage. 
Wang, Q. (2004). "Labor market concentration of Asian ethnic groups in US metropolitan areas: A disaggregated study." Population, Space and Place 10: 479494.

Wennekers, S., A. v. Stel, et al. (2008). The relation between entrepreneurship and economic development: is it U-shaped? Zoetermeer, EIM.

Weterings, A., E. Dammers, et al. (2009). De waarde van de kantooromgeving. Effecten van omgevingskenmerken op de huurprijzen van kantoorpanden. Den Haag/Bilthoven, Planbureau voor de Leefomgeving.

Weterings, A., J. Knoben, et al. (2008). Werkgelegenheidsgroei op bedrijventerreinen. Achtergrondstudies. Den Haag/Bilthoven, Planbureau voor de Leefomgeving.

Wever, E. (1984). Regionaal-ekonomisch perspectief; een literatuurverkenning naar het ruimtelijk patroon van bedrijvigheid in Nederland, Vakgroep Economische Geografie, Geografisch en Planologisch Instituut Nijmegen.

White, P. (1998). Ideologies, social exclusion and spatial segregation in Paris. Urban segregation and the welfare state: inequality and exclusion in Western cities. S. Musterd and W. Ostendorf. London, Routledge.

Wilcox, J. and W. C. Roof (1978). "Per cent Black and Black-White status inequality: Southern versus Nonsouthern patterns." Social Science Quarterly 59: 421-434.

Wilpert, C. (2003). Germany: From workers to entrepreneurs. Immigrant entrepreneurs: Venturing abroad in the age of globalization. R. Kloosterman and J. Rath. Oxford, Berg: 233-259.

Wilson, F., J. Kickul, et al. (2007). "Gender, entrepreneurial self-efficacy, and entrepreneurial career intentions: Implications for entrepreneurship education." Entrepreneurship Theory and Practice 31(3): 387-406.

Wilson, W. J. (1987). The truly disadvantaged: The inner city, the underclass, and public policy. Chicago, University of Chicago Press.

Wood, C. H. (1982). "Equilibrium and historical-structural perspectives on migration." International Migration Review 16(2): 298-319.

Zorlu, A. and T. Traag (2005). Opleidingsniveau en taalvaardigheid. Jaarrapport Integratie 2005. Den Haag/Voorburg, SCP/WODC/CBS: 44-56. 



\section{Samenvatting}

De onderzoeksvraag die in dit proefschrift centraal staat is de vraag of en zo ja, hoe de locatie van niet-westerse immigranten in Nederland uitmaakt voor hun economisch succes op de arbeidsmarkt en als zelfstandige ondernemers. Meer concreet kijk ik naar de wijze waarop de lokale woonomgeving en de omgeving van bedrijven (voor de zelfstandige ondernemers) het economisch succes van immigranten beïnvloeden. Deze onderzoeksvraag is niet alleen van belang voor Nederland, maar ook voor veel andere Europese landen die de laatste decennia te maken hebben gekregen met een toenemende maatschappelijke marginalisatie van niet-westerse immigranten. Tegenwoordig zitten veel niet-westerse immigranten zonder baan of verrichten zij werkzaamheden tegen lage lonen en onder precaire arbeidsomstandigheden. De oorzaken voor deze economische marginalisatie kunnen divers zijn: het kan het gevolg zijn van problemen met verblijfs- of arbeidsvergunningen, een laag opleidingsniveau, aanraking met criminaliteit en/of gebroken families. Deze economische marginalisatie gaat vaak gepaard met ruimtelijk marginalisatie en dat laatste leidt ertoe dat niet-westerse immigranten in stedelijke achterstandswijken komen te wonen. Aangezien het tot op heden onduidelijk is of de locatie van niet-westerse immigranten in Nederland en/of binnen stedelijke gebieden effect heeft op hun economisch succes op de arbeidsmarkt of als ondernemers, biedt dit voldoende reden voor onderzoek.

Door het onderzoek slechts op een enkel immigratieland, namelijk Nederland, te concentreren, heb ik de mogelijkheid om in een aantal complementaire onderzoeksprojecten het effect van de genoemde ruimtelijke implicaties op zowel de arbeidsmarktuitkomsten als ook op de uitkomsten van ondernemers te analyseren. Elk project volgt daarbij zijn eigen onderzoeksmethodologie. Hoewel de onderzochte herkomstgroeperingen van immigranten per onderzoek verschillen, levert het onderzoek een reeks interessante bevindingen op over de relevantie van de locatie voor het economische succes van niet-westerse immigranten in Nederland.

Uit de algemene onderzoeksvraag wordt in de hoofdstukken twee tot en met vijf een aantal meer specifieke vragen gedestilleerd. Zo wordt in hoofdstuk twee de basis gelegd voor de empirische analyses later in het proefschrift. Daarvoor wordt de sociaal-economische positie van niet-westerse immigranten in Nederland beschreven in het licht van de unieke Nederlandse immigratiegeschiedenis en het daarmee samenhangende beleid over de laatste 50 jaar. In hoofdstuk drie wordt de vraag gesteld of het wonen in 'migrantenbuurten' (buurten met een hoog aandeel niet-westerse immigranten) de arbeidsmarktkansen van asielzoekers bevordert of 
juist beperkt. Het bedrijfssucces van eerste en tweede generatie migrantenondernemers wordt in hoofdstuk 4 met elkaar vergeleken en daarbij wordt de vraag gesteld of en zo ja, hoe dit succes wordt beïnvloed door de lokale marktomstandigheden, de lokale aanwezigheid van andere leden uit de coetnische groep (afkomstig uit hetzelfde land) en de sectorkeuze van de economische activiteit. In hoofdstuk vijf wordt de vraag onderzocht of, en zo ja, hoe de bebouwde omgeving en de daarmee samenhangende regelgeving in stedelijke woongebieden de ontwikkelingsmogelijkheden van migrantenondernemers beïnvloedt.

Ter beantwoording van de centrale onderzoeksvraag worden in dit proefschrift kwantitatieve en kwalitatieve onderzoeksmethoden gecombineerd. Waar mogelijk maak ik gebruik van reeds beschikbare data: data van het Centraal Bureau voor de Statistiek (CBS), het Centraal Orgaan opvang Asielzoekers (COA) en bestanden uit het Handelsregister van de Kamer van Koophandel. Om de bevindingen uit deze kwantitatieve analyses diepgaander te kunnen onderzoeken, heb ik aanvullend kwalitatieve data verzameld uit acht focusgroepsdiscussies met deskundigen en uit veertig face-to-face interviews met ondernemers. Daarnaast heb ik ook de bestemmingsplannen van vijf stedelijke onderzoekswijken in de vier grote steden bestudeerd.

In hoofdstuk twee wordt de sociaal-economische positie van niet-westerse immigranten in Nederland beschreven in het licht van de Nederlandse immigratiegeschiedenis en het daarmee samenhangende beleid over de laatste 50 jaar. Ter verkrijging van inzicht in het niveau van integratie van de herkomstgroeperingen van immigranten in de samenleving, wordt de sociaaleconomische positie zowel absoluut als ook in verhouding tot autochtone Nederlanders geanalyseerd. Het niveau van integratie van immigranten wordt in het algemeen gemeten door een vergelijking te maken tussen de 'scores' van immigranten en autochtonen op een aantal kernvariabelen die de sociaaleconomische positie van mensen in de samenleving weerspiegelt.

In hoofdstuk drie wordt het causale effect onderzocht van woonsegregatie van niet-westerse immigranten op hun arbeidsmarktuitkomsten. Meer specifiek stel ik hier de vraag of het wonen in migrantenbuurten de arbeidsmarktkansen van asielzoekers bevordert of juist beperkt. Om deze vraag te kunnen beantwoorden, maak ik gebruik van een uniek natuurlijk experiment, namelijk de willekeurige toewijzing van de eerste woonlocatie van asielzoekers in Nederland. Door een combinatie van aantal administratieve bronnen is het mogelijk om ongeveer 92.000 asielzoekers over de periode van 1999-2004 te volgen en hun ontwikkelingen op de arbeidsmarkt te bestuderen. Gelet op deze 'rijke' data heb ik ook analyses kunnen 
uitvoeren voor deelgroepen, voor de niet-lineaire relatie tussen concentratie en arbeidsmarktuitkomsten, en voor selectie effecten.

In hoofdstuk vier onderzoek ik de stelling dat tweede generatie migrantenondernemers in vergelijking met de generatie van hun ouders substantieel betere economische posities met veelbelovende toekomstperspectieven hebben. Specifiek biedt dit hoofdstuk een systematische weergave van eerste en tweede generatie migrantenondernemers van de vijf grootste groepen niet-westerse ondernemers in Nederland. De focus ligt hierbij op hun bedrijfs- en locatiekenmerken. Het onderzoek illustreert de grote verschillen in integratie tussen de vijf herkomstgroeperingen en legt een verband met het succes in ondernemerschap.

In hoofdstuk vijf wordt gekeken naar de potentiële relatie tussen wijkkenmerken en het bedrijfssucces van migranten. Meer specifiek wordt er onderzocht of, en zo ja, in welke mate de bebouwde omgeving van een wijk en de daarmee samenhangende regelgeving de ontwikkelingsmogelijkheden van migrantenondernemers beïnvloedt. Ter bestudering van deze onderzoeksvraag contrasteer ik twee typen van stedelijke woonwijken, namelijk vooroorlogse en naoorlogse wijken. Beiden kennen een zeer uiteenlopende ruimtelijke inrichting. In vooroorlogse wijken is er weinig functionele scheiding tussen commerciële functies en woonfuncties en daarom worden deze wijken ook wel gemengde wijken genoemd. Naoorlogse wijken daarentegen zijn uitsluitend voor woondoeleinden gebouwd. Deze wijken geven maar weinig ruimte aan commerciële functies, die bovendien sterk ruimtelijk gescheiden worden van de woonfunctiegebieden. Naoorlogse wijken worden daarom ook wel mono-functionele wijken genoemd. De verschillen in de bebouwde omgeving en de daarmee samenhangende regelgeving tussen voor- en naoorlogse wijken vormen een belangrijke verklaring voor de differentiatie in de ontwikkelingsmogelijkheden van migrantenondernemers. Vooroorlogse wijken zijn vitaler en attractiever voor ondernemers, naoorlogse wijken bieden vooral gemaks- en kostenvoordelen.

In hoofdstuk zes wordt de centrale onderzoeksvraag beantwoord en in het licht daarvan wordt een selectie van de resultaten uit hoofdstuk twee tot en met vijf bediscussieerd. De belangrijkste conclusie uit dit proefschrift is dat de locatie van niet-westerse immigranten in Nederland inderdaad uitmaakt voor hun economisch succes op de arbeidsmarkt en als zelfstandige ondernemers. De onderzoeken leiden daarnaast tot een reeks bevindingen die aanleiding kunnen zijn voor vervolgonderzoek. Deze bevindingen kunnen in vier thema's worden samengevat: ten eerste, implicaties van regionale en stedelijke verschillen voor het economisch succes van immigranten; ten tweede, de relevantie van de lokale sociale omgeving voor het economisch succes van immigranten; ten derde, 
implicaties van de bebouwde omgeving en de daarmee samenhangende regelgeving voor het economisch succes van immigranten; ten vierde, andere (nietgeografische) factoren die invloed hebben op het economisch succes van immigranten.

Het eerste thema ziet op de ongelijke verdeling van niet-westerse immigranten over Nederland en op de verschillen tussen regio's en steden ten aanzien van arbeidsmarktmogelijkheden en mogelijkheden voor ondernemers. De mogelijkheden in deze gebieden hangen af van ondermeer vier factoren: de structuur van de economische sectoren, de welvaart, de arbeidsmarktconcurrentie en de afzetmarkten voor specifieke goederen en diensten. Deze laatste twee factoren zijn ook afhankelijk van de lokale aanwezigheid van andere niet-westerse immigranten die vaak concurreren op het gebied van onderneming (b.v. lokale groentewinkels of snackbars) of banen aan de onderkant van de arbeidsmarkt. De resultaten uit mijn onderzoeken onderstrepen de relevantie van regionale en stedelijke verschillen voor het economisch succes van immigranten op de arbeidsmarkt en als zelfstandige ondernemers. Een interessante conclusie voor ondernemers is dat het bedrijfssucces in de vier grote steden niet per se hoger is dan elders; ook al bieden deze steden attractieve markten, door de sterke competitie kan maar een deel van de ondernemers zich in de markt profileren.

Het tweede thema onderstreept de betekenis van de lokale ruimtelijke woon- en bedrijfsomgeving voor het economisch succes van niet-westerse immigranten op de arbeidsmarkt en als ondernemers. In dit verband, bevestigt dit proefschrift vooral de relevantie van de lokale bevolkingssamenstelling en de bebouwde omgeving met de daarmee samenhangende regelgeving. De lokale bevolkingssamenstelling in een bepaald gebied kan op drie manieren het economische succes van niet-westerse immigranten beïnvloeden. Allereerst kan de lokale aanwezigheid van de co-etnische gemeenschap het sociale en economische gedrag van de leden vormen; ten tweede, kennen migrantenbuurten unieke sociale omstandigheden die impact kunnen hebben op de bevolking; en ten derde, bepalen de algemene sociaal-economische bevolkingskenmerken van een gebied het lokale niveau van welvaart en het lokaal aanwezige sociale kapitaal, hetgeen allebei beslissend kan zijn voor het succes van niet-westerse immigranten op de arbeidsmarkt en als ondernemers. De relevantie van de bebouwde omgeving wordt bij het derde thema besproken.

Het derde thema onderstreept, naast de bovengenoemde lokale bevolkingssamenstelling, de betekenis van de lokale bebouwde omgeving en de daarmee samenhangende regelgeving voor het economisch succes van nietwesterse ondernemers. Zo bestaan er duidelijke verschillen in ontwikkelingsmogelijkheden tussen ondernemers uit vooroorlogse en uit 
naoorlogse wijken. De verschillen tussen de twee wijktypen worden bepaald door het soort gebouwen, de ruimtelijke inrichting en de bestemmingsplannen. Het onderzoek laat zien dat de restrictieve zonering in mono-functionele, naoorlogse woonwijken niet alleen potentiële ondernemers bemoeilijkt om zich in de wijk te vestigen, maar ook de ontwikkelingsmogelijkheden van bestaande ondernemers belemmert. Ondernemers hebben immers geschikte bedrijfsruimte nodig om zich te kunnen vestigen en om te kunnen groeien. Ook laat het onderzoek zien dat markten in het algemeen ruimtelijk begrensd zijn en dat (potentiële) ondernemers plaatsgebonden zijn door huisvesting, sociale banden en kennis van een specifiek gebied. Verder leidt het onderzoek tot de interessante conclusie dat een hoger lokaal voorzieningenniveau (b.v. cafés, restaurants) de buurt van meer 'overlevingspotentiaal' kan voorzien. Dit kan weer de ontwikkelingsmogelijkheden van andere bedrijven in de buurt bevorderen, met name die van die bedrijven die een sterke klantenbinding aan de buurt hebben. Het niet voorhanden zijn van lokale voorzieningen zou een deelverklaring kunnen vormen voor de reden waarom sommige (vooral naoorlogse) buurten ondernemers alleen op basis van gemaks- en kostenvoordelen kunnen aantrekken (b.v. door de beschikbaarheid van gratis parkeermogelijkheden).

Het vierde en laatste thema belicht een aantal (niet-geografische) algemene integratiegerelateerde aspecten die de economische uitkomsten van niet-westerse immigranten op de arbeidsmarkt en als ondernemers sterk kunnen beïnvloeden. Hoewel in dit onderzoek de integratiegerelateerde factoren niet duidelijk aanwijsbaar zijn, omdat zij conceptueel enigszins vaag en daarmee moeilijk meetbaar zijn, heeft dit proefschrift hun relevantie wel verduidelijkt en kunnen zij als verklaring dienen voor een aantal bevindingen van dit proefschrift. Zo verbeteren arbeidsmarktuitkomsten van niet-westerse immigranten naarmate men langer in het gastland verblijft en meer gastlandspecifieke culturele en taalvaardigheden verwerft. Voor migrantenondernemers lijkt vaak juist het gebrek aan deze vaardigheden te verklaren waarom deze ondernemers met problemen kampen die voortkomen uit het niet kennen van officiële en inofficiële regels en een gebrek aan essentiële bedrijfsinformatie. Verder lijken verschillen in bedrijfskenmerken en bedrijfssucces tussen drie herkomstclusters van nietwesterse migrantenondernemers (het arbeidsmigrantencluster, het koloniale cluster, en Chinezen) samen te hangen met een belangrijke differentiatie tussen hun opleidingsniveau en hun gastlandspecifieke culturele en taalvaardigheden. Deze differentiatie tussen de drie clusters zou kunnen verklaren waarom Turkse en Marokkaanse ondernemers (arbeidsmigrantencluster), die gemiddeld lager zijn opgeleid en minder succesvol zijn op de arbeidsmarkt, ook minder vaak aan te treffen zijn in de veel belovende ondernemerschapsectoren. Eveneens zou deze differentiatie kunnen verklaren waarom het arbeidsmigrantencluster in het algemeen minder succesvol in ondernemerschap is dan ondernemers uit het 
koloniale cluster (Surinaamse en Antilliaanse) en Chinezen. Tot slot onderstrepen de bevindingen van dit proefschrift het sterke verband tussen de arbeidsmarkt en het zelfstandig ondernemerschap. Mijn onderzoek toont aan dat ondernemerschap geen onafhankelijke route voor sociale stijging is die de voor de arbeidsmarkt bekende afhankelijkheid tussen opleiding en economische kansen weet te omzeilen. Dit toont opnieuw het belang aan van een goede integratie van immigranten in de Nederlandse maatschappij, niet alleen ter bevordering van hun arbeidsmarktkansen, maar ook ter bevordering van succesvol migrantenondernemerschap. 


\section{Biography}

Pascal Beckers was born on May 5, 1981 in Cologne, Germany. He grew up in Germany and Canada, where he started his university studies at the University of Toronto.

In 1999 Pascal moved to the Netherlands to study economics at Maastricht University where he received his Master's degree in Economics with specialisation International Management in 2003. During this period he also studied a semester abroad at the Universidad del Pacifico, in Lima, Peru. In 2005 Pascal returned to Maastricht to start his PhD in the European Graduate Programme in Social Protection Policy offered by the Maastricht Graduate School of Governance. Next to his research, he worked as project manager to develop a private Master's programme in European Migration Studies and as lecturer and academic advisor to Master students and professionals at the School. Throughout his academic work he has collaborated with experts from various other organizations, such as the World Bank, Unicef, EIPA, research groups at the universities of Amsterdam and Utrecht, and FORUM. He was a visiting researcher at the Institute for Migration and Ethnic Studies (IMES) and the Amsterdam Institute for Metropolitan and International Development Studies (AMIDSt) at the University of Amsterdam.

Since February 2010 Pascal is employed as researcher at the PBL Netherlands Environmental Assessment Agency (Planbureau voor de Leefomgeving) in The Hague, where he conducts research on urban regeneration and spatial planning of industrial estates. Also, Pascal continues with his work as lecturer at the Maastricht Graduate School of Governance and his research cooperation with colleagues at the University of Utrecht in a project on the neighbourhood economy. 


\section{Maastricht Graduate School of Governance Dissertation}

\section{Series}

Pascal Beckers

Local space and economic success. The role of spatial segregation of migrants in the Netherlands

MGSoG Dissertation Series, nr. 12 (2010)

Victor Cebotari

Conflicting Demands in Ethnically Diverse Societies

Ethnopolitical Contention and Identity Values in Europe

MGSoG Dissertation Series, nr. 11 (2010)

Dennis Gyllensporre

Competing and Complementary Perspectives on the EU as a Crisis Management Actor:

An Examination of the Common Security and Defence Policy through the Lenses of

Idealism and Realism

MGSoG Dissertation Series, nr. 10 (2010)

Judit Vall Castello

Business Cycle and Policy Effects on Labour Market Transitions of Older and Disabled Workers in Spain

MGSoG Dissertation Series, nr. 9 (2010)

Keetie Roelen

False Positives or Hidden Dimensions: the definition and measurement of child poverty MGSoG Dissertation Series, nr. 8 (2010)

Denisa Maria Sologon

Earning Dynamics in Europe

MGSoG Dissertation Series, nr. 7 (2010)

Melissa Siegel

Money and Mobility: Migration and Remittances

MGSoG Dissertation Series, nr. 6 (2010)

Jessica S. Hagen-Zanker

Modest Expectations: Causes and effects of migration on migrant households in source countries

MGSoG Dissertation Series, nr. 5 (2010) 
Mirtha R. Muniz Castillo

Human Development and Autonomy in Project Aid: Experiences from four bilateral projects in Nicaragua and El Salvador

MGSoG Dissertation Series, nr. 4 (2009)

Christiane Arndt

Governance Indicators

MGSoG Dissertation Series, nr. 3 (2009)

Britta Augsburg

Microfinance - Greater Good or Lesser Evil?

MGSoG Dissertation Series, nr. 2 (2009)

\section{Geranda Notten}

Measuring and Managing Poverty Risks

MGSoG Dissertation Series, nr. 1 (2008) 